\title{
Marcel Tabuteau's System of Phrasing Applied to the Primary Themes in Carl Maria von Weber's Second Clarinet Concerto
}

Christopher Charles Bowmaster

West Virginia University, cbowmast@mix.wvu.edu

Follow this and additional works at: https://researchrepository.wvu.edu/etd

Part of the Music Performance Commons

\section{Recommended Citation}

Bowmaster, Christopher Charles, "Marcel Tabuteau's System of Phrasing Applied to the Primary Themes in Carl Maria von Weber's Second Clarinet Concerto" (2019). Graduate Theses, Dissertations, and Problem Reports. 7447.

https://researchrepository.wvu.edu/etd/7447

This Dissertation is protected by copyright and/or related rights. It has been brought to you by the The Research Repository @ WVU with permission from the rights-holder(s). You are free to use this Dissertation in any way that is permitted by the copyright and related rights legislation that applies to your use. For other uses you must obtain permission from the rights-holder(s) directly, unless additional rights are indicated by a Creative Commons license in the record and/ or on the work itself. This Dissertation has been accepted for inclusion in WVU Graduate Theses, Dissertations, and Problem Reports collection by an authorized administrator of The Research Repository @ WVU.

For more information, please contact researchrepository@mail.wvu.edu. 


\title{
Marcel Tabuteau's System of Phrasing Applied to the Primary Themes in Carl Maria von Weber's Second Clarinet Concerto
}

\section{Christopher C. Bowmaster}

Research Document submitted to the College of Creative Arts at West Virginia University

in partial fulfillment of the requirements for the degree of

Doctor of Musical Arts in Clarinet Performance

\author{
John Weigand, DMA, Chair \& Research Advisor \\ Lynn Hileman, DMA \\ Travis Stimeling, PHD \\ Michael Vercelli, DMA \\ Pablo Garcia-Loaeza, PHD \\ School of Music
}

Morgantown, West Virginia

2019

Keywords: Clarinet, Analysis, Orchestra, Marcel Tabuteau, Philadelphia, Woodwind, Phrasing, Numbers, Performance Copyright 2019 Christopher C. Bowmaster 


\title{
ABSTRACT \\ Marcel Tabuteau's System of Phrasing Applied to the Primary Themes in Carl Maria von Weber's Second Clarinet Concerto
}

\author{
Christopher C. Bowmaster
}

This research document provides a biographical sketch of Marcel Tabuteau's life beginning with his childhood and extending to his retirement from the Philadelphia Orchestra and Curtis Institute of Music. The sketch provides a thorough timeline explaining how each colleague, teacher, student, and ensemble influenced his phrasing system.

Following a series of handwritten notes completed by Tabuteau in his native language in chapter two, application of the system to Carl Maria von Weber's Second Clarinet Concerto takes place in chapters three to six. The four portions of the system used are the Interrogative/Affirmative/More-Affirmative, Note Grouping, Up and Down Gestures, and Phrasing Numbers. The document culminates with a detailed explanation for implementing each principle cohesively, resulting in a performance that exceeds reasonable expectations. 
For my siblings Ryan Bretschneider R.I.P., Blake Bretscneider, and Abbie Bowmaster

For my parents, Beverly Bretschneider, Rosemary Bowmaster, and Charles Bowmaster

For my clarinet teachers, Dr. John Weigand, Dr. Dennis Nygren, Dr. Alice Wang, Bob Fitzer R.I.P., and Sandy Stuart 


\section{TABLE OF CONTENTS}

Acknowledgements

Chapters:

1. A Biographical Sketch of Marcel Tabuteau

2. Marcel Tabuteau's Handwritten Notes and Translations

3. Interrogative/Affirmative/More-Affirmative Applied

53

4. Note Groupings Applied

68

5. Up/Down Gestures Applied

82

6. The Phrasing Number System Applied

97

7. Conclusion

Appendices:

A. A List of Marcel Tabuteau's Students 116

B. Interrogative/Affirmative/More-Affirmative

C. Note Groupings

120

D. Up/Down Gestures

126

E. The Phrasing Number System 


\section{A Biographical Sketch of Marcel Tabuteau}

Marcel Tabuteau is considered one of the greatest oboists to perform and teach in the United States of America. Known for his evolving analytical approach to music, Tabuteau believed that musicians should perform with systematic thought, rather than portraying emotion. David McGill, former principal bassoonist of the Chicago Symphony and currently a professor of bassoon at Northwestern University, states the following regarding music as a thought: Truly musical phrasing is musical thought in sound. Rationalized phrasing has the potential to reach far deeper into the psyche of the listener than performance-based solely on instinct, however good that instinct may be. All musicians can learn to play more expressively through carefully directed thought. ${ }^{1}$

This chapter provides a biographical sketch explaining each advancement throughout Tabuteau's career and his influence on musical phrasing.

Born in Compiegne, France in 1887, Tabuteau grew up in a musically talented family. His father, Francois Tabuteau, played the bass drum and actively encouraged the entire family to study a string instrument and sing solfege. Tabuteau's wife, Charlotte, played the violin; their daughter Therese, the cello; both Marcel and his brother Andre studied violin. ${ }^{2}$

In 1896, with the formation of the Harmonie Municipale, which replaced the earlier Harmonie Jeanne d'Arc (a group of young musicians known as the Enfants de Compiegne), more wind players were needed. ${ }^{3}$ Tabuteau started playing the oboe alongside his brother, Andre, who played the clarinet. When Marcel showed a special talent for the oboe, it was Emile Letoffe (Tabuteau's brother-in-law and prized violinist) who could be helpful, perhaps even making the

\footnotetext{
${ }^{1}$ David McGill, Sound in Motion (Indiana University Press, 2007), 1.

2 Laila Storch, How Do You Expect to Play the Oboe If You Can't Peel a Mushroom? (Indiana University Press, 2008), 8.

${ }^{3}$ Ibid, pg. 8
} 
first contact with the famous oboe professor Georges Gillet. ${ }^{4}$

Georges Gillet, the founder of the French school of oboe playing, instructed Tabuteau from 1900-1904 both privately and at the Paris Conservatoire. These were formative years for Tabuteau, stating, "Gillet was the greatest musician I have ever known."5 Gillet was monumental in Tabuteau's development of phrasing style, and his admiration for the master teacher continued for the length of his career. After his retirement and return to France, Tabuteau arranged for a plaque to be placed on Gillet's grave in Cimetiere Montmartre in Paris with the inscription "Au grand Maitre Georges Gillet 1854-1920, ses admirateurs” (To the great teacher Georges Gillet, 1854-1920, from his admirers). ${ }^{6}$

In 1905, Tabuteau ceased his formal studies with Gillet and moved to New York City to perform with the New York Symphony Orchestra. After only one year, he was quickly forced to return to France to serve a 3-year military enlistment. Due to a law passed on July 11, 1892, graduates from the Paris Conservatoire were only required to complete one year of enlistment. Tabuteau returned to the United States in 1907 to play with the New York Symphony for the 1907-08 season.

Following Tabuteau's second arrival to the United States, the musician's union attempted to expel him on a technicality concerning the break in his continuous U.S. residency. ${ }^{7}$ Walter Damrosch, the conductor of the New York Symphony Orchestra, pursued a resolution in hopes of keeping Tabuteau in the United States. Damrosch's representative then wrote a letter to attorney Guernsey Price asking, "Could Tabuteau get an injunction against the Musicians Mutual Protective Union preventing it from expelling him until the courts have decided that it has this

\footnotetext{
${ }^{4}$ Laila Storch, How Do You Expect to Play the Oboe If You Can't Peel a Mushroom? (Indiana University Press, 2008), 14.

${ }^{5}$ Ibid., 21.

${ }^{6}$ Ibid., 22.

${ }^{7}$ Ibid., 53.
} 
right, so that he can in the meantime earn his living?"8

Not only did Damrosch support Tabuteau's U.S. citizenship for his playing, but also to improve the immigration process for other musicians as well. Following Tabuteau's second season (1907-08), he chose to leave the New York Symphony Orchestra to play with the Metropolitan Opera for their 1908-1909 season.

Playing with the Metropolitan Opera from 1908-1914 as principal oboe provided the opportunity for Tabuteau's noticeable progression. This advancement created two challenges for Tabuteau as a performer, and a person. As a performer, he was forced to sight read his music due to missed rehearsals following his late arrival to the country. On the personal side, the conflict with Damrosch after leaving the New York Symphony Orchestra lowered his spirits because he was the sole reason for having been able to remain in the United States.

As his career progressed performing in the pit orchestra, Tabuteau refined his process of learning and approach to performing due to the opera's length and new exposures to some of the world's finest singers and conductors. Tabuteau was fortunate enough to perform with the most luminous singing personalities in operatic history: Marcella Sembrich, Johanna Gadski, Olive Fremstad, Geraldine Farrar, Louise Homer, Enrico Caruso, and Pasquale Amato. ${ }^{9}$ He also performed under the batons of Giulio Gatti-Casazza, Arturo Toscanini, Alfred Hertz, and Gustav Mahler. His time with the Metropolitan Opera lasted until 1914 when he was yet again forced to return to France because of World War 1.

After the Metropolitan Opera, Tabuteau moved to San Francisco to perform in the Panama-Pacific International Exposition Orchestra (PPIEO). Although he only lived there for six months, this proved to be beneficial to his career as the PPIEO was a full-sized orchestra that

\footnotetext{
${ }^{8}$ Laila Storch, How Do You Expect to Play the Oboe If You Can't Peel a Mushroom? (Indiana University Press, 2008), 53.

${ }^{9}$ Ibid., 65.
} 
played significant repertoire, comprised of many soon to be Philadelphia Orchestra colleagues.

Tabuteau began his career with the Philadelphia Orchestra in 1915 under the baton of Leopold Stokowski and continued to perform with them until 1940. There are at least three versions of how Tabuteau came to be engaged as principal oboe of the Philadelphia Orchestra. ${ }^{10}$ These stories include:

1) One account says that in the spring of 1915, while Tabuteau was in San Francisco, he heard of the oboe position from some of the Philadelphia Orchestra men who were playing with him in the Panama-Pacific International Exposition. ${ }^{11}$

2) Another, concerns the role Alexander van Rensselaer. He was the respected president of the Philadelphia Orchestra Association that chose Tabuteau. Alexander was a fervent supporter of the orchestra and a confidant of Stokowski who could make suggestions, even concerning personnel, were taken seriously. ${ }^{12}$

3) The final question comes from a citation in the New Grove Dictionary, no less an authority than Philip Bate states that Stokowski decided to hire Tabuteau after hearing him play in a performance of Tristan und Isolde. ${ }^{13}$

The Oboe community generally accepts the notion that Stokowski was responsible for hiring Tabuteau after hearing his grand performance in Tristan und Isolde. Once earned, this position motivated Tabuteau to pursue a higher level of musicianship. Stokowski states the following: "In working with the Philadelphia orchestra, my dream was, and we partly achieved that dream, to express to the utmost the spirit, the inner spirit, of every kind of music. I say "every kind" because every composer as an individual, as his life develops,

${ }^{10}$ Laila Storch, How Do You Expect to Play the Oboe If You Can't Peel a Mushroom? (Indiana University Press, 2008), 88.

11 Ibid., 88 .

12 Ibid., 88 .

13 Ibid., 89. 
produces/creates, different kinds of music...And, of course, the differences between the two composers who lived in the same period, like Brahms and Wagner, are like the difference between the North Pole and the equator...In order to do all that with the Philadelphia Orchestra, I begged the players to notice all those differences, and I said to them, "Each one of you must be a poet as well as a great player of your instrument, and through your poetic feeling, you can express every kind of music."...Do not permit yourselves to become, as is the tendency in the world today, standardized, so that you all think and feel the same way...Give your personality, all your inner feeling, give that expression through the music. Do not all be alike. No two bows are alike. No two hands are alike. No two nervous systems are alike. No two minds are alike. No two emotional characters are alike. You are all different. Be different! Don't Standardize yourself. And put all ties into music." They finally did that and the orchestra became so flexible and so extraordinary." 14

Stokowski's statement is profound because it lays the foundation for American orchestral performing. Tabuteau utilized Stokowski's approach collaboratively with what he learned from Georges Gillet at the Paris Conservatoire to create his system of phrasing. Laila Storch, a former student of Tabuteau, states the following about his process:

When I remember the intensity with which Tabuteau worked to find the specific tonal quality and style of expression demanded for each different composer, I realize that whether or not he originally had these concepts, he was actively fulfilling Stokowski's vision. Philadelphia Orchestra members who remember this era have said that Stokowski would often stay after a rehearsal and ask Tabuteau to play a particular phrase over a number of times. The next morning Stokowski would propose that same phrasing to the

\footnotetext{
${ }^{14}$ Laila Storch, How Do You Expect to Play the Oboe If You Can't Peel a Mushroom? (Indiana University Press, 2008), 90.
} 
whole violin section. For Tabuteau, to have his search for color and imaginative interpretation not only encouraged and appreciated by the conductor, must have affected his lifelong striving to make the exact reed he needed-painstakingly scraping the cane to a point that would best allow the expression of his musical ideas and at the same time have the particular quality of sound he envisaged for Mozart, Brahms, or Wagner. ${ }^{15}$

Supported by the financial backing of Mary Louise Curtis, Stokowski opened the Curtis Institute of Music in 1924. From the time of its opening, the Curtis Institute of Music aimed to train first-class orchestral musicians in all instruments. ${ }^{16}$ In addition to Tabuteau, many famous Philadelphia Orchestra musicians were asked to teach at the institute. The orchestra's training would be under the direction of Stokowski. ${ }^{17}$ Tabuteau became the oboe instructor and assumed many additional responsibilities including a solfege class in the orchestral training program. He also taught a course concentrated on the techniques of musical phrasing. The class addressed how phrasing, rhythm, delicate points of shading and dynamic variety are worked out on the different orchestral instruments. ${ }^{18}$ Amazingly, Tabuteau only taught a total of 57 students during his 30-year career at Curtis. (See Appendix A)

Tabuteau created his system of phrasing for his students. The primary purpose was to provide a means to perform at a higher musical level. He taught the system to each student explaining the musical structure and its connection to performance expressivity. A progression of his system is apparent in the description his students ascribe, as his older students describe a less intense system than his younger students. In addition to coaching a woodwind ensemble and teaching a reed making class, he also assumed the responsibility of a string course instructor. Not

${ }^{15}$ Laila Storch, How Do You Expect to Play the Oboe If You Can't Peel a Mushroom? (Indiana University Press, 2008), 90.

${ }^{16}$ Ibid., 177.

${ }^{17}$ Ibid., 177.

${ }^{18}$ Ibid., 180. 
only was this important to Tabuteau because of his youth violin studies, but he also believed the institute needed a string instructor following the Second World War. "Tabuteau's influence spread far beyond his oboe progeny to affect the other instrumentalists who attended his woodwind and string class." ${ }^{~} 19$

Following Tabuteau's retirement in 1953 from the Curtis Institute of Music and the Philadelphia Orchestra in 1954, he left behind a legacy still highly regarded today in the United States until his death in 1966. He not only influenced some of the greatest oboists but musicians of other instruments as well. Even though he, "teaches with an iron fist," his students had tremendous respect for him and did whatever was necessary to learn from the master teacher/performer.

${ }^{19}$ David McGill, Sound in Motion (Indiana University Press, 2007), 4. 


\section{Marcel Tabtueau's Handwritten Notes and Translations}

Toward the end of Marcel Tabuteau's career, his students repeatedly asked for him to compile a document explaining his complete system of phrasing. Unfortunately, nothing extensive materialized in written form from Tabuteau, but there are notes recorded by his former students. Below, are examples of those notes in three parts believed to be completed by both Tabuteau and his former student, Elaine Shaffer Kurtz. The handwritten notes are from the estate of former Cleveland Orchestra principal oboist, John Mack, and approved for use in this research document by its controller, Danna Sundet in Kent, Ohio. The first set is in Tabuteau's

handwriting and native French language with translations completed by Michael Finkelman, and the second and third sets are believed to have been completed by Mrs. Shaffer Kurtz.

Mrs. Shaffer Kurtz was a flutist that studied with William Kincaid at the Curtis Institute of Music. Efrem Kurtz, her soon to be husband at the time, was the conductor of the Kansas City Philharmonic, where Mrs. Shaffer won her first job as the second flutist. Efrem and Elaine followed each other to different orchestras around the United States based until deciding to move to Europe. This move led to the pursuit of a solo flute career by Mrs. Shaffer. Her solo career involved worldwide travel while living in Gstaad, Switzerland. In addition to becoming good friends with Tabuteau, she also briefly studied with him in Nice, France.

The following handwritten notes and translations also serve as an introduction to the next four chapters. Michael Finkelman completed the translations of the handwritten notes below and Marcel Tabtueau's handwritten notes on www.marceltabuteau.com. 
10 Wind critrole.

2: Toufore cnsidéges niptrumint enfine votx busiane.

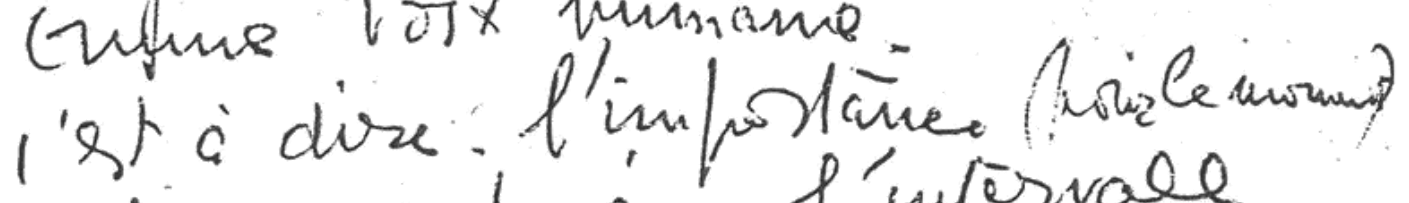
a dimerest é l'utervale

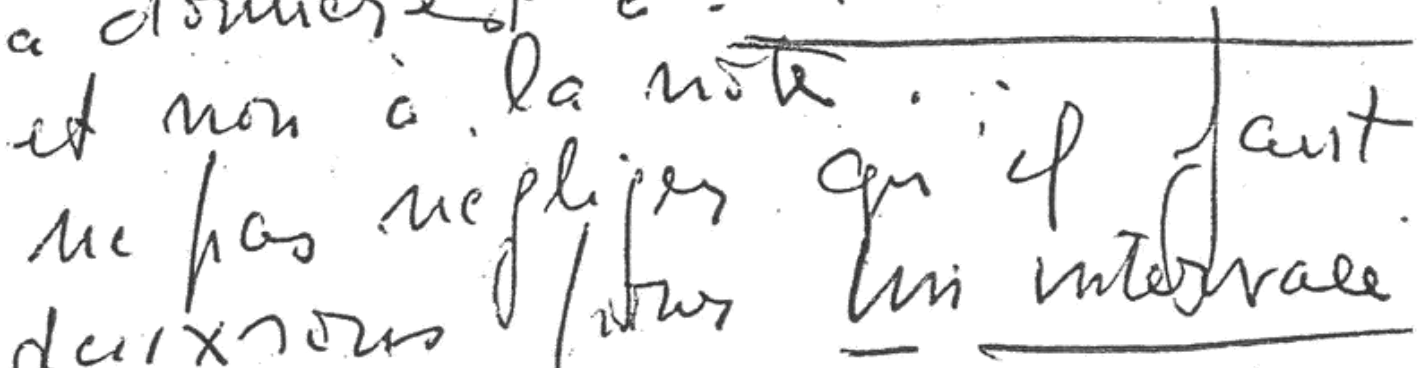

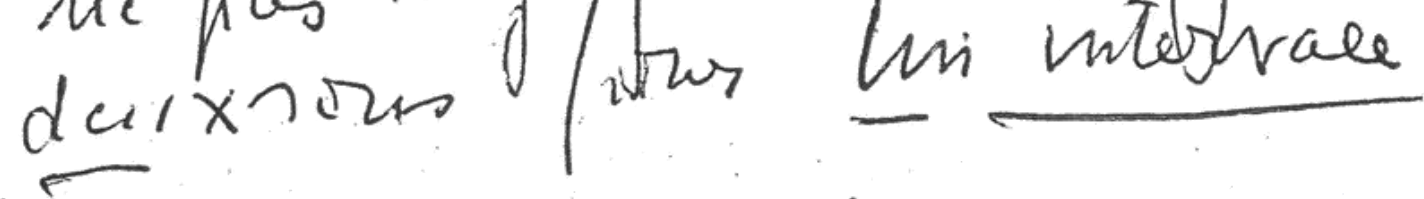
'S = coullar srisité pores vanior montrue son nit instrumentile is est ongère - de determines our une vite: differentes

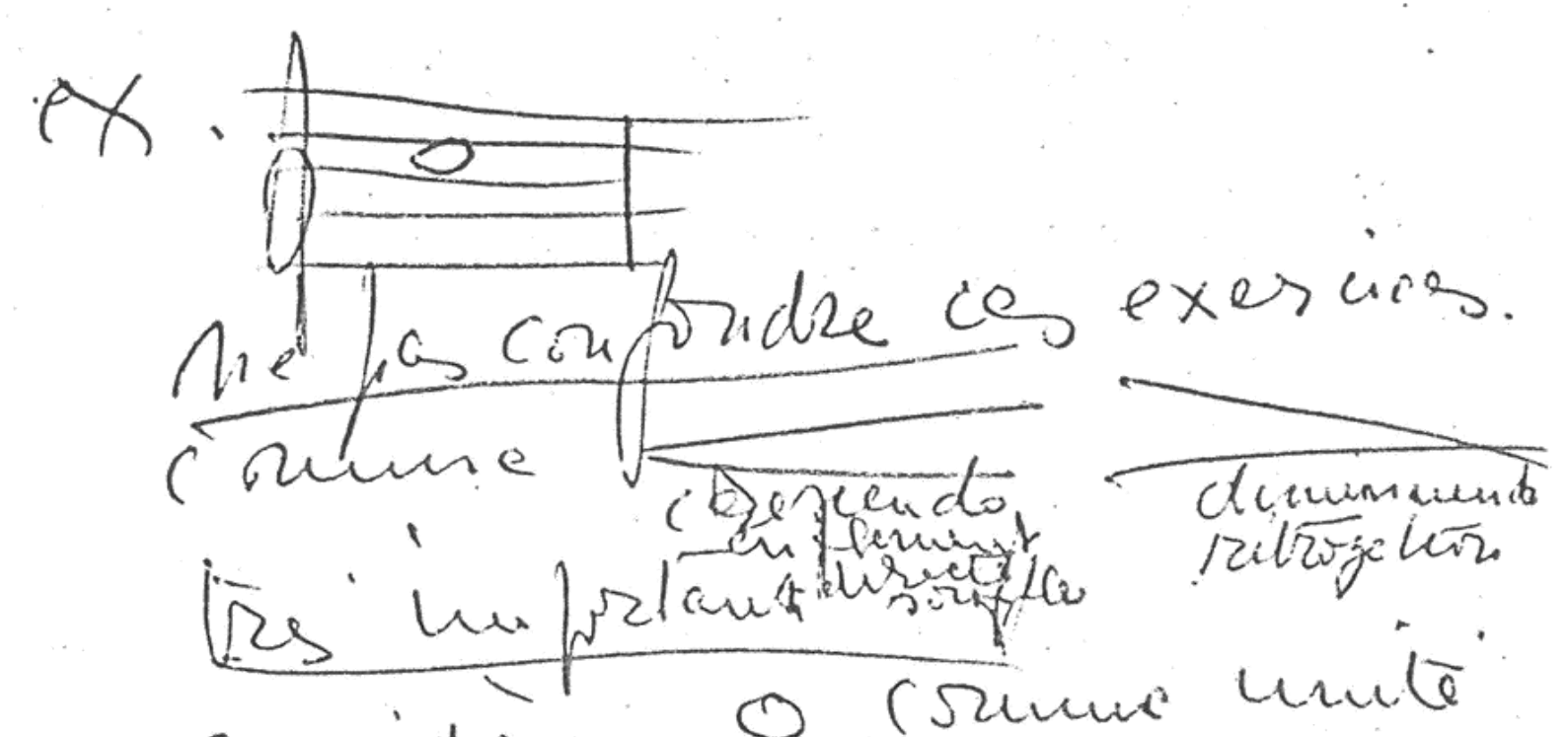
cpasideross O crimus unite siluce. 


\section{Translations of page 9:}

\section{Wind Control}

2. Always consider the instrument as a human voice; that is to say the importance is to be given (for the moment) to the interval and not to the note. Do not ignore that this applies to every interval.

3. Color / sonority: to conquer monotony in instrumental sonority, it is suggested to focus different colors on a single note. [i.e. give different colors to held notes to avoid monotony], for example [notated third-space $\mathrm{C}$ ]. Do not confuse these exercises with crescendo and diminuendo: very important in closing a direct breath that the effect is to unite silence. 


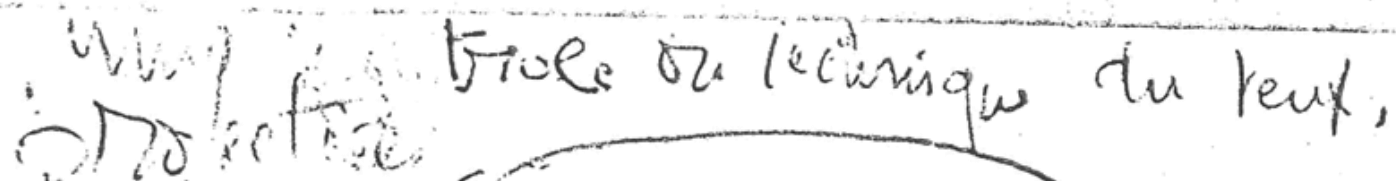
filviation kalew / by new notes. gatini: Waid and abos.

$$
\text { is piscatio }
$$

inn t. masta.

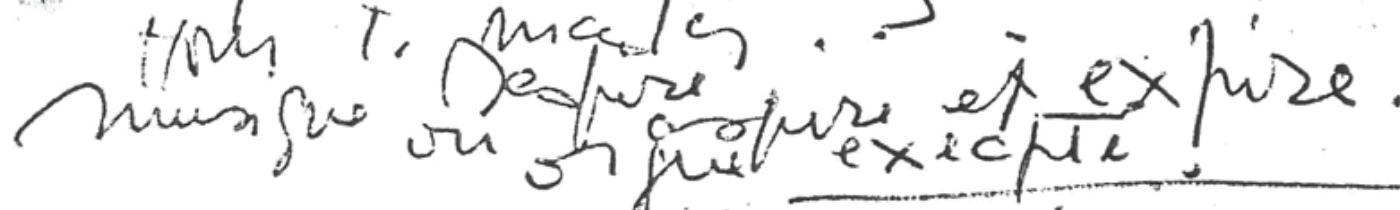
inflexion. punitutition. distribution

nowass = mitionimique

in ic apurant tos

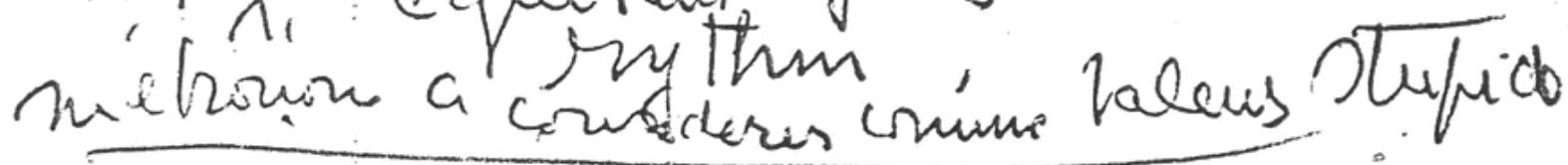
articulation.

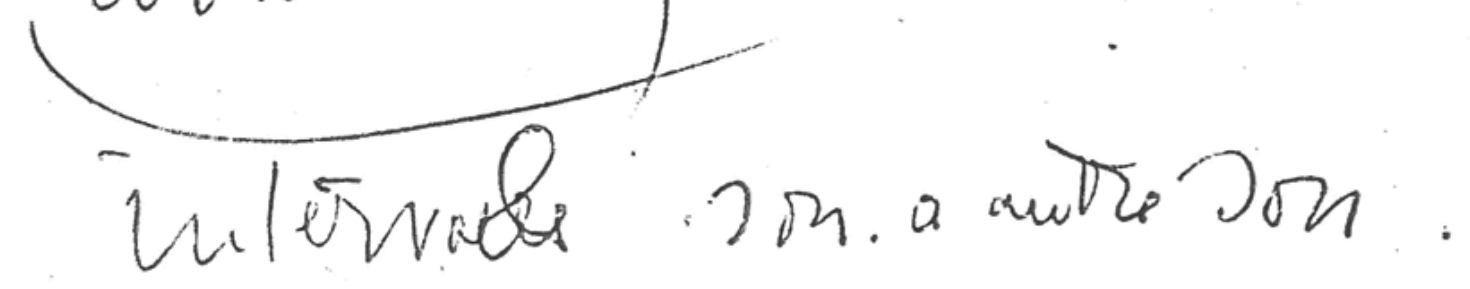

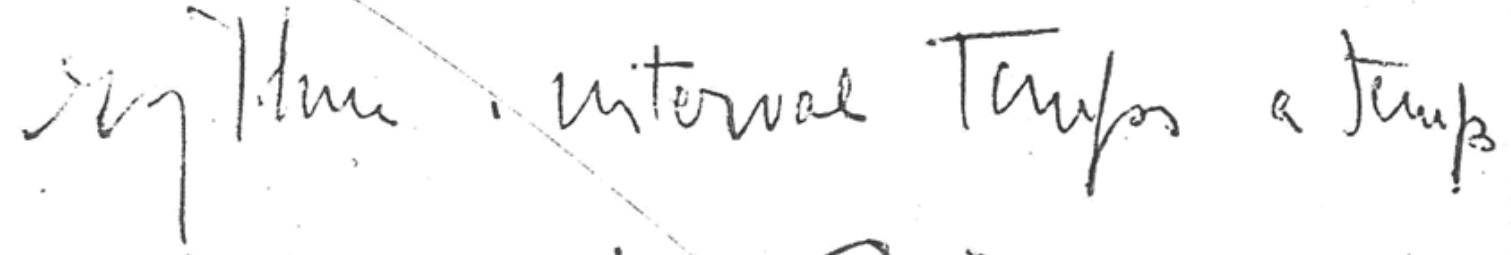
cuefritince chi $O<20$.

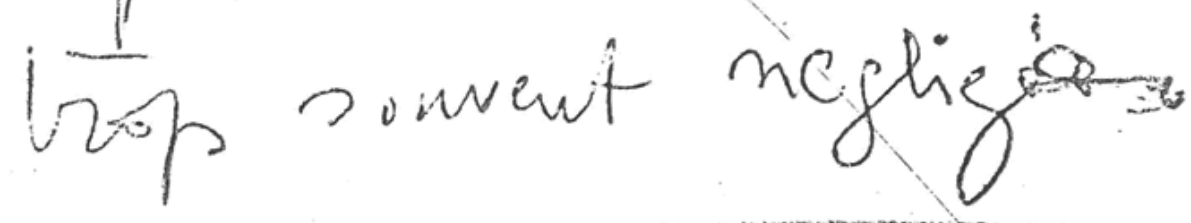

11 


\section{Translations of page 11:}

- Music breathes, or inhales and exhales.

- Inflection - Punctuation - Distribution [of the phrase]

- Precision $=$ the Metronome, not the equivalent of [musical] rhythm

- The metronome is to be considered a stupid value.

- $\quad$ Interval = one sound to another

- Rhythm = interval tempo to tempo

- The importance of zero [of silent punctuation] too often ignored [in these respects] 


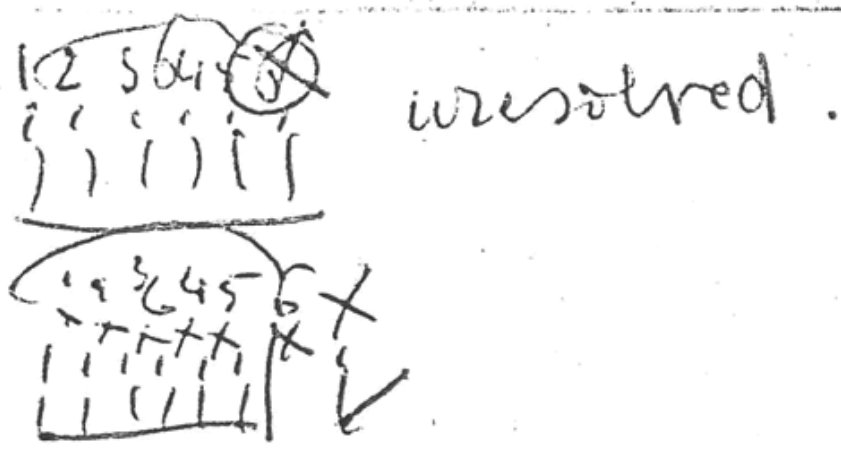

(rimancer.

Dis fruss on Mesolution

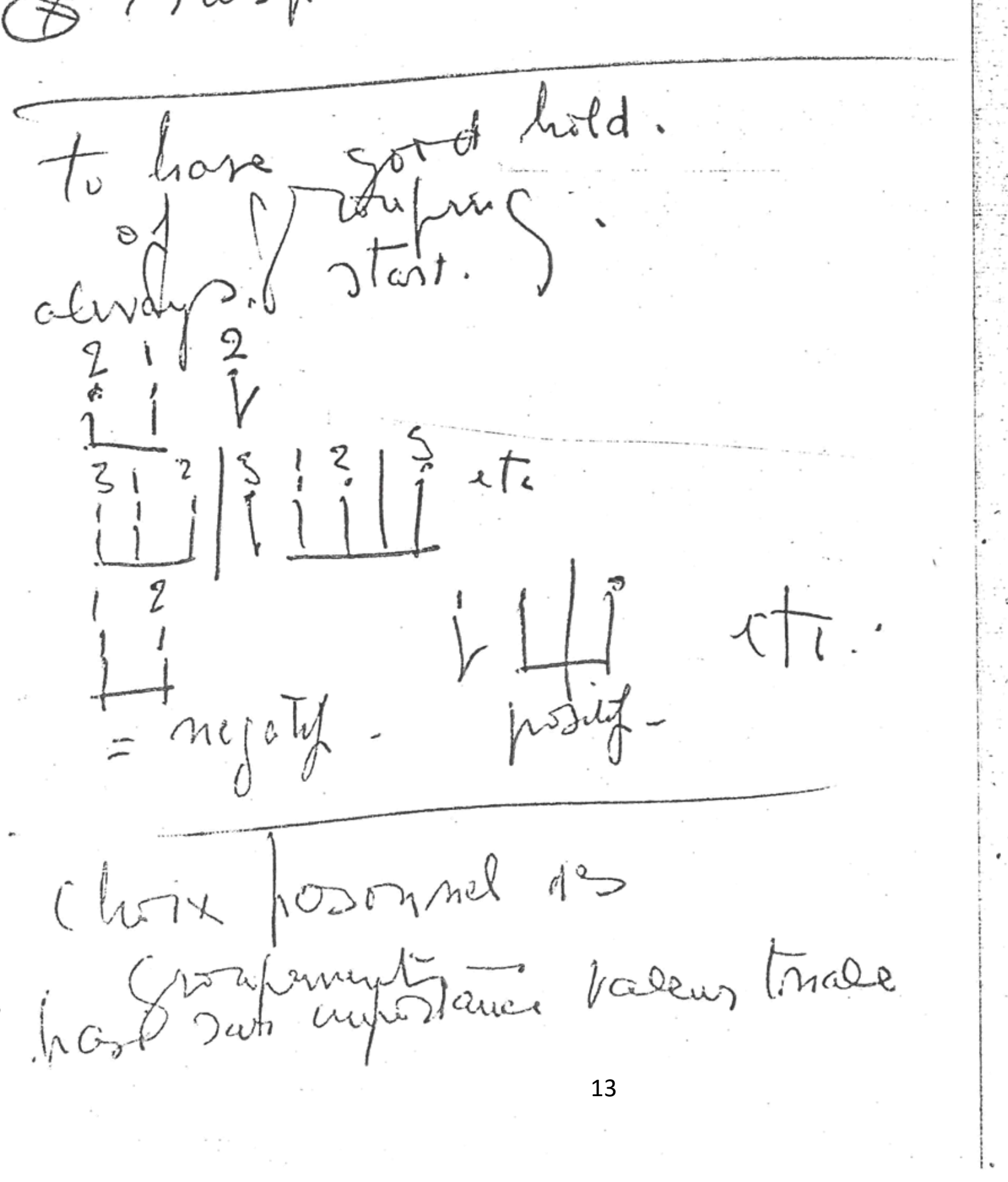




\section{Translations of page 13:}

- Unresolved suspension or resolution:

- To have good hold [control] over grouping, always start [examples given]/ negative - positive [ebb \& flow]

- Personal choice in grouping has its own importance in the final result. 


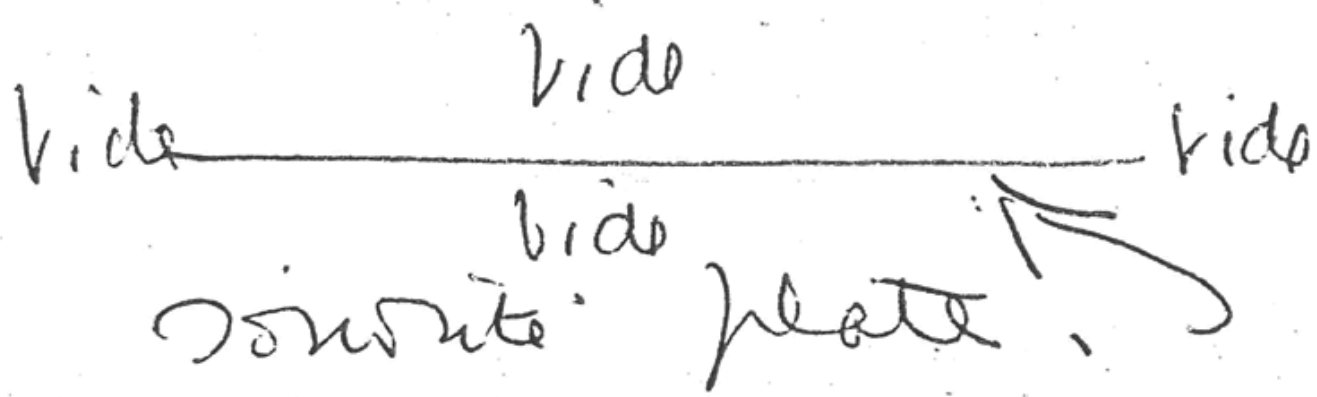

$$
\begin{aligned}
& \text { Mềne tripucur presenté }
\end{aligned}
$$
differennument.

Prnite
Réme,
qualite.

Désumi, pensef ligique it hean la prefterin me fient mangion d'on itre isficter.

ergat

jetrmo opleine d ofiecation.

1200 de la nite, ingutitimat

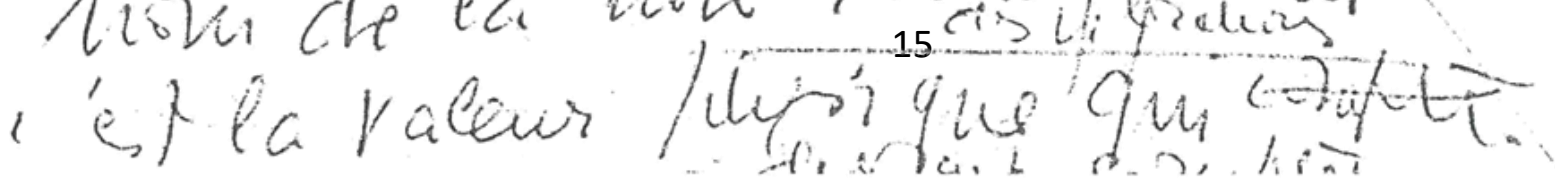




\section{Translations of page 15:}

- Empty-empty-empty-empty (north-east-south-west)

- Sonority: even long-held notes can be presented differently.

- In sum: think logically and beautifully that the [sound] projection does not lack affect [i.e., emotional impact]. See Jean-Jacques Rousseau on articulation.

- The actual note [name] does not matter, it's the value [of same that does]. 


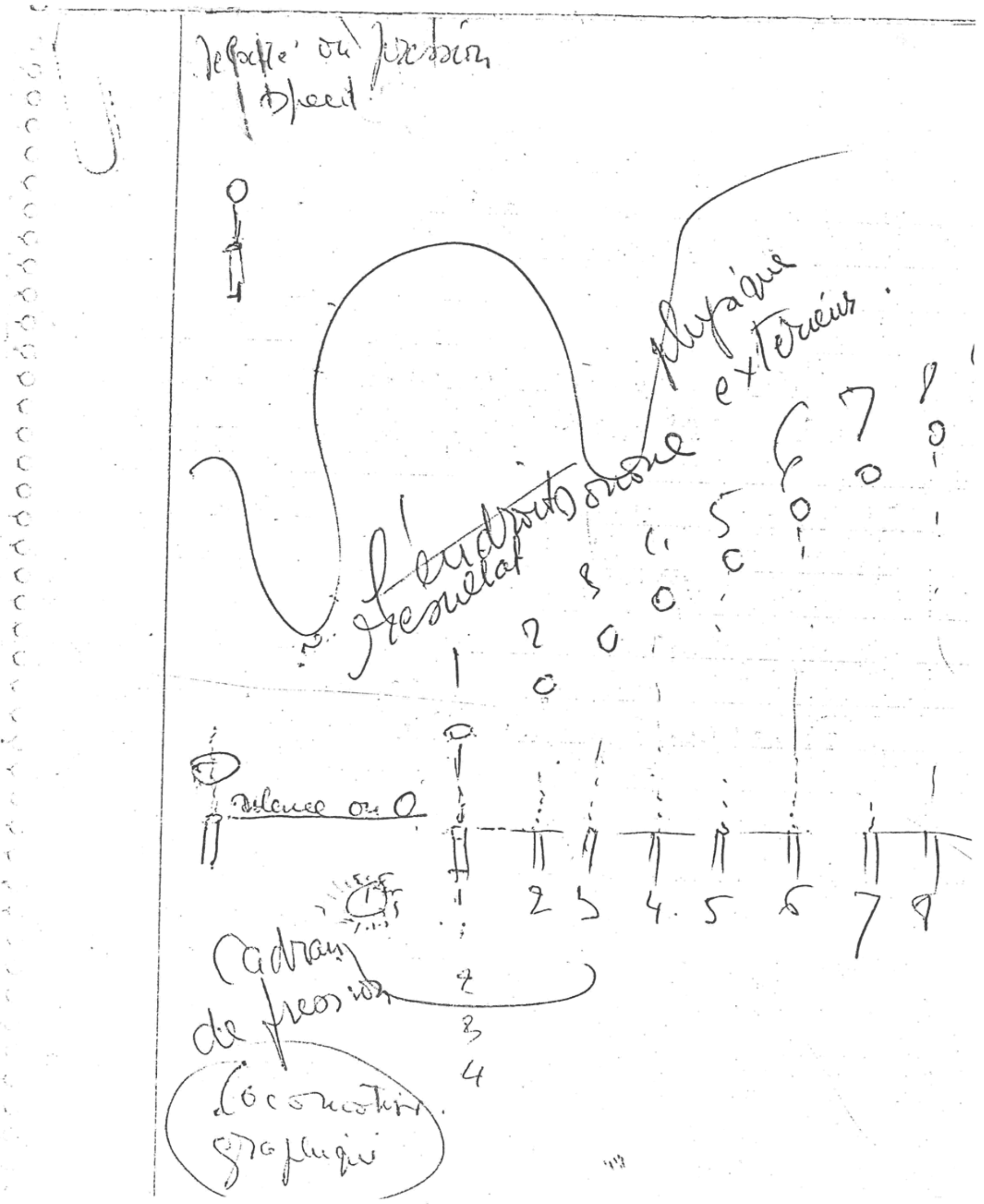

17 
in

Lar on cestrumatistras.

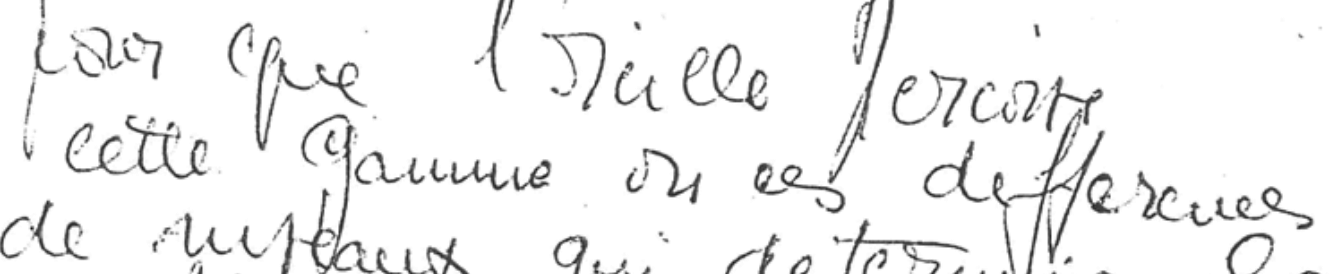

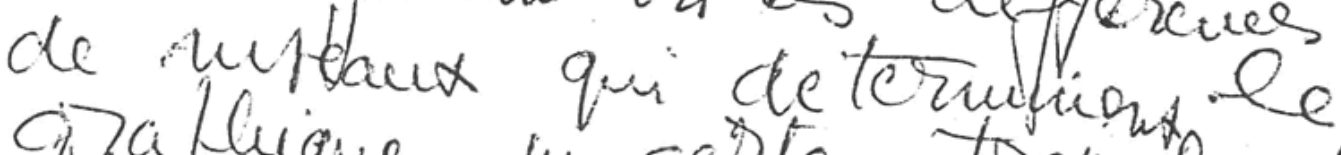

graflique me certan tratail doid

o accomflir rofon oi ex commox

wacouse ewnent or, aree elerelure

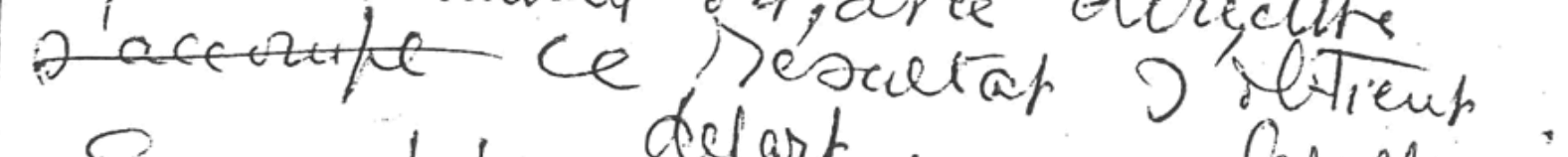

A a fresentefart deajel -

centy de lóphariol plito

revers ruedaide.

Pobvit d cau ix

Saflin, auto mateus échele frosutälior.

18 


\section{Translations of page 18:}

- In order that the ear hears from an instrument this scale or these differences in the particulars that determine these graphics (pg. 6) some work needs to be done. See where and how unconsciously and yet how direct the result [is]. 


\section{Translations of page 20:}

- Subdivisions to the infinite. Talent, value and quotation [from Andre Caplet?]

- Similarity between the technique of wind instruments and those of the strings. \{Here as elsewhere, Tab seems to be briefly reviewing something he must have gone over orally in detail with the student.\} 


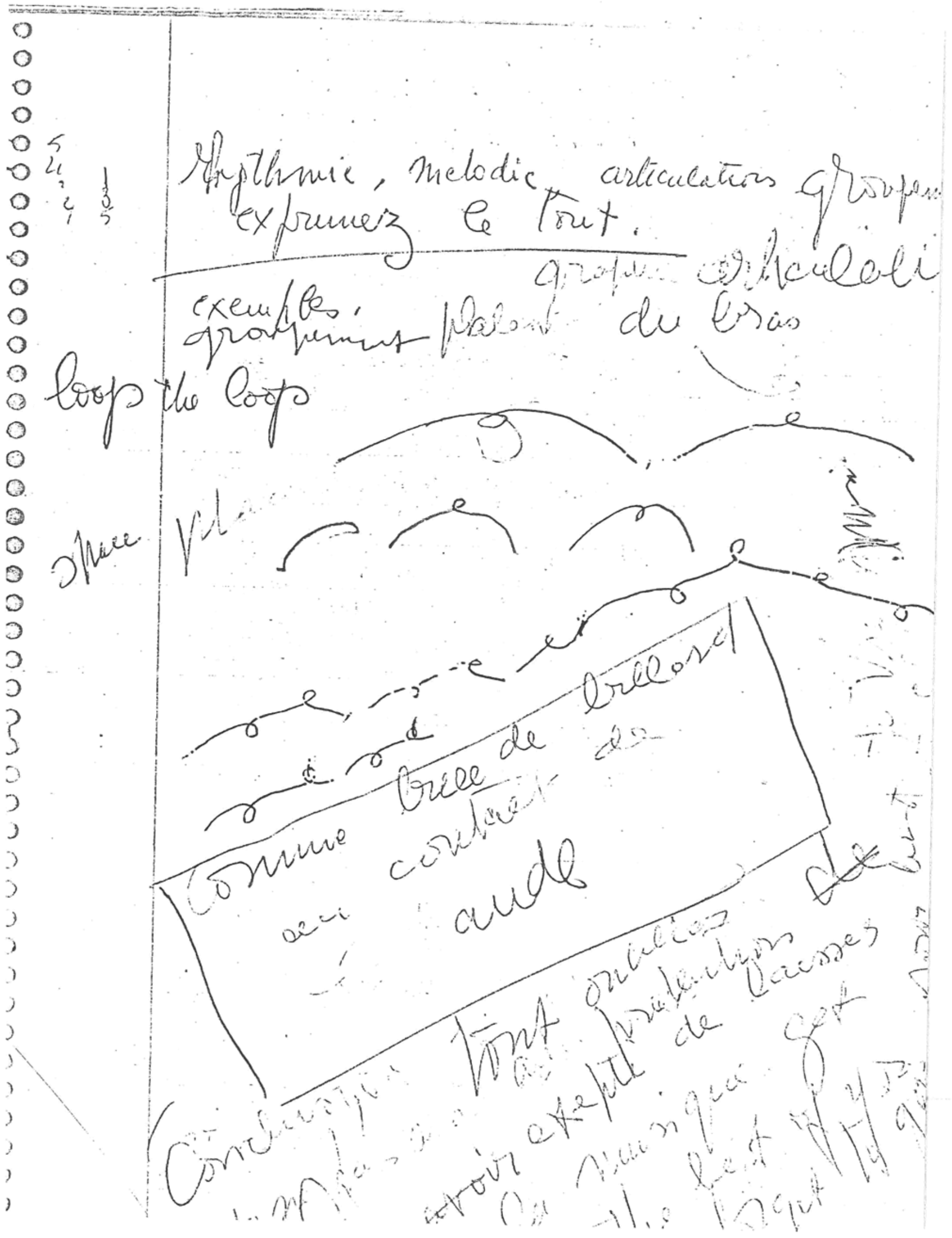

22 
Translations of page 22:

- Rhythmic, melodic and articulated groupings express everything.

- Example: articulated grouping making a "loop-the-loop" (with illustrations) 


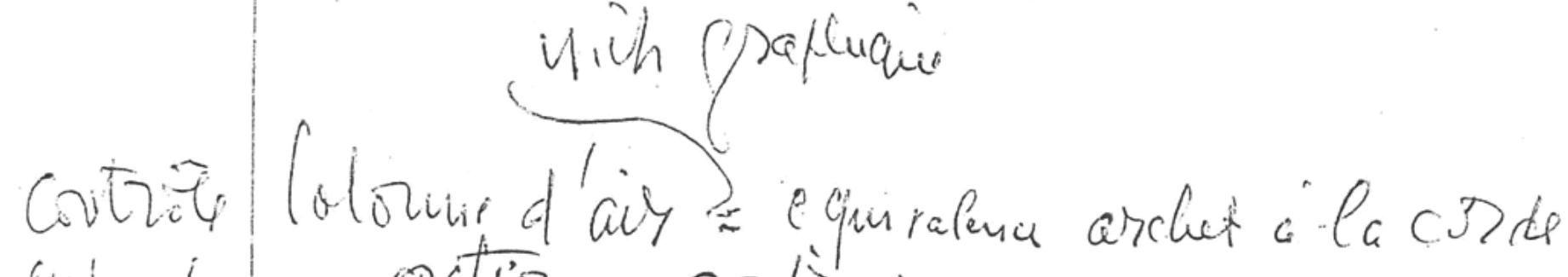
muinhiz" action. coultavo.

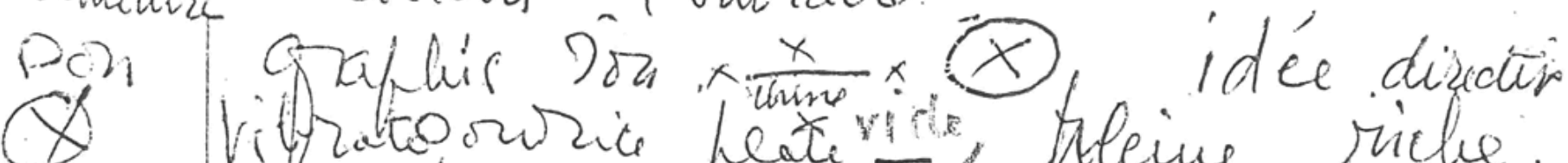

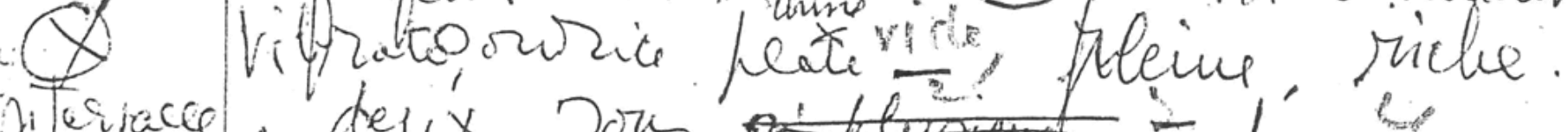
articuiation difléreucs.

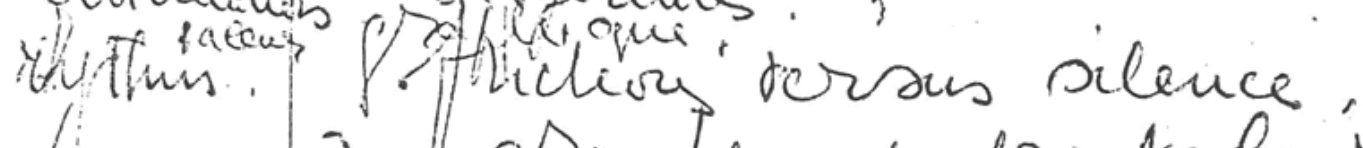

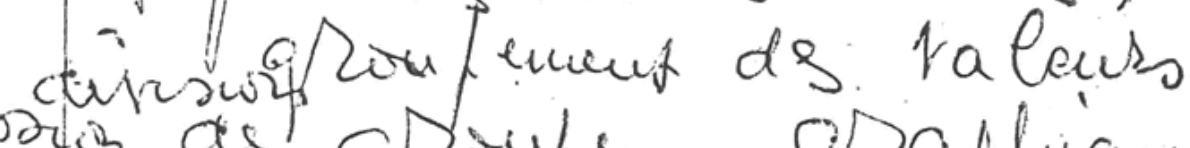

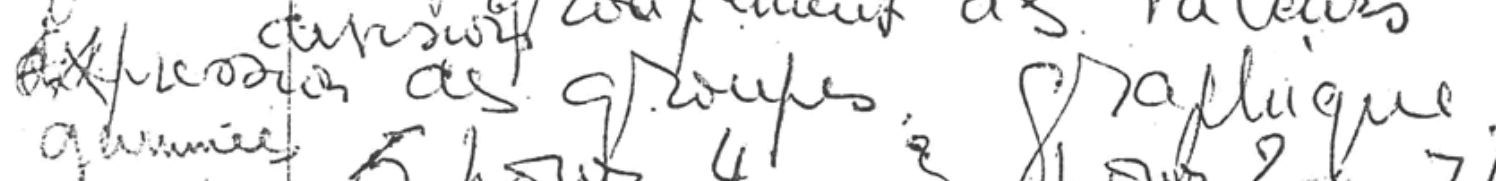

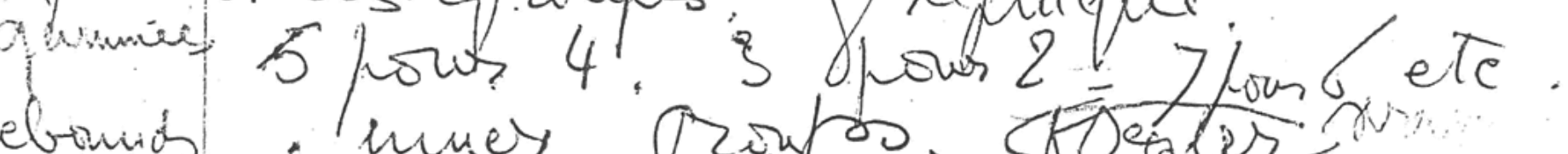

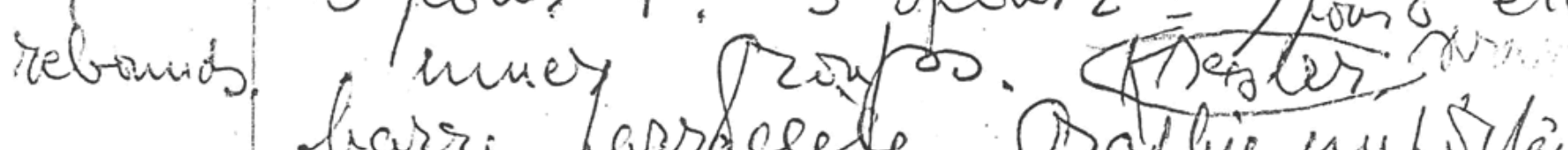

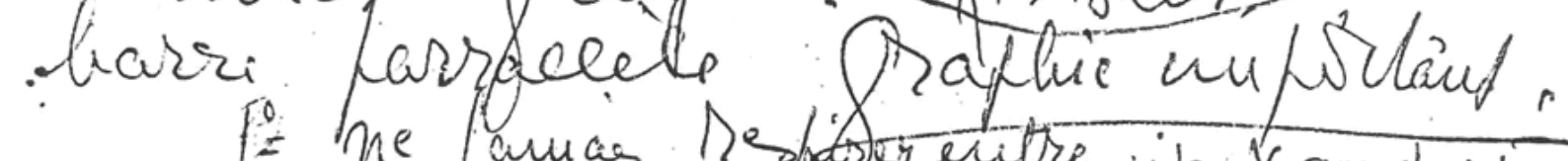

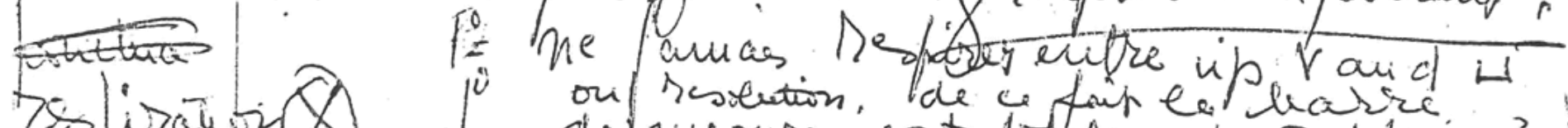

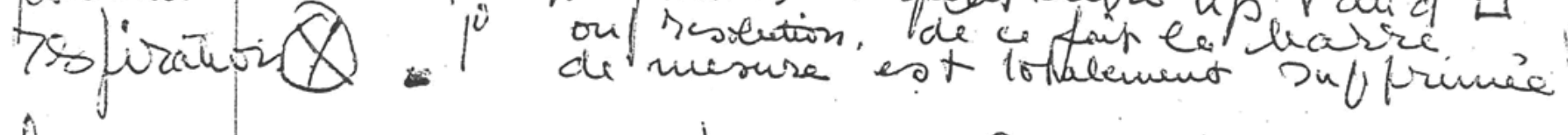
lerrenisuze, Oa oufpression?

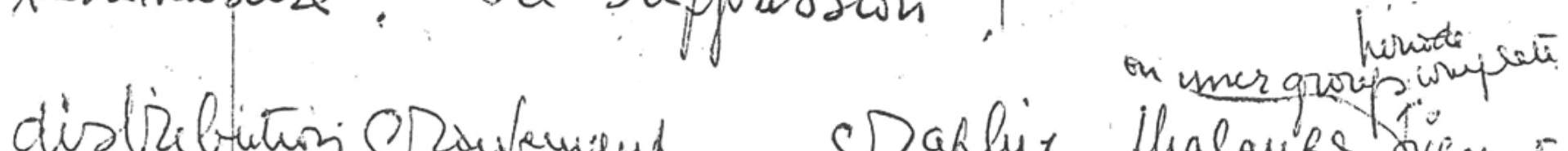

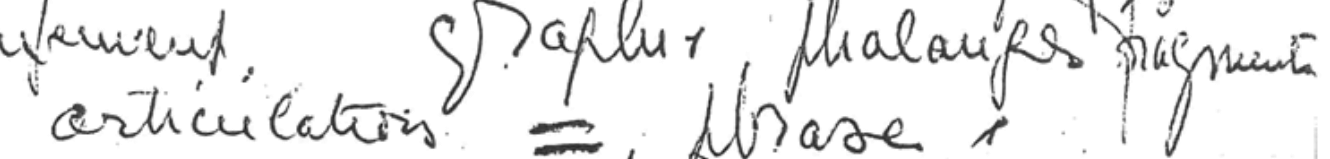
articulation $=$ flrase

Ainitiation, hasies $x$ da.

vifexion, alfirmatip, "vérorofater Eovaliti Midulation, Juspenses Dosolutioss.

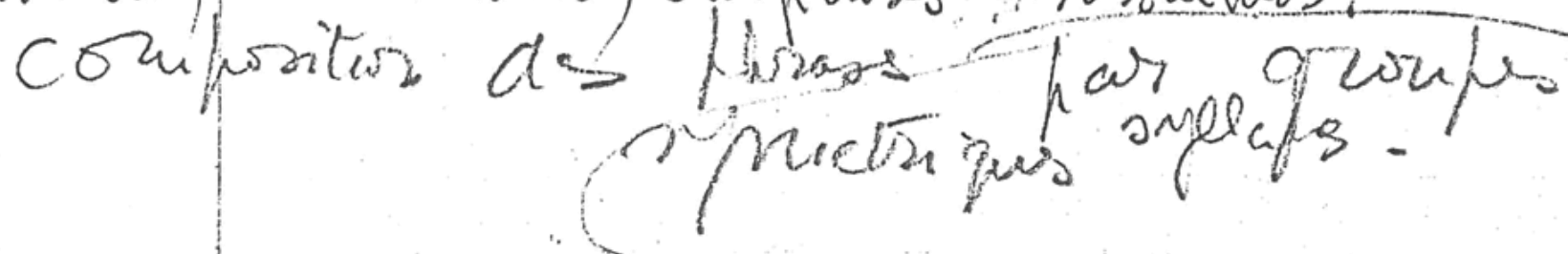




\section{Translations of page 24:}

- Control of the air column = the balance of the bow on the string. [Examples of contrasts in the way this may be used, again a review of what undoubtedly was gone over in much greater detail previously, orally.]

- Inflection - affirmative - interrogative - tonality - modulations - suspensions resolutions - composition of phrases by groups: all things musicians must pay attention to. 
divit sims, friel

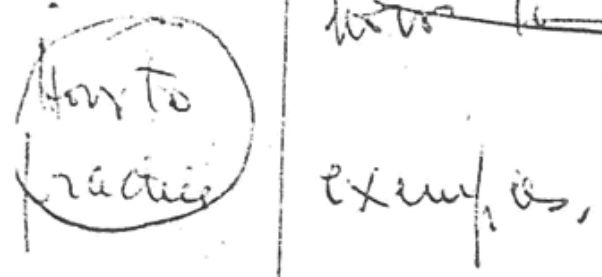

Yhucip

onledit.

ielocite ioloune d'ais.

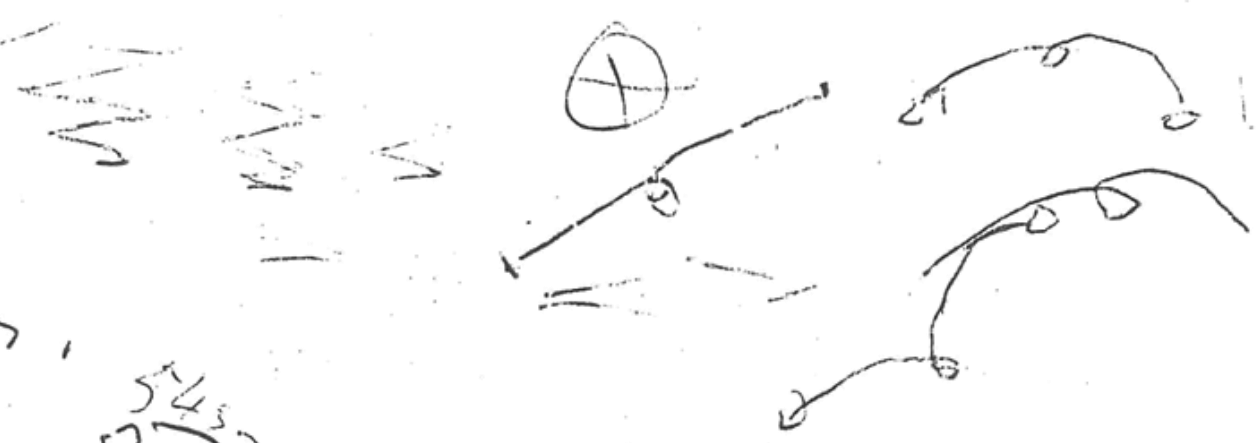

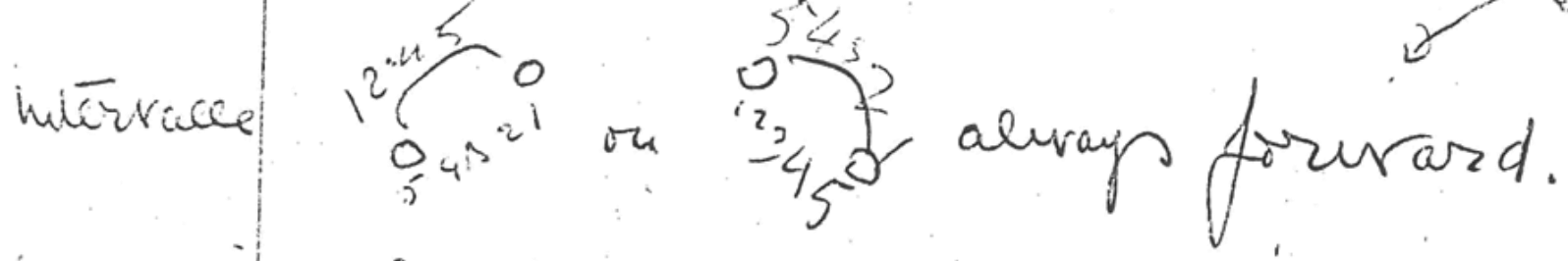

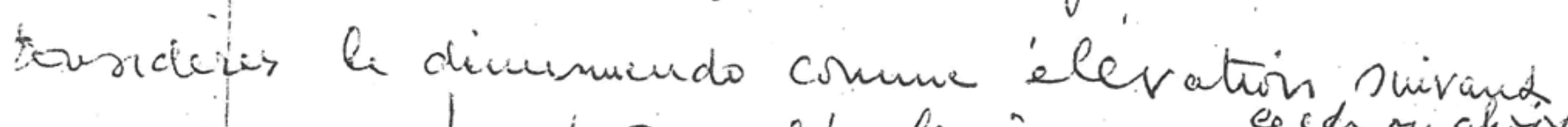
has es our l'uflexion.

ee ids ou choix
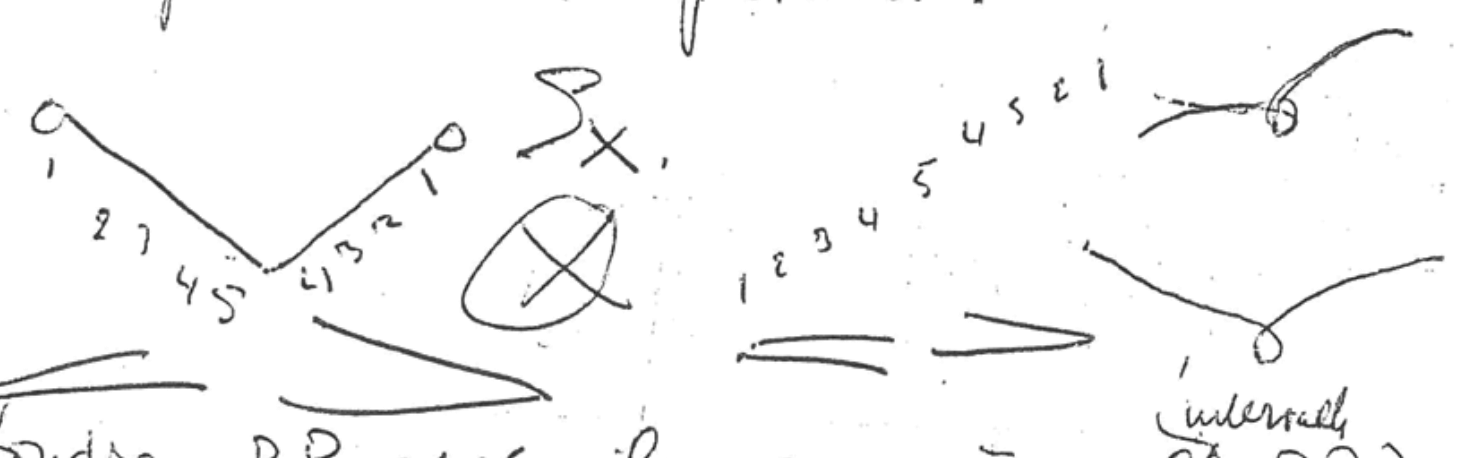

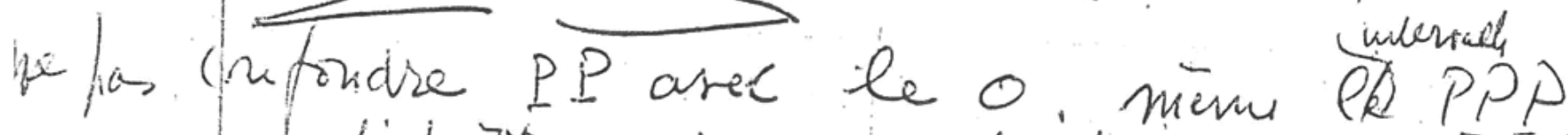

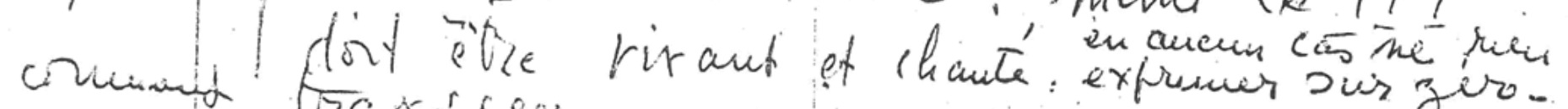
deteinion trasacees:

deterniones le traces or gotz de P'arabesque

D Dur la colorne d'ais auss lérfsession ow une ds nots de lo fhras los quie cetur fritasation termunée. "eliafifute

26 


\section{Translations of page 26 :}

- Rebound: like a billiard ball (bouncing off a bumper)

- Consider a diminuendo as the raising [of a foot] after taking a step (upon the inflection). \{diagrams\}

- Don't confuse pianissimo with [zero], not even the pianississimo. These have to be lively and singing. In no case is there any expression at zero.

- Determine the shape of the arabesque fully to encompass it to its end, and tailor your phrasing to that objective. 


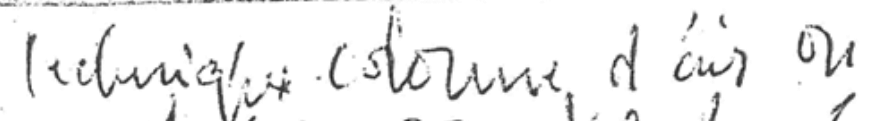
(Afunce d lav or lent 1 ) unstrunenc a lentialfirmque de et e'equivalent na larchit four les unstrumants a c r de.

infomite adreisils di l'uxhed les go ca 40 cutt. dín 1, it vient del'orichet Jin (D)des dorimte arantogenses du fait puels decerument wne vie = intale exhale.

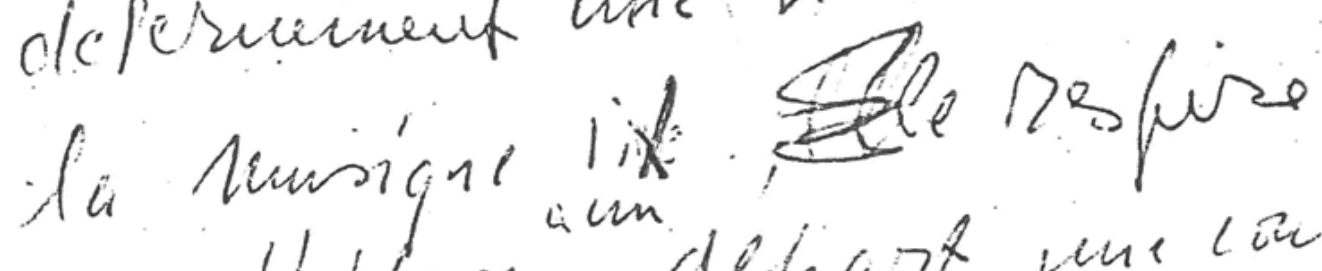

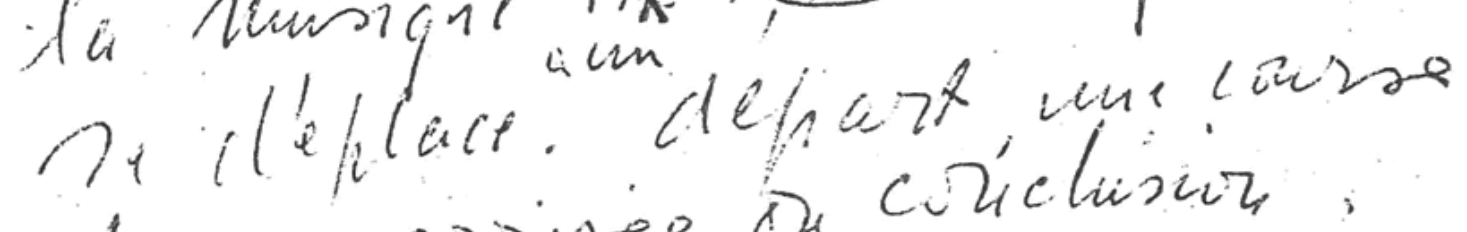
et une arrise on conclision.

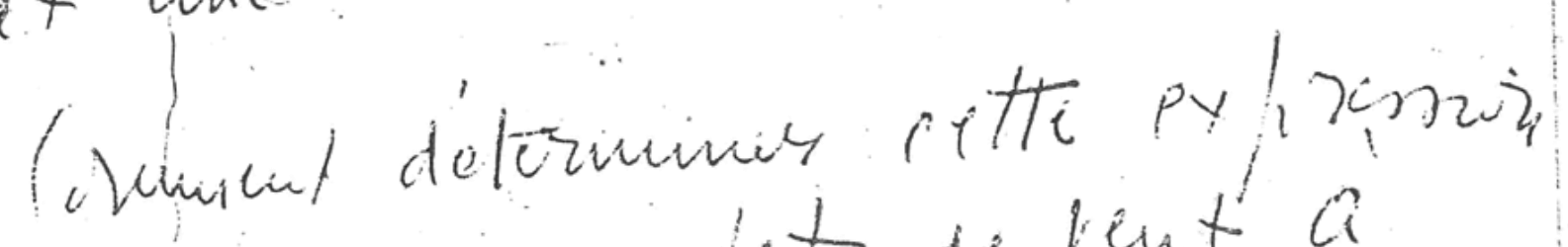
de lie swim fet de lent a decarique, an remir aloof

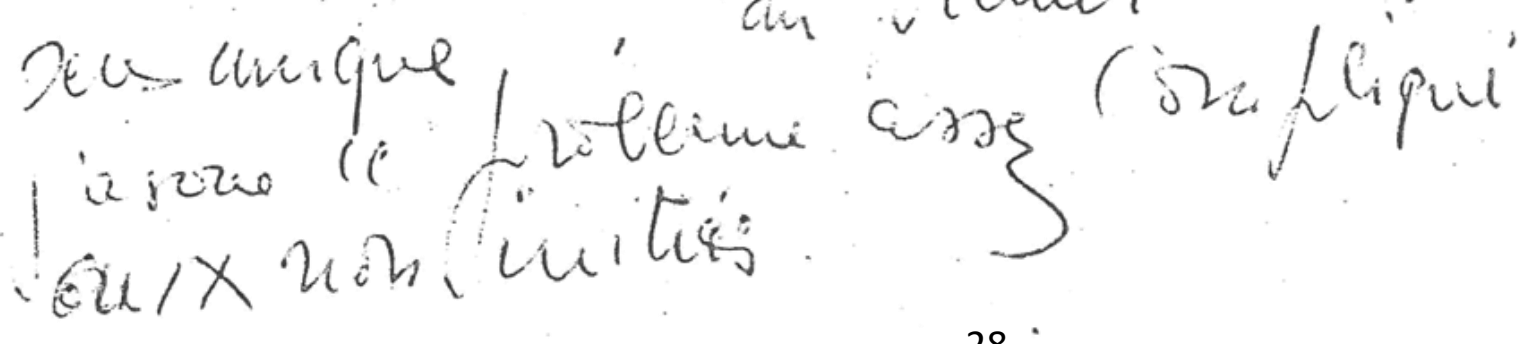

$28^{\circ}$ 


\section{Translations of page 28:}

- The techniques of the wind and string instruments are equivalent in these objectives. \{rest of page is very disjointed elaboration of same, basically saying that music has a breath and a life and life has a propulsion from beginning to end.\} 


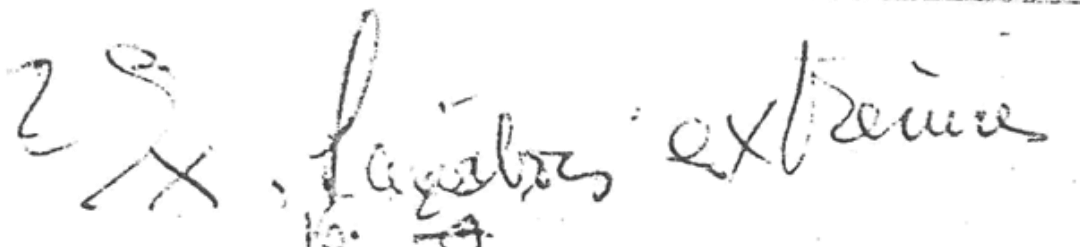

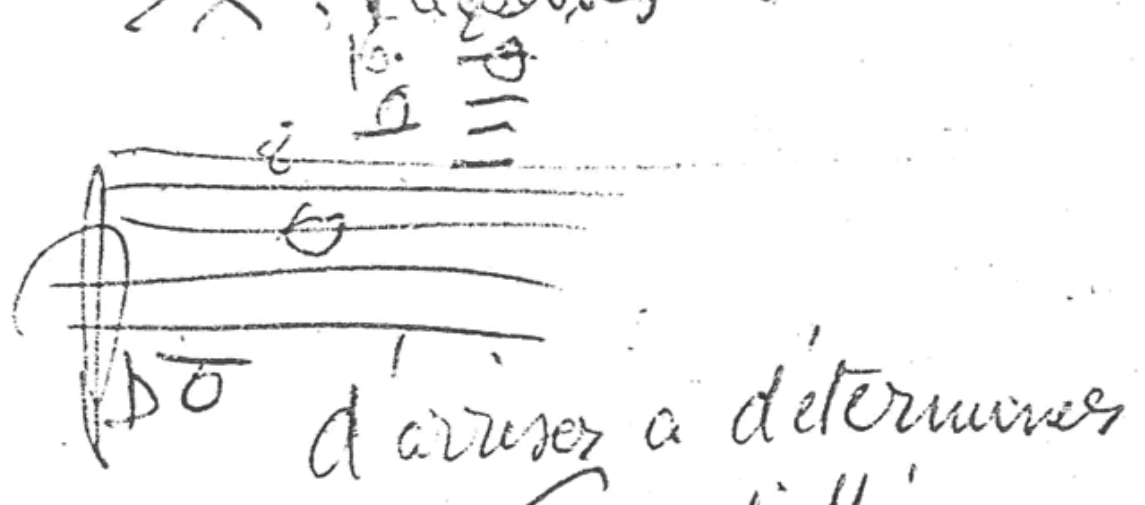

20 differen

ryeditions surcue ats nites.

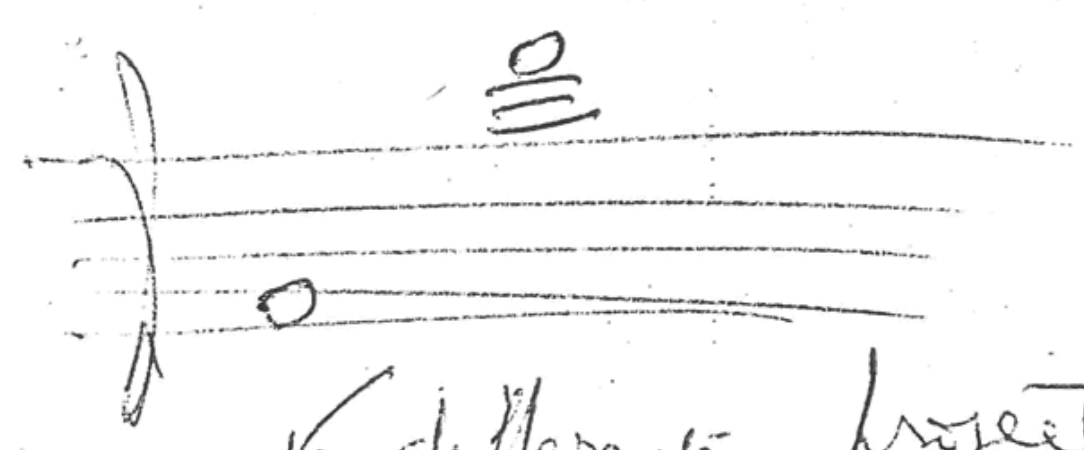

Tdeforate prjeztions

our une des wots

dir iefistre Raismable

aps prelques mir délads

afpliques, l'abir do hendic

contre tur hay abtem $e_{0}$

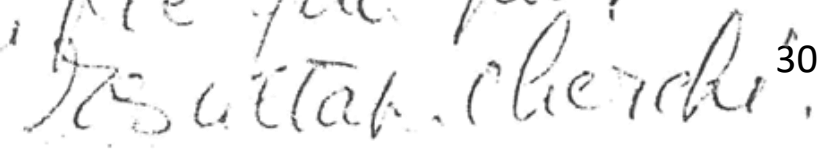




\section{Translations of page 30 :}

- $\quad$ regarding practicing the oboe from low to high $F$, each note of which has to be practiced fully until a full range of timbral projection can be obtained on each.\}

- 16 different projections [timbres, etc.] on each note throughout the reasonable range of the instrument. After several months of study in refining this work, the student will become aware of what is needed to achieve the sought-for results. 
2i un lastres di princile que

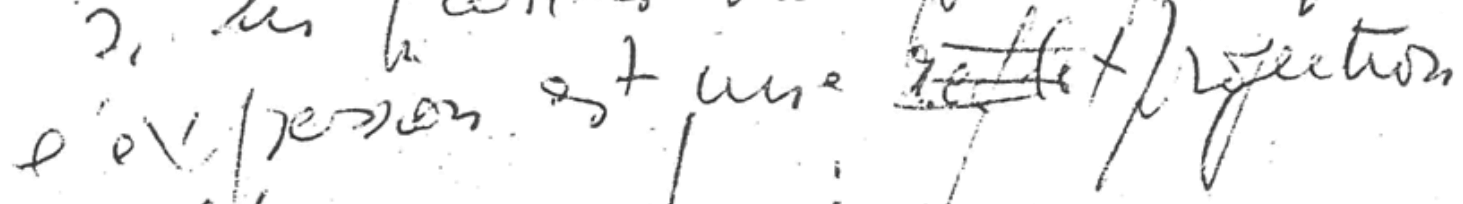
de $f^{\prime \prime}$ dée $=$ on finvie.

inevore por eximble

$\mathrm{cm} \operatorname{deu} x \operatorname{ten}$ frs $=\frac{2}{4}$

cinndoros on unalyols tiry

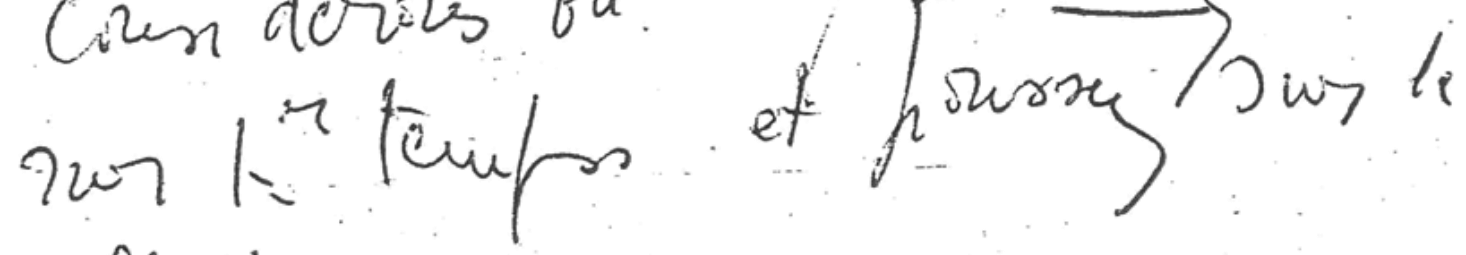
elux ete i $V \pi$ V $\Pi$

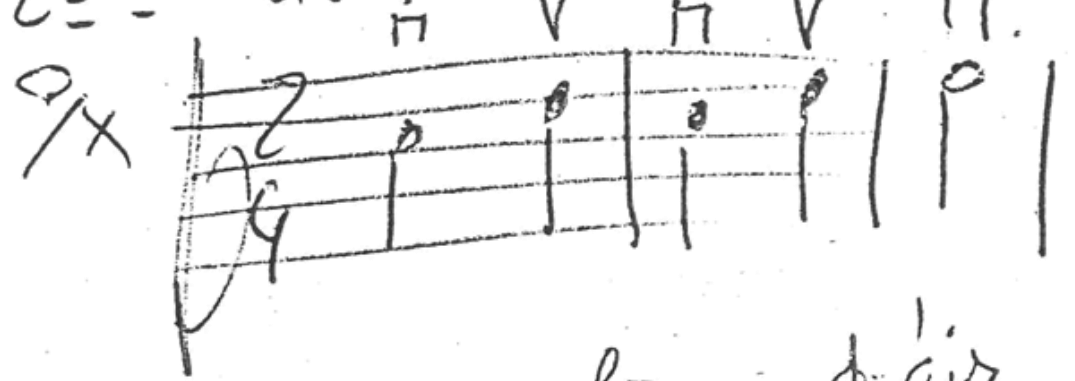

le tent on come diar ra

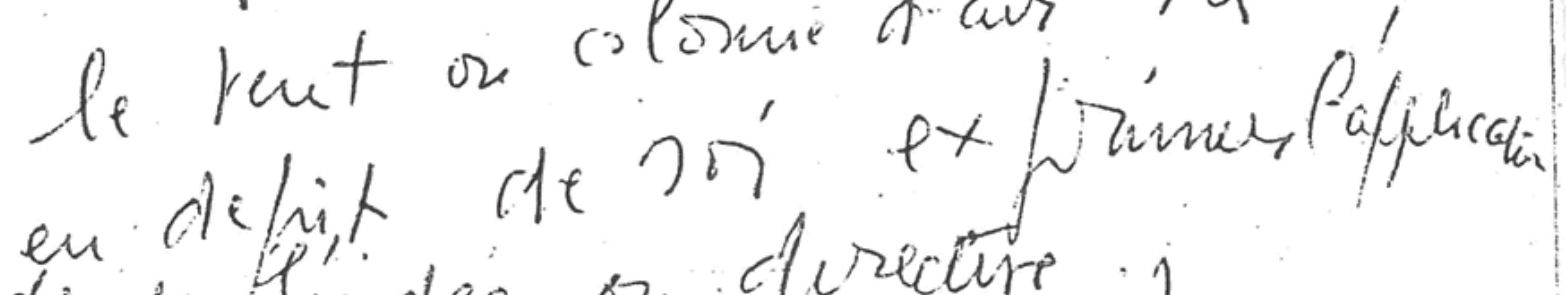
on dtye idce on equectire i

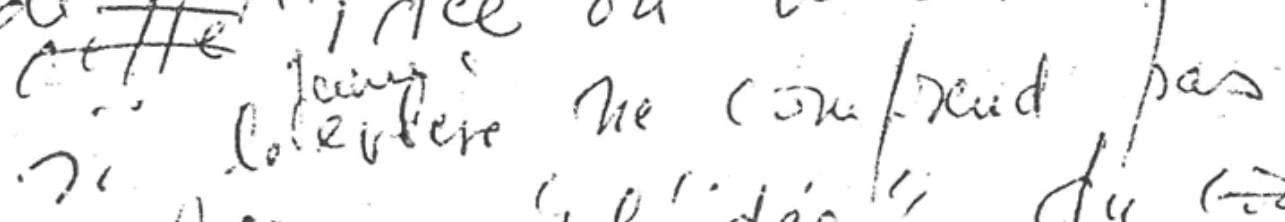
+xlequirs "lidée" dir tato Martear Jur un olyet.

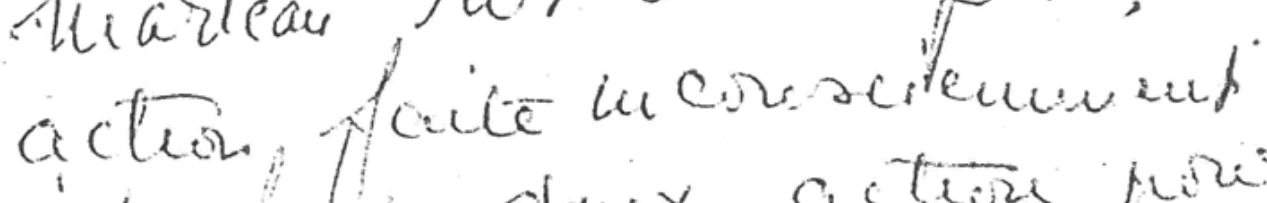
1 cant deax acters puris

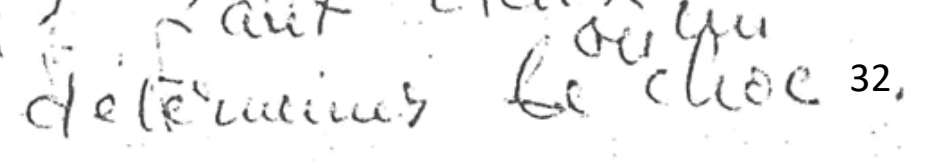




\section{Translations of page 32:}

- The art of expression is a projection [in performance] of the idea or thought [of the composer]. For example, in duple (2/4) time, pull on the first beat and push on the second (with illustrations).

- The wind or air column must, in spite of itself, express the application or directive. \{I think he means that unlike bowing, the air column is being constantly depleted, but must nevertheless be directed toward expressing the composer's idea.\}

- The young student must not allow himself to "hammer" the idea. It must all be done unconsciously: the two actions [push and pull] to achieve the [needed result]. 
Aloubrax les curienx ex

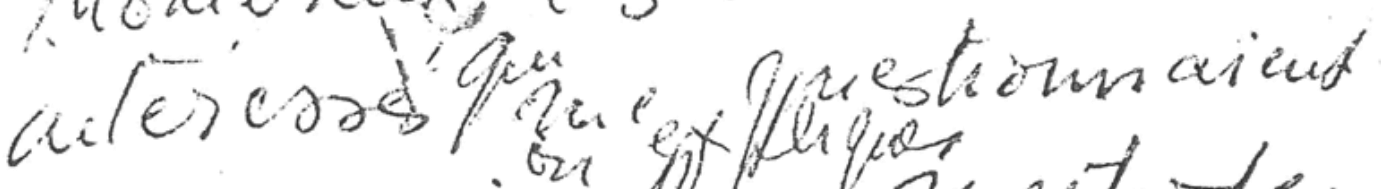
kas Darits the nuectiode eruployer fow totens u. itbato daus la Dorysité. clas is en barasse pos keus druios satisfaction puesque le tibsato de rochupaid natwreeleyment en aph'puant ta exprivithy siques de l'aubin. chure et la kelocite detome d'ais tque le xy etas.

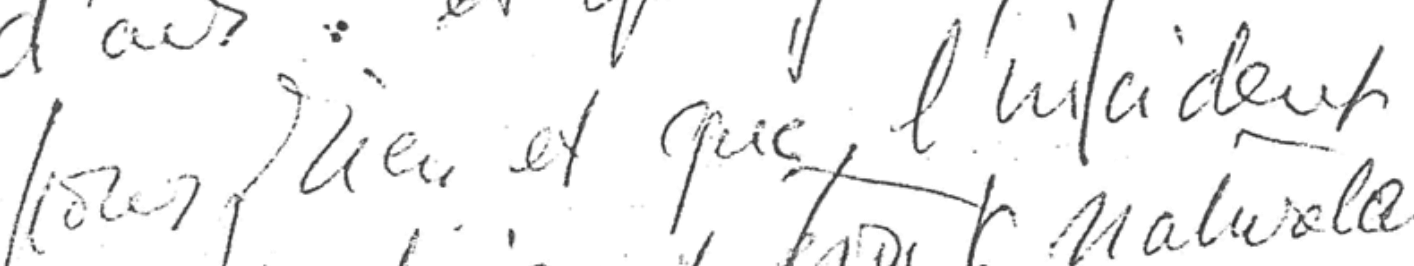

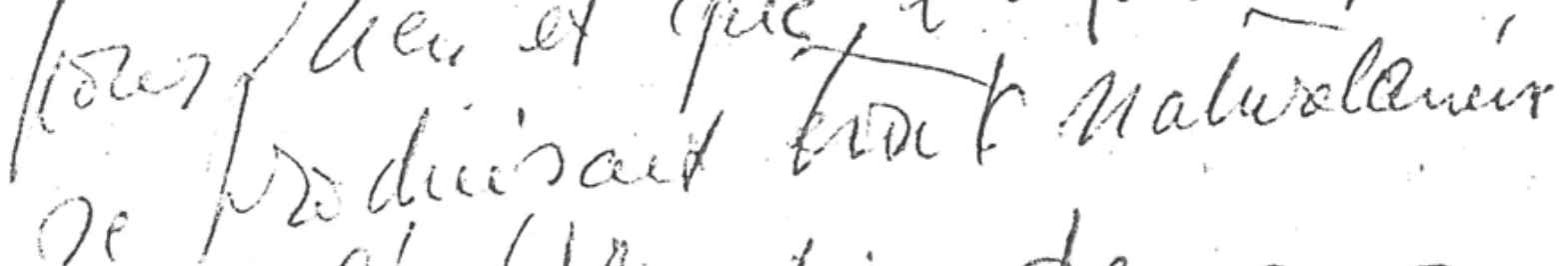
or éafflicalion de r. lideé.

34 


\section{Translations of page 34:}

- I've had many and curious questions relating to how I obtain a vibrato in the sound. I've had some embarrassment in attempting to satisfy these people, as the vibrato is produced in applying the physical pressure of the embouchure and the speed of the air column. I was never able to [interpret] the way these matters [combined] in a natural way [to produce the needed effect]. 
than lia Nicite coloun diais ot laible flus l'enbrachure otút teuse

Ex yir que t'deille on (indinurat enregastras ?) porotie. Une qaunue de crecurs sion me seub note.

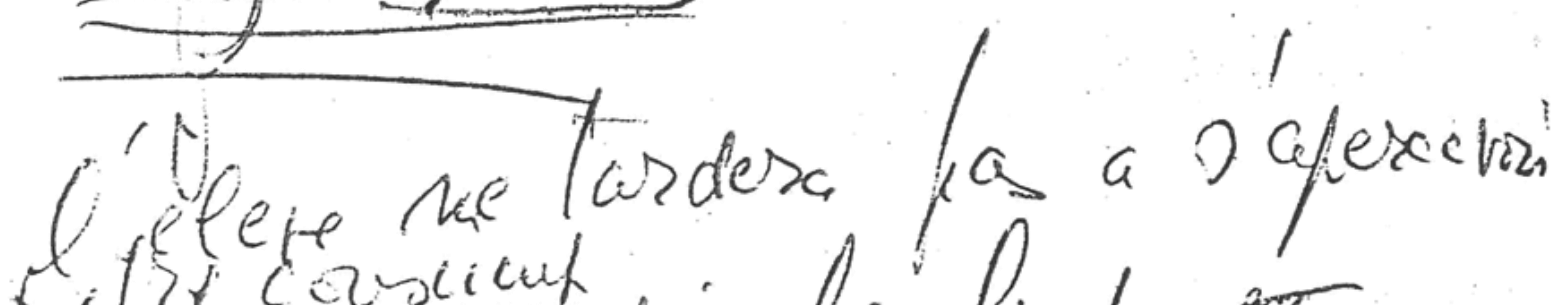

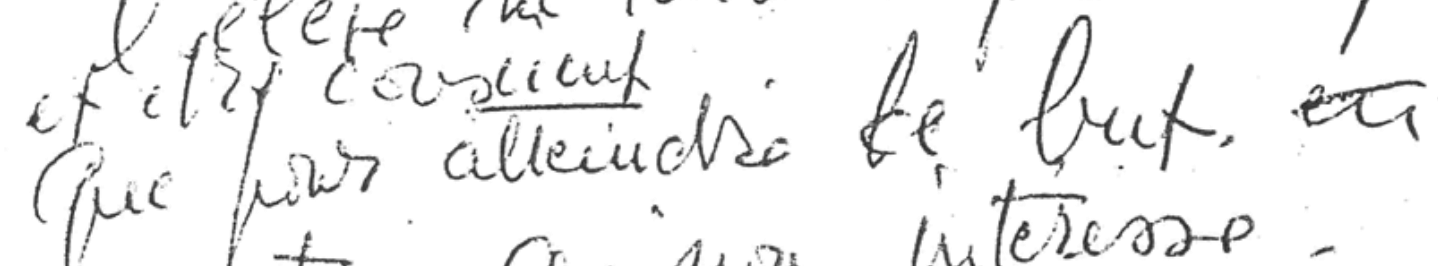

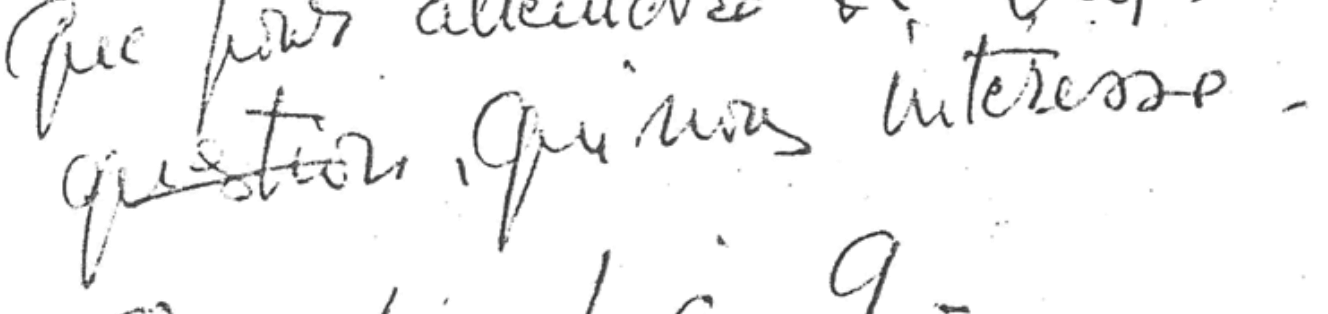

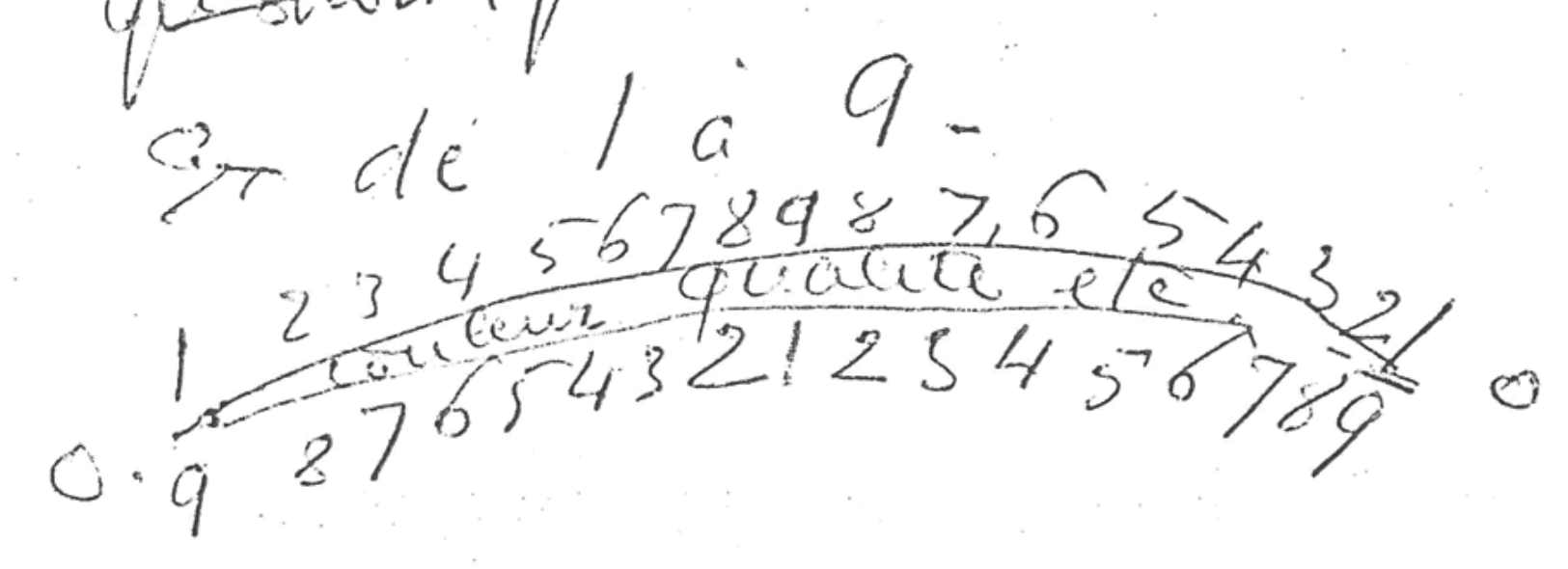

36 


\section{Translations of page 36:}

- The embouchure by itself is worthless without [being used in conjunction] with the speed of the air column.

- For the ear or the recording machine, a whole gamut of colors must be able to be produced on a single note.

- The student must not delay in making himself aware and being conscious that in order to reach the objective that interests us, the 1 through 9 [diagram, including color and character.] 
destibutionsor

la hes dance equivant. a la dabilite d' l'avion qui est déruit borsqu'l sicucontre me resistance defferente on air podset.

lection que alsis a extramas 9 Tauds lifors a pow conds Dol a d asclet on coloune d ais trows vestruments a teut.

38 


\section{Translations of page 38:}

- The distribution of the resistance [in the wind column] is equivalent to the stability of an aircraft if it encounters some [unequal] resistance or an air pocket.

- The technique of the stringed instruments via the bow in expressing the long line [must be achieved similarly] by the wind instruments via the air column. 
Pin d air

now bily coufrandse of - clubiliation

$\rightarrow$ Llawiakor du fet =

* déflecenciris volume

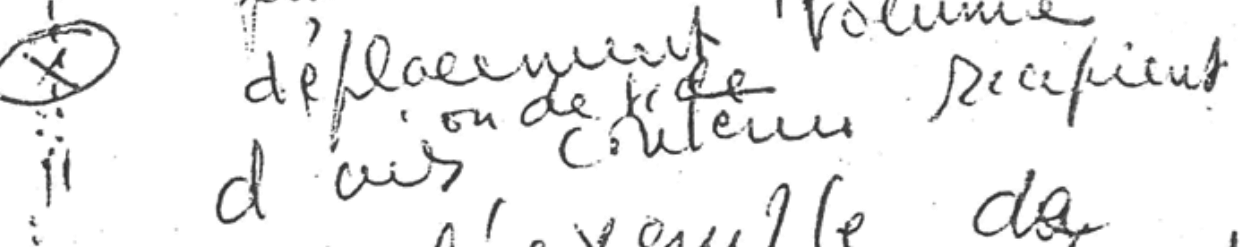
à l'exemple da ea, coquices d ourt an lause ous le fot d ean ds

tors fir anving cequicu en notes Drit places our la clome d'air.

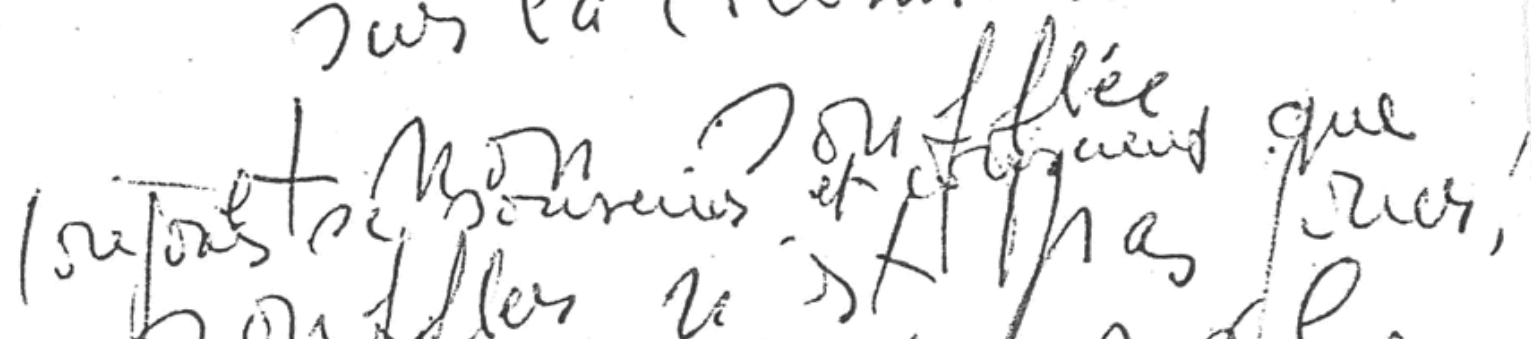

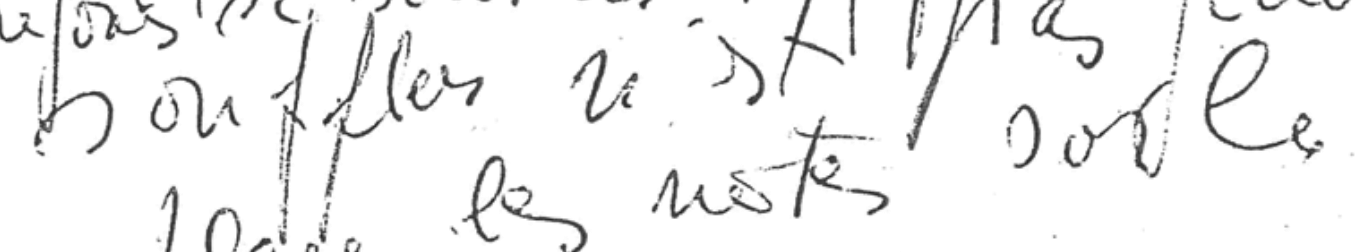
or place lo moks ot ruon

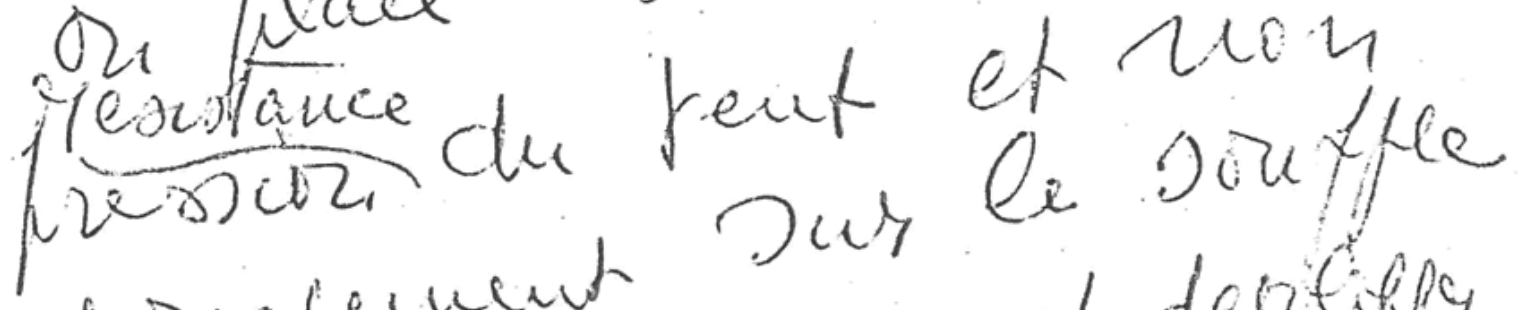

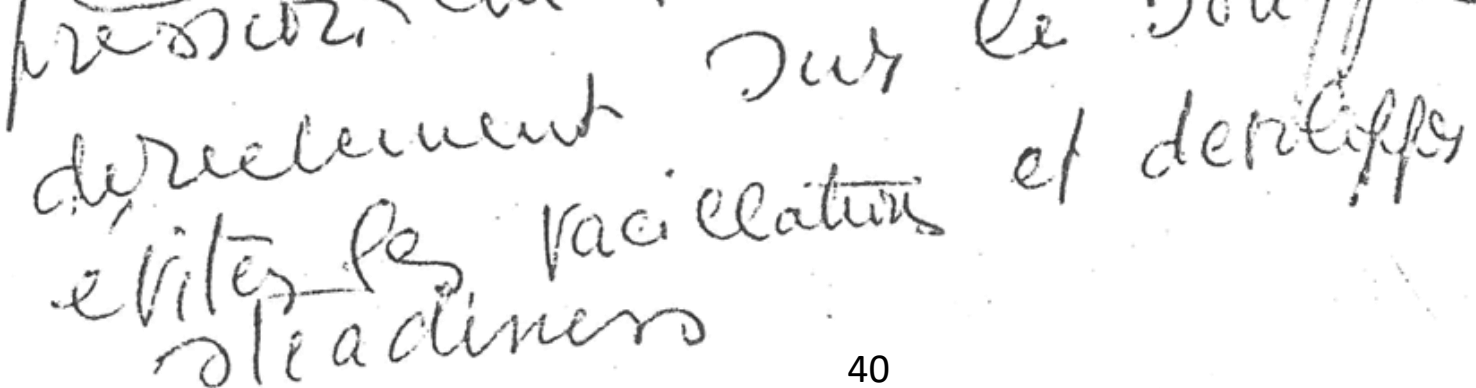




\section{Translations of page 40:}

- Column of air: in order to understand well its distribution -fluctuation of the stream $=$ displacement of the volume of air as it empties.

- Like an eggshell balancing on a water jet, so must the notes be placed on the air column, and not breathed like an inflation: that is not playing. \{

- The notes must be placed on the resistance: pressure of the wind and not its dissipation. Avoid vacillations in the wind: steadiness [is the objective]. 
il sot pupisi a alaques auss frial des 0. Zers. ie, qui lequitandra a 1 . deternumies conleas.

attaque dy noriee quorque e 0 sera but jon I sera d'in lo ti en vibrations - et 280 maximum du 13 à $15=$ résuelat laude

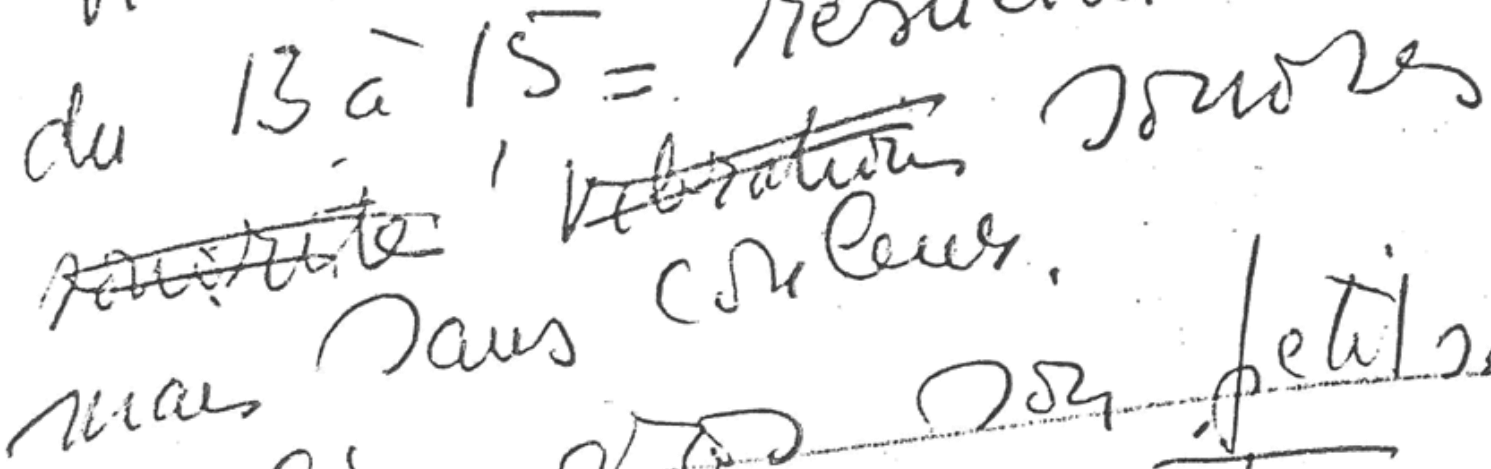
derli for or fetilon

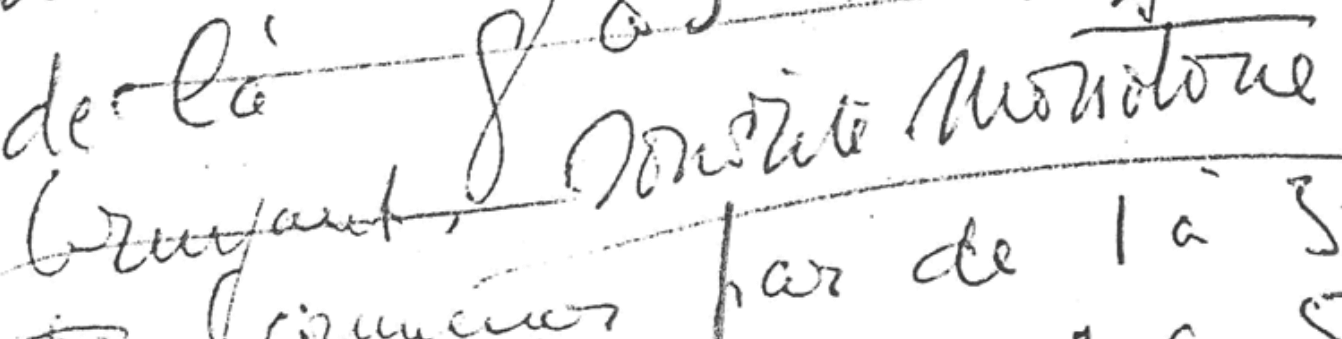
整e cinucious far de la 3.1

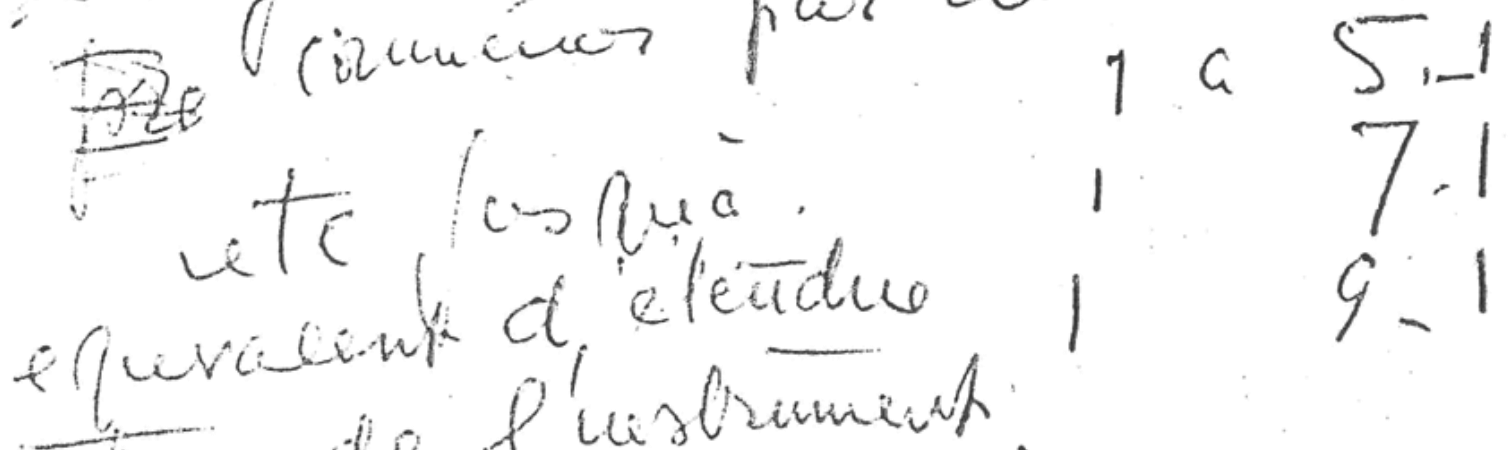
Hace de l'usbriment.

42 


\section{Translations of page 42:}

- Attack the note as quietly as possible: aim for a zero, although a one will result, which is entirely correct. This forms the basis for all dynamic levels of attack: they must be based upon a zero objective. (paraphrase) Without this, a loud attack will be heavy: sonorous, but colorless. \{l.e., the zero objective as basis allows the full colors to emerge, irrespective of the volume level.\} 
$-11$

;

Playing yind Instruments-a Method

Outline

Introduction

I Tonal Equalization

A. Speed of

B. Wind Speed in Relation to Iip Pressure

C. Potential Wind Pressure (Line)

11 Tonal Levels

II Phrasing

A. Chan $\frac{6}{7 n g}$ Tonal Level

B. Articulation

C. Silence, Space, and Time

Conclusion 
Playing Wind Instruments-a Method

Wherever wind instrument players gather:--back stage, chugging show trains, regearsal halls, and even across the poker table, the Tabuteau method eventually enters the conversation. The interpretations are always varied and range from the dyed-in-wool enthuisiasts to the pure inspirationalists, who claim that mathmatics has no place in music. Neither group approaches understanding. The few that do, remain silent, while the others rave on.

One of the common mistakes is the failure to comprehend that the system is both indivicual and flexible and that successful application is in direct ratio to the ability and musicianship of the user. It is a method of teaching, and an aid to interpretation; it permits and encourages individuality by giving direction and purpose; and finally, it is a method of projection. Numbers are used as aids (I) to tonal equalization (2) to differentization of tonal level and (3) to phrasing. Other principles are treated under these groupings and, in the folloring, practical applications are used to clarify wherever possible. To do is to understand and so, take out your instrument and

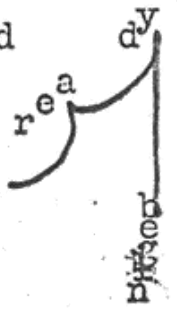




\section{Tonal Equalization}

A. Speed of Wind

Tonal equalization is accomplished by the speed of the wind.

In example $I$ the wind speeds necessary to equalize thesettones

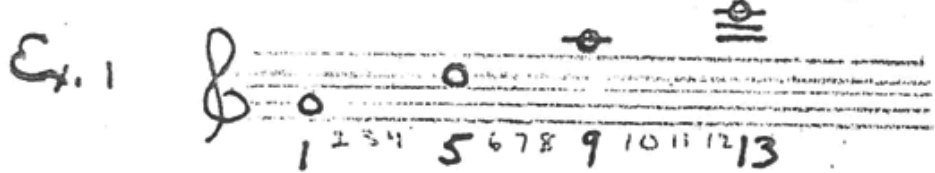

would result in a cresc. on the same note

but make these different notes of equal volume.

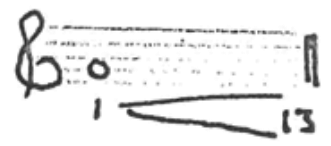

The player can prove this to himseiff by sustaining

a "G" on his instrument and increasing the intensity of same from the count of I (which is the lowest level of speed necessary to produce this tone) to the count of 13. Then play ex. I changing tones on the air speeds necessary for equalization.

B. Tind Speed and Lip Pressure

$\mathrm{E}=$

In playing the above did you not find a relationship between wind speed and lip pressure(i.e. the control of the size of the openingthru which the air flows)? This relationship is a direct one and is illustrated by the following chart.

Relationship of Wind and Lip Pressure

WIND

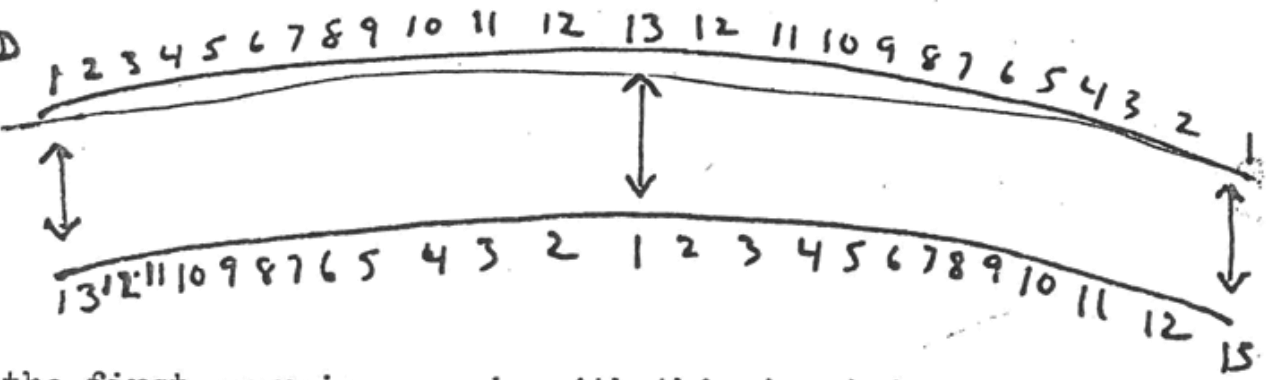

Try the first exercises again with this in mind.

C. Potential Wind Pressure (Line)

Potentially, the wind speed of 13 was in back of the attack on 1 or it could not have gathered momentum. Since control and a smaller opening slowed it down, it lay dormant, awaiting opportunity. This principle then, insures a graduated tone production 
(see below) in which all of the notes are played on the wind,

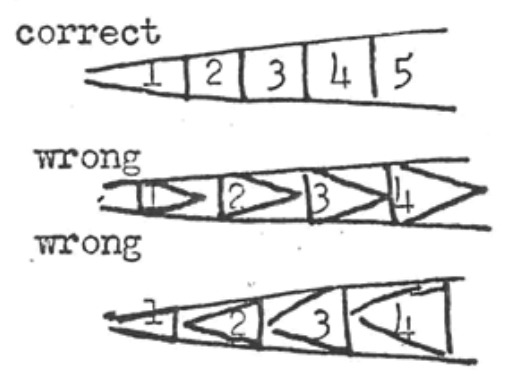

(which is interrupted but never discontinued) making a beauty and continuity of line not otherwise obtainable.

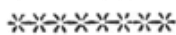

The following exercises will perhaps clarify the above principles to the reader. Try to apply them as you play. Afterwards you may use them in whatever you do because they apply to all music.

1)Attack G and cresc.

a.
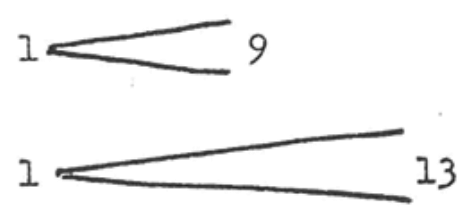

Attack G (on counts of) *

b.
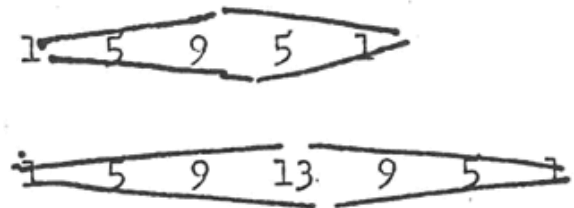

Attack $G$ on every count from I -9-P
(4) $1-13--1$
c. (1) \|\|\|\|\|\|\|\|$\| 11$

*always take breath, when needed, after $5,9,13$, etc.,never before. 
2.) Now play a. 1--5--9--13 (Ex 1) of the scale, first detached and then slurred, always attacking and holding the last note.

b. Repeat with 13 (of greatest intensity) on the lowest note and I (of least intensity) on the highest.

3) Finally--try a scale--l to 13 and back. As you increase the wind speed, decrease the lip pressure to insure a larger opening for the wind and move your fingers. The scale should be perfect. Isn't it? Well, try again-once staccato, once legato, and hold the last note intil it disappears. Be careful about the attacks too. They shouldn't be hard but a continuation of the breath or wind from the previous note. On the wind-remember.

Now apply all of the foregoing to every note and scale on the instrument. Each note and scale starts upon a higher or lower level according to its position in the scaling of the instrument. The limit of the scaling will depend upon the combined capacities of instrument, reed, and player. The system is a transposing one for purposes of convenience. 1.e."G" may be donated as $I$ and yet be on the sixth level in the scaling of the instrument which leads us to the second principal--

\section{Tonal Ievels}

Until now we have been concemed with equalizing the various tones of our instruments: \%balancing wind-speed,resistance and lip pressure to glide on one level from note to note. To play on different levels is, of course, essential and applying nambers helps the musician to analize what wishes and intends to do. On a night without inspiration he can still be musically intelligent and interesting.

Start with the scale and let it live up to its name. Scale each tone so that the lowestis played with the least intensity, and the highest rith the most. Call the lowest 1 and the highest 13, 15, 17, or 19, depending upon the range of your instrument. Then reverse process and let the high note be $I$ and the low note 15 . Any no note can be tailored to any level, depending upon the musical line desired. Thy the following:-

Ex. 2

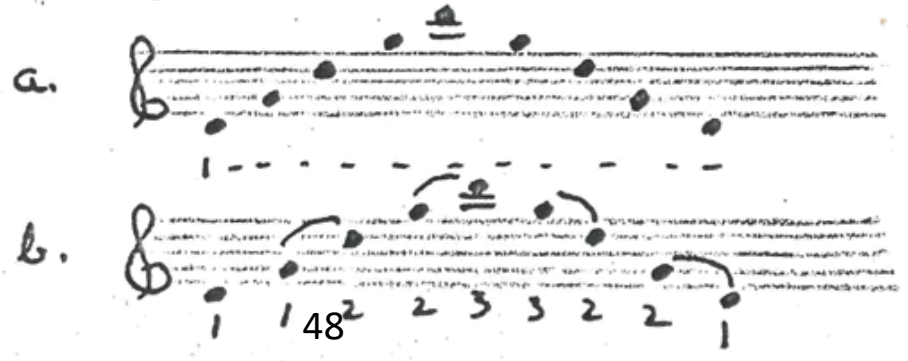


In ex. 2, w the air speed increases and decreases to play the notes evenly on one level. In ex. 2, b. the same process takes place but to a much greater extent so that the phrase is played on three different levels, automatically giving shape and meaning to the group. The proper air speed, however, is always attained on the preceding note. When such has been attained the fingers change and the note comes by itself.

\section{Phrasing}

A. Changing Tonal Ievel

You have seen in the preceding example how changing tonal levels brought about phrasing. No note, even when played upon the same level, is static. It has direction berause it is always changing and its destination is that of the entire composition. It is related to the whole and to the sections and phrases within the whole.

Stuay the folloring:

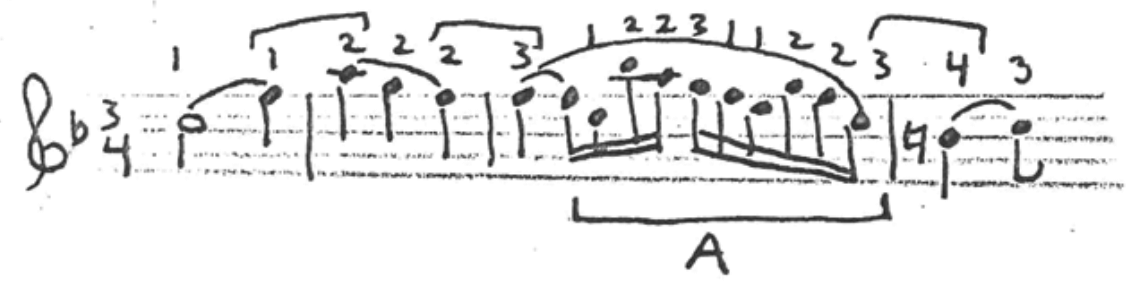

It is on four levels with the climax on 4 . Between 3 and 4 , (bracket $A$ ) the tonal level is still a progression from 3 to 4 but, for the sake of speech facility, the numbers are transposed, permitting a smaller phrase within the larger. The choice of numbepand distribution of level is, of course, an individual matter, changing with the mood and intention of the player. Now play it. Fou, too, can phrase by tonal level.

\section{B. Articulation}

A section on phrasing would not be complete without a brief consideration of articulation, which necessarilyfgoes hand in hand. A simple sixteenth note scale patterm not only has varying wind speeds and tonal levels, but different stresses and articulations, as well. In the following pattern the odd numbered notes have a

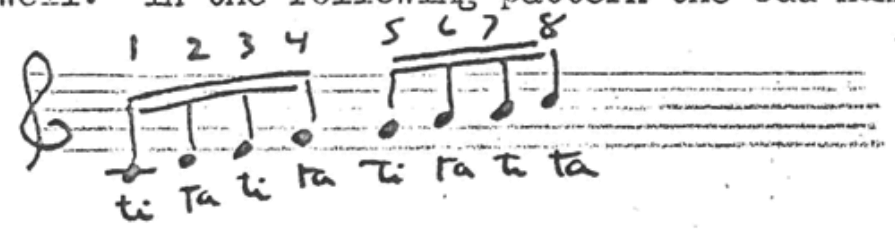

down stress which is greater than the up stress of their even companions. This is facjlitatgeg by the attack ti and ta. As the phrasing is changed so is the corresponding attack. 
For example--
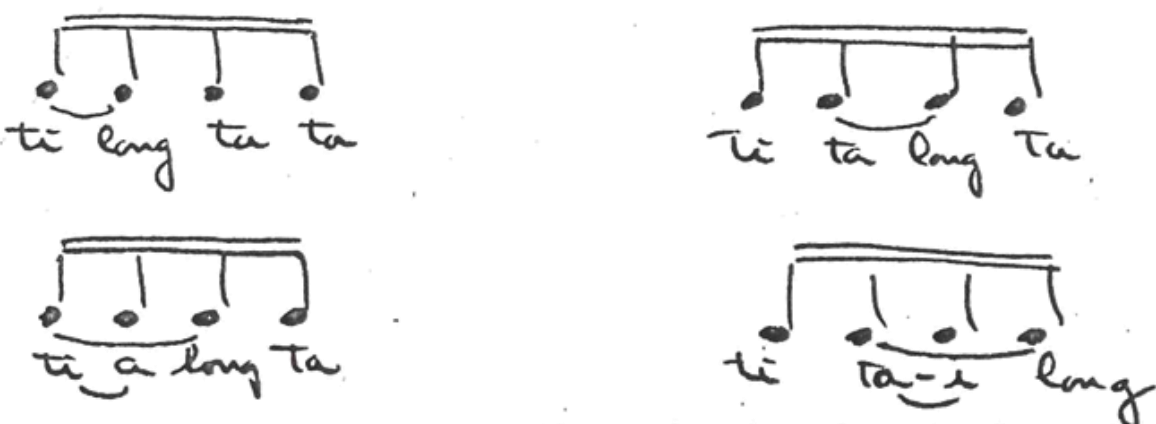

In playing these articulations the end note of each slurred group is always long and moves toward its successor. It is a common error to chop it off and harry on.

c. Silence, Space, and Time

These three factors must also enter into any consideration of plirasing. Silence is bounded by sound and space and bothx exist in time, in the sense of rhythm and stress. Take one note and attack it on varying intensities from 1 to 9.

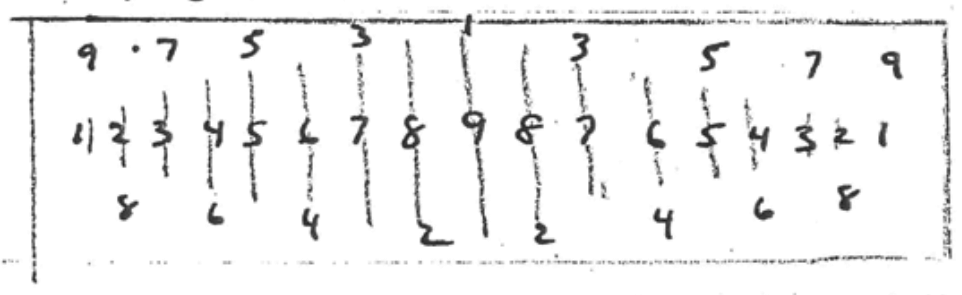

You will see that as the tone increases in wind speed the silence around it varies in inverse ratio and that the space between notes changes progressively. These two principles, then, can be applied to rhythmic patterns, which, modify, continue, and clarify the musical line, giving it added form and substance.

In conclusion, I hope you are not tired out. Don't get discouraged because to approach perfection takes many years. Neither is unders standing reached in a day. I sincerely hope that the preceding principles will help you and I wish you good luck. 


\section{Iesson $\underline{1}$}

up beats re, di, - I
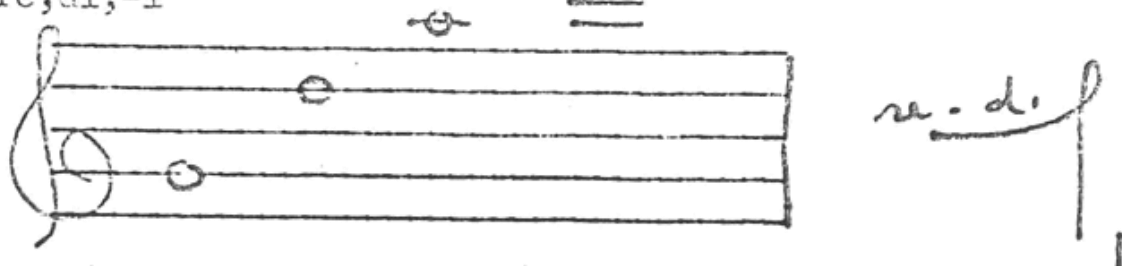

ind pressure to equalize these tones of scale would result in a cresendo on the same note but maire these different notes of equal volure. Theory--each note has fixed wind.pressure and is always the same--eliminates chance.

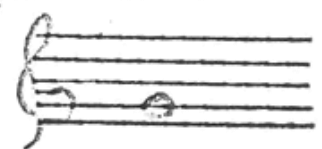

1) Aitack G 1--9--1 $1--13--1$

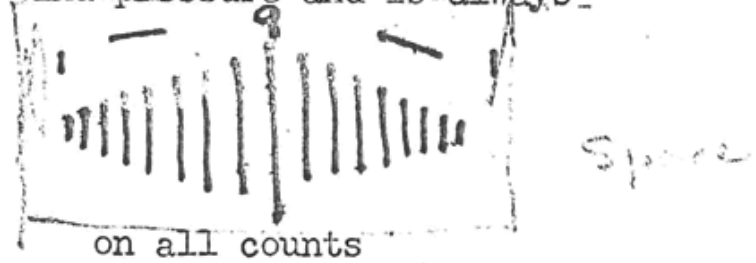

2: Attack G

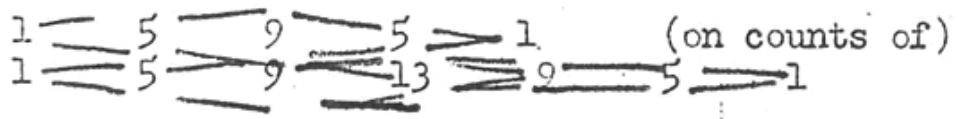

3) Attack G and crescendo

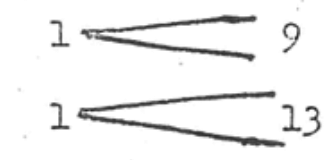

4) Attack and slur

$$
\text { 1-- 5-- } 9 \text { - 13--of G scale }
$$

Apply lesson to every note on instrument.

\section{Lesson 2}

The attack on 1 to 9 must be this

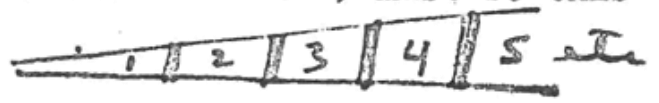

not

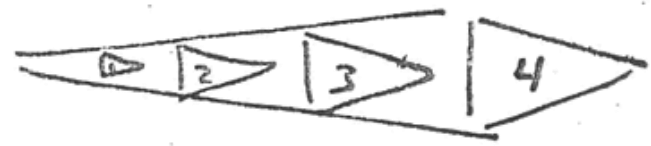

or

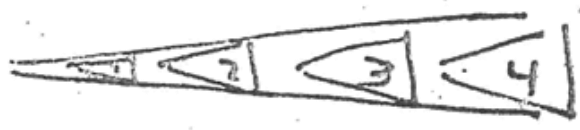

Iay 1--5-9-13--on same note

Take breath after 13, attack 12. Repeat. 
Chart

UIND MND IIP PRESSURE

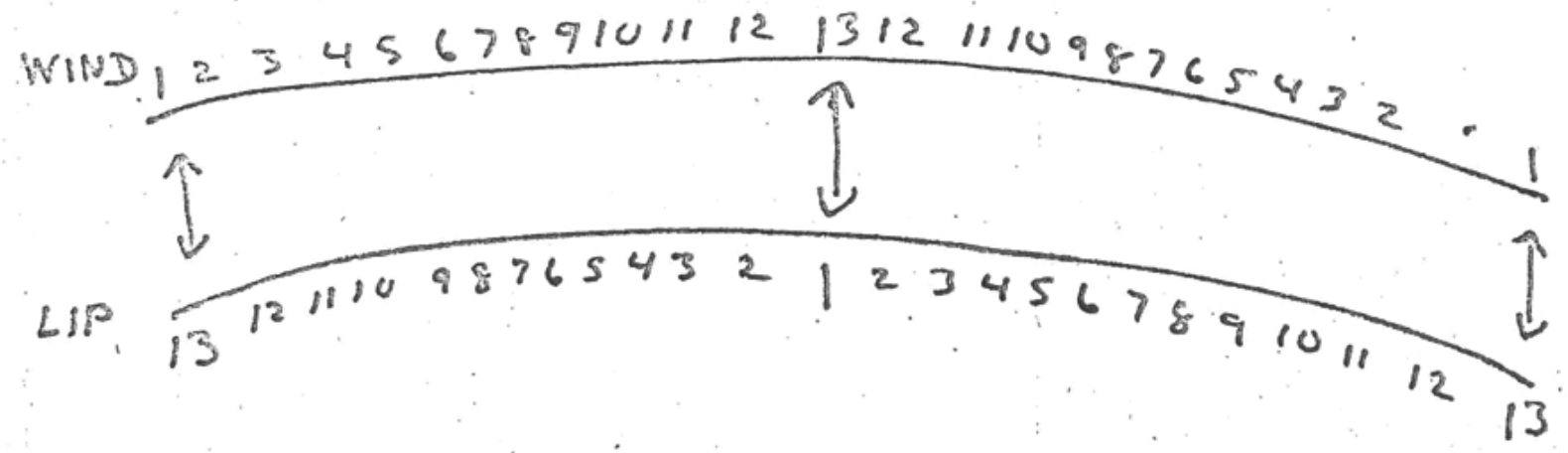

Wotes must all be on the breath--no wah--don't flap arms.

1) Iay 1--5--9--13 of scale,first detached and then slurred (twice) Hold last note.

2) Repeat with 13 (of greatest intensity) on lowest note:--1 (of least intensity) on highest note.

Playing a sport like boxing--not just blows--foot work. Giide like a skater.

Scales--see chart of wind and Ijip Pressure

$C$ เง $\mathbb{E}$

Once staccato, once legato. May take breath at top.

Do all scales--major and harmonic minors.

\section{Lesson $\underline{3}$}

1) Octaves $A--A_{1}$ '

Start on 13 (Iow) to $I$ on octave above (slurred). On this note increase to 13, diminish, and back to octave below on 1 . Space

between 2 and 1 . Practice attacking $1--5--9--13$.

2) Repeat in reverse i.e. 1 low, 13 high.

3) Scales as before--no cresc.--increase in air pressure balances and evens notes.

Never take breath between 4 and $I$. All notes on the breath--no pinching or wobbling.

a. Detach

Not hard attack but continuation of breath of

previous note.

b. Slur

Attabik 1 


\section{Interrogative/Affirmative/More-Affirmative Applied}

This chapter applies the Interrogative/Affirmative/More-Affirmative portions of Marcel Tabuteau's system of phrasing to the primary themes in Carl Maria von Weber's Second Clarinet Concerto. Below, are the terms used synonymously with each to avoid confusion:

Interrogative - Question

Affirmative - Answer

More-Affirmative - More Answer

The Interrogative is the question part of a phrase. Typically, phrases are symmetrical; however, this is not always the case. In a 4-measure phrase, the first two measures can normally be considered the Interrogative. The Interrogative is driven by the harmony to the most tense point in the phrase.

The Affirmative is defined as the answer. Considering the aforementioned 4-measure phrase, the two measures following the Interrogative are the Affirmative. The final two measures will release the tension created until the final note of the phrase.

The More-Affirmative is a phrase extension, or an elongation of the Affirmative. For example, there could be a 6 -measure phrase that is asymmetrical, $2+2+2$. The harmony builds in the Interrogative like that in a symmetrical phrase; however, the would-be Affirmative contains a number of measures not equivalent to the total amount found in the Interrogative. This instance is when the More-Affirmative option makes the most sense.

The example below follows the Interrogative/Affirmative/More-Affirmative phrase structure. The second measure begins with the Interrogative and shifts from the tonic chord to a second-inversion dominant seventh. The Affirmative starts in the third measure and releases 
the tension in the fourth measure by resolving back to tonic. The More-Affirmative section is the final two measures of the phrase. From beat two of measure four through measure five, there is an extension moving back to the dominant seventh chord in root position. The extension makes this an asymmetrical phrase allowing measures one through five to be labeled as the Interrogative/Affirmative/More-Affirmative.

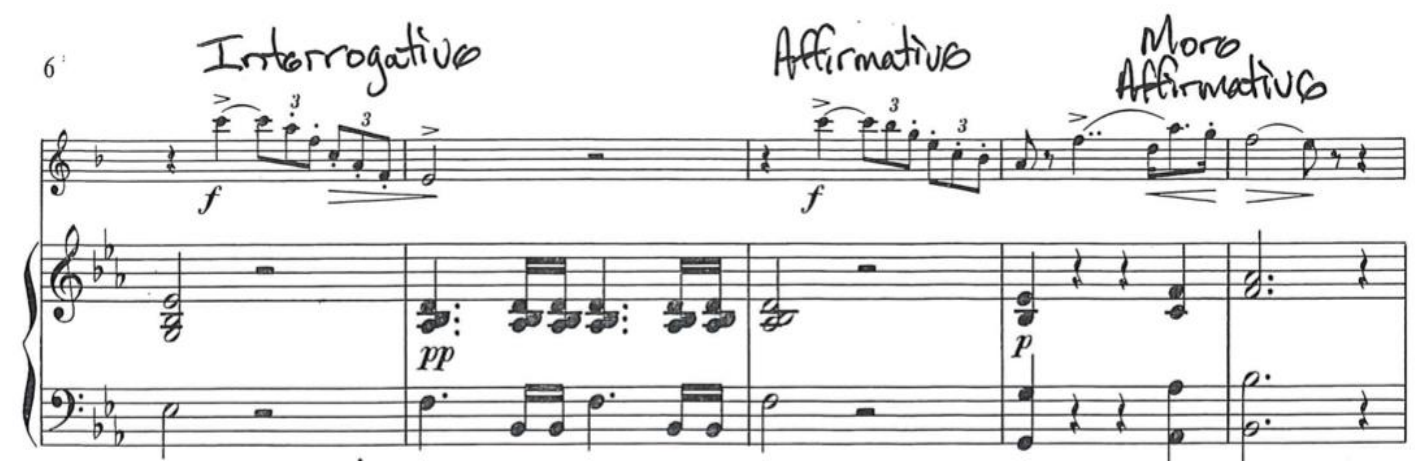

The Interrogative/Affirmative/More-Affirmative have been applied below to the rest of the main themes in Weber's Second Clarinet Concerto. See Appendix B for additional information. 

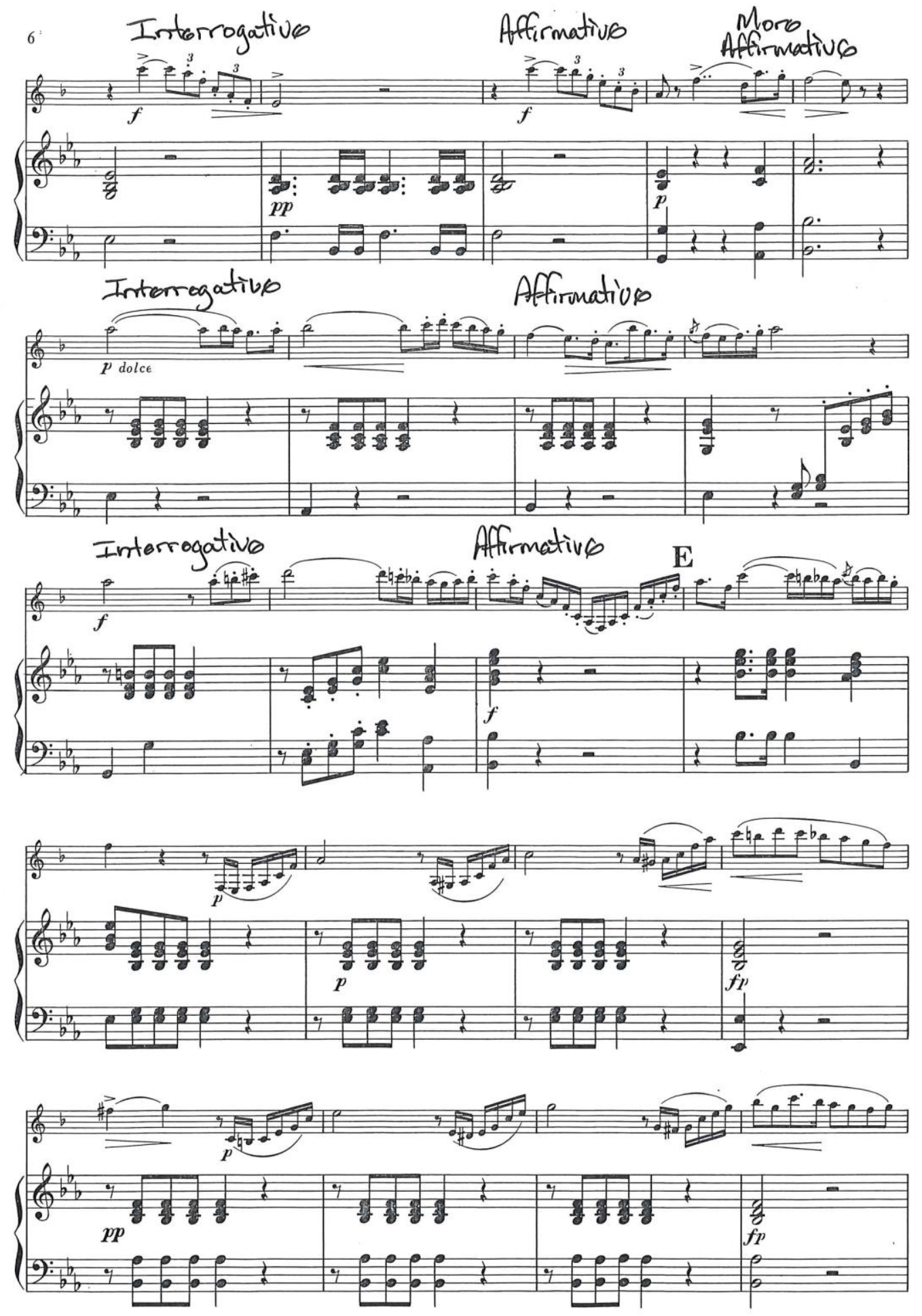

ST. -86 

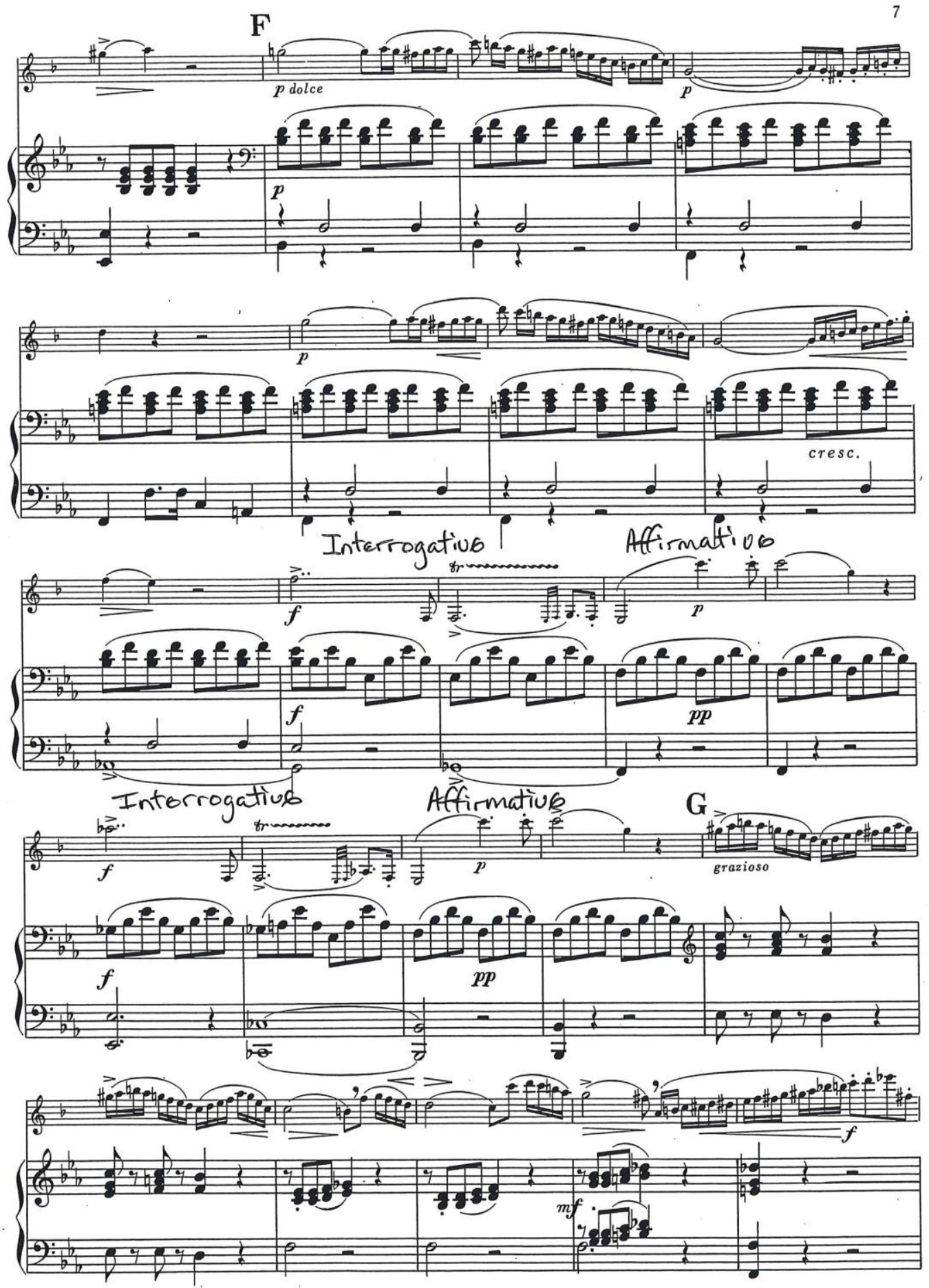

$\mathrm{ST}-86$ 
Intorrog. Affirmative
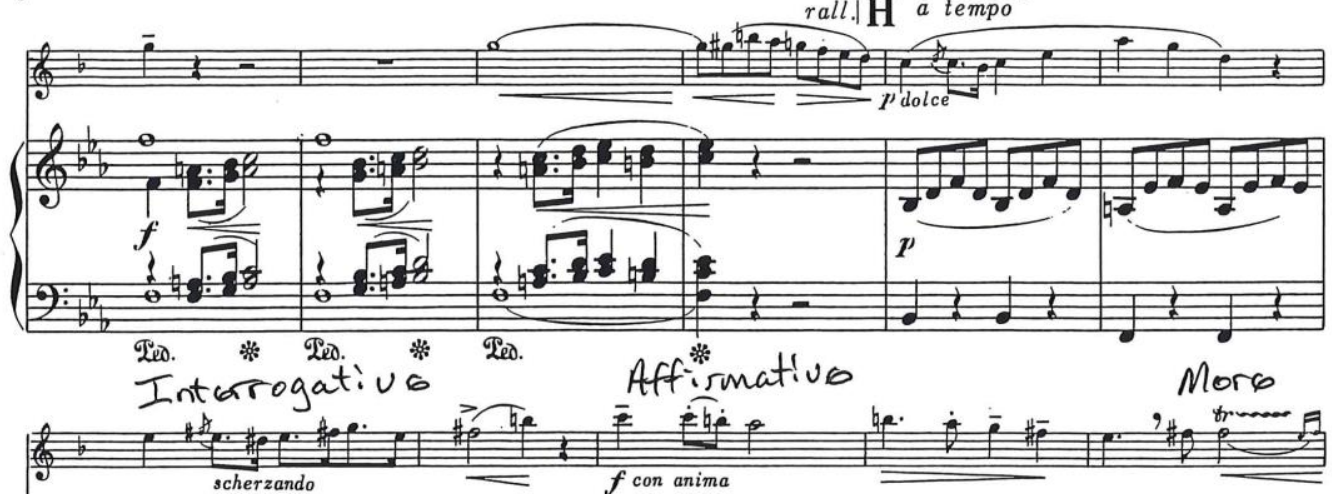

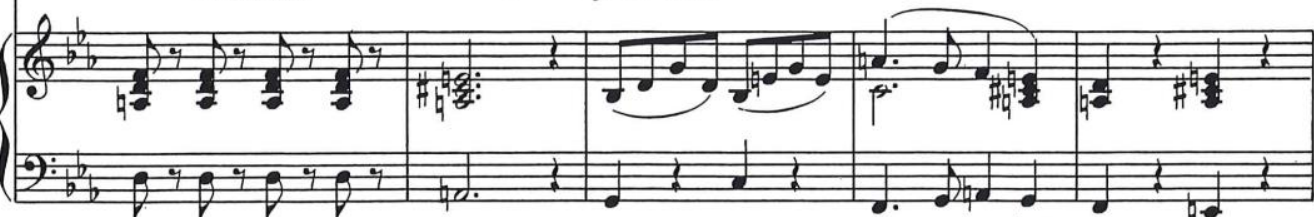

Affirmative Intorrog. Affirmative Intorrogative
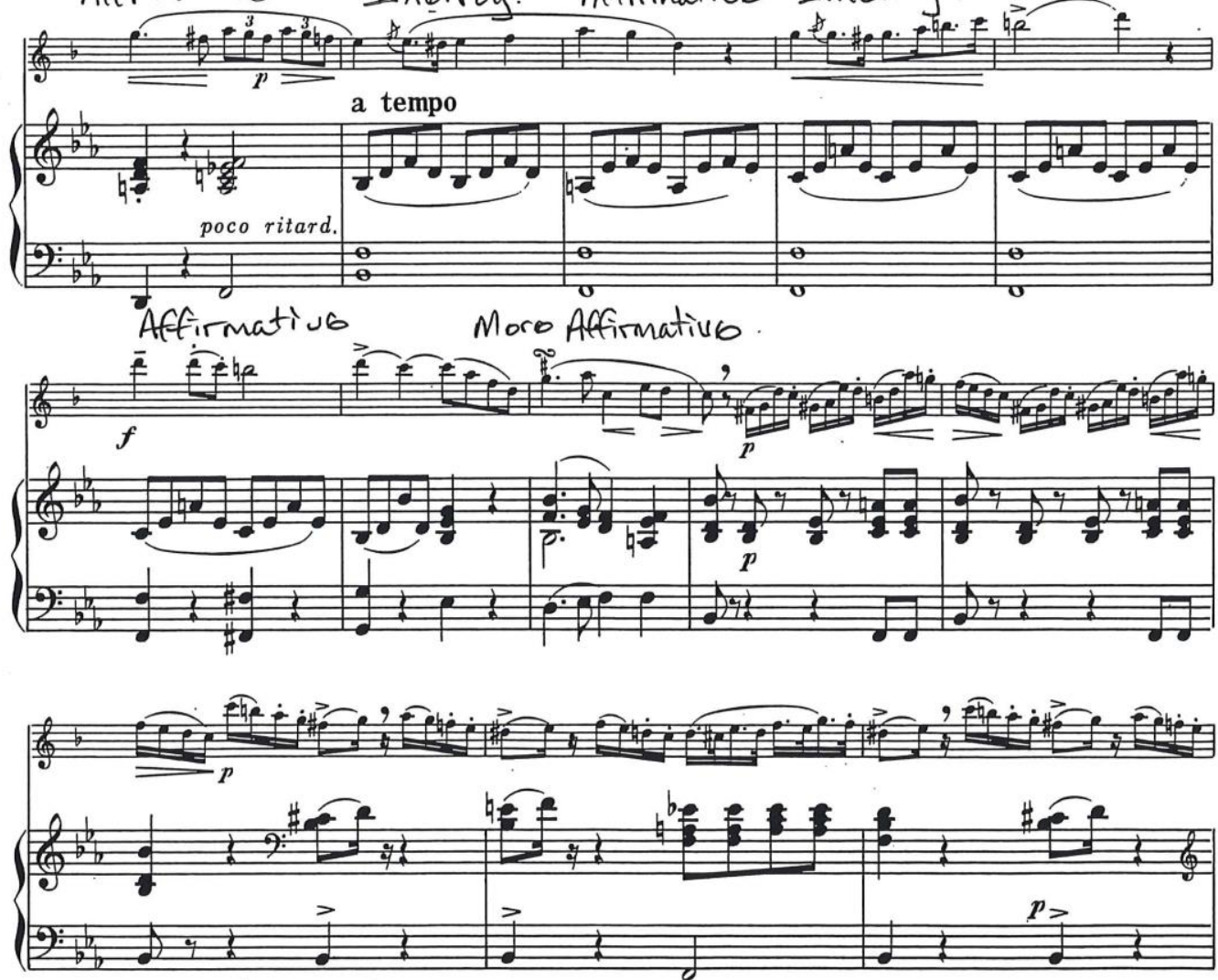

ST -86 

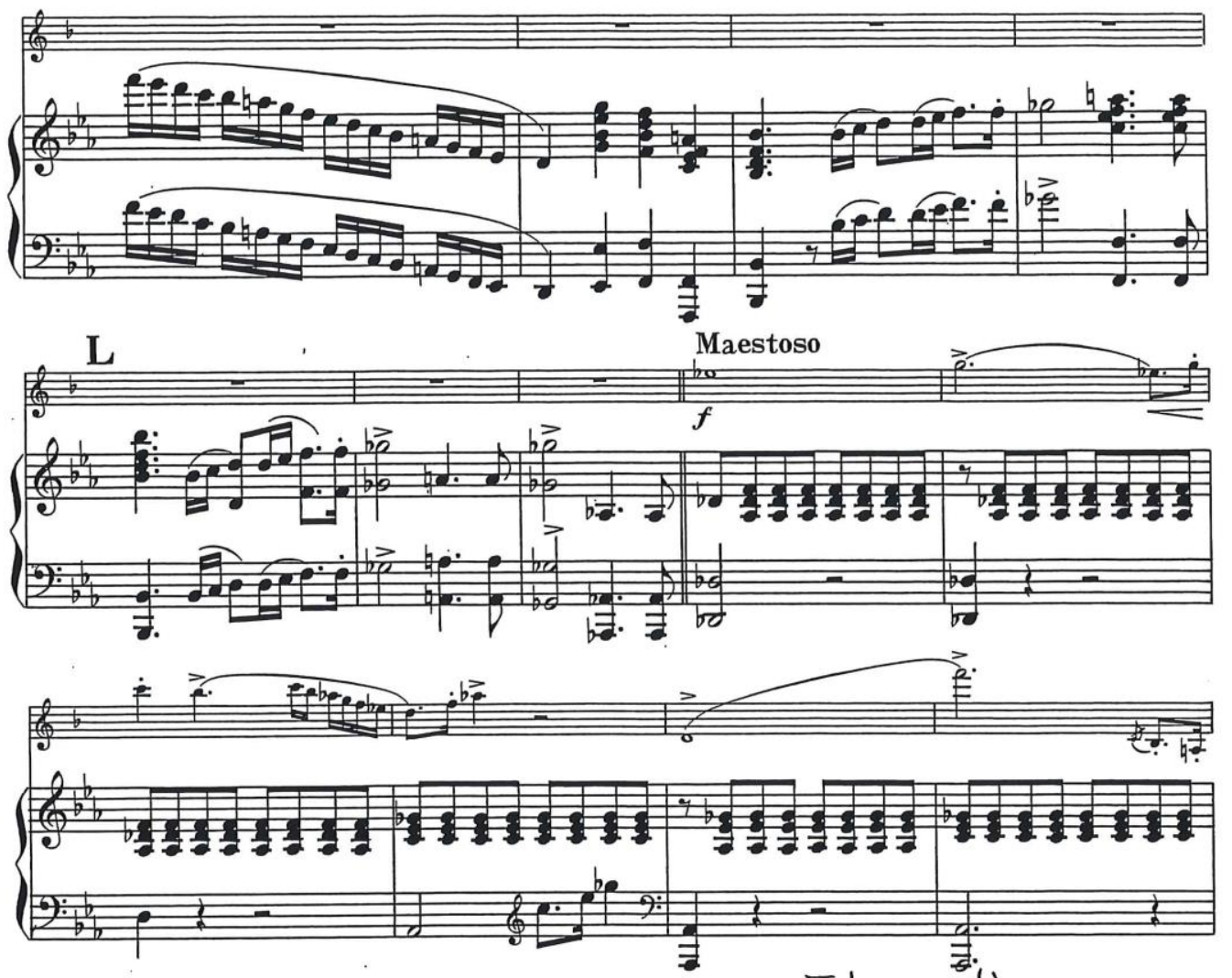

Intorrogative

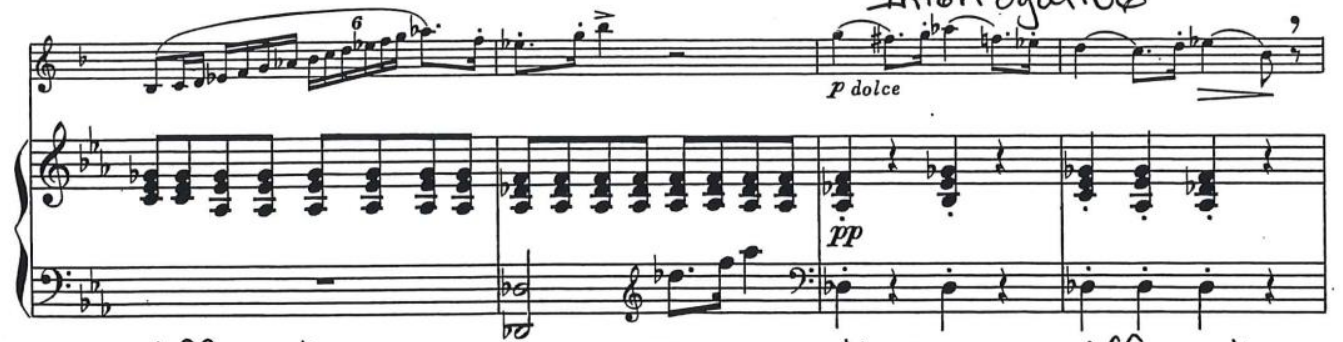
Affirmative Intorrogative Affirmatios

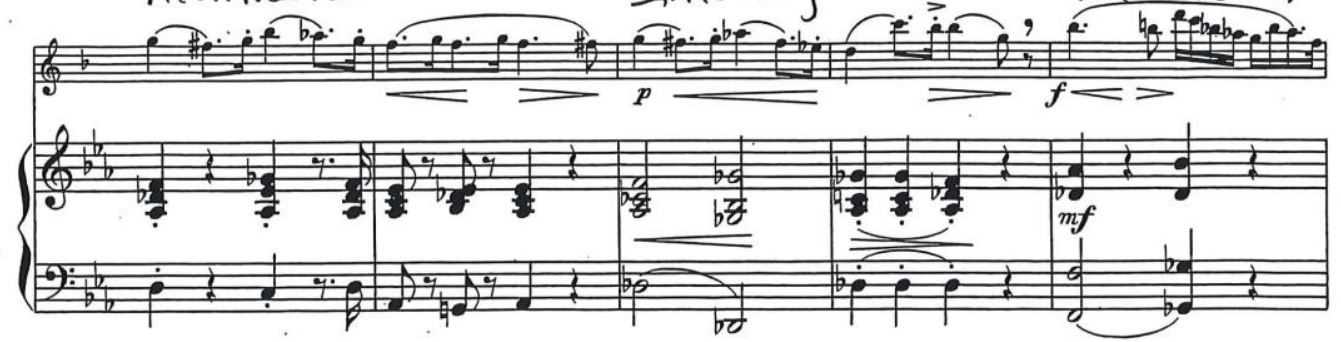

ST1-86 

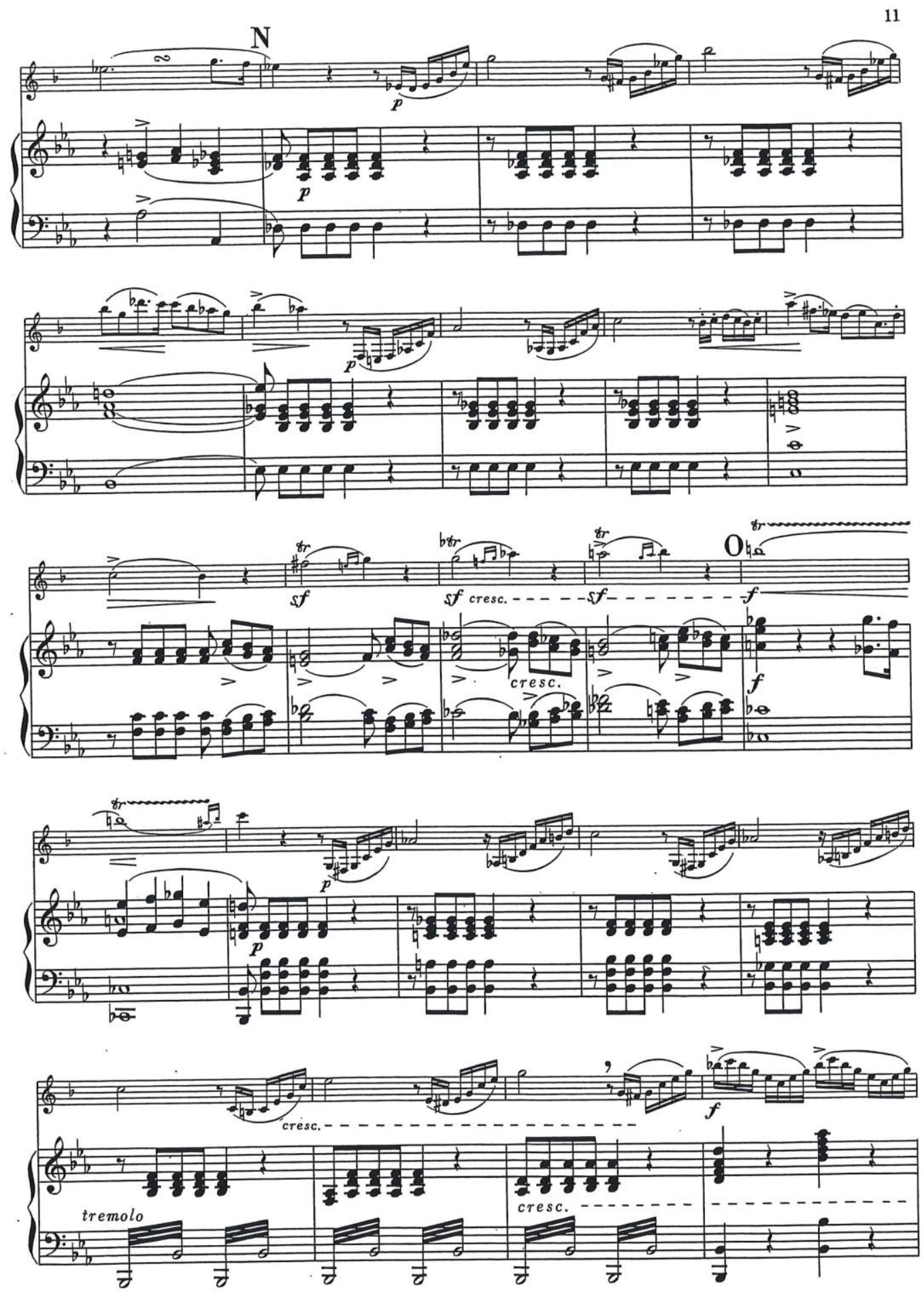

ST -86 

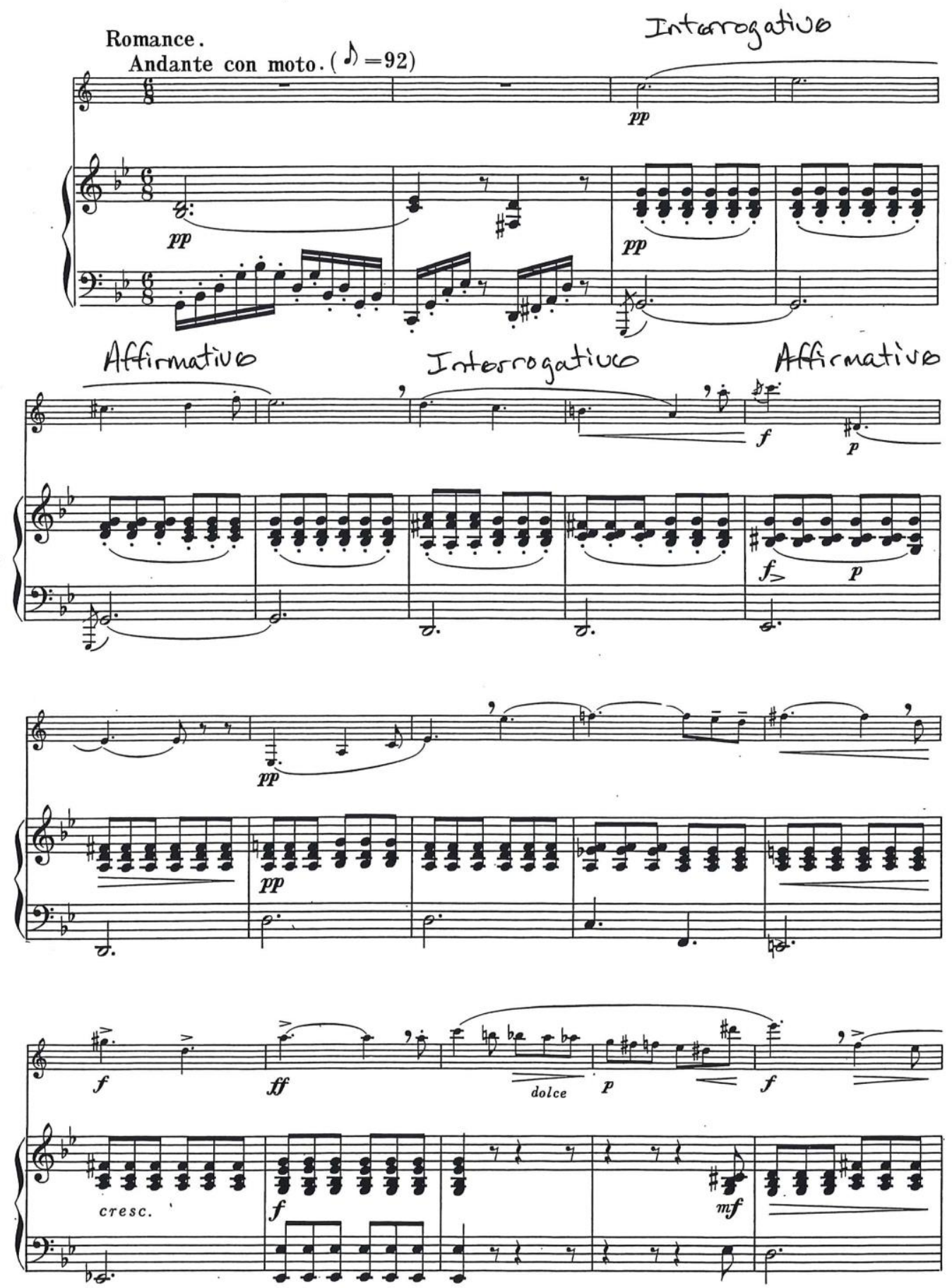

ST -86 

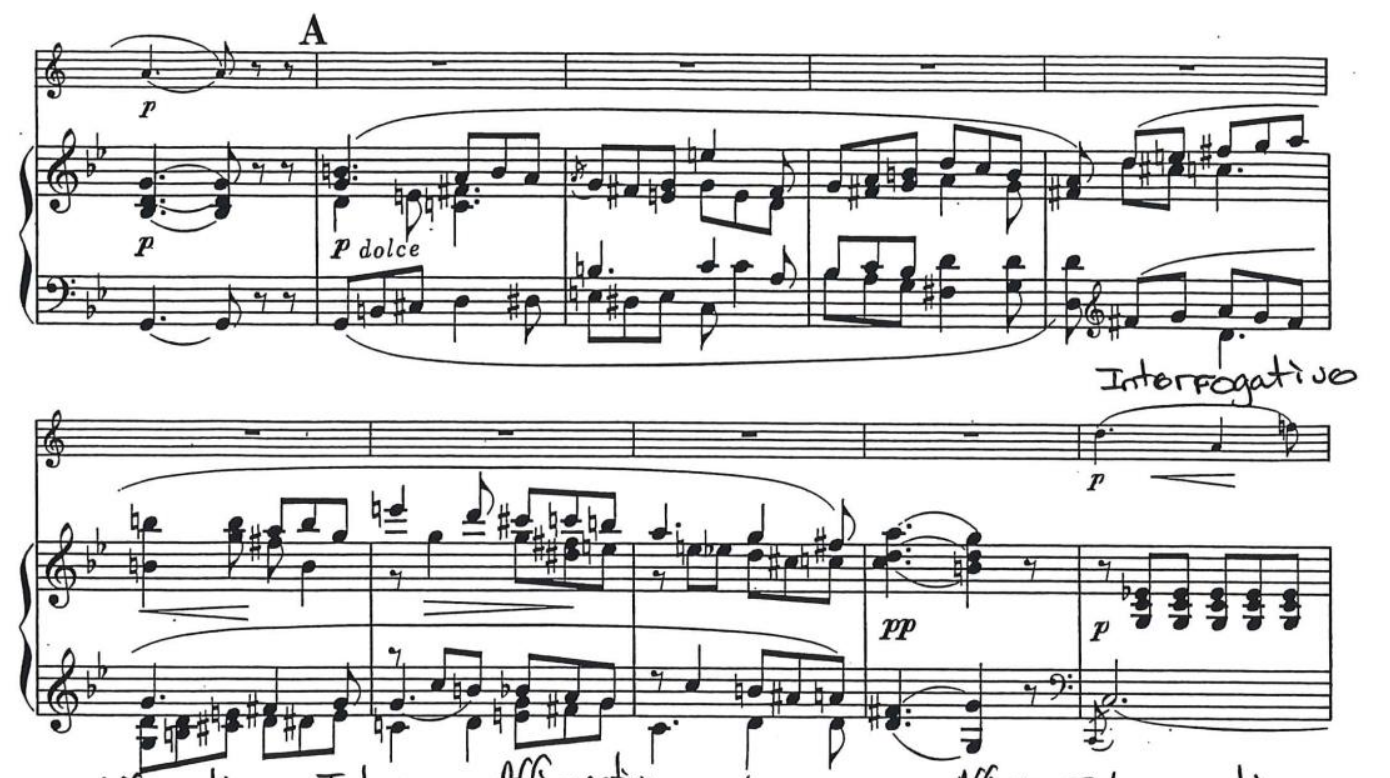
Affirmative Intor. Affirmatule Intor, Affirmg Interrogative

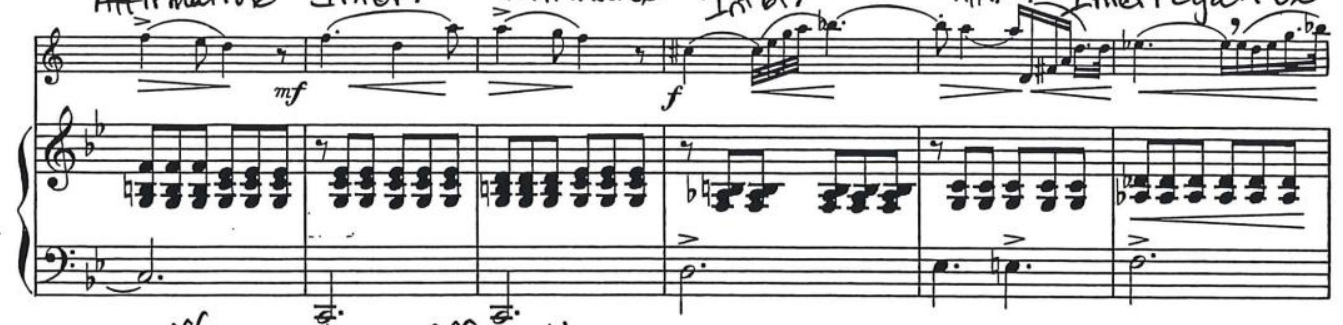
Afirm, Moro Affirmatico
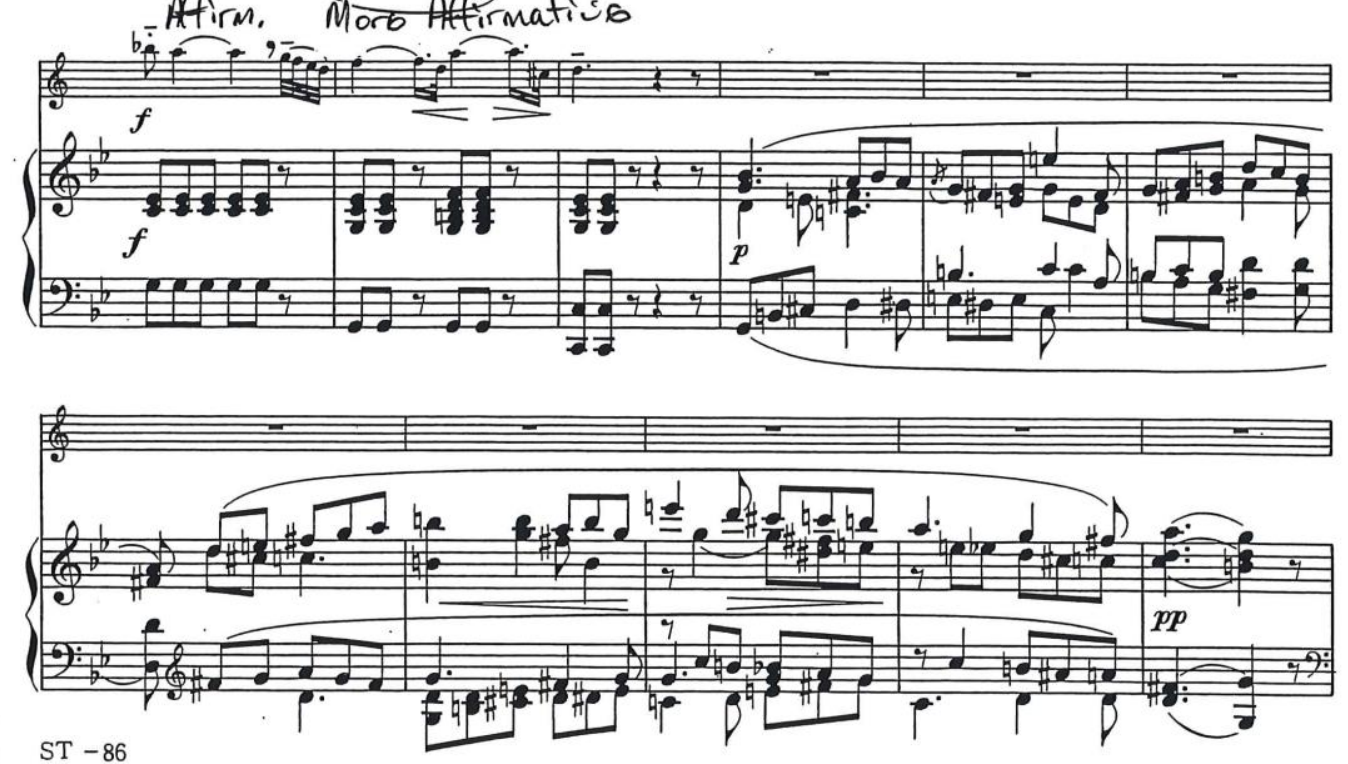

$\mathrm{ST}-86$ 

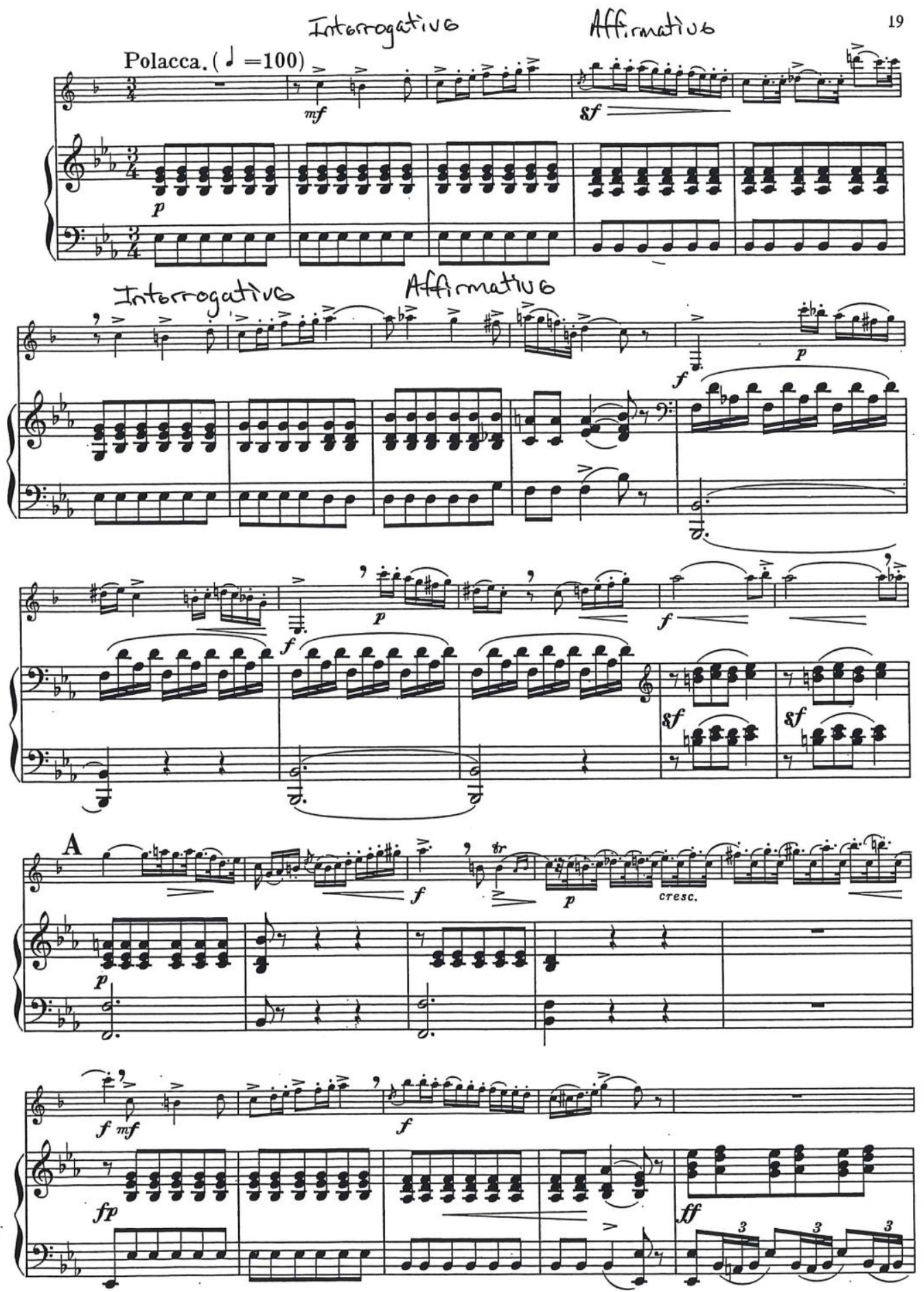

ST -86 
20
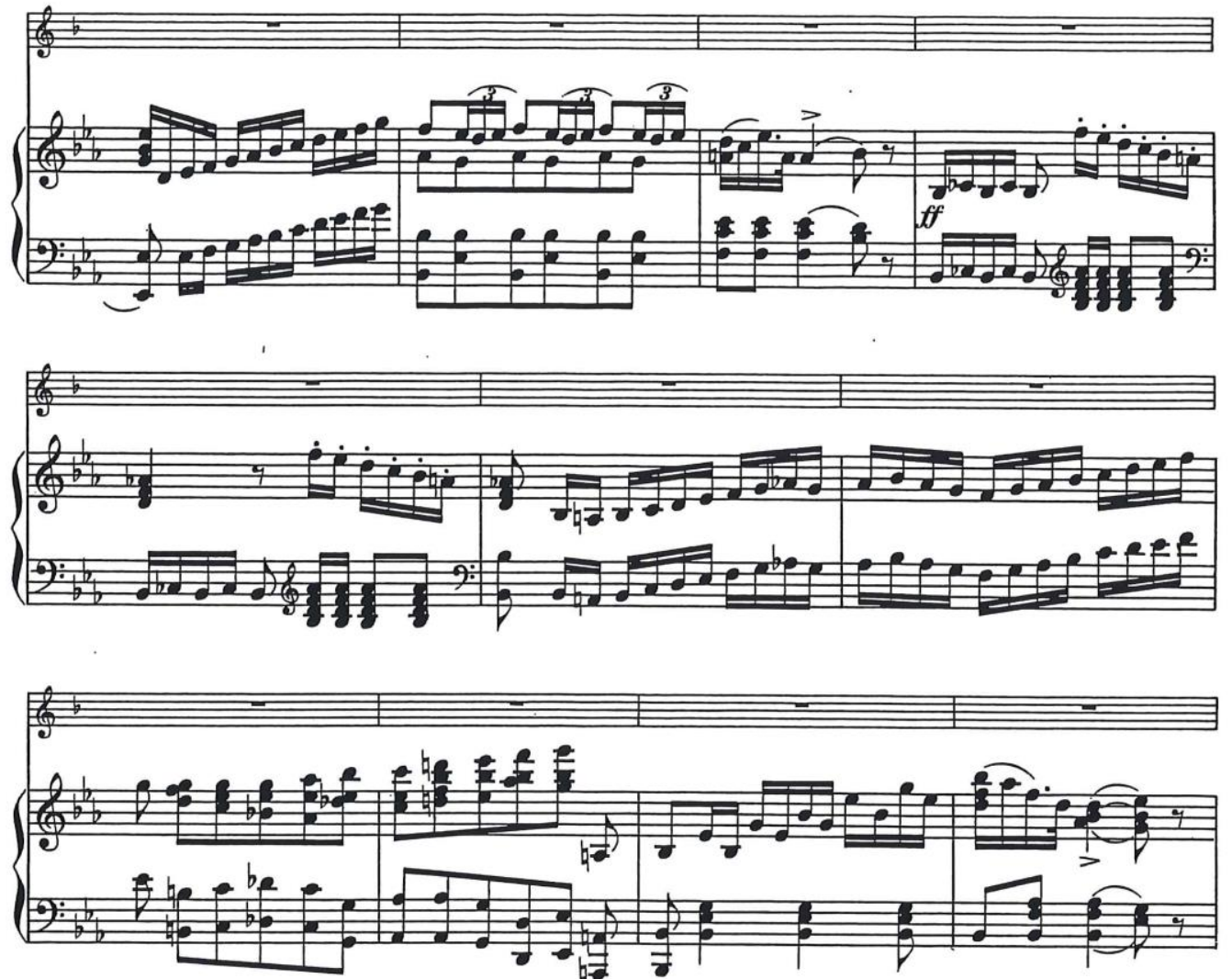
Intorrogative Affirmative Interrogative
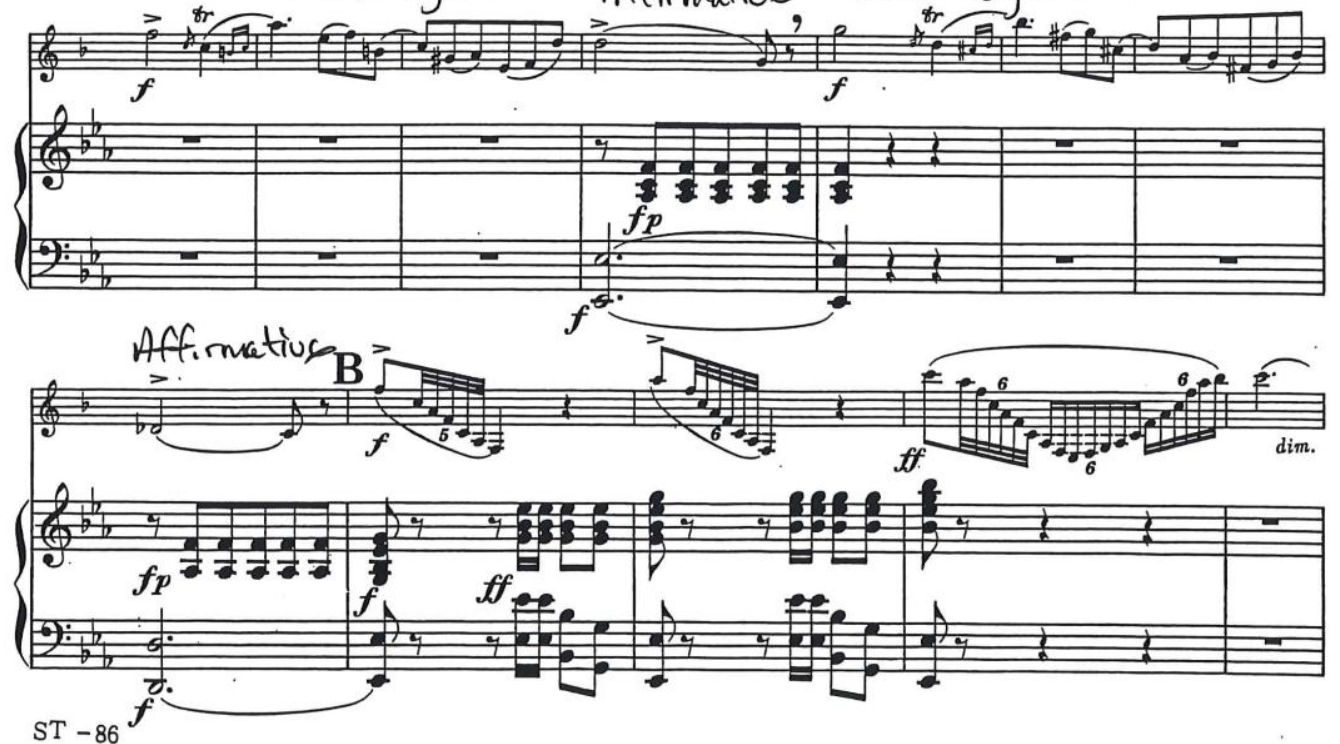

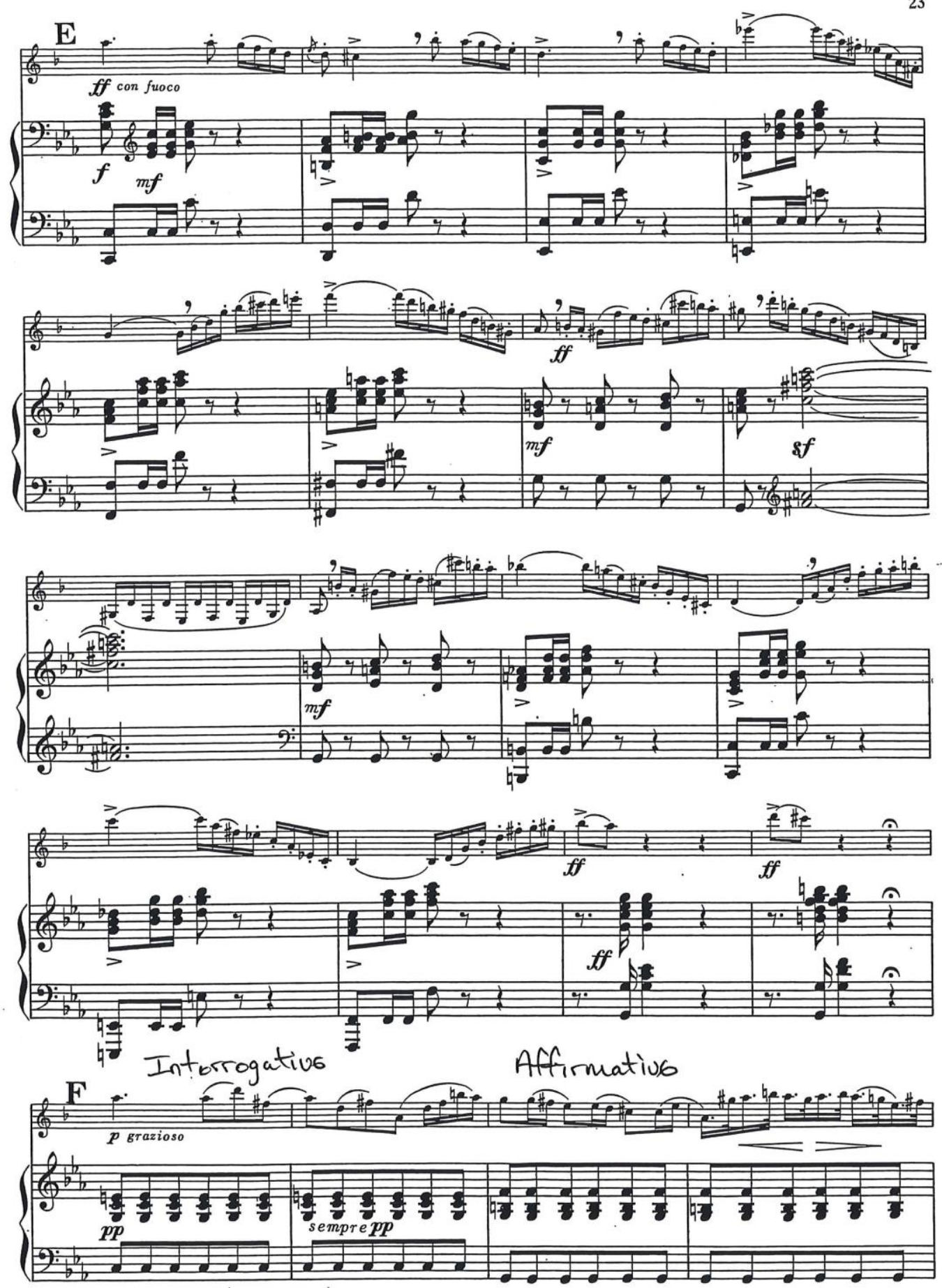

ST -86 

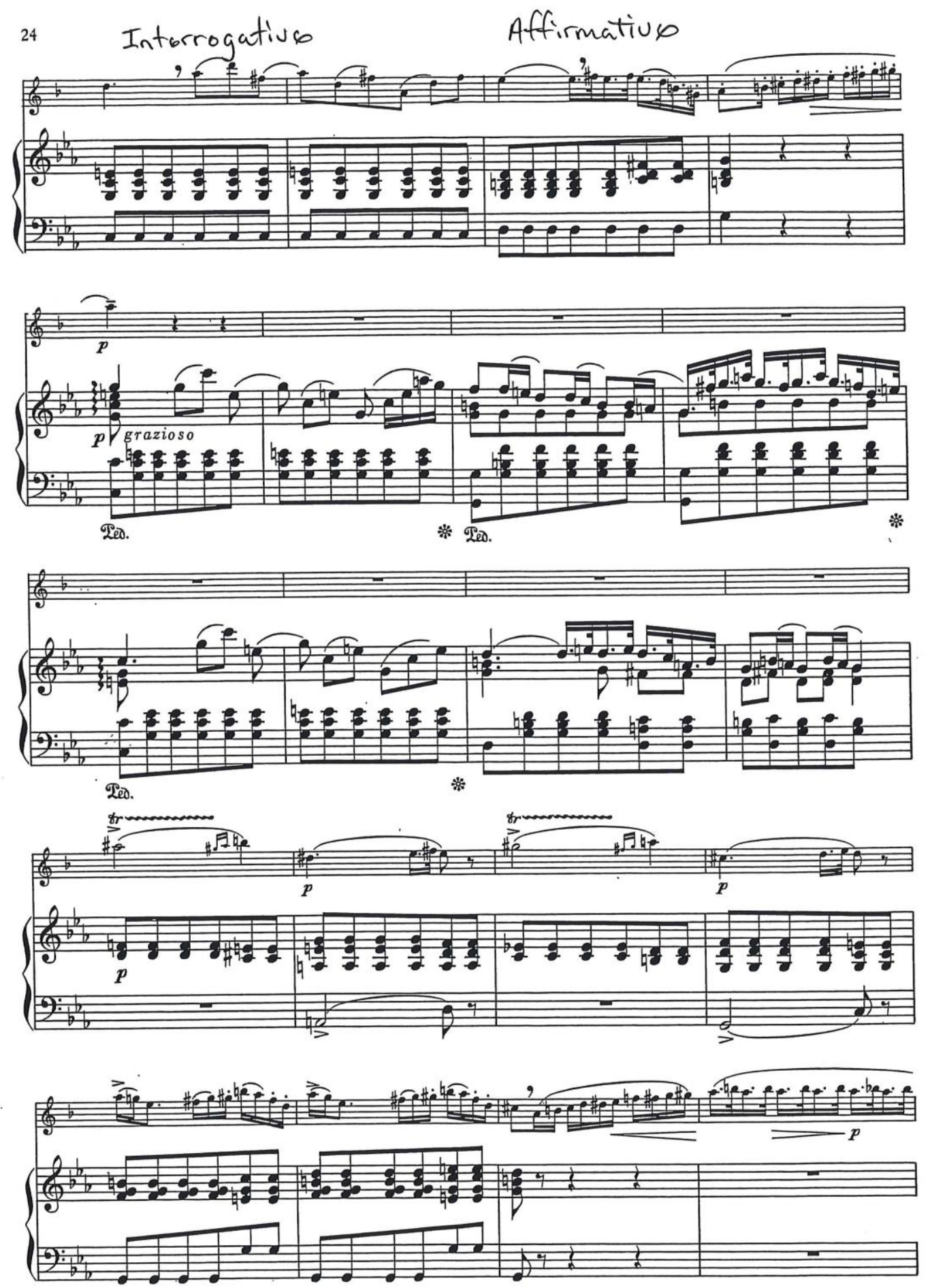

ST -86 

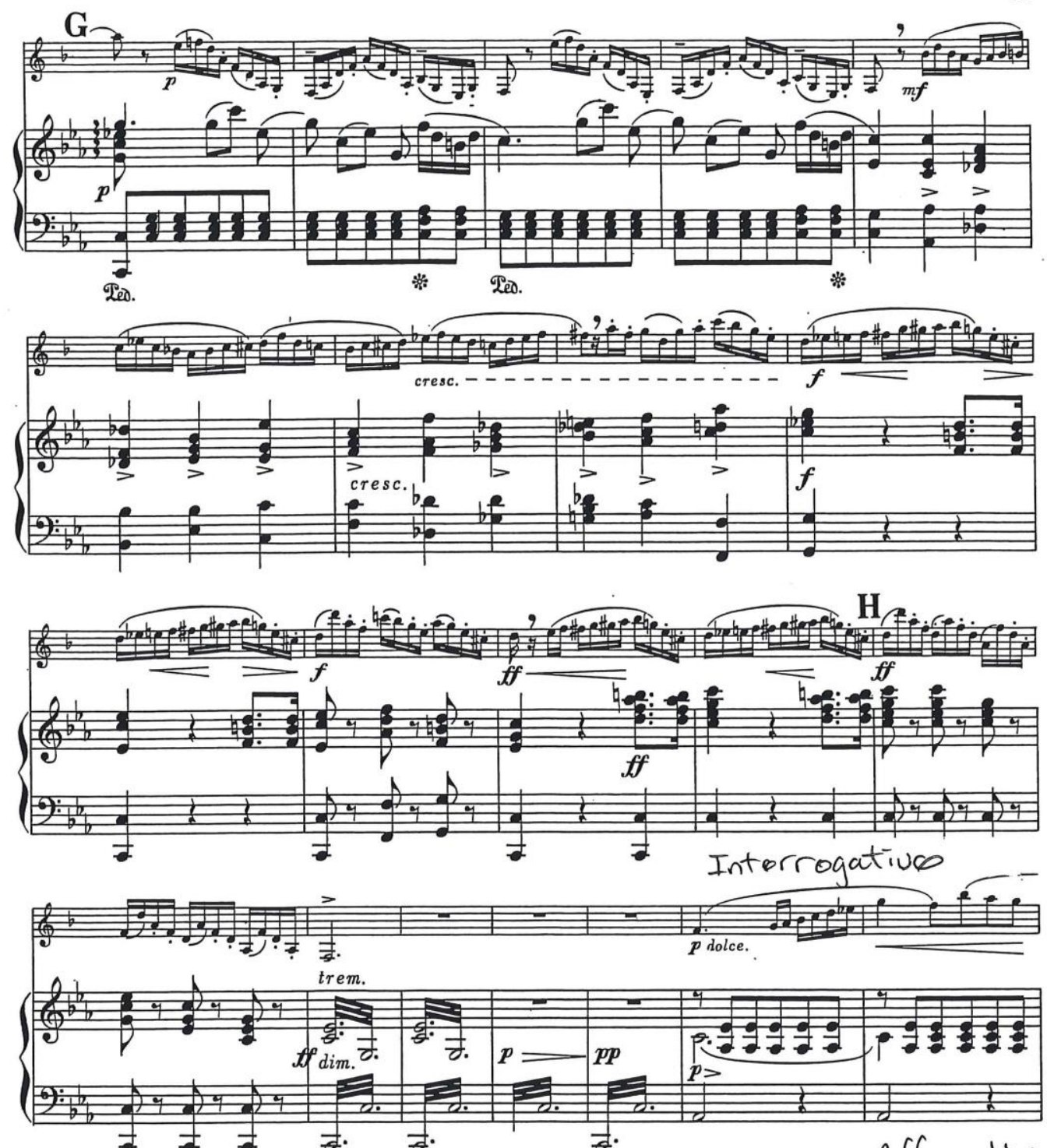
Affirmatius $F$. Intorogatiun Affirmative

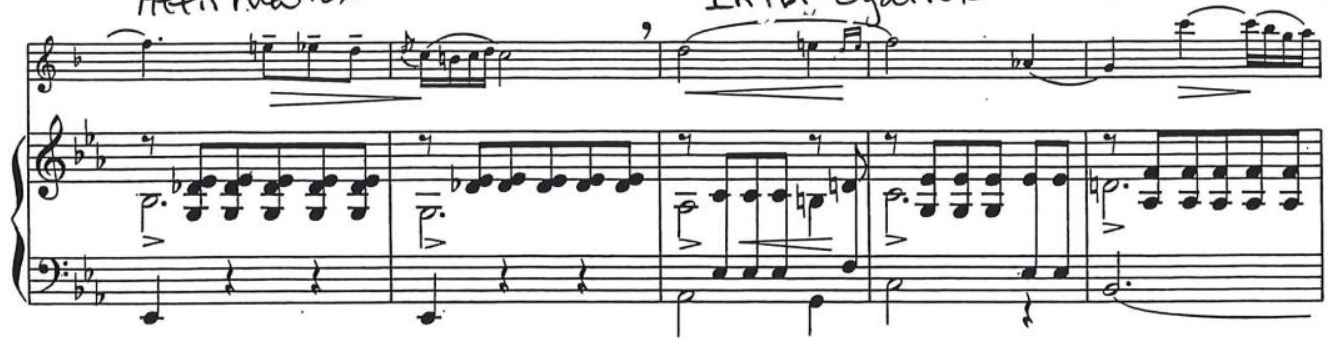

ST -86 

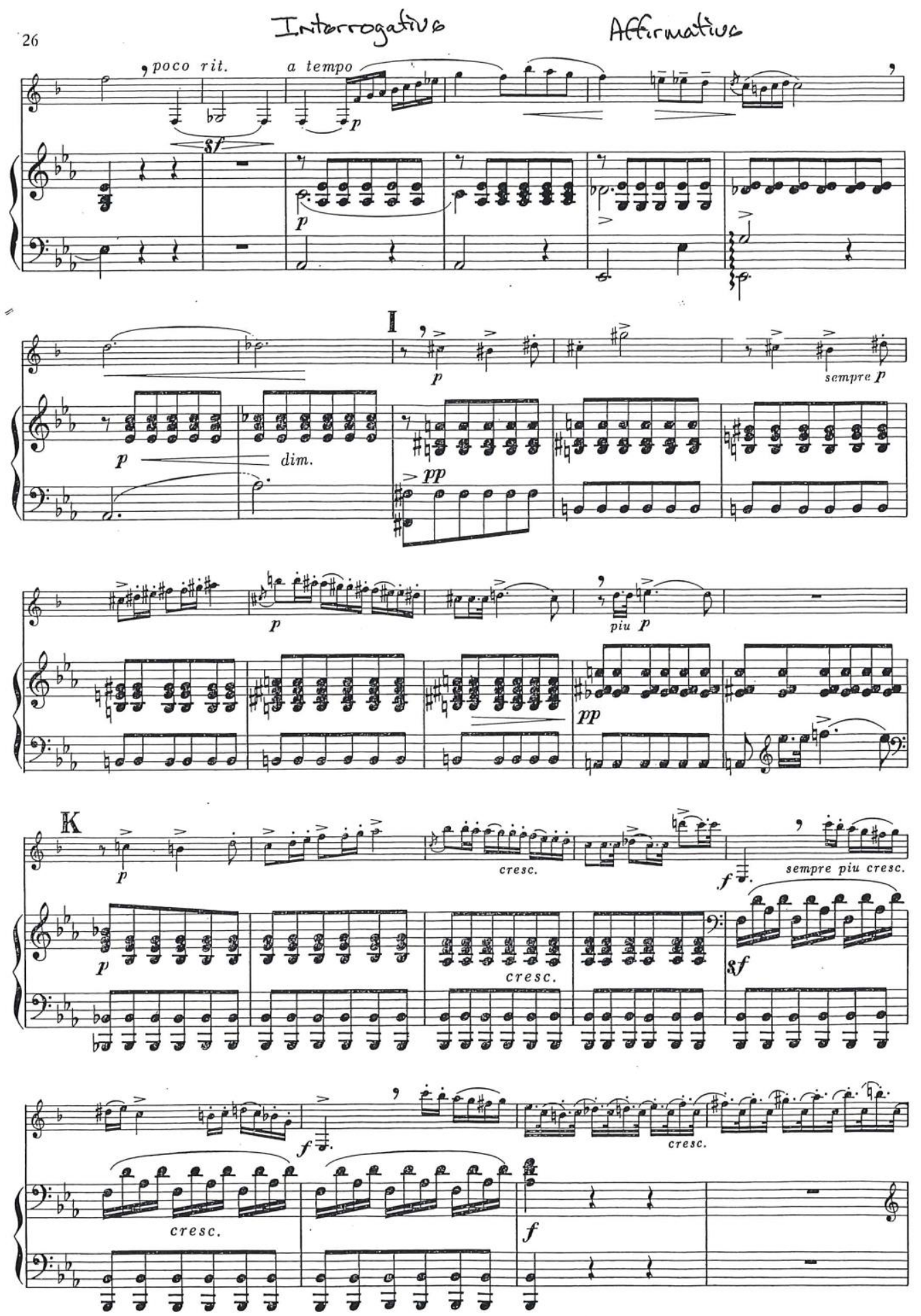

ST -86 


\section{Note Groupings Applied}

Note Groupings were used by Marcel Tabuteau to show 2, 3, or 4 note relationships and how they interact progressing the music forward via the harmony. The groupings must be carefully chosen depending on where the harmony's tension lies. Throughout Tabuteau's search for constant forward motion, he was able to utilize these tiny cell groups as a means to lay the foundation for structuring phrases. Each grouping should coincide with the Interrogative/Affirmative/More-Affirmative techniques in the previous chapter.

Below, are the first five measures of the clarinet part in Weber's Second Clarinet Concerto with the added Note Groupings. Groupings one to three all support the harmonic shift from tonic to dominant in second-inversion. A crescendo should be added instead of the composer's selection of a decrescendo because of the tonic to dominant shift that naturally increases the tension into measure two. Note groupings four to six then decrescendo to the tonic triad in first-inversion in measure four. Groupings seven and eight is where the most tension lies in the phrase by ending with a dominant seventh chord in root position.

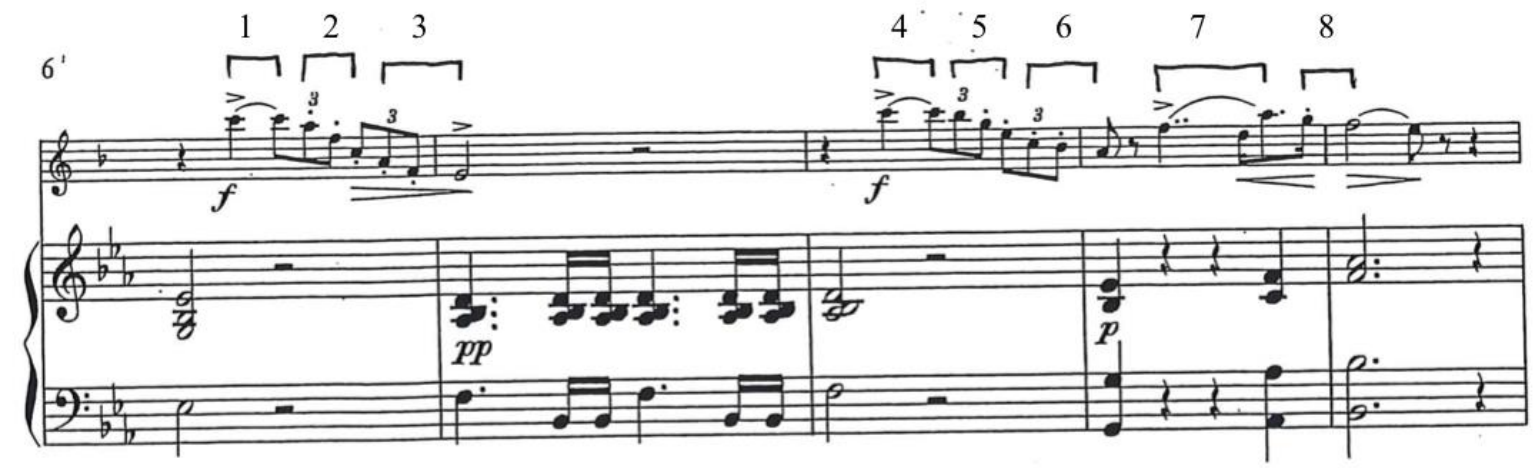

Depicted below is the entirety of Weber's Second Clarinet Concerto's primary themes analyzed with Tabuteau's Note Grouping technique. See Appendix D for additional information. 

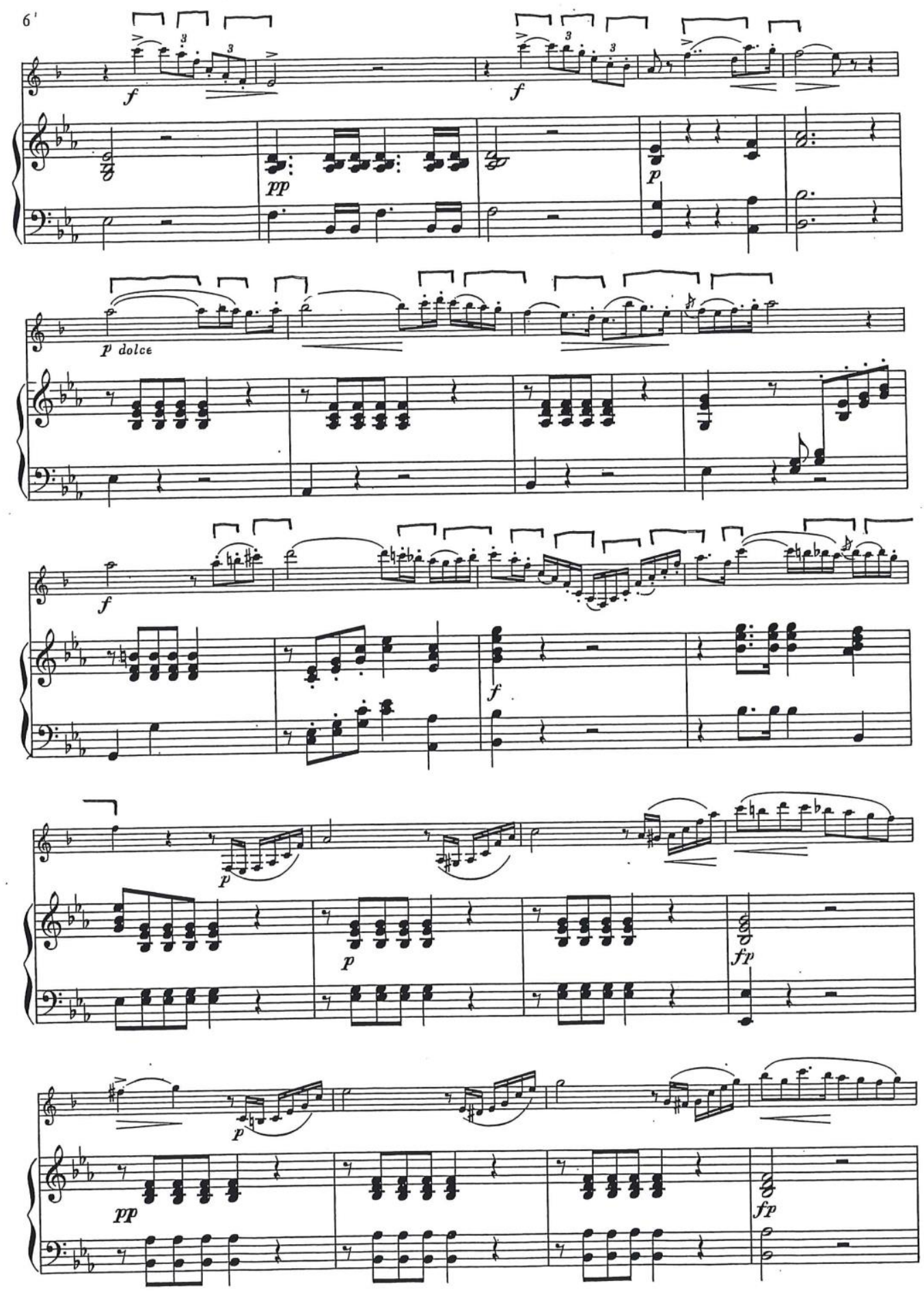

ST. -86 

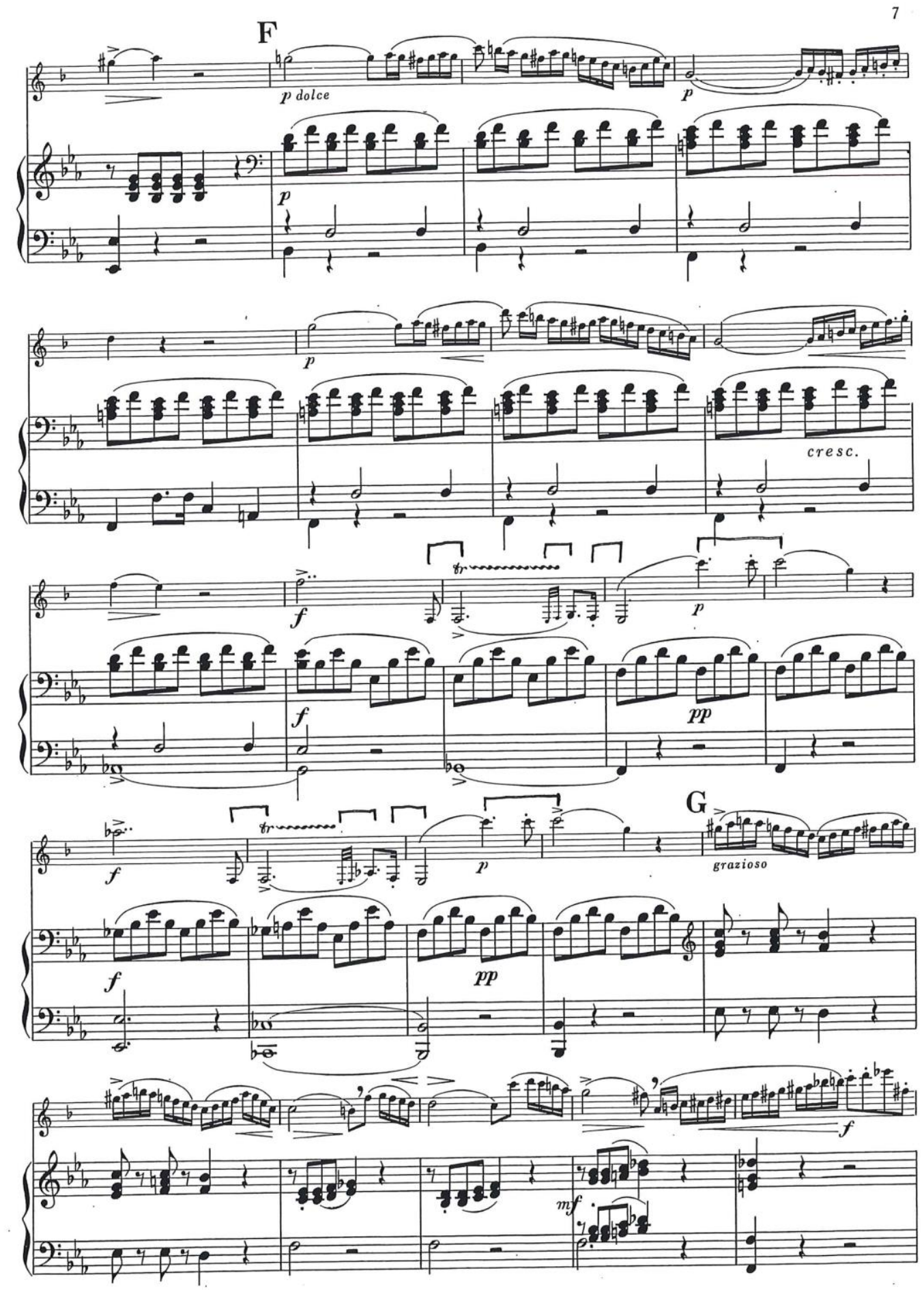

ST -86 

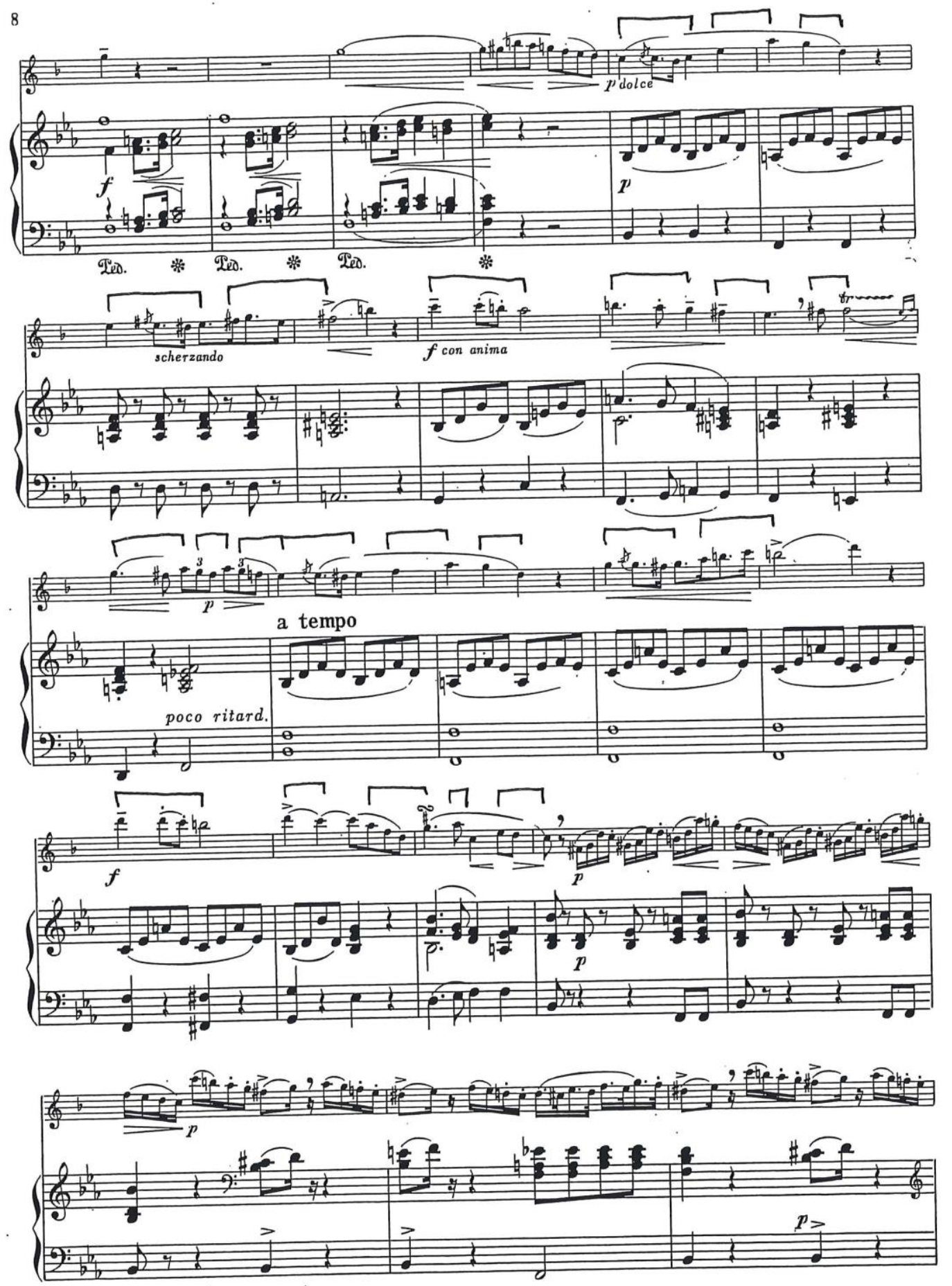

ST -86 
10
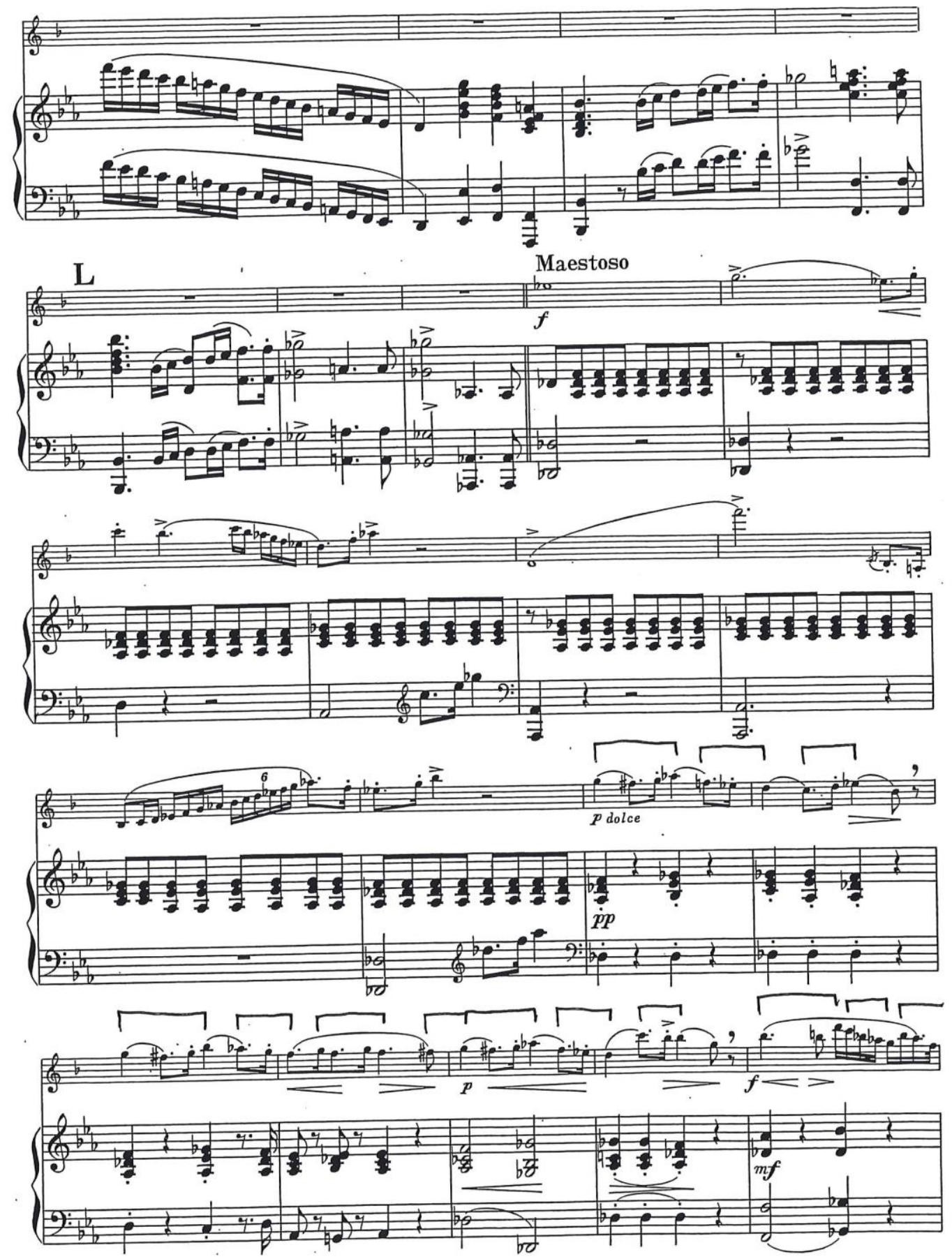

ST1-86 
11
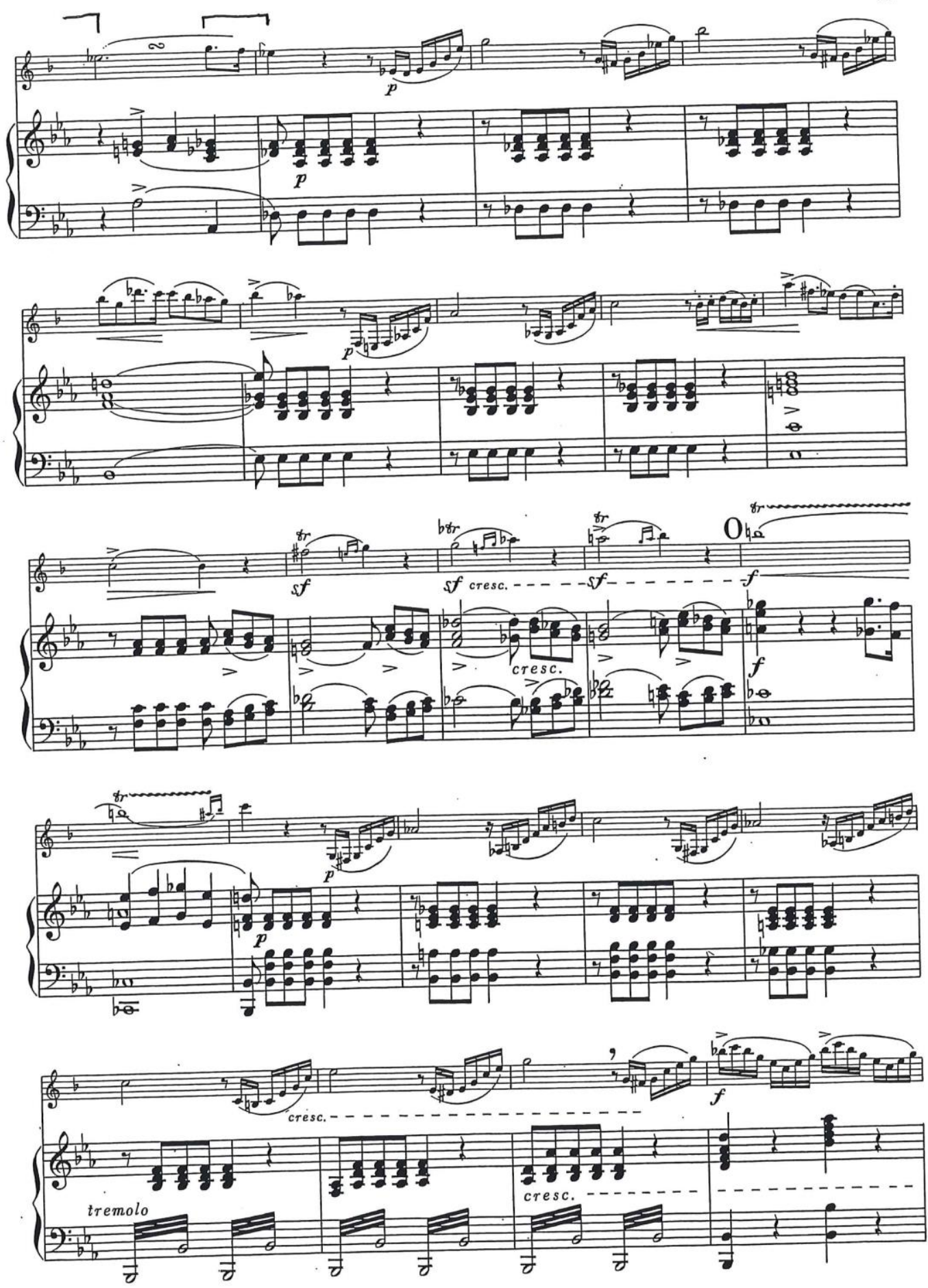

ST -86 

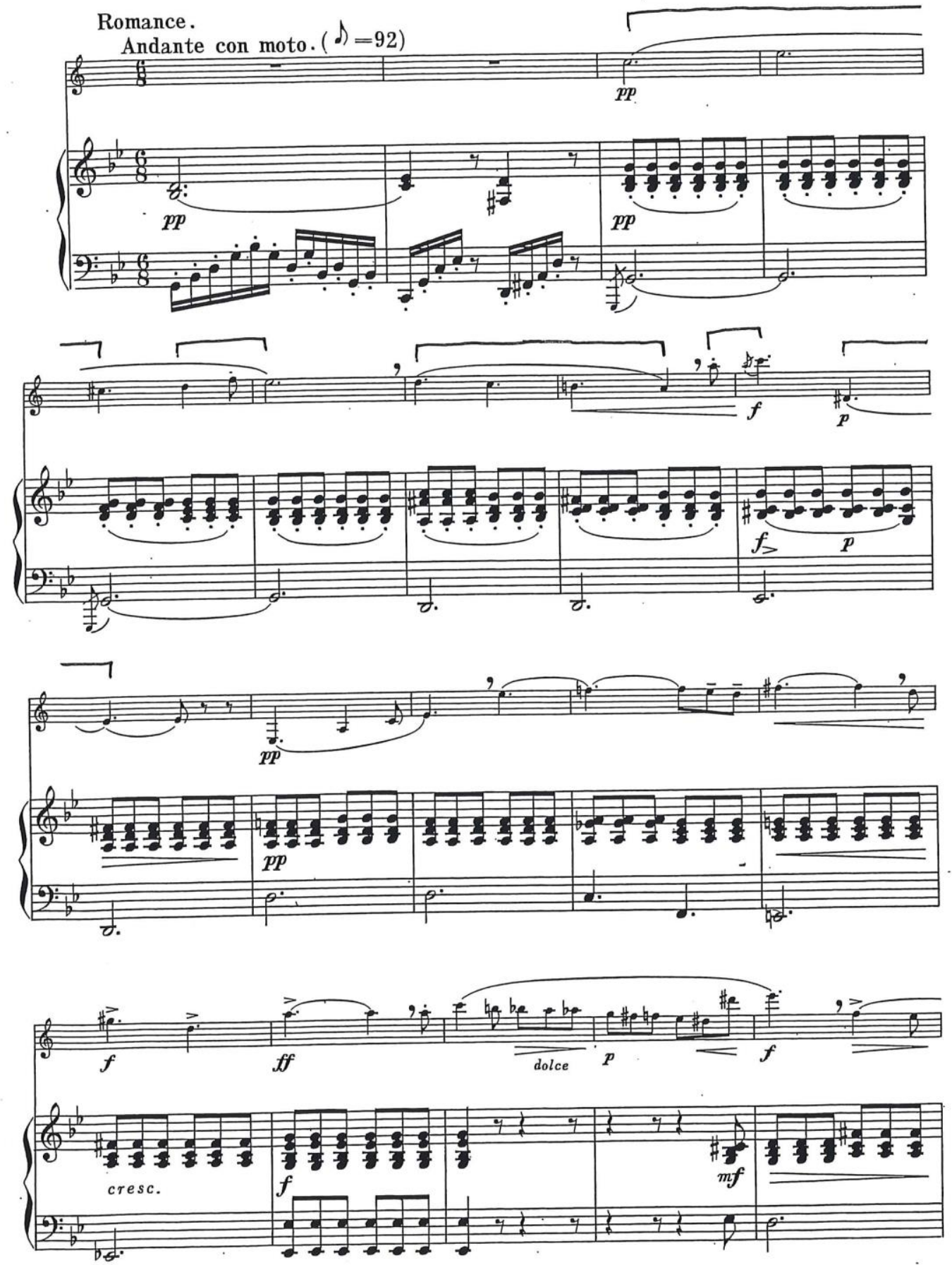

ST -86 
16

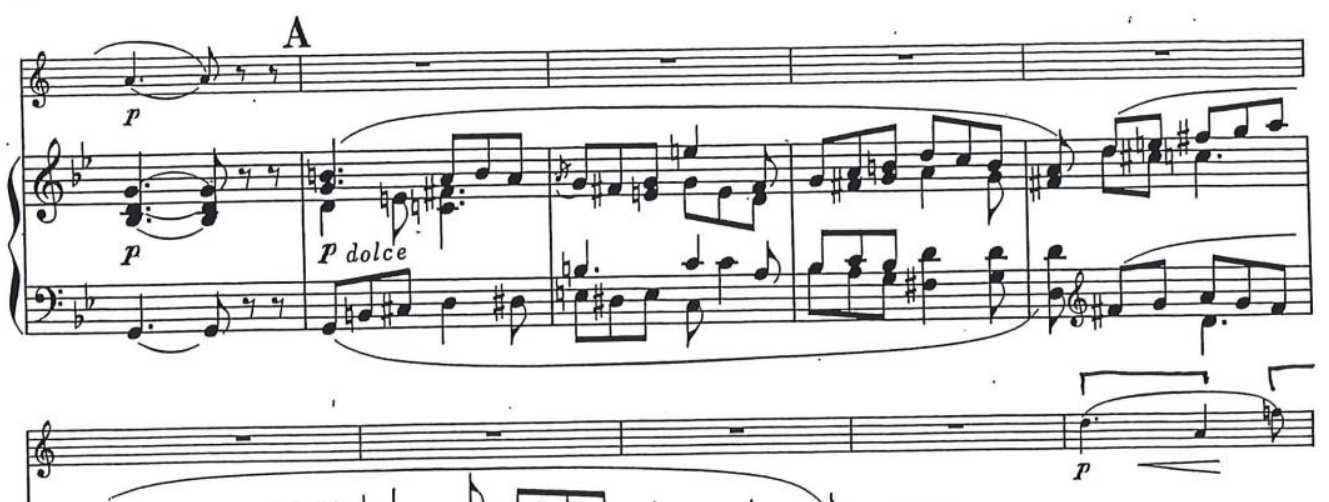

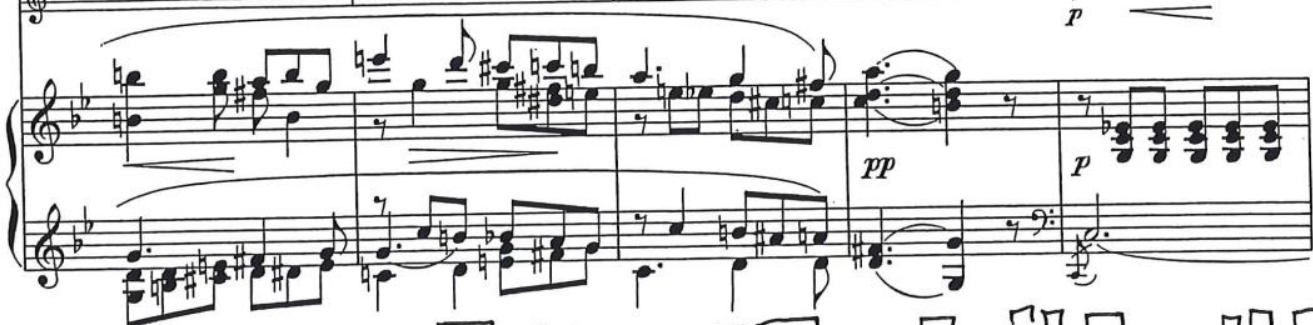
(1)

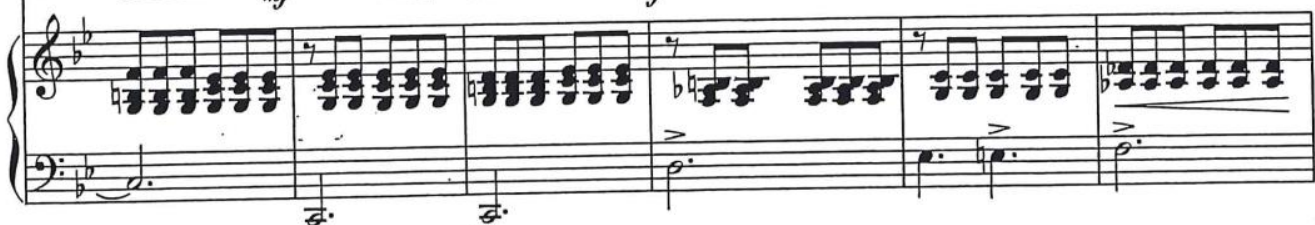

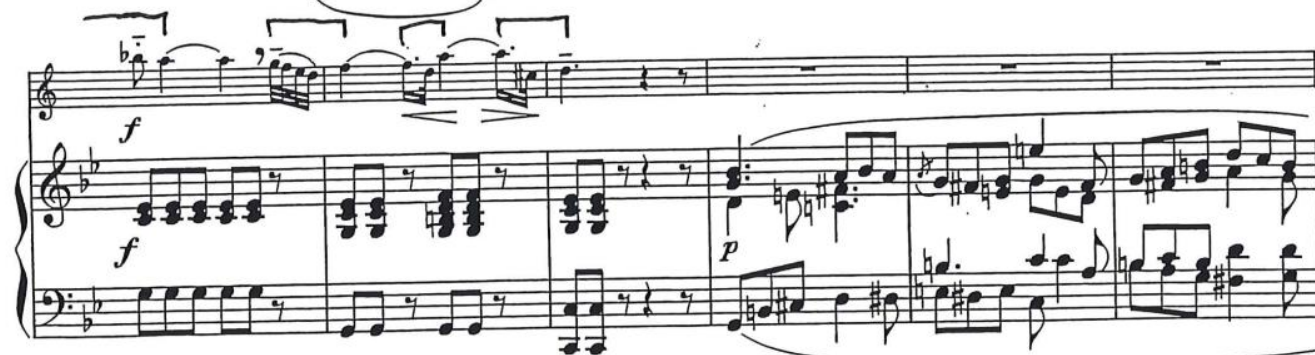

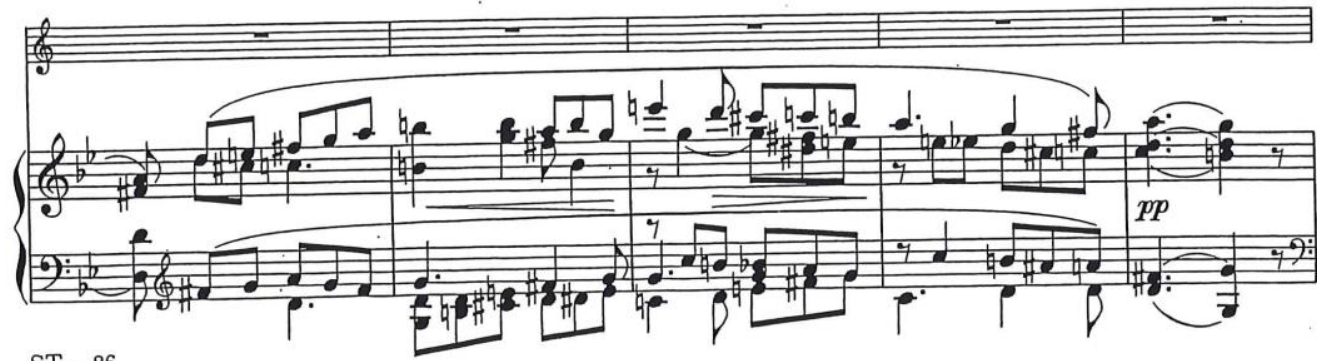
ST -86 

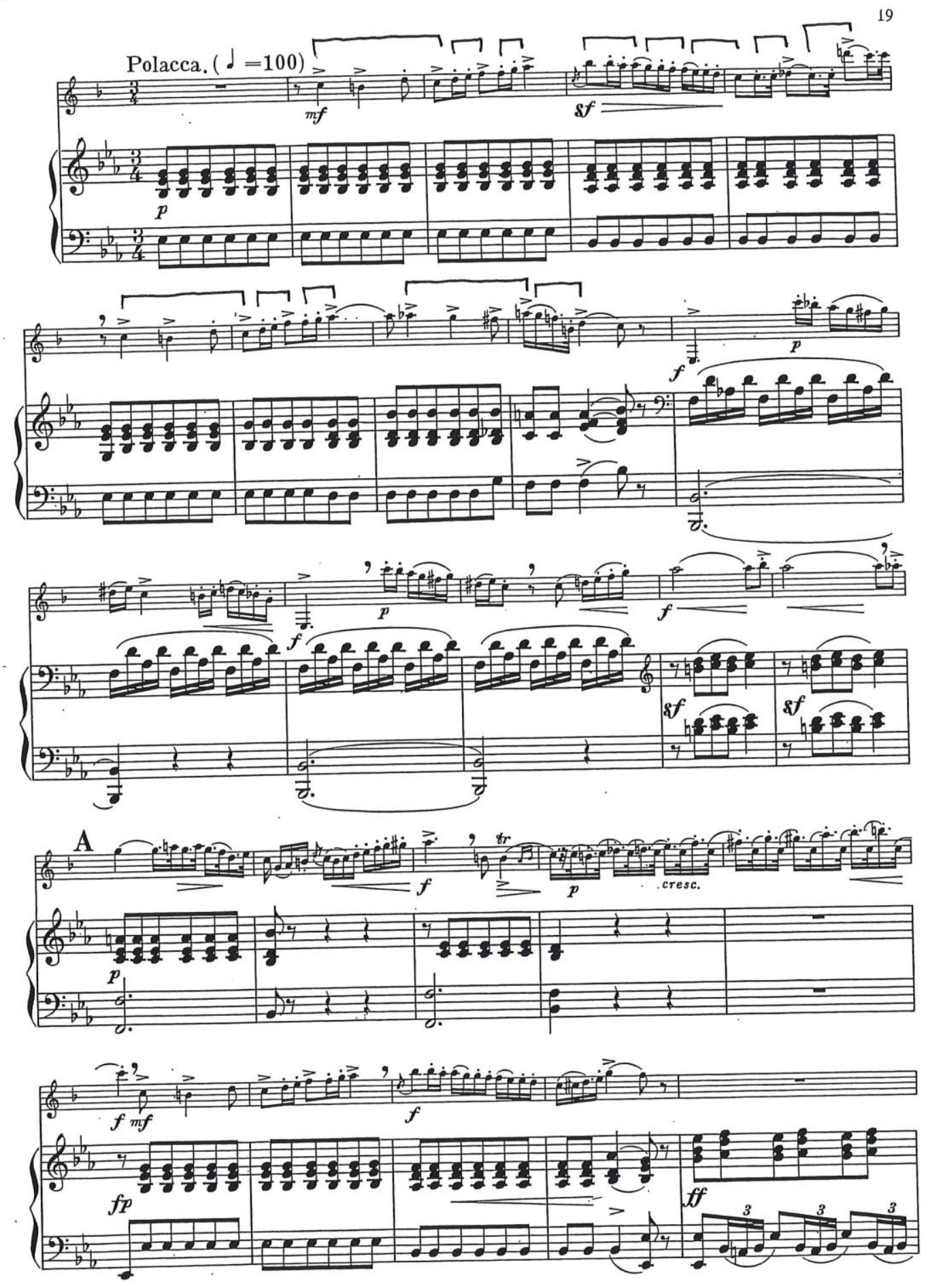

ST -86 
20
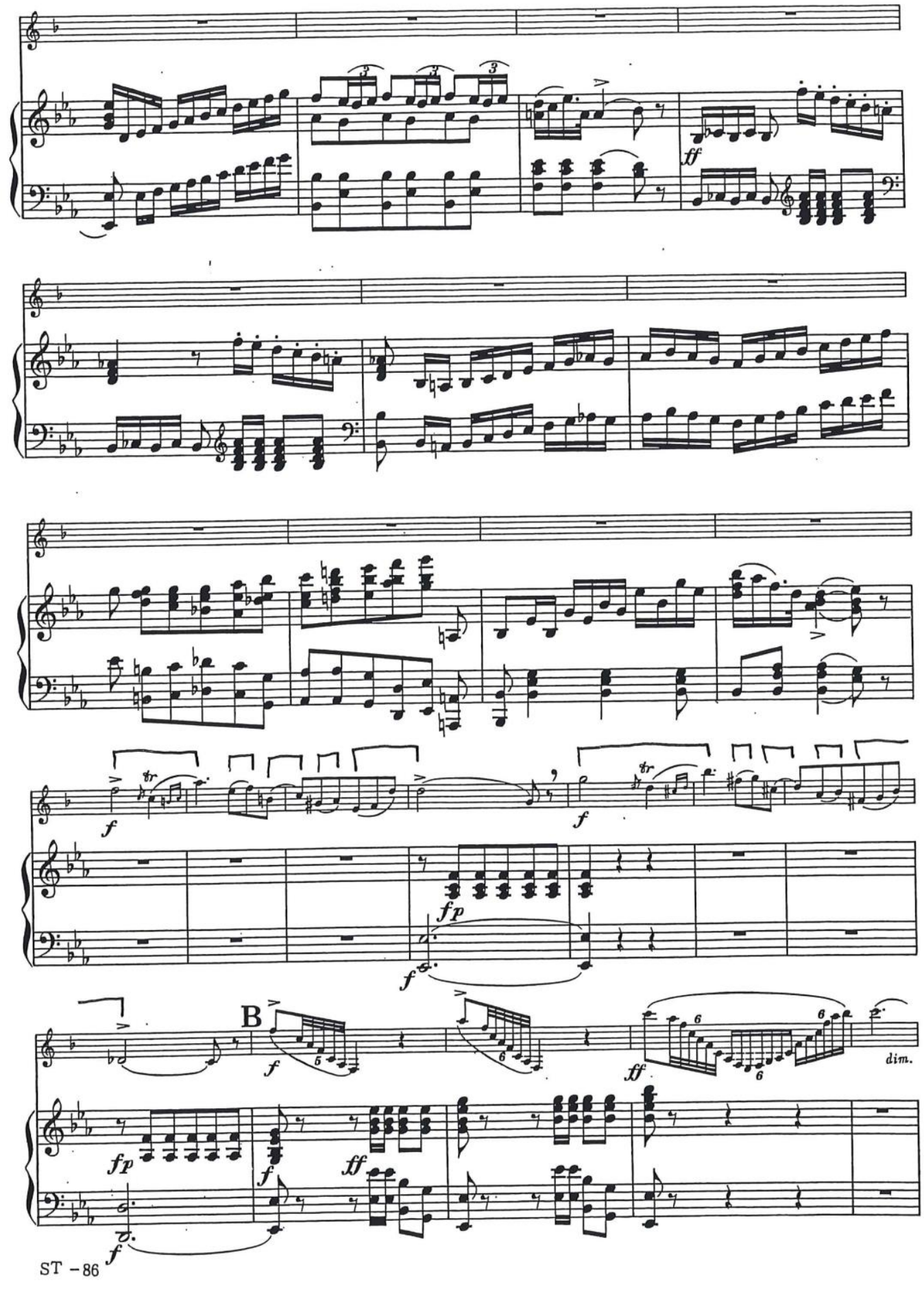

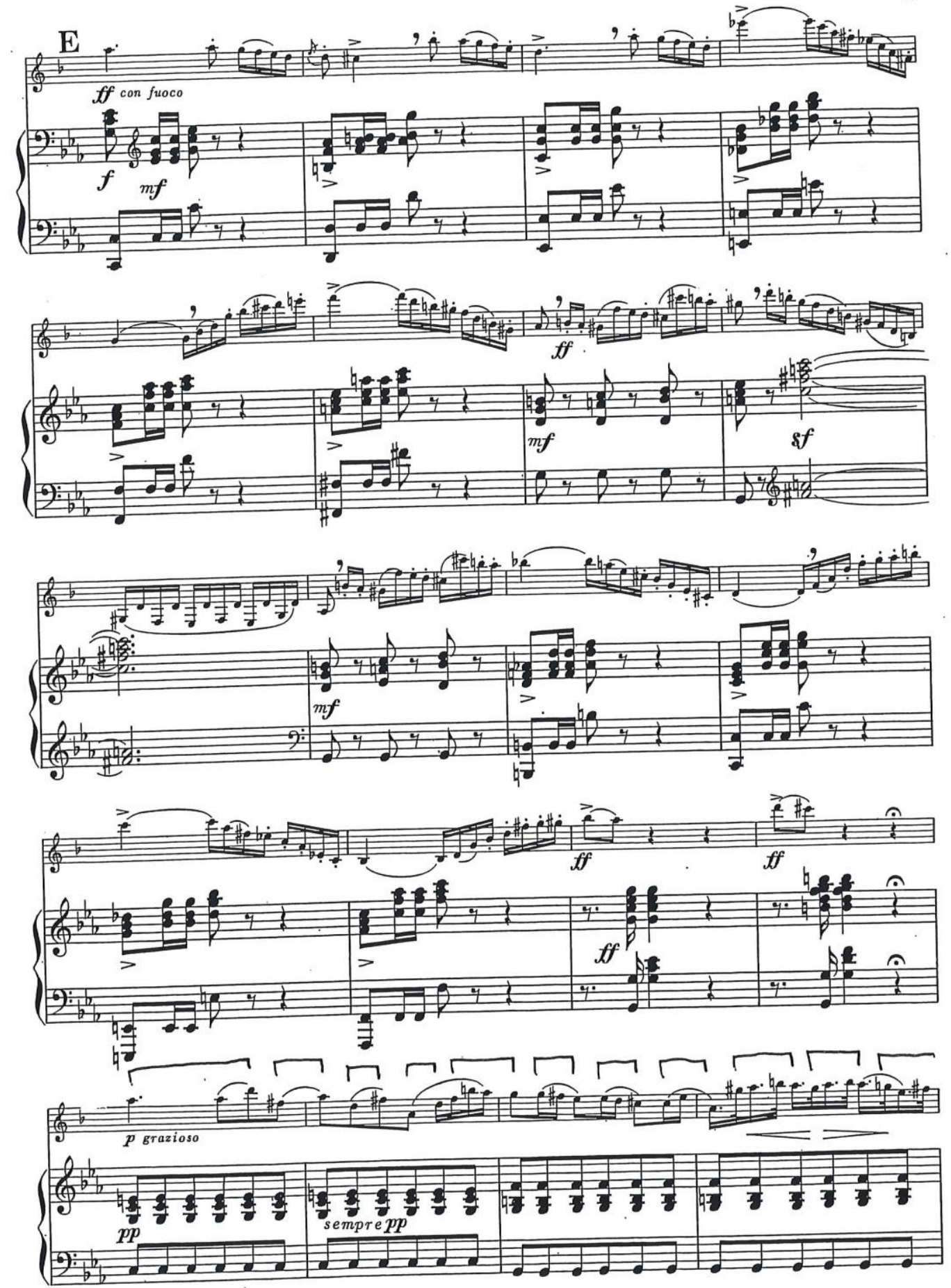

ST -86 

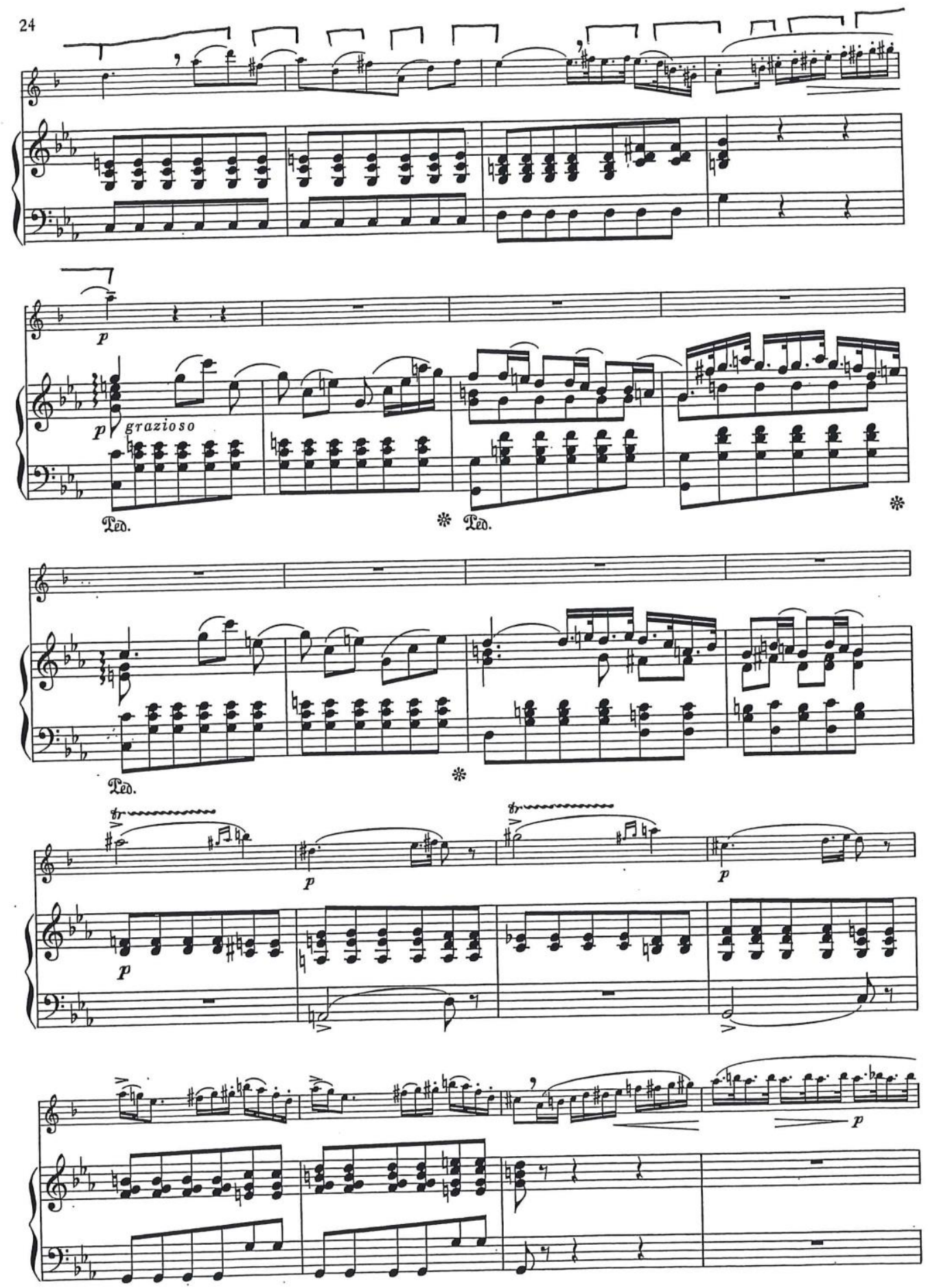

ST -86 

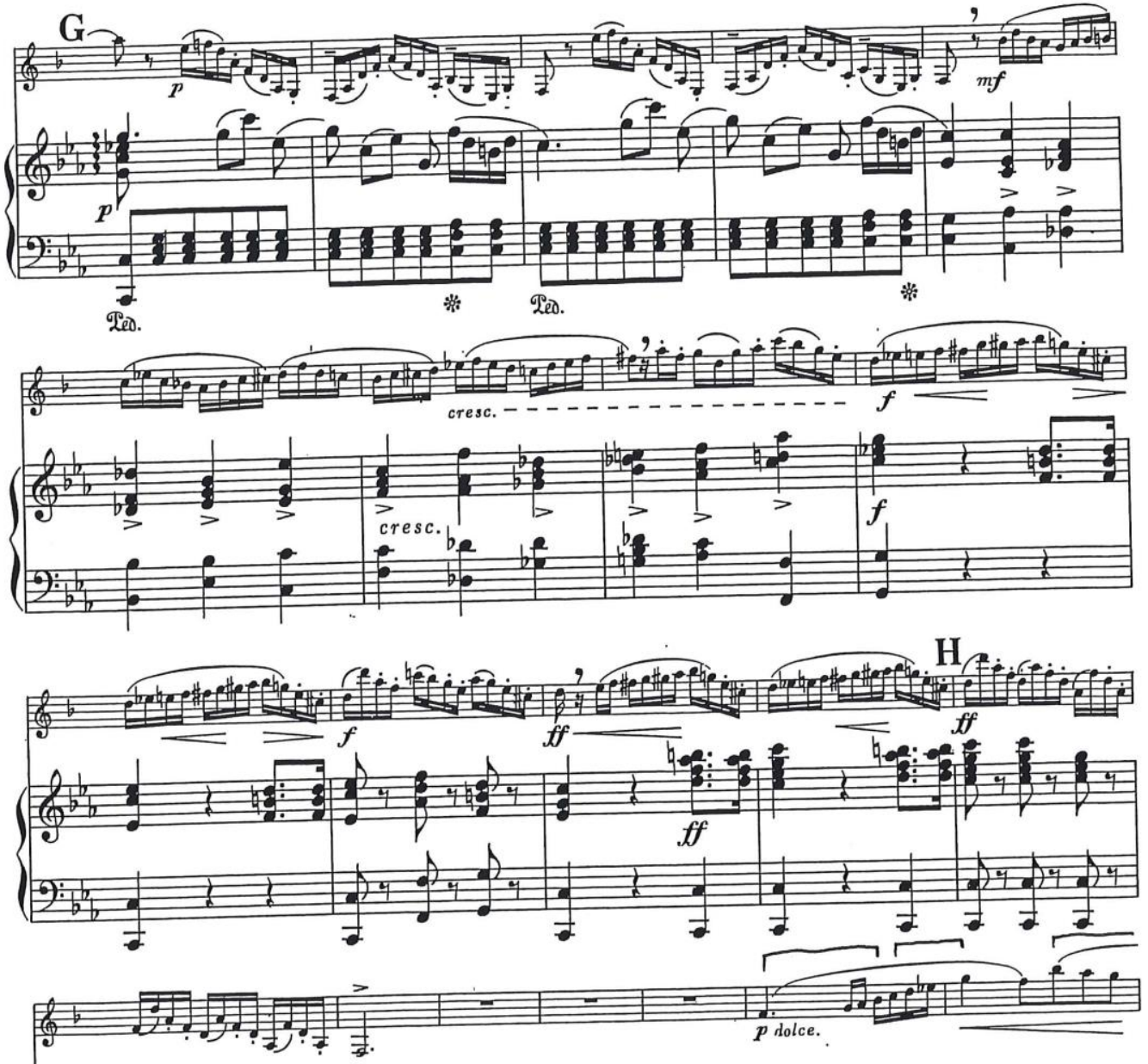

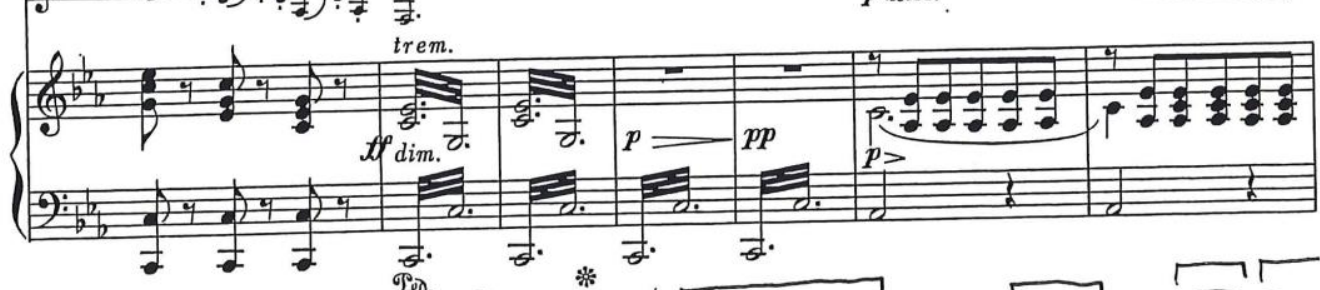

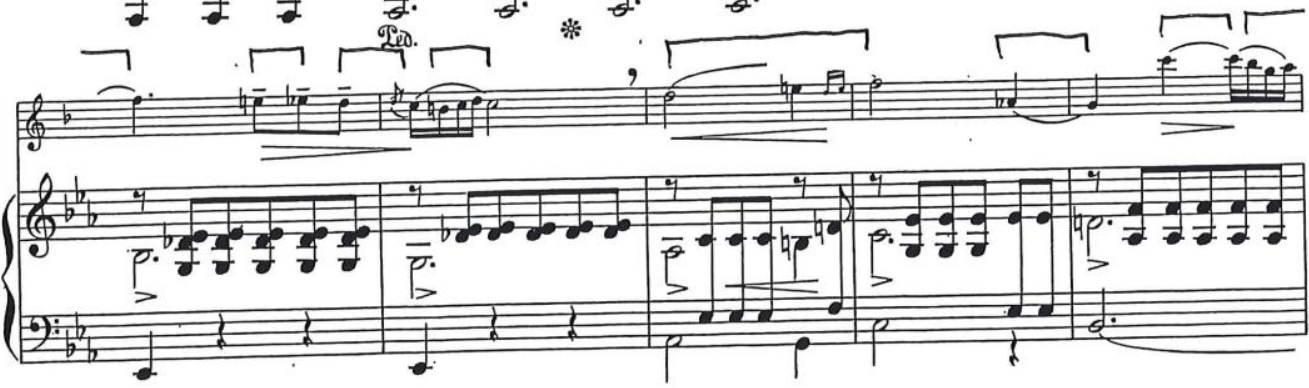

ST -86 

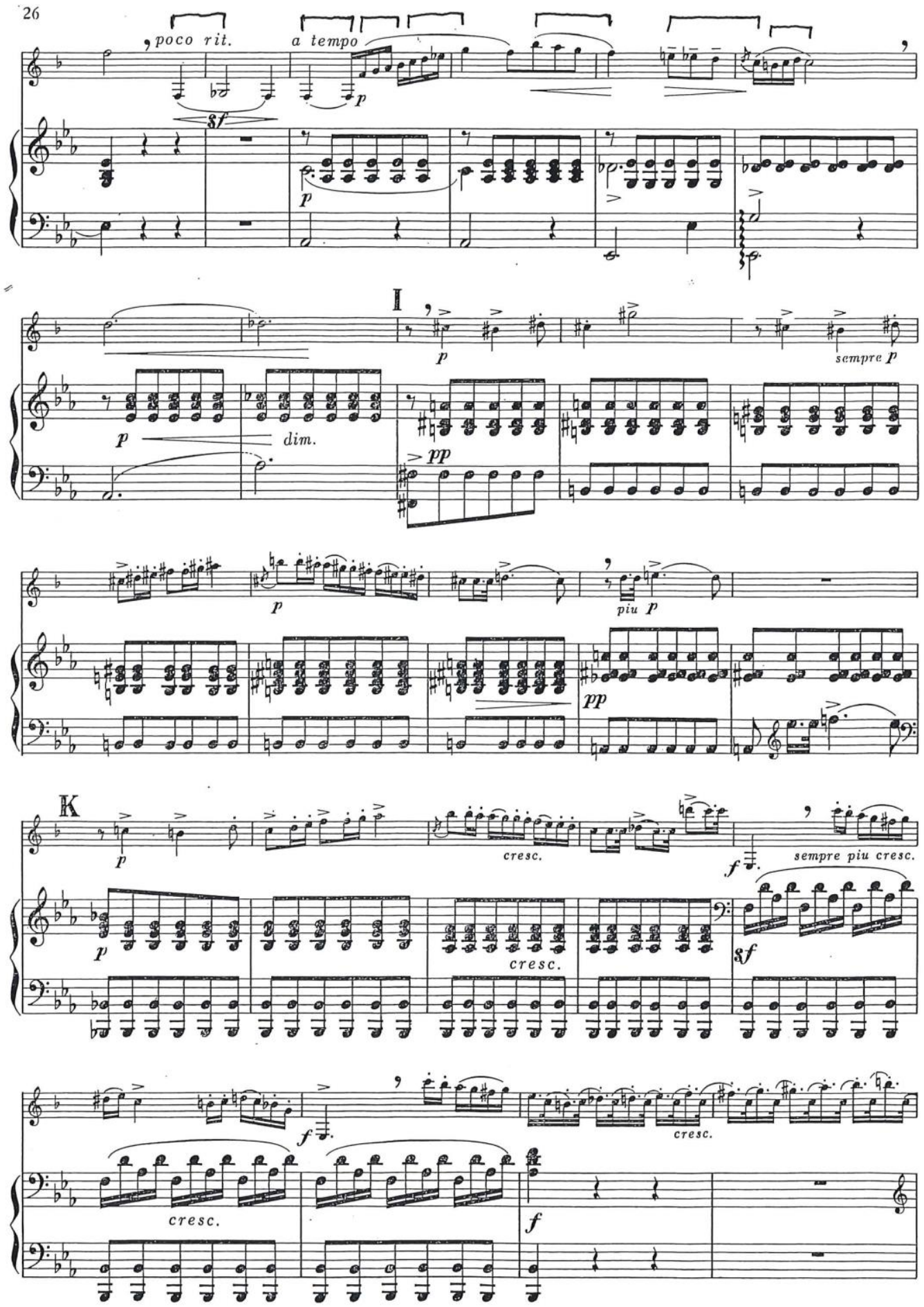

ST -86 


\section{Up/Down Gestures Applied}

Marcel Tabuteau's experience playing the violin as a child lead him to create the Up/Down system. This gestural system parallels the oboe to the violin's bowing patterns. He emulates the Up/Down bow strokes to inhales and exhales of a wind player's breathing patterns. When a person inhales, there is a sense of a lift that leads to an arrival point of where an exchange to an exhale takes place. Once the exhale begins, tension is released outward and downward until the end. When considered within a phrase, the first note will more than likely be a "down" marking that will either go to an "up" or a "down" depending on the meter and harmony. This process is essential in constructing a phrase correctly as it directly correlates to the evenness of how it will sound overall.

An example of the Up/Down system is illustrated in the first five measures of the solo below. Using bow markings to label the ideas, the performer should follow the outline laid out in the previous chapter and add the bow markings to each note following the phrase's harmonic structure. Down bows, one, two, and three lead the change from tonic to dominant. Down bows four, five, and six return to the tonic from the dominant in the previous measure. The next two down bows, seven and eight, lead back to the dominant on the downbeat of measure five.

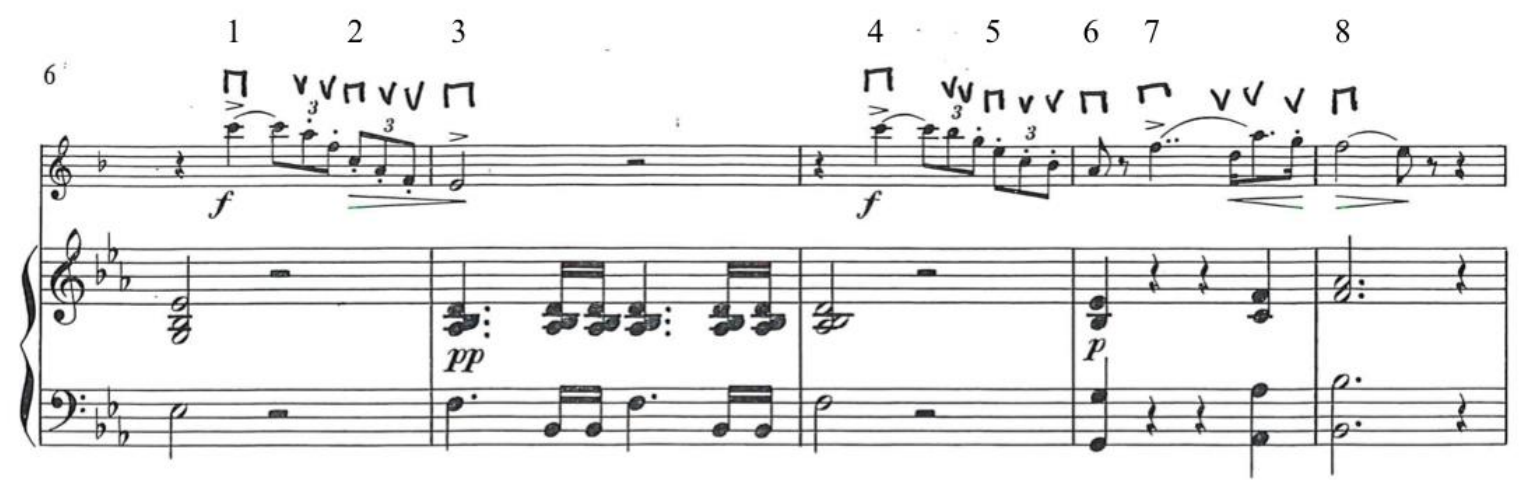


The selected down bow locations lead a progression towards each shift in the harmony. Even though these bowings are in small groups, each one is a small segment of something more substantial leading to each arrival point. Bowings one to three are part of the first group, bowings four, five, and six are part of the second group, and bowings seven and eight are part of the third group. Measure one leads to the dominant in measure two; however, this dominant spot is not as prominent as the dominant in measure five. The dominant in measure two begins in second-inversion with the third of the chord in the bass while the dominant in measure five is in root position, which means that the tensest point of the phrase is on the downbeat of measure five.

The pages below contain the rest of the up and down markings for each primary theme in Weber's Second Clarinet Concerto. See Appendix C for additional information. 

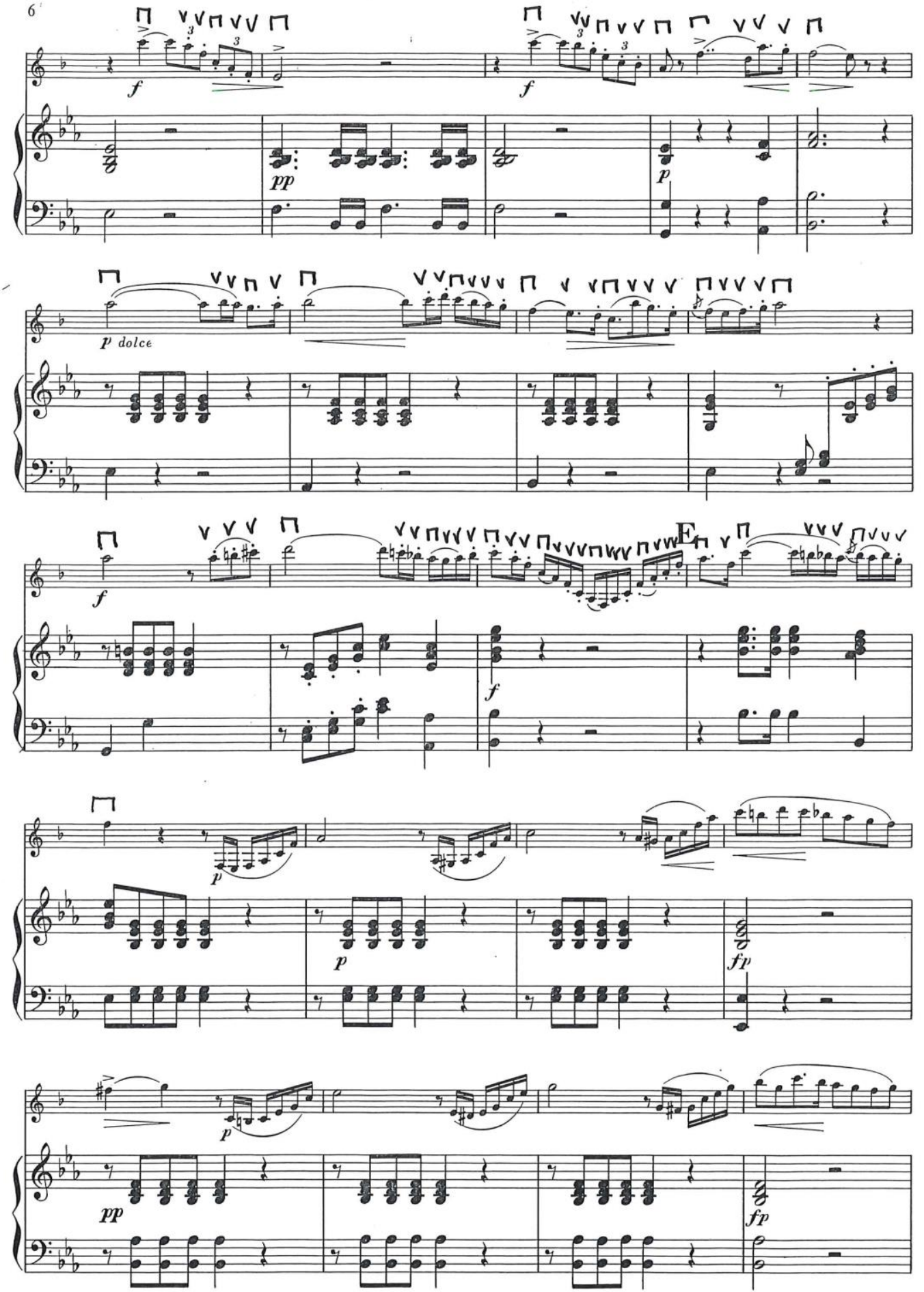

ST -86 

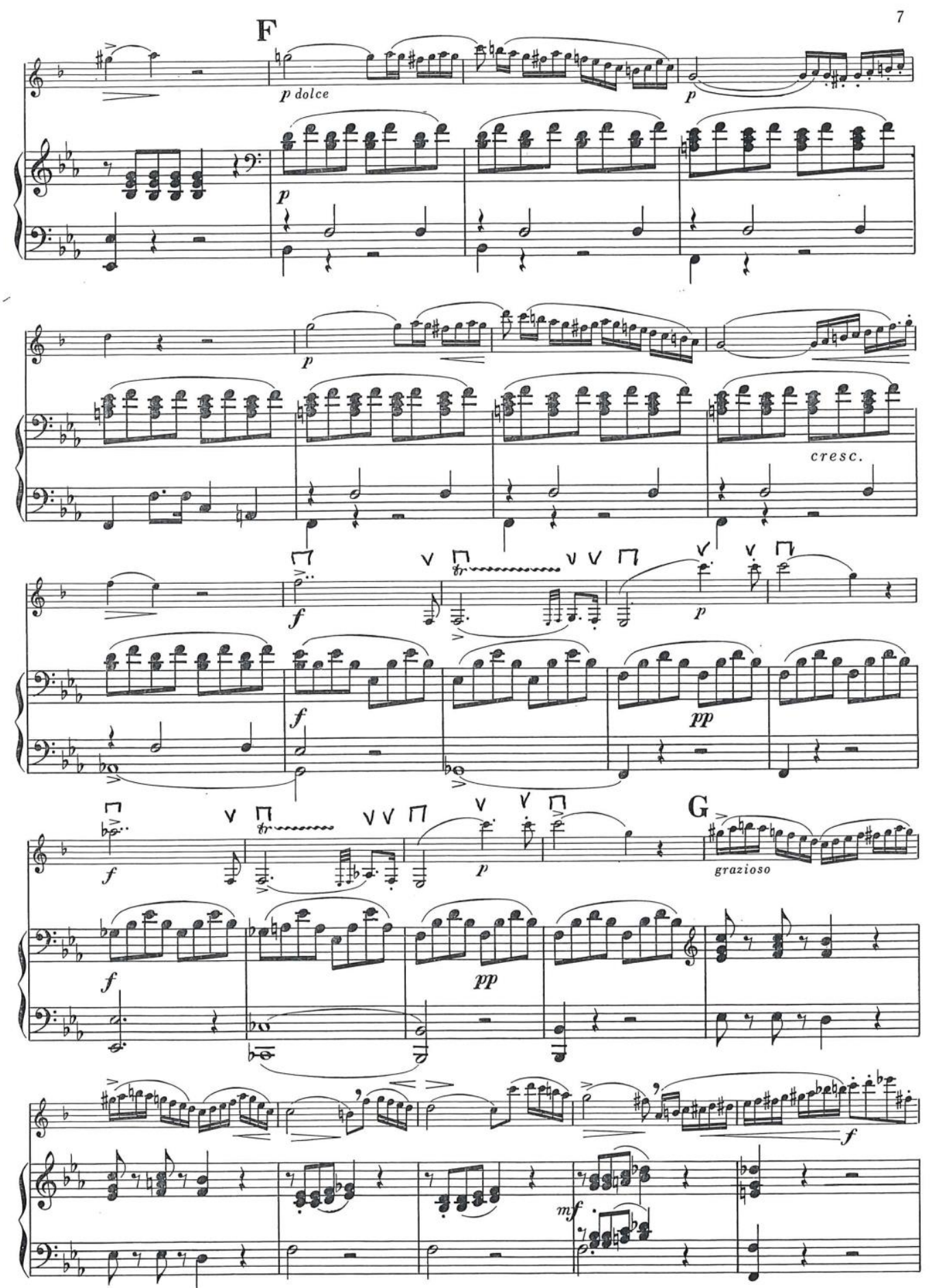

ST -86 

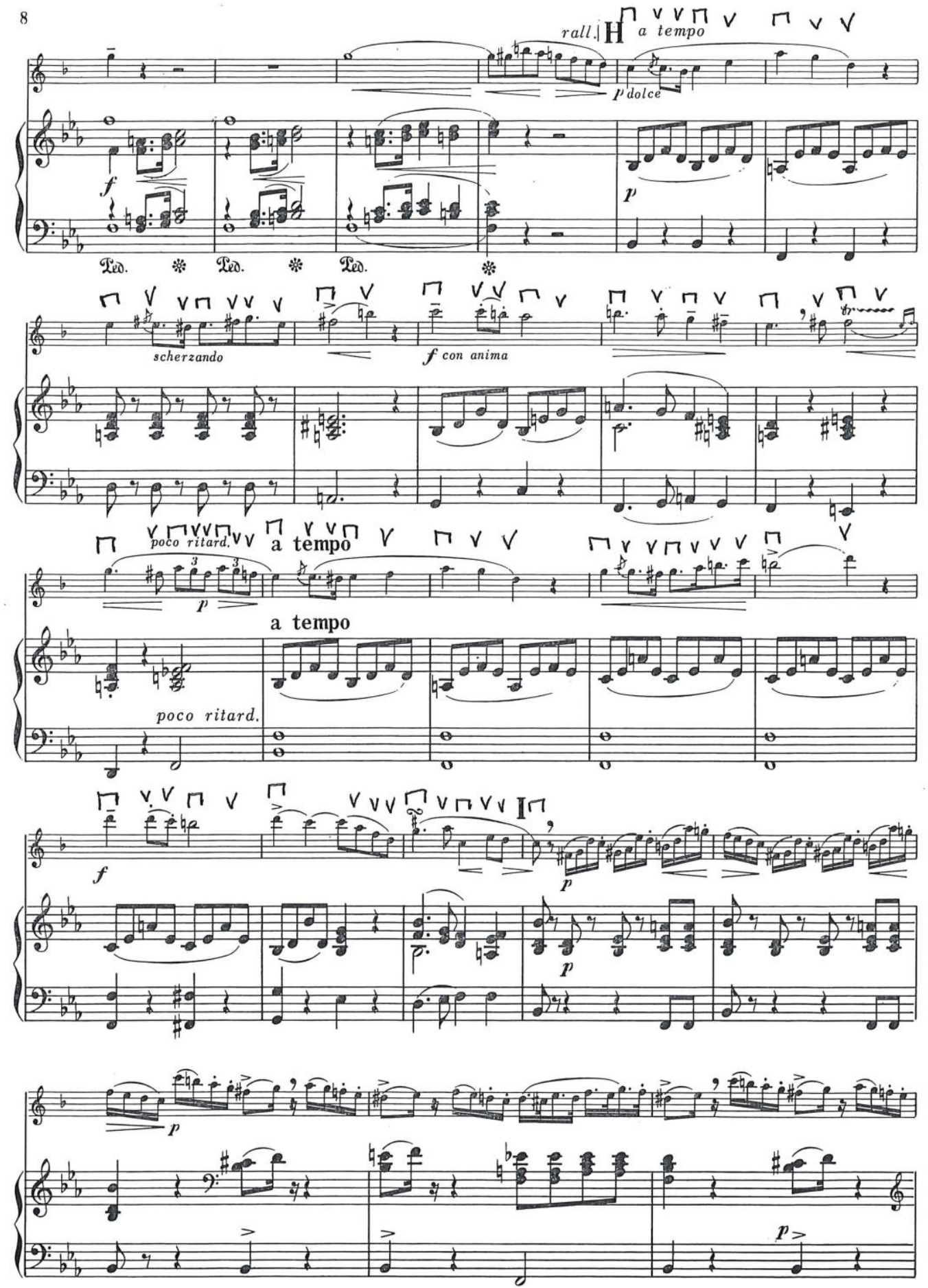

ST -86 
10
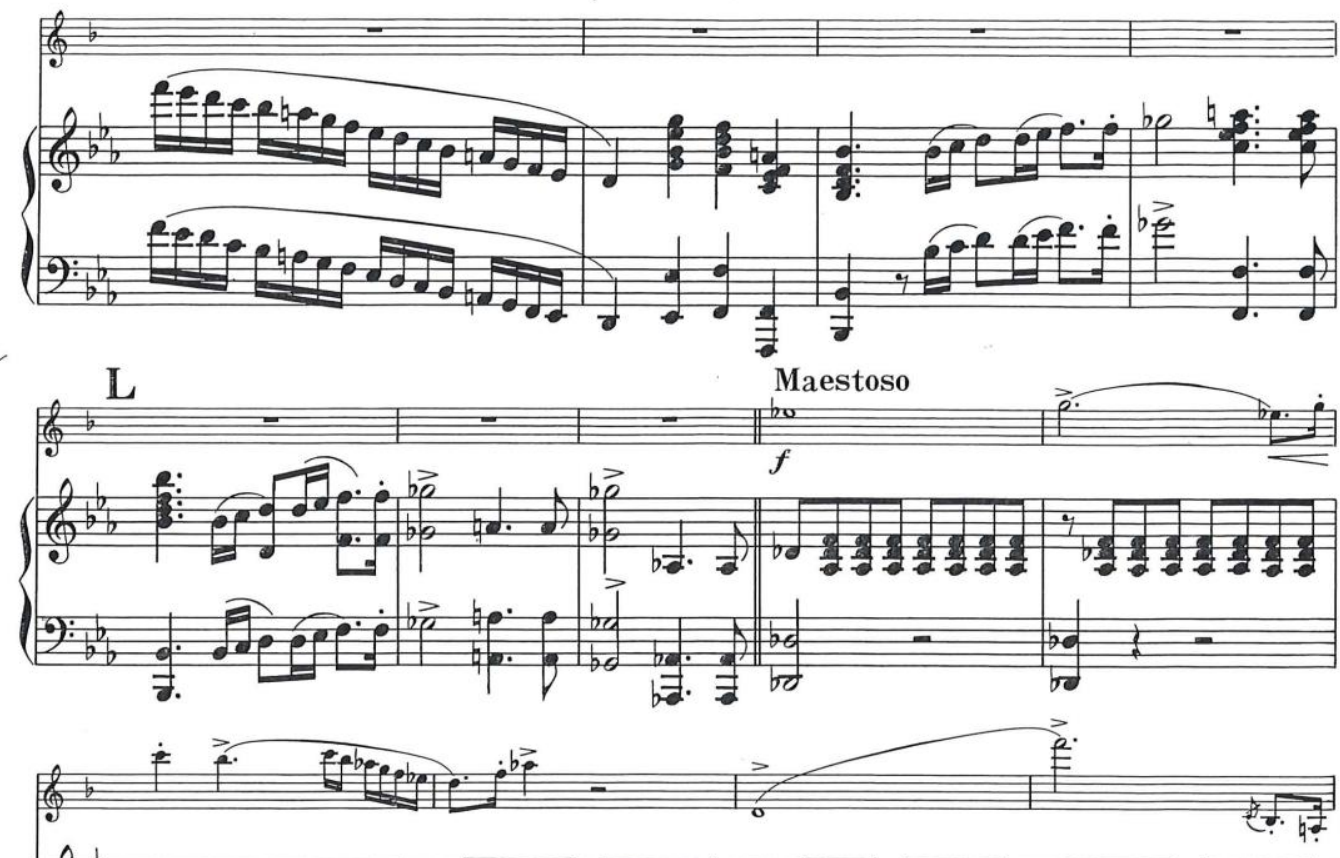

(3)

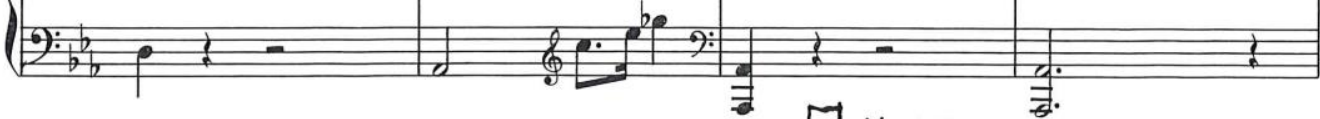

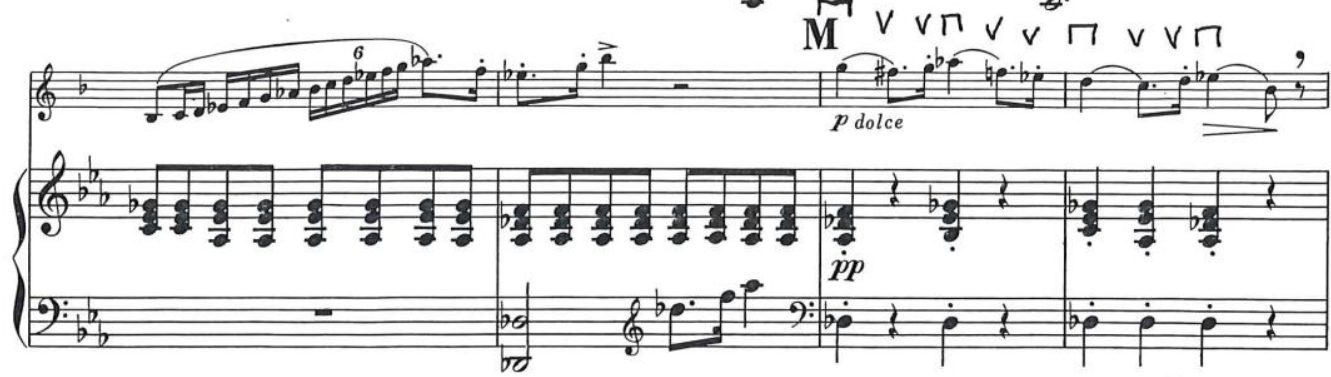

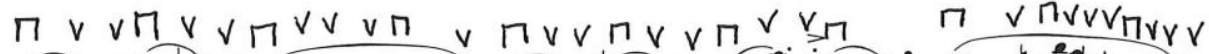

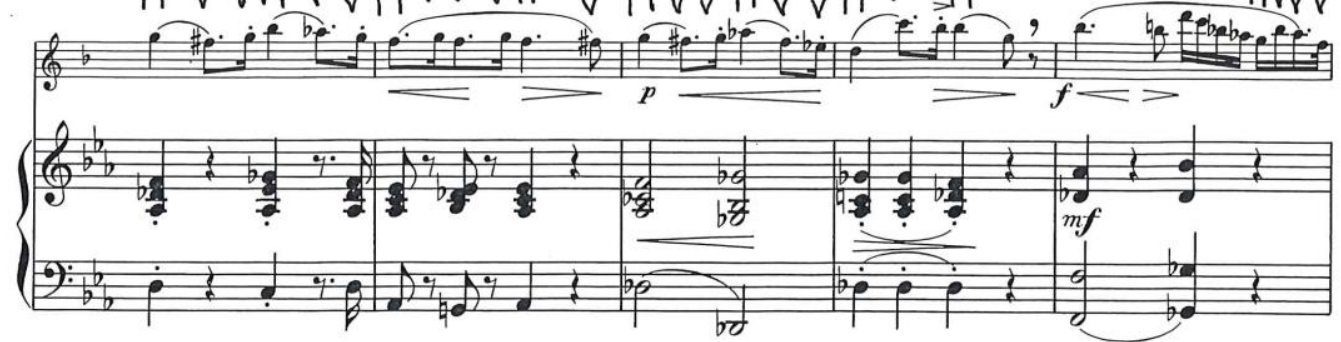

$\mathrm{ST}-86$ 

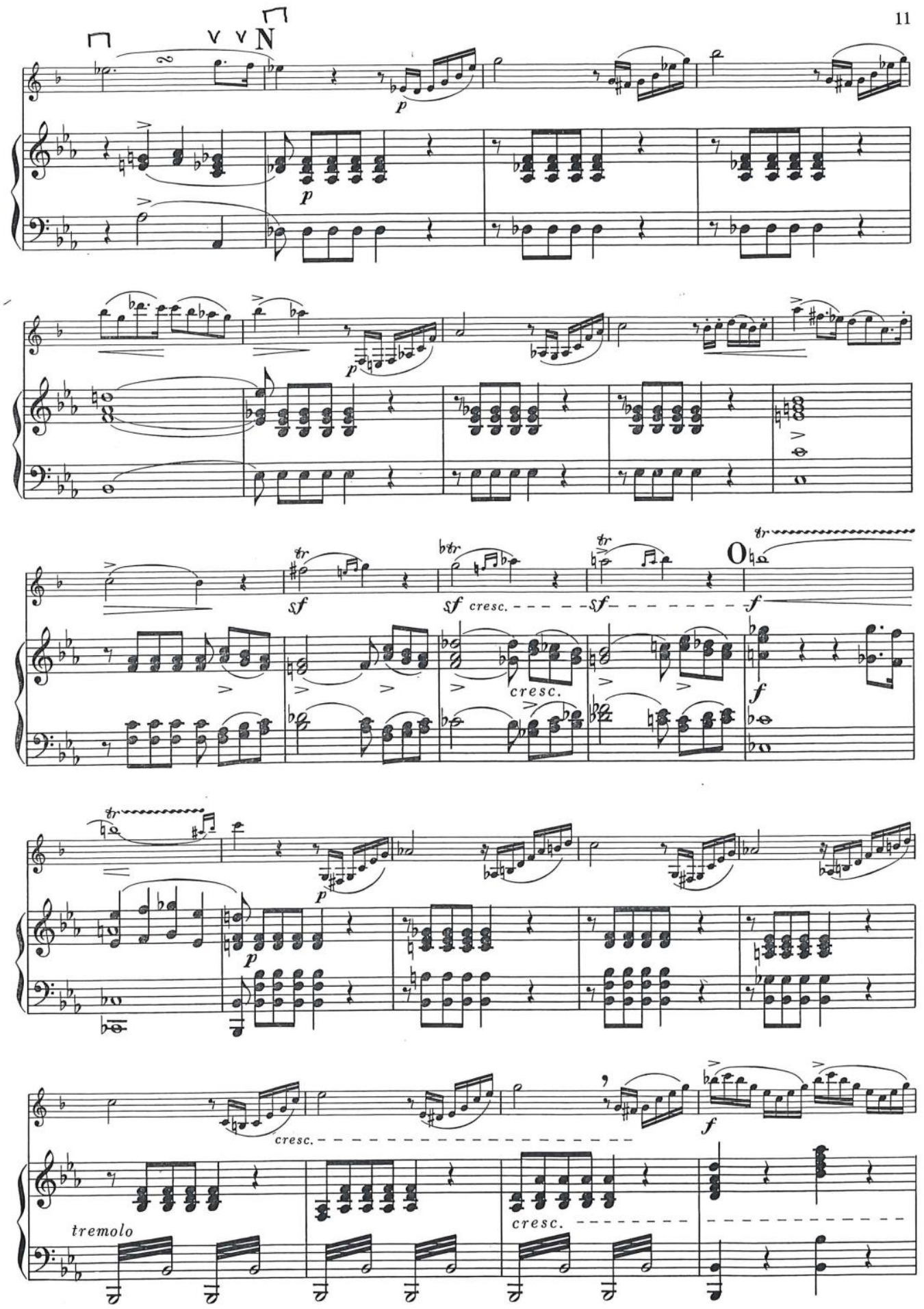

ST -86 

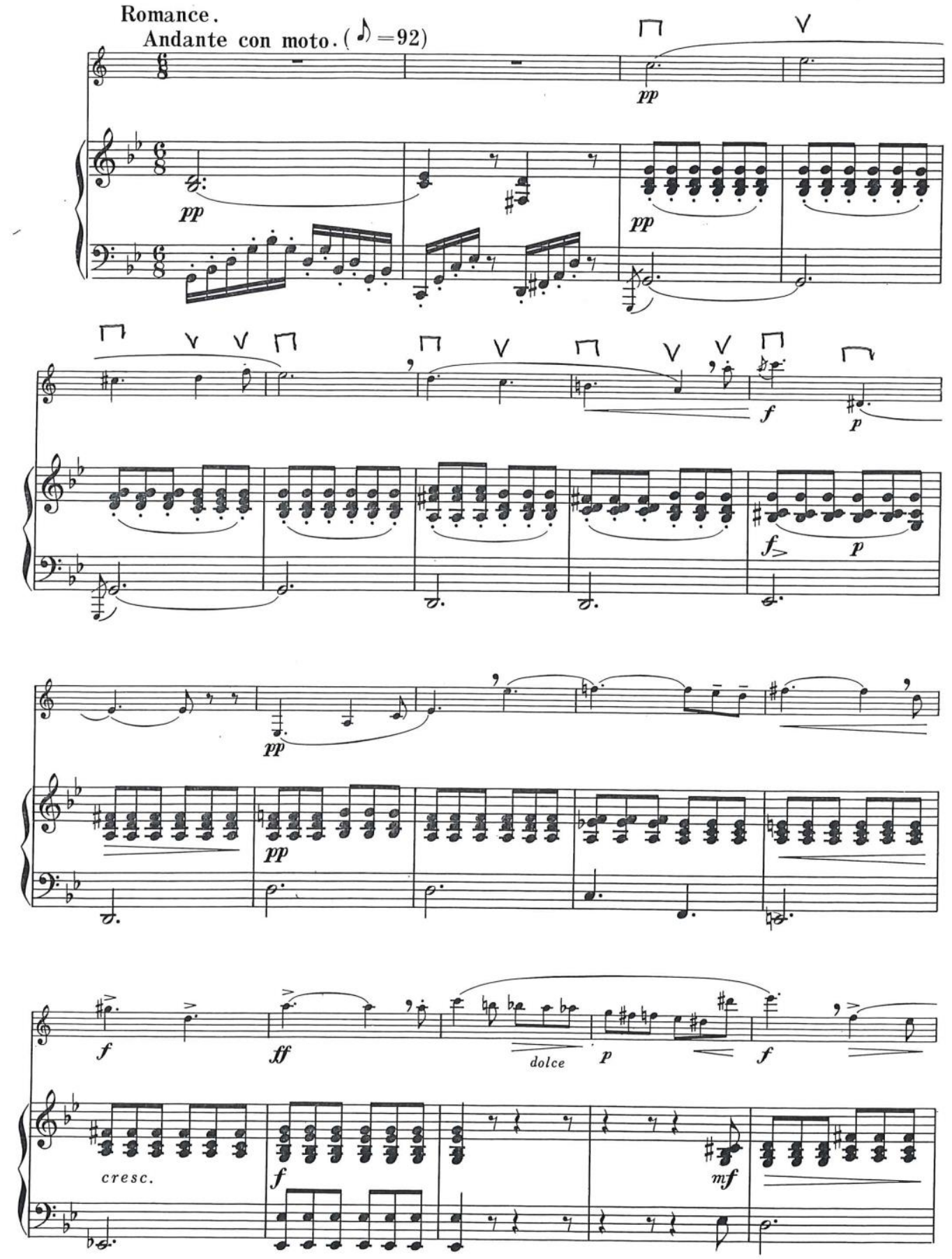

ST -86 
16
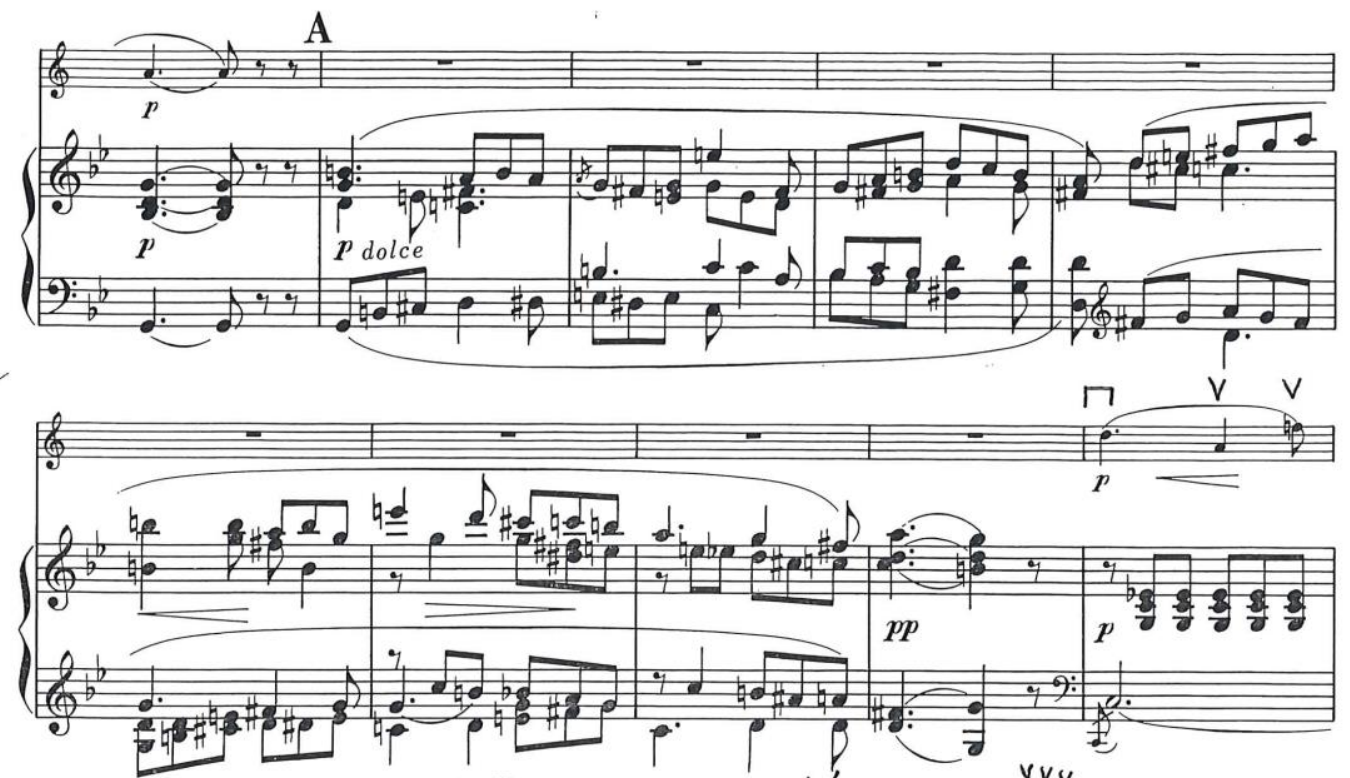
$\Pi \sqcap \vee \vee \sqcap \quad \Pi$ vav
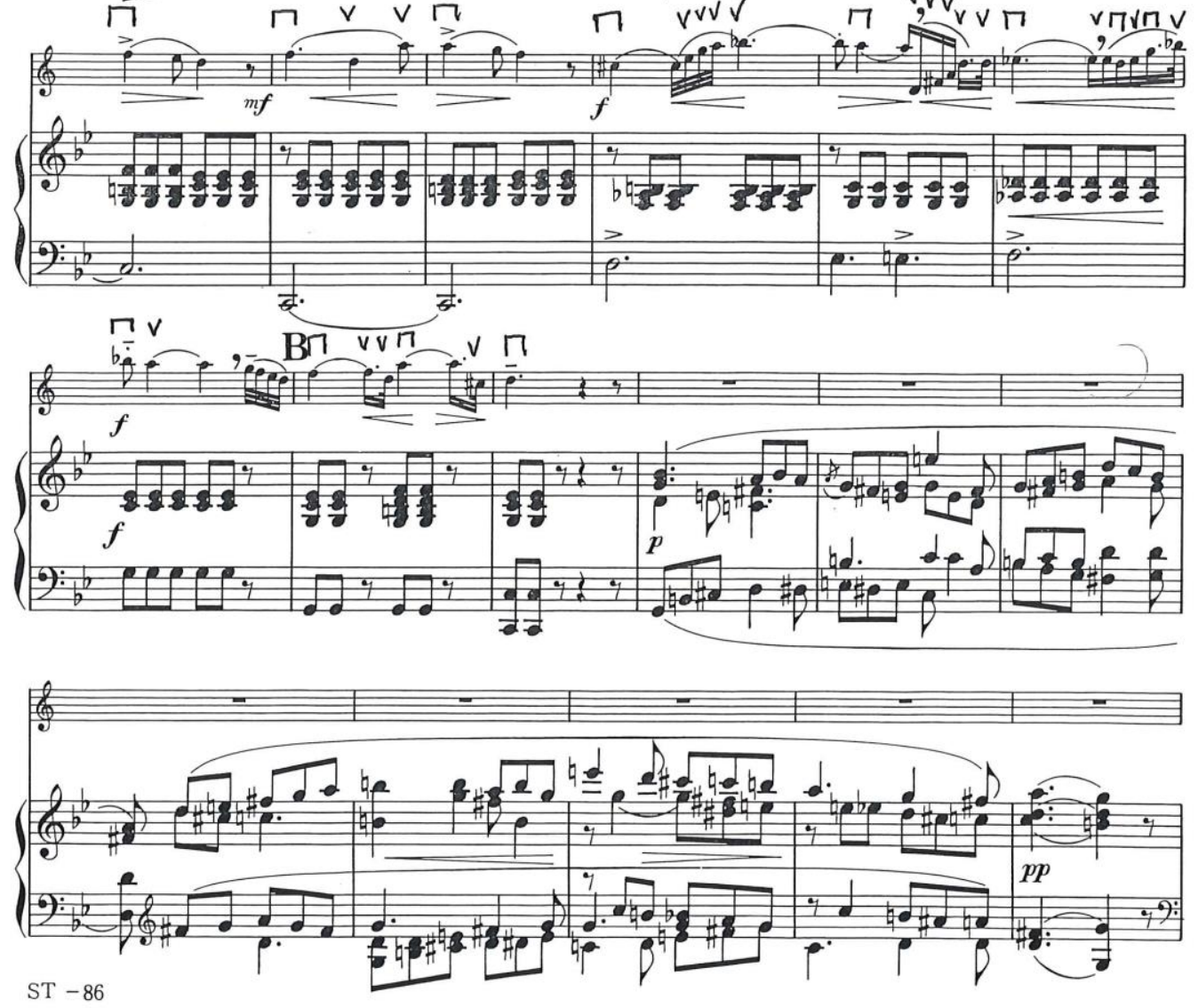


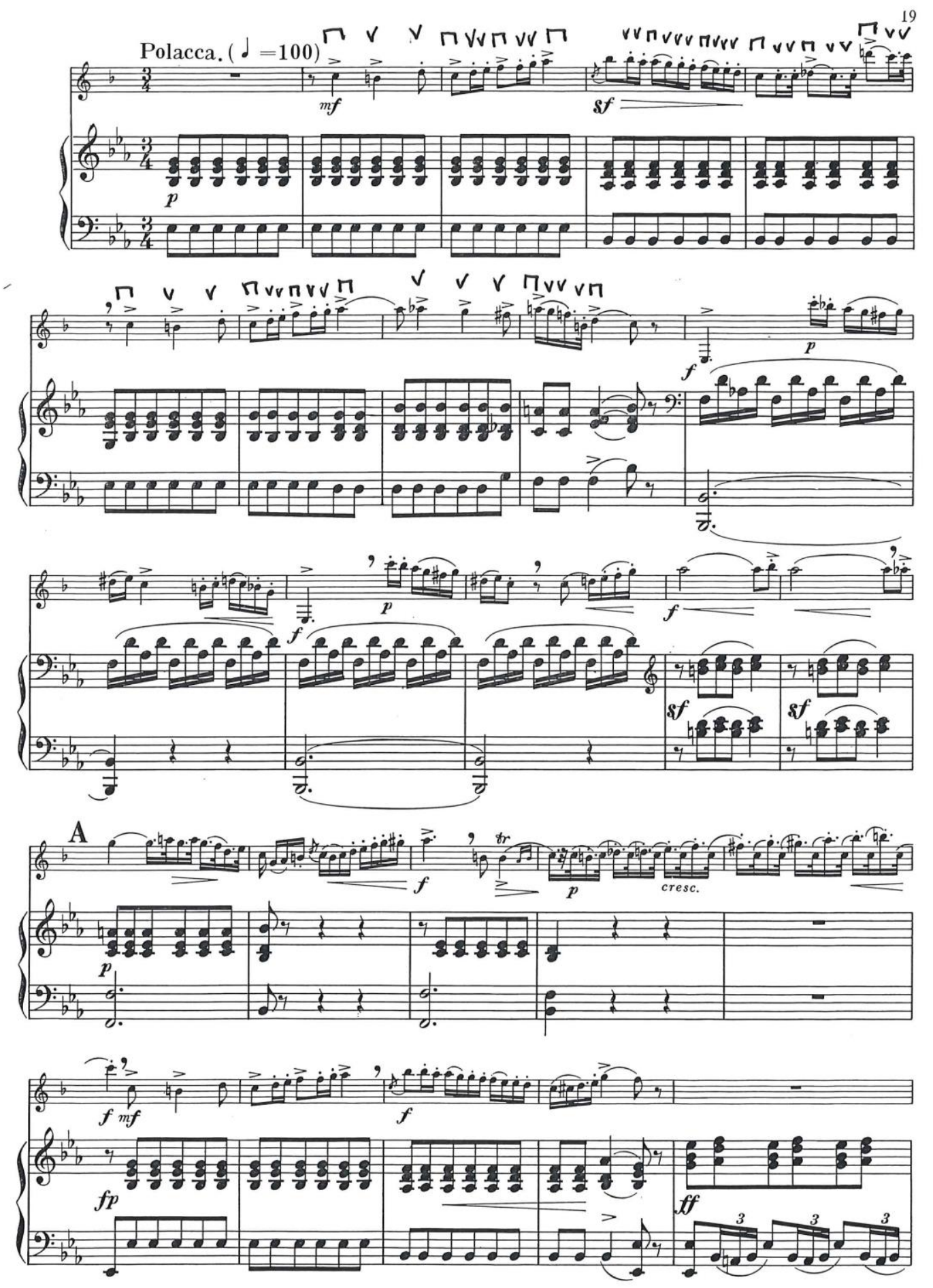

ST -86 

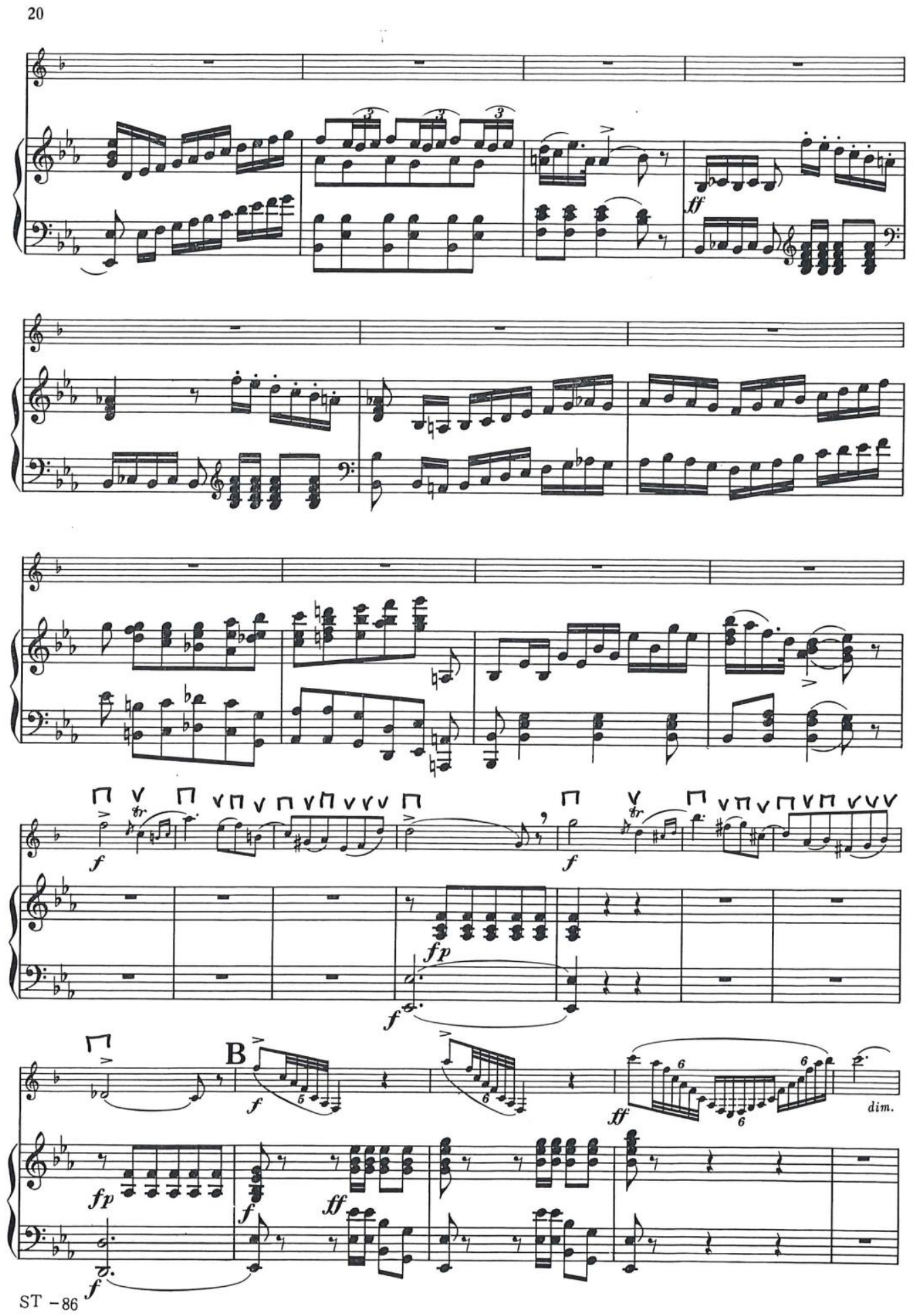

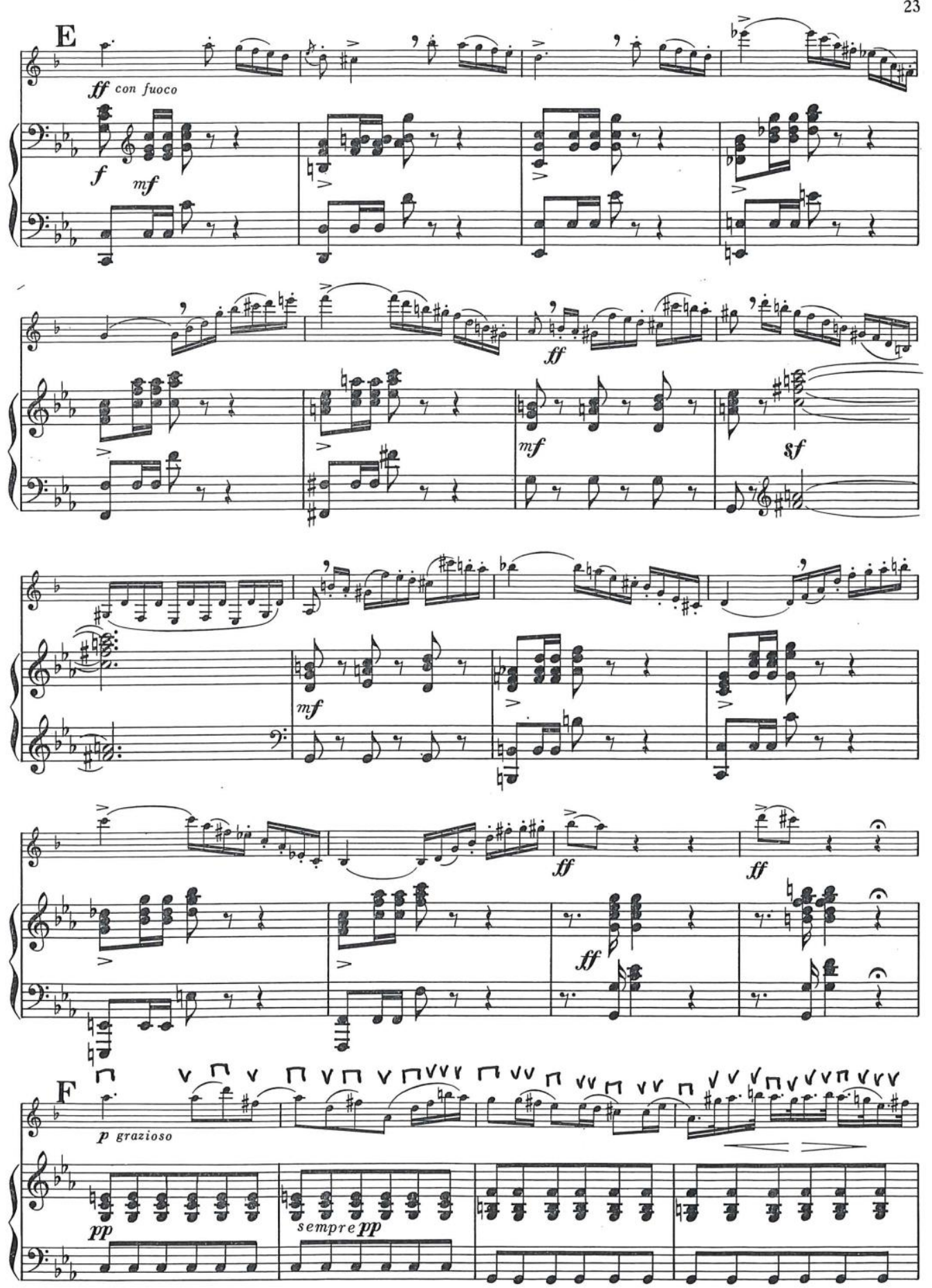

ST -86 

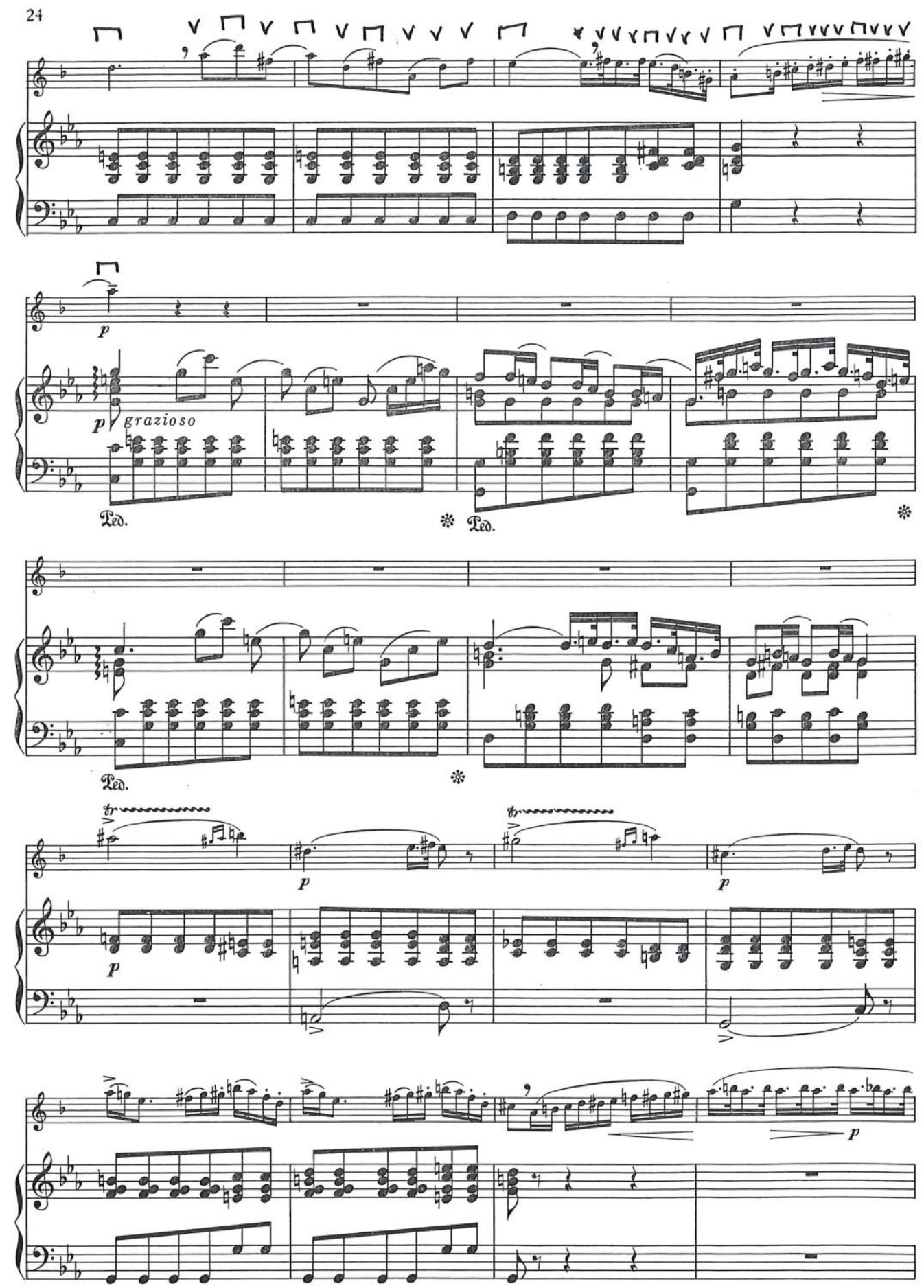

ST -86 

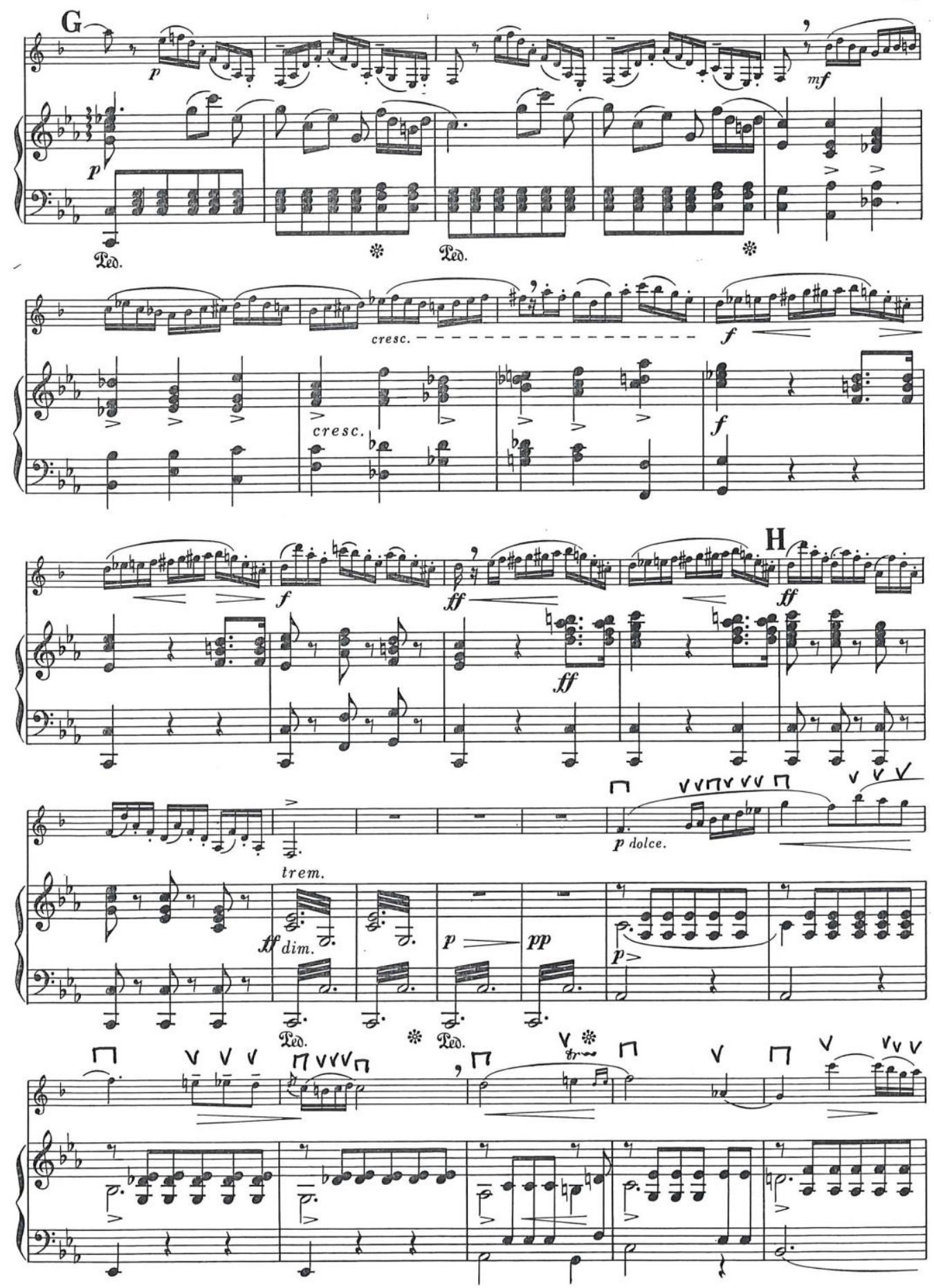

ST -86 

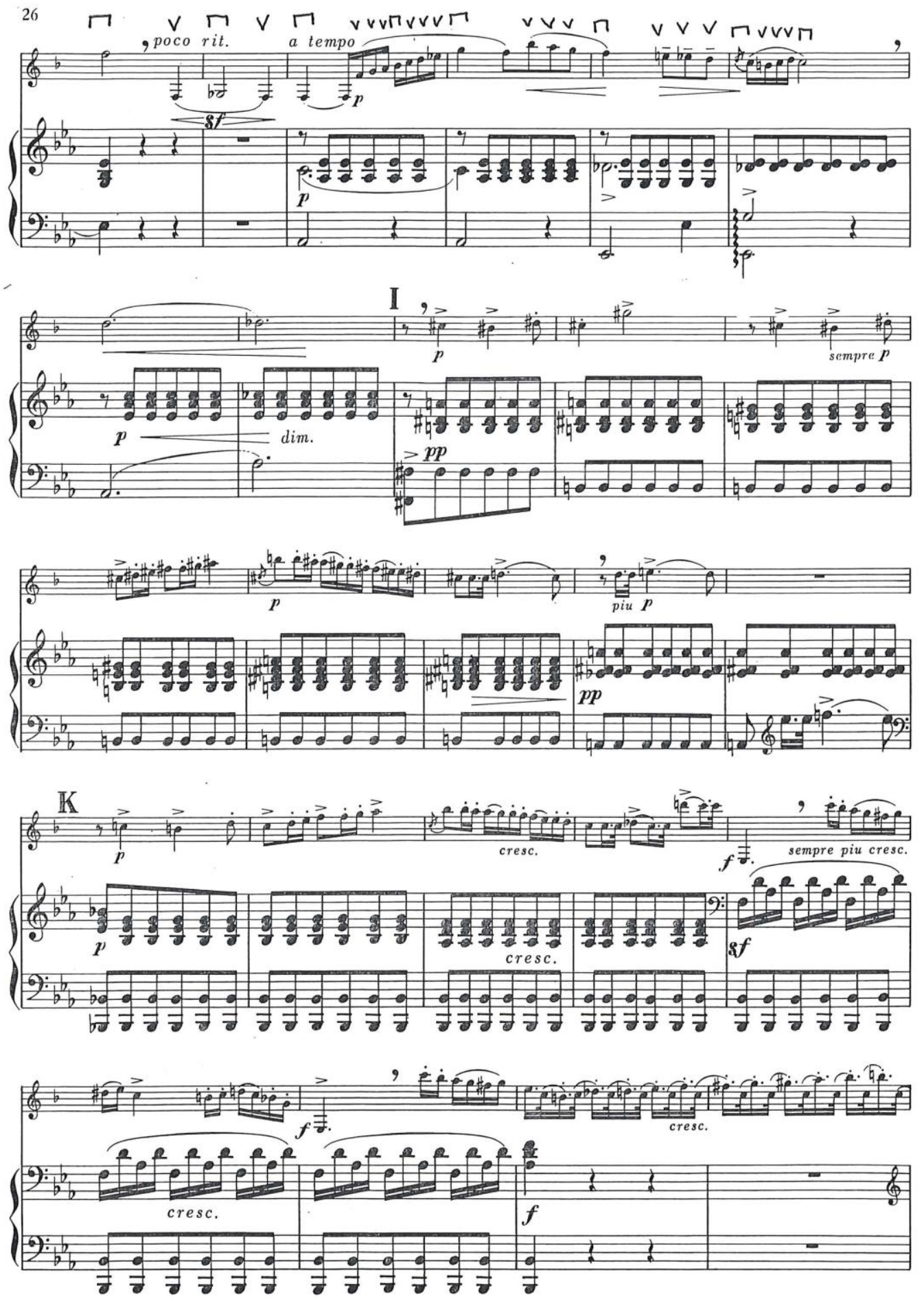

ST -86 


\section{The Phrasing Number System Applied}

Marcel Tabuteau developed his numbering system to create micro-dynamics. He did not believe that the standard dynamic system was sufficient or sophisticated enough to be exponentially musical. According to students of all instruments at the Curtis Institute, he used numbers that would range from 1-30 or 1-35 in their place. These numbers allowed Tabuteau to achieve a series of sound levels emphasizing the harmony and motivic material. Regularly, he placed one number per note shorter in length (quarters, eighths, or sixteenths) and used multiple numbers in secession for notes held for more than a single beat (quarters, halves, wholes, or larger). Quarter notes can be a crossover depending on the music's tempo.

Although Tabuteau created this portion of the system to extend to the numbers 30 or 35 , he rarely reached these extreme dynamic levels on the oboe due to the instrument's limited range. Tabuteau himself used numbers up to 20 or 22 in addition to a plethora of timbre shadings to counter the range issues. Danna Sundet confirmed this idea from John Mack's lesson notes, explaining that Tabuteau expanded the number system to 30 or 35 for other instrumentalists enrolled in his phrasing class at the Curtis Institute of Music.

The beginning stage of Tabuteau's number system was scaling and used patterns of 1-5-

$1,1-9-1$, and 1-13-1 on a series of whole notes tied together. The exercise's purpose was to learn how to play from the softest dynamics to the loudest while maintaining complete control of the instrument and musical line in small increments. The numbers climax at 5, 9, and 13 so that the idea of playing across the bar line is retained.

Doubling numbers is another essential part of constructing a phrase with the system. In order to comprehend this correctly, a complete dissection of the music and the harmony's 
intrarelationship must be thoroughly understood. For example, a number sequence of 3-3-4 over two-quarter notes is number doubling. Instead of moving from only 3-4 or 3-4-5 over the same two-quarter notes, the 3-3-4 sequence allows for the slightest crescendo using coloring instead of an increase in the volume of sound. This technique portrays the illusion that a dynamic change is taking place without getting significantly louder. Decrescendos can also achieve the same effect.

The numbers in the score below are labeled to show the rise and fall of dynamic levels in the clarinet's first phrase in Weber's Second Clarinet Concerto. Measures one to two rise from level one to five because of the harmonic shift from tonic to the dominant in secondinversion. Measures three to four lower from level five to one due to the change from the dominant to tonic in first-inversion. The second beat of measure four begins the rise to the loudest part of the phrase located in measure five returning to the dominant in root-position. Again, the treatment of the dominant in measures two and five should be different due to the chord's inversions.

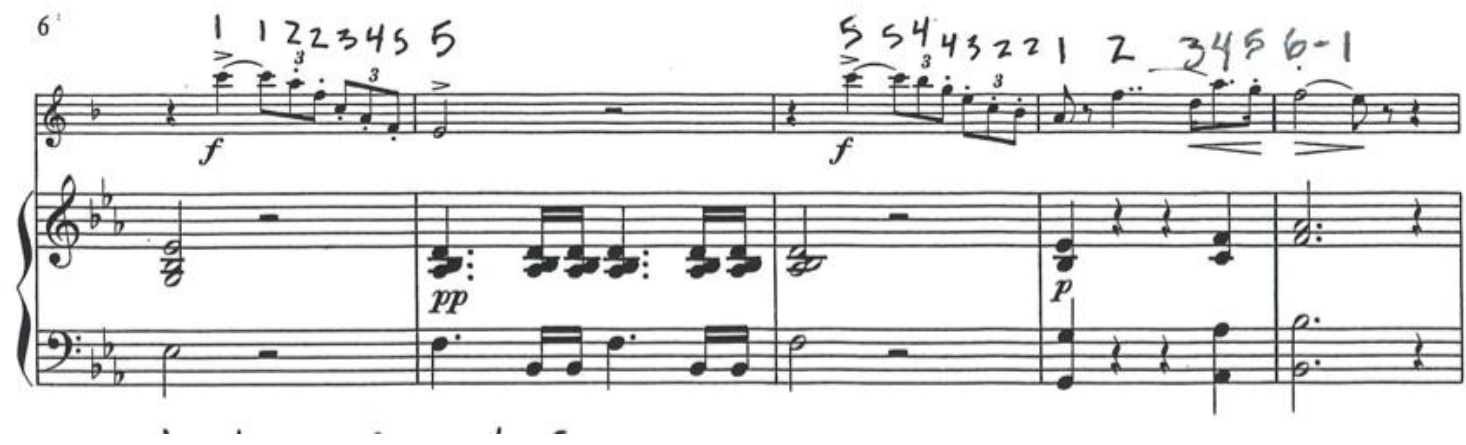

The following pages contain Tabuteau's phrasing numbers to the primary themes in Weber's Second Clarinet Concerto. Due to spatial limitations in the score, the arrows portray a succession of numbers. See Appendix E for additional information. 

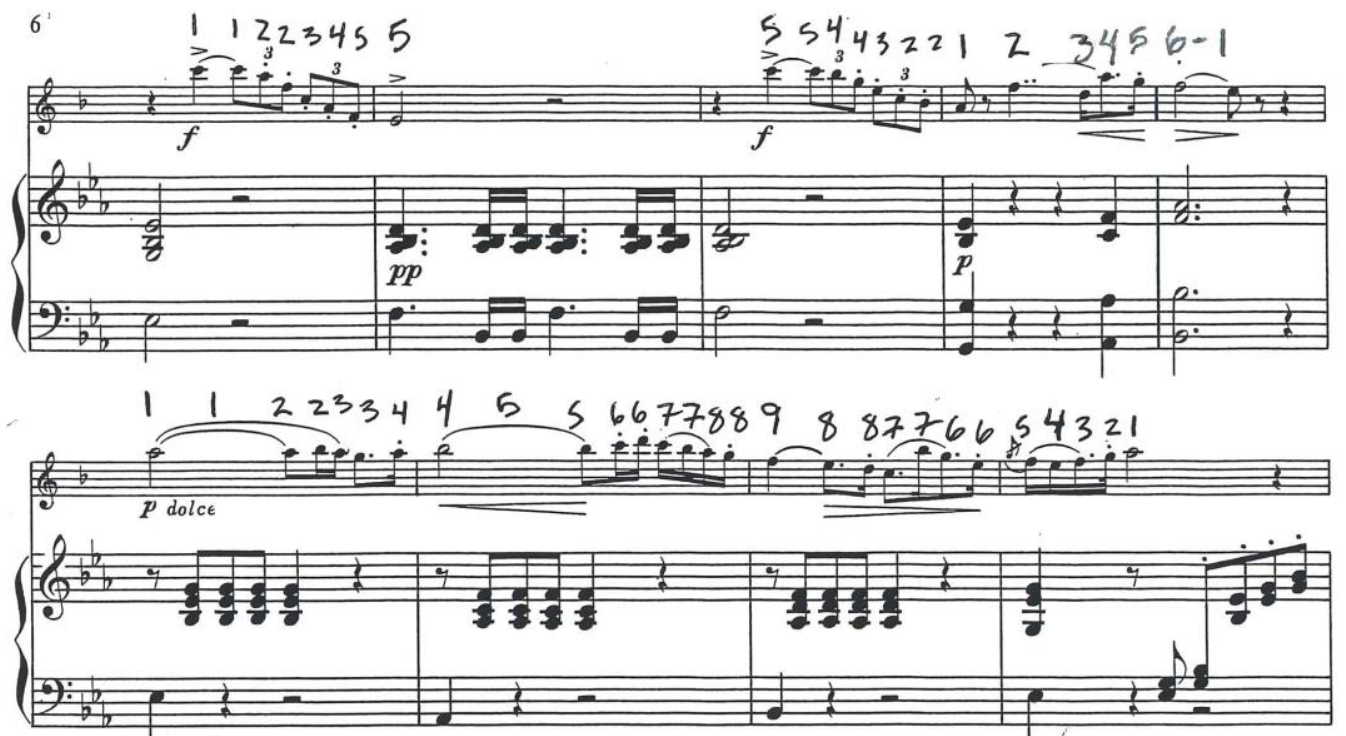

$\begin{array}{lllllllllllllll}9 & 9 & 101011 & 11 & 12 & 12131314141515 & 16 & 17 & 18 & 19 & 20\end{array}$
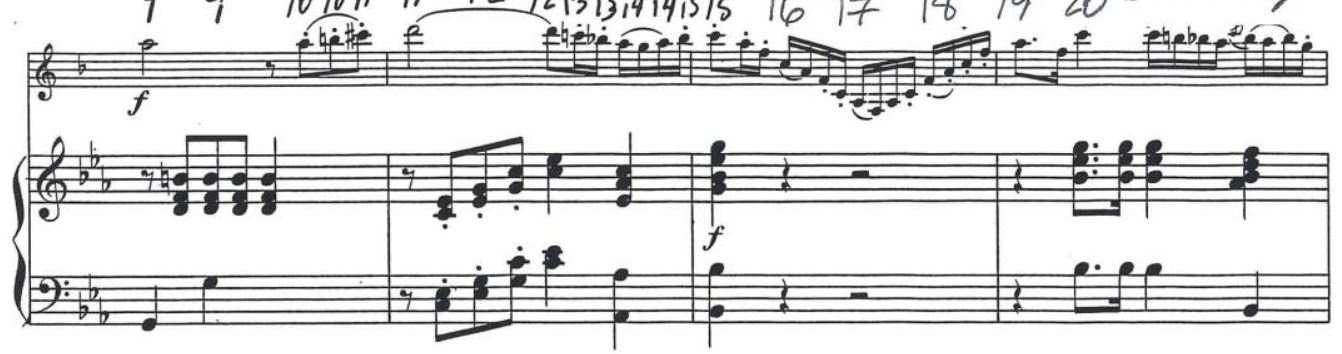

9
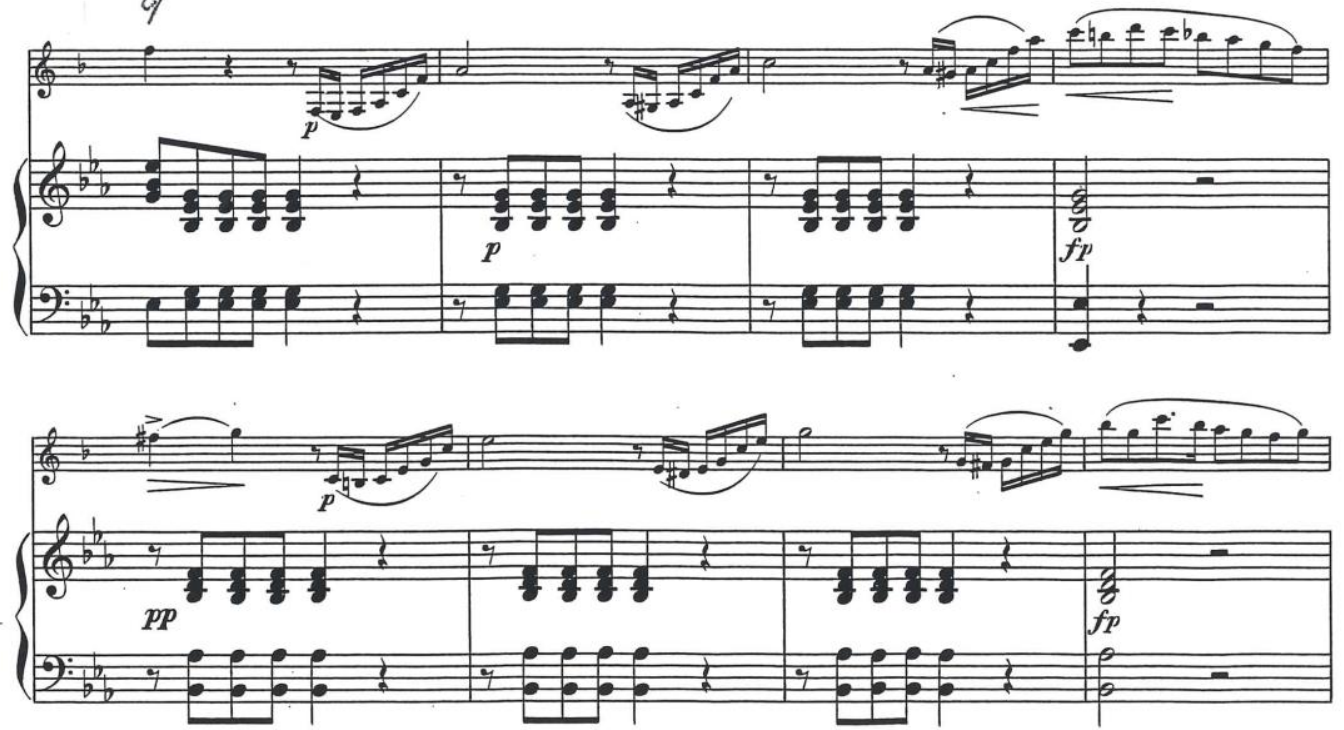

ST. -86 

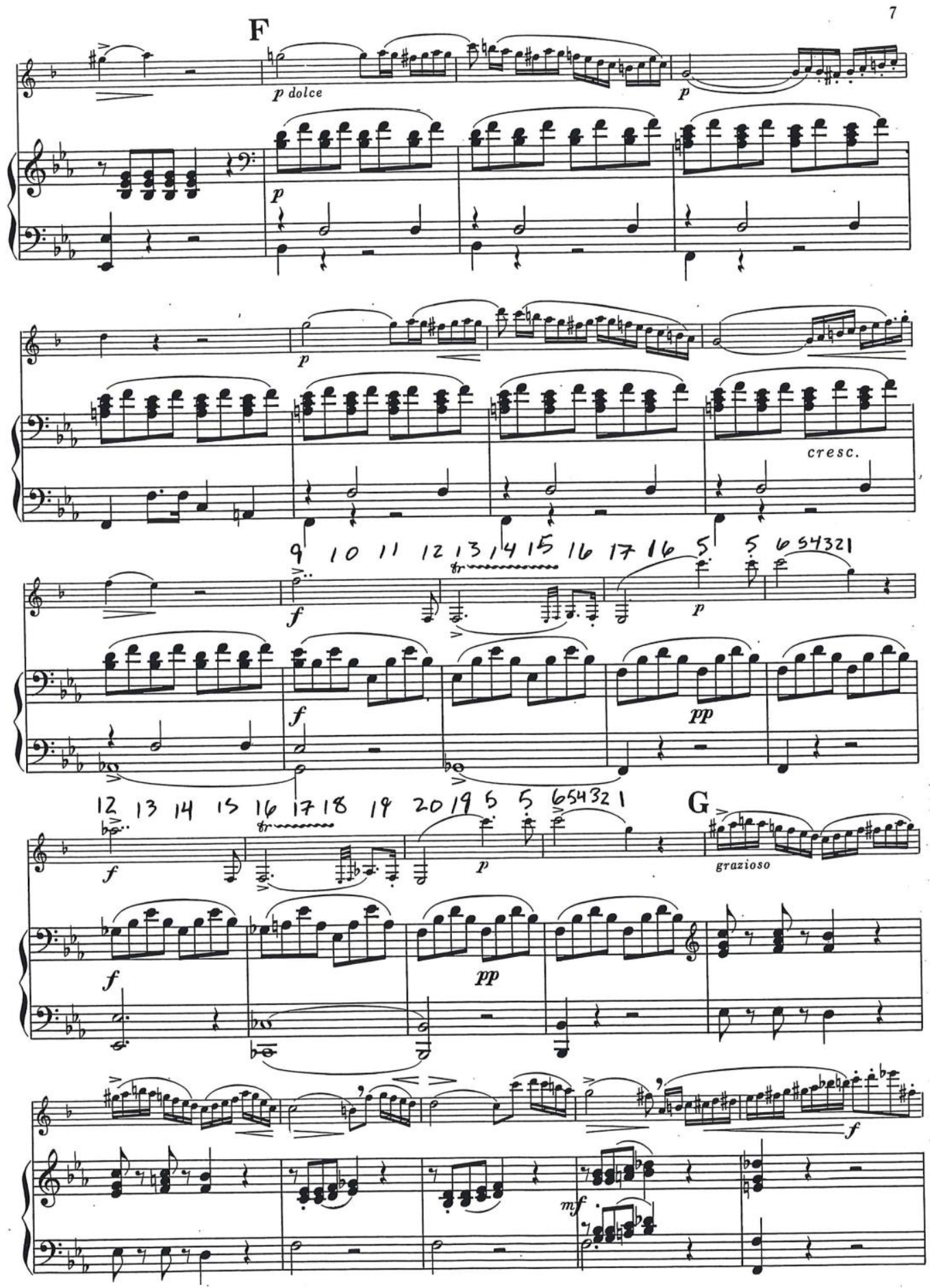

ST -86 


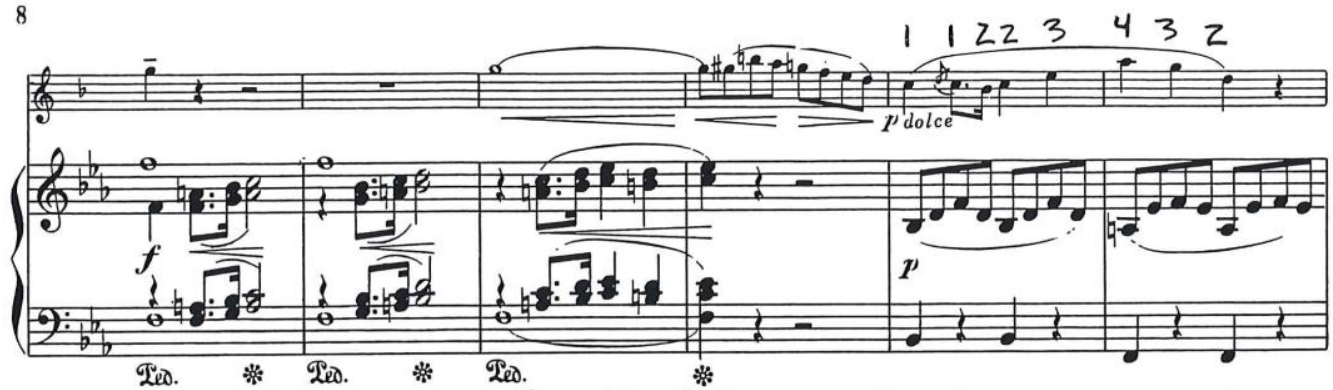

33443567891098789876596 scherzando

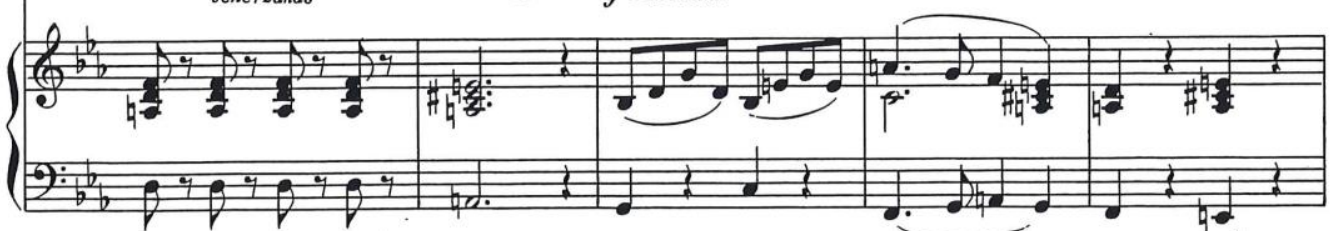
$7787654322334543 \quad 556677891011$ (2)

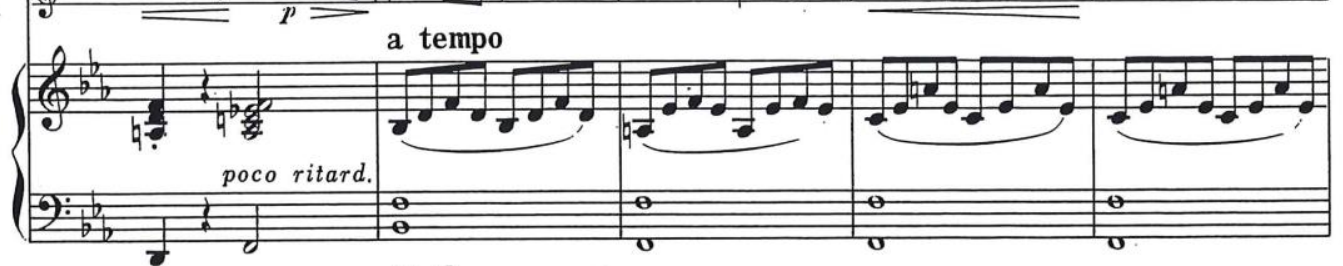
11109891098778985654

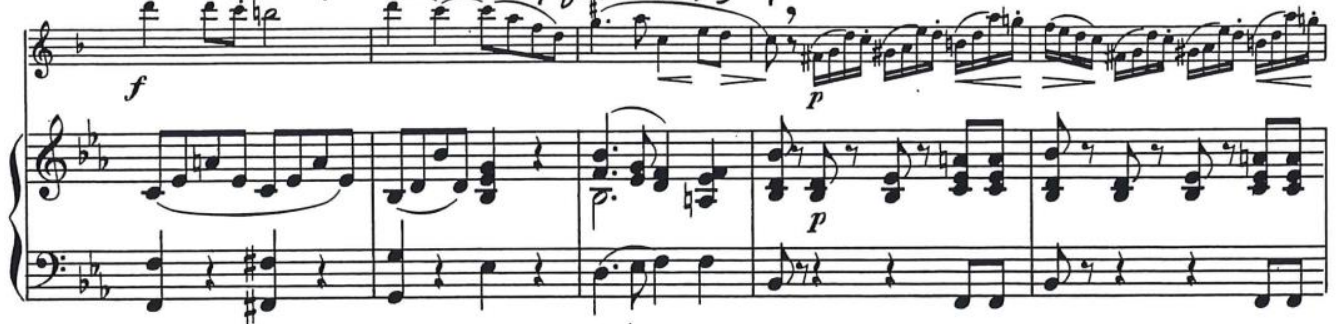

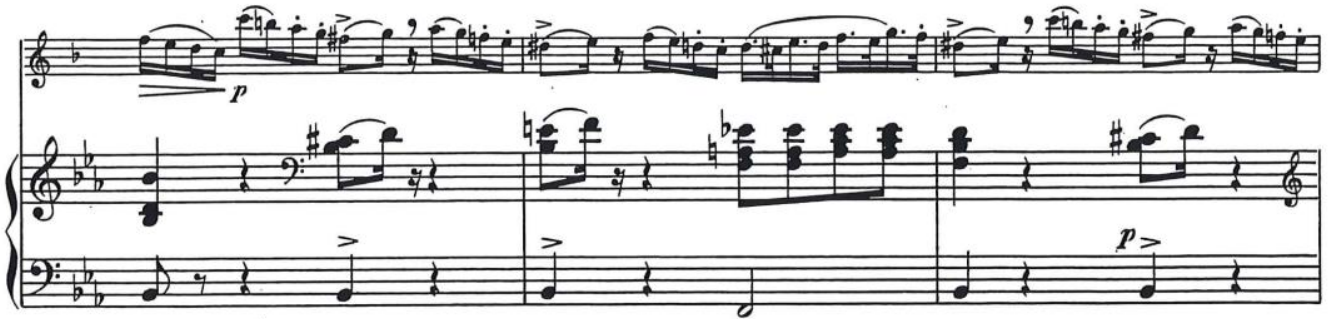

ST -86 
10
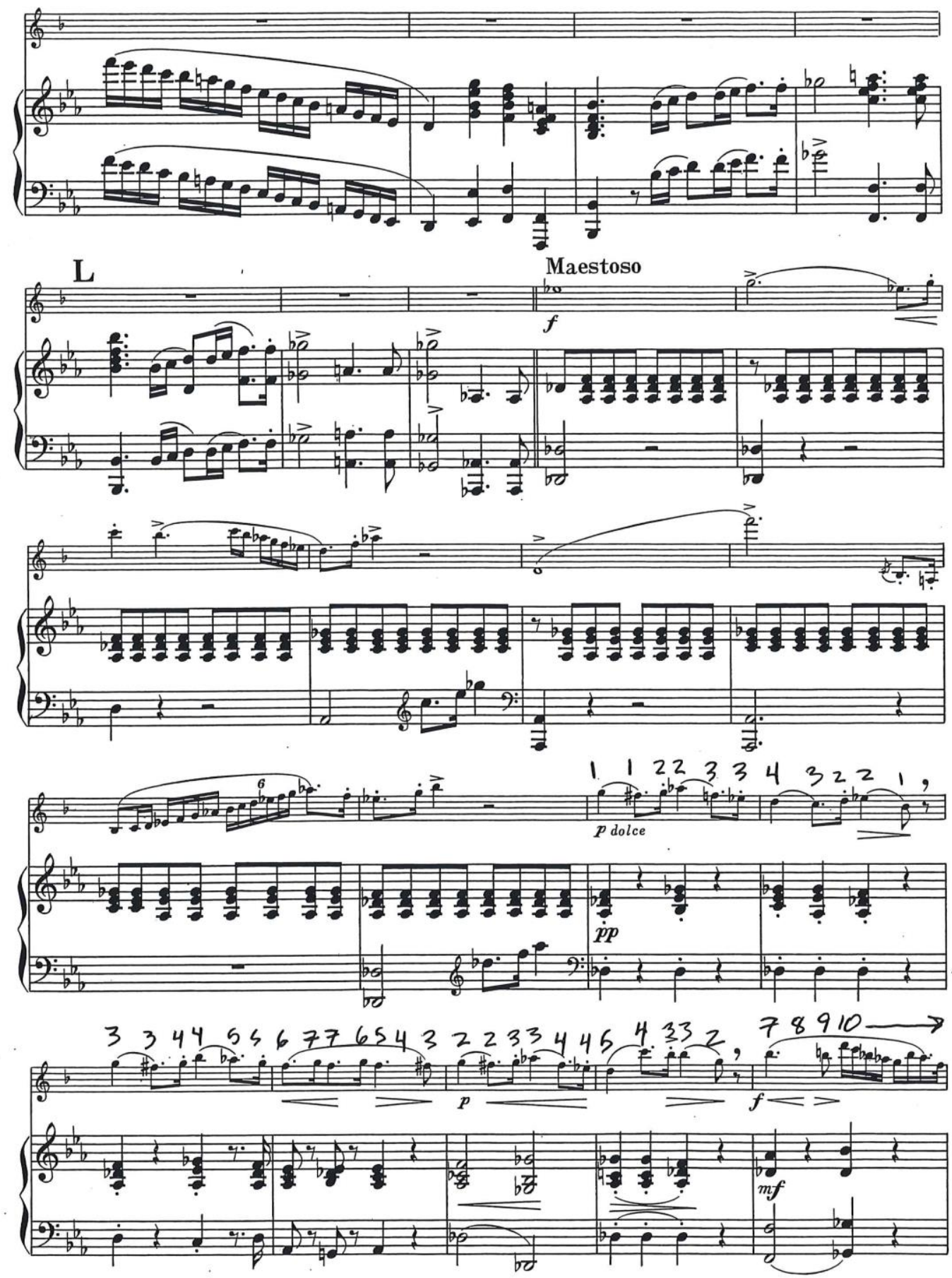

ST $1-86$ 

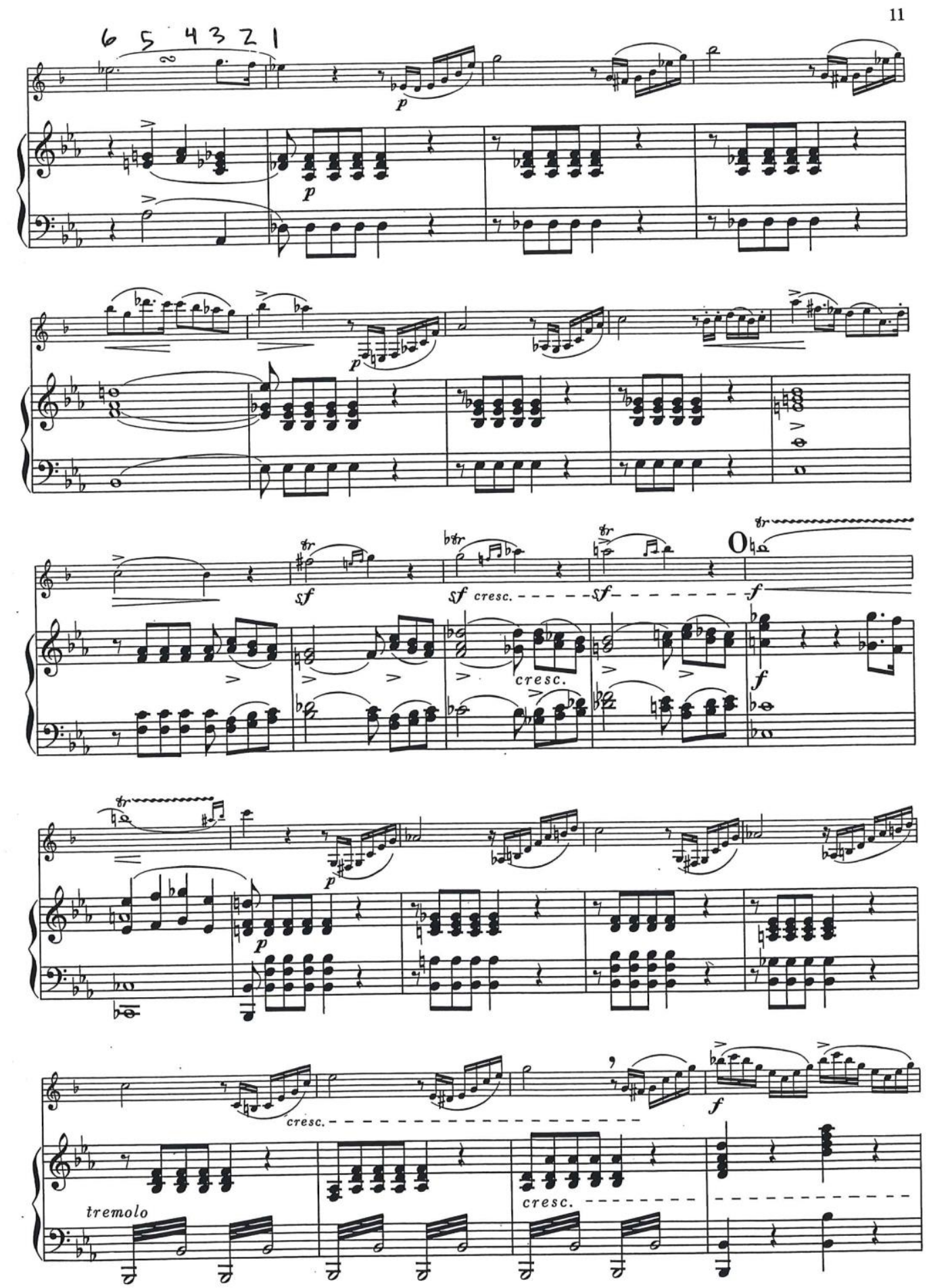

ST -86 
Romance.

Andante con moto. $(\delta=92)$

112233445566

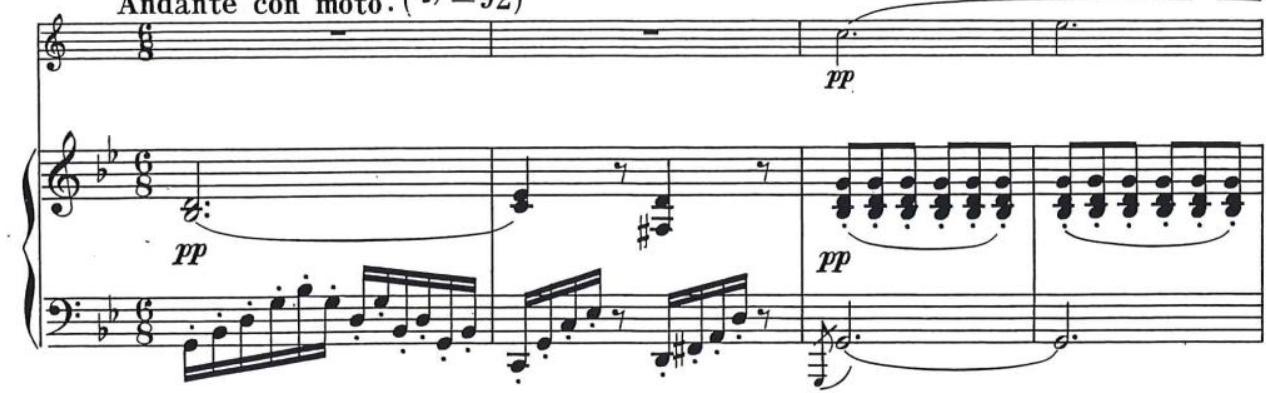

776655433221,11223345678910109887

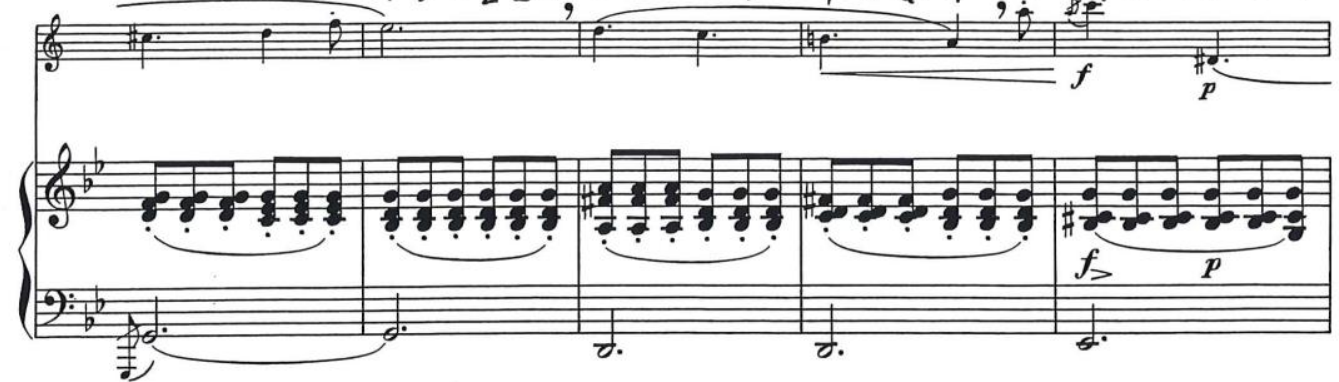

6543
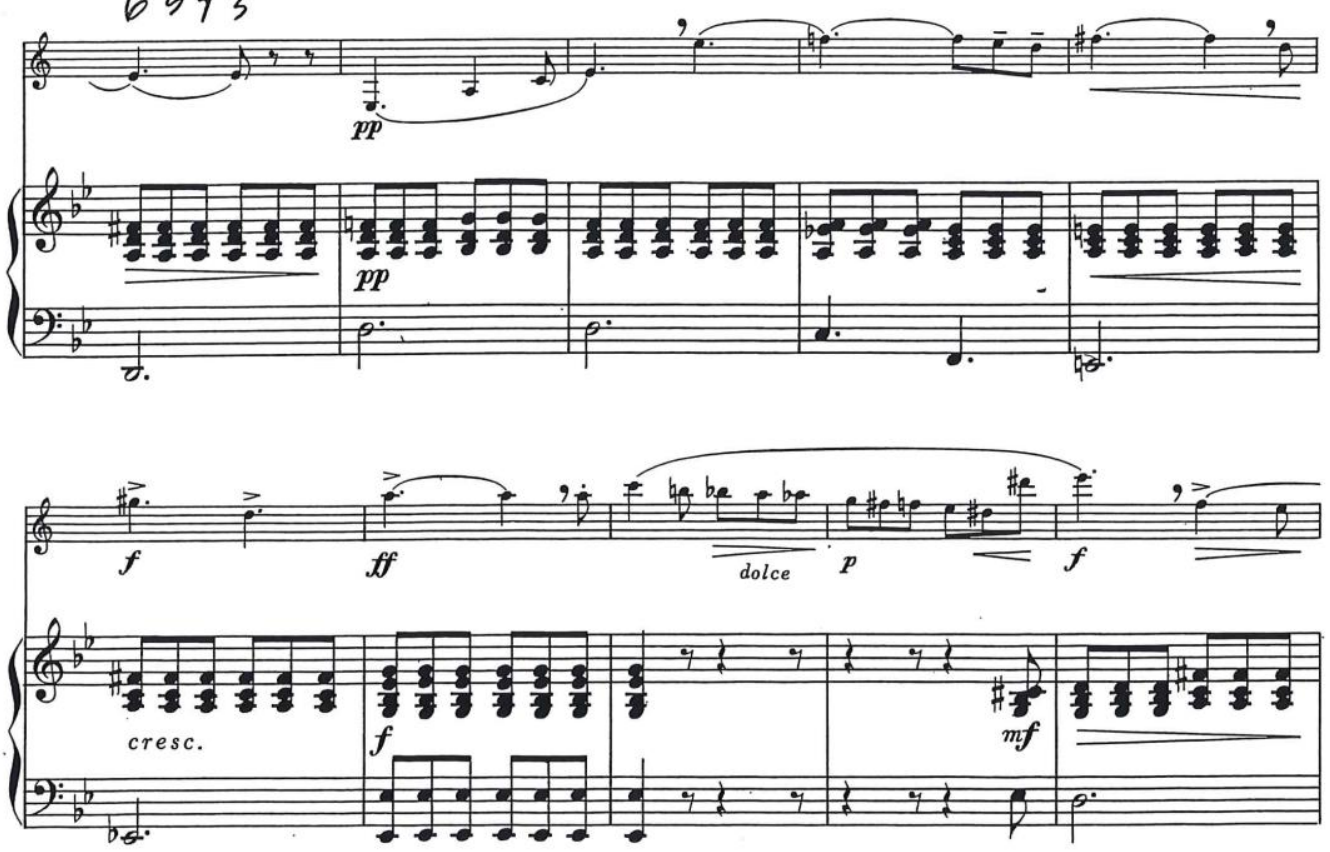

$\mathrm{ST}-86$ 
16

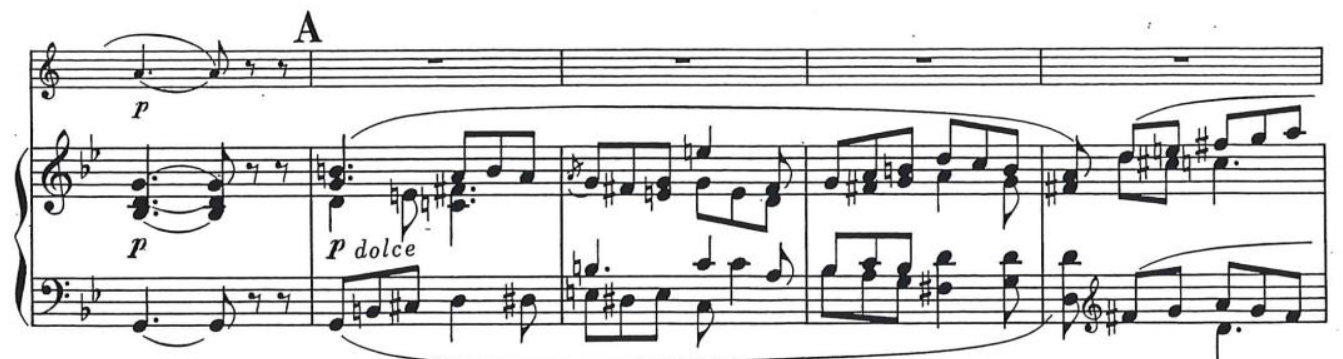

112233

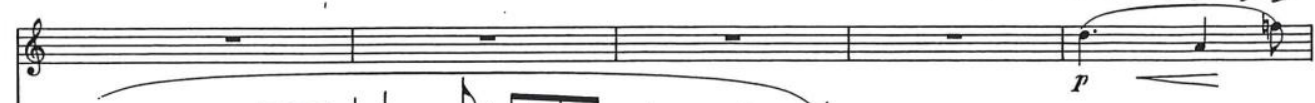

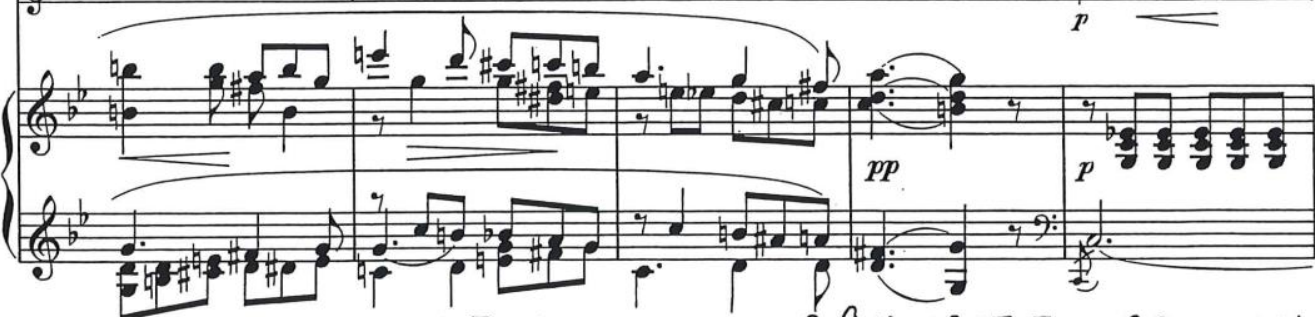

4432,445566776547789910109877899910101111 =

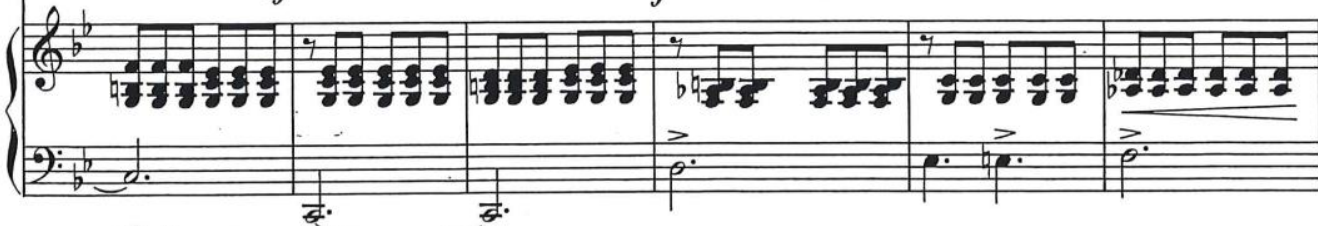
121110981223443321
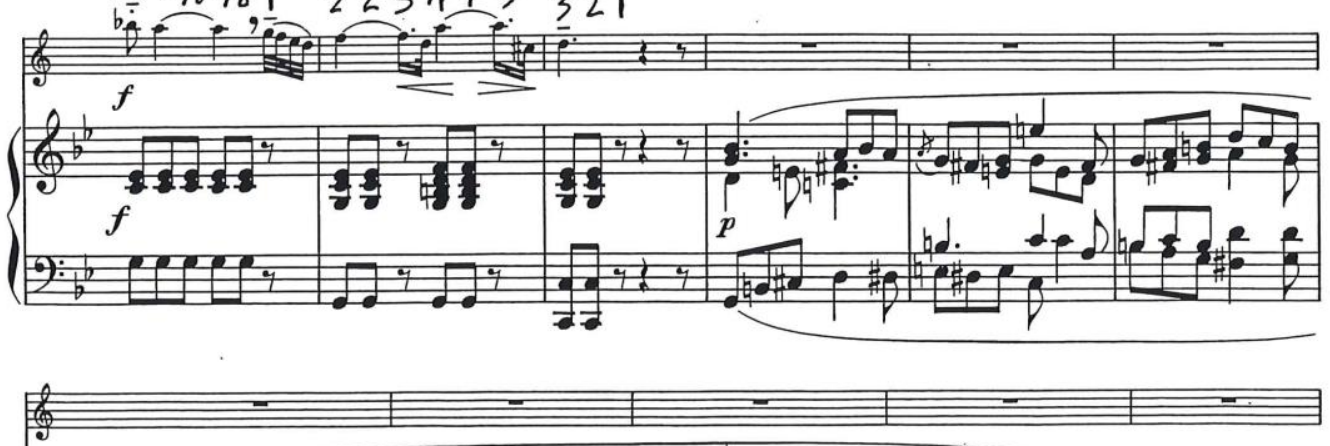

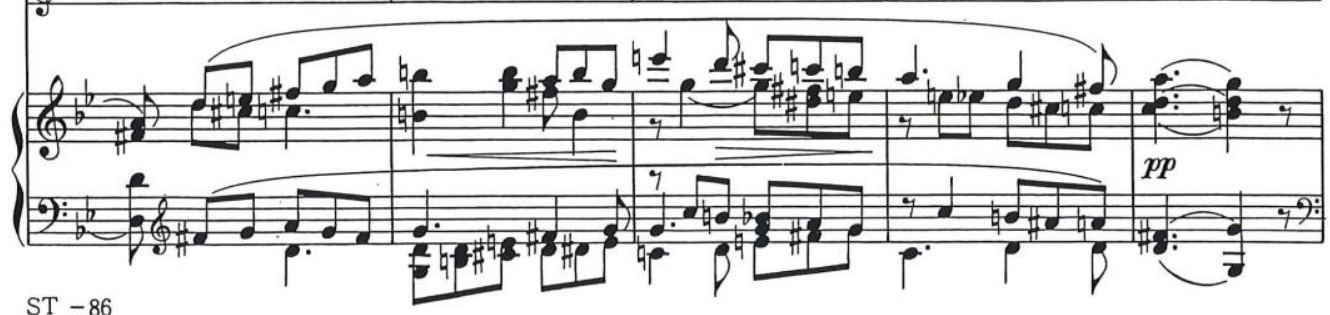



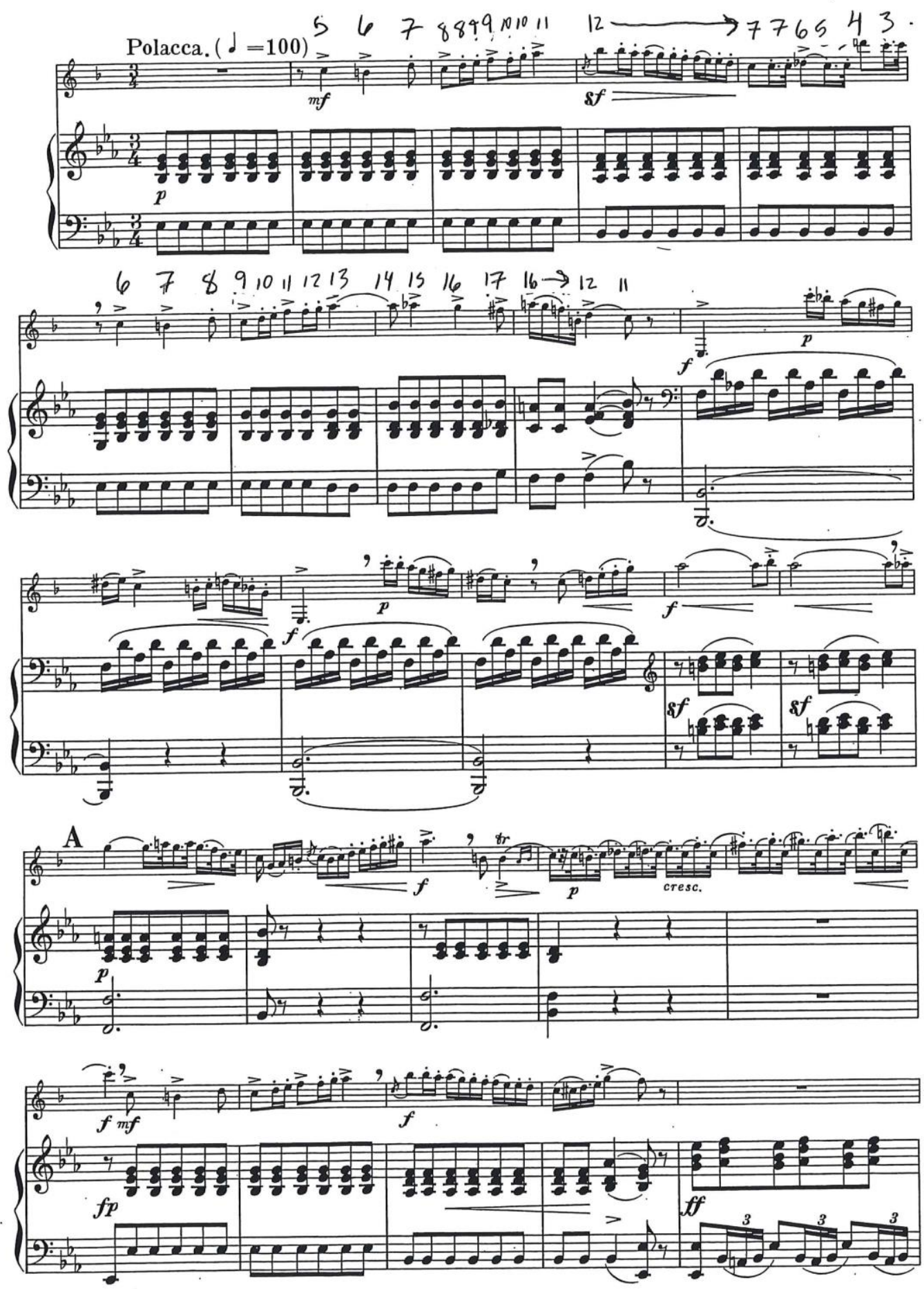

ST -86 

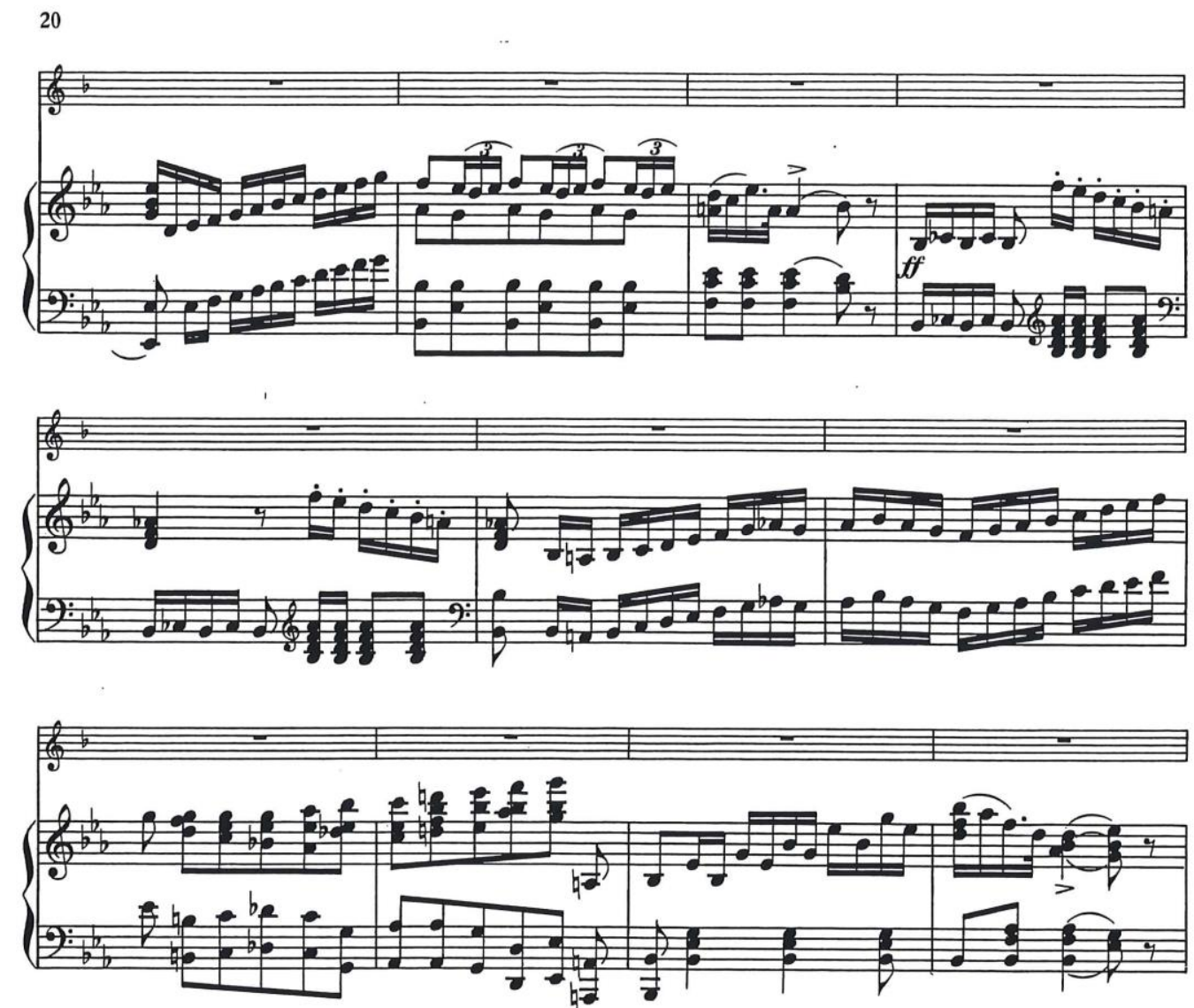

$891011.2131314141515161718 \rightarrow 14,910 \mathrm{fr} 1213141415151617819$ con $f$
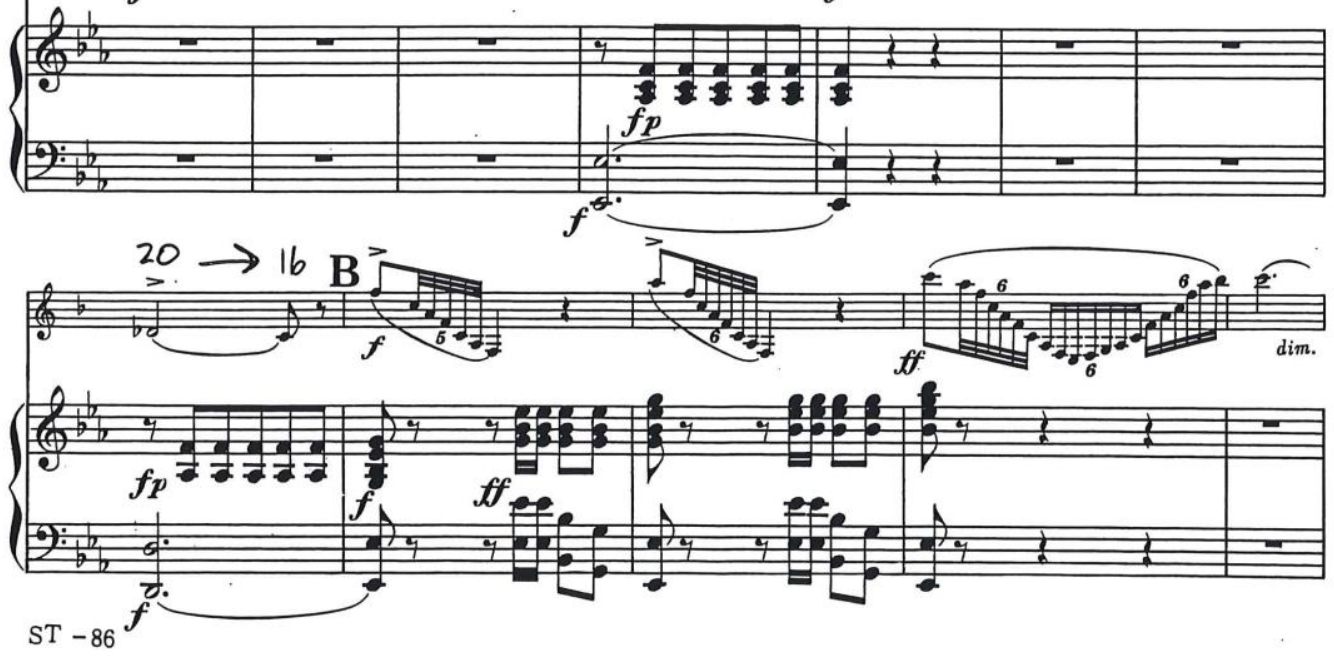

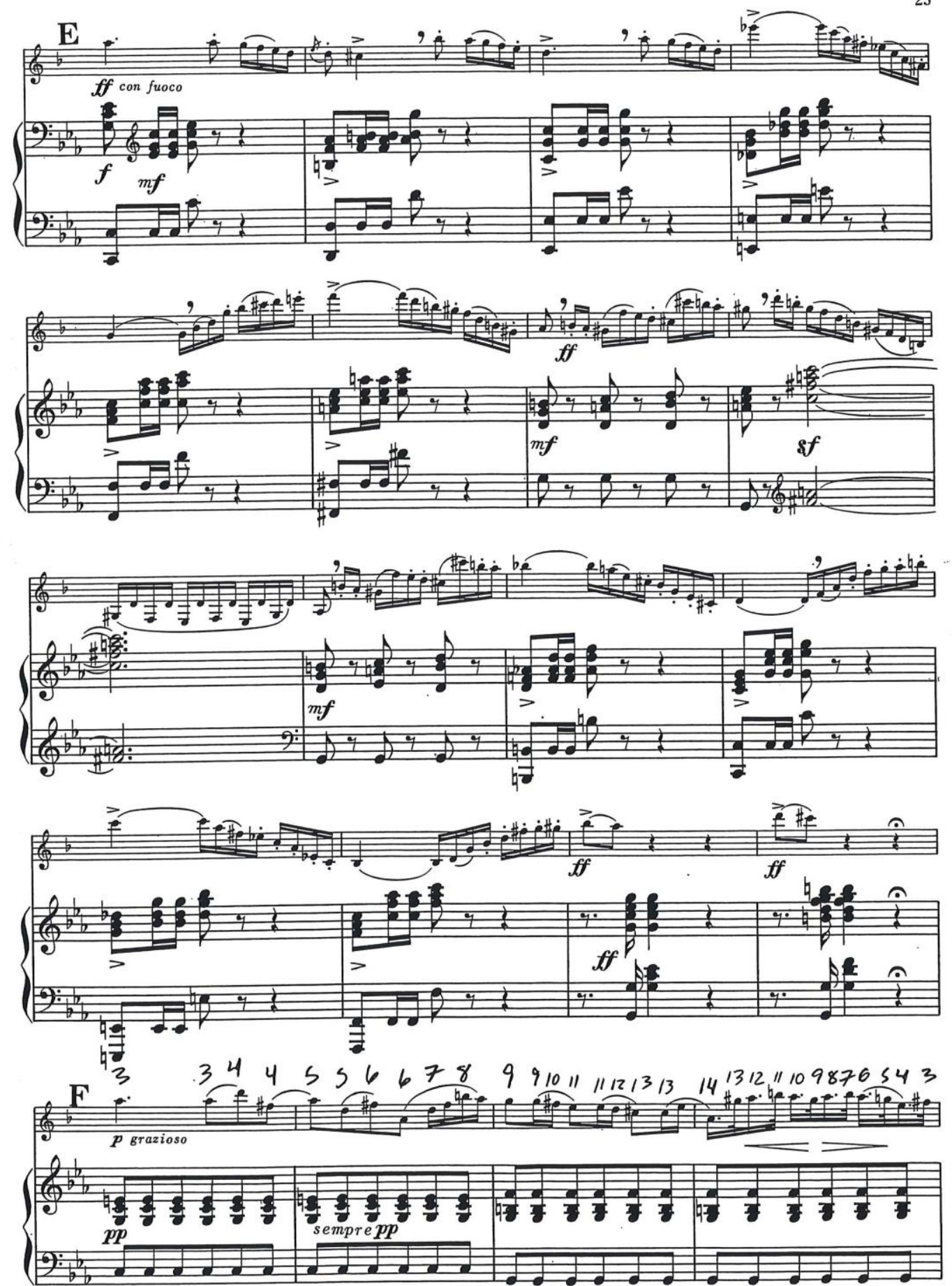

ST -86 

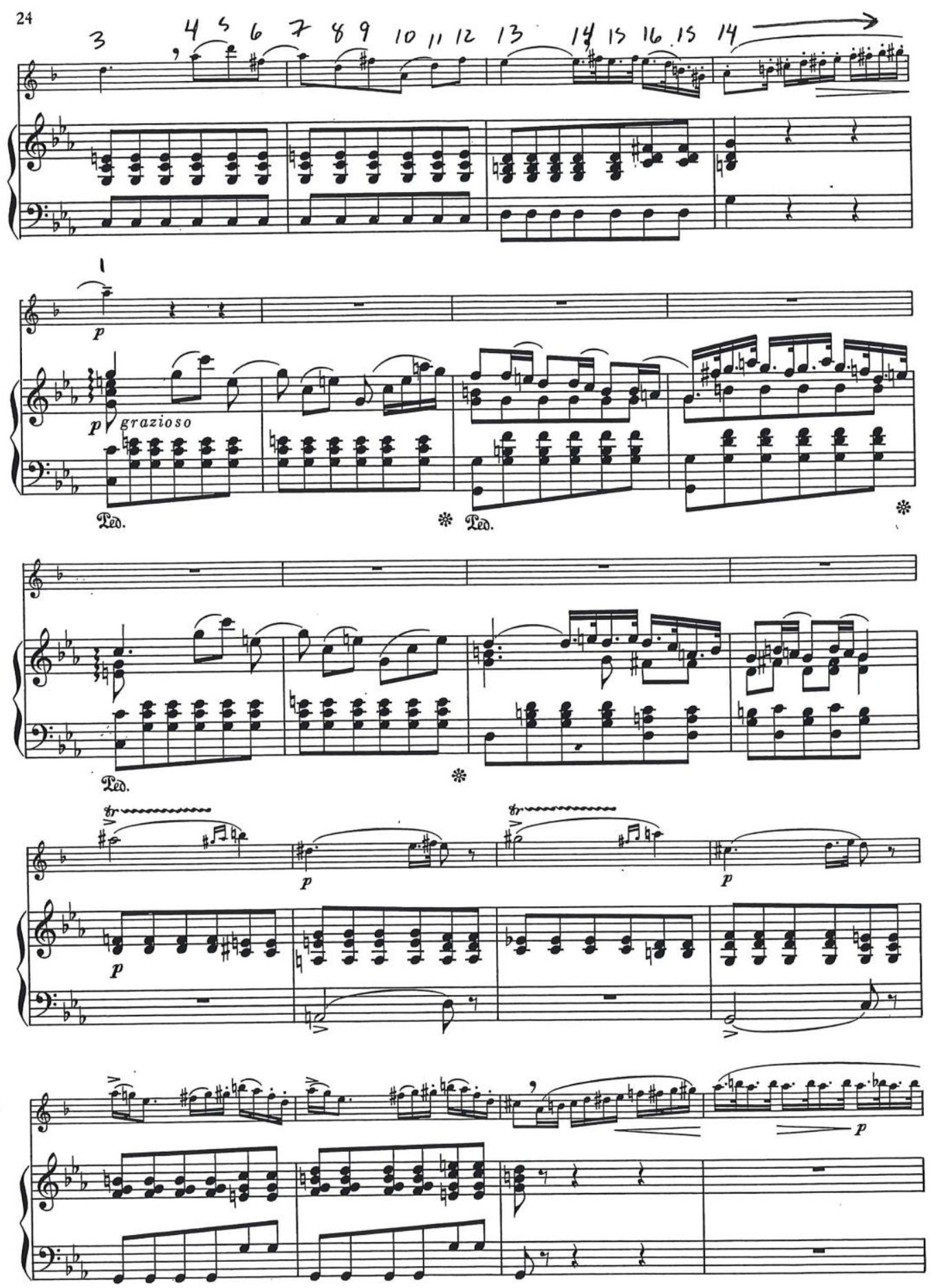

ST -86 

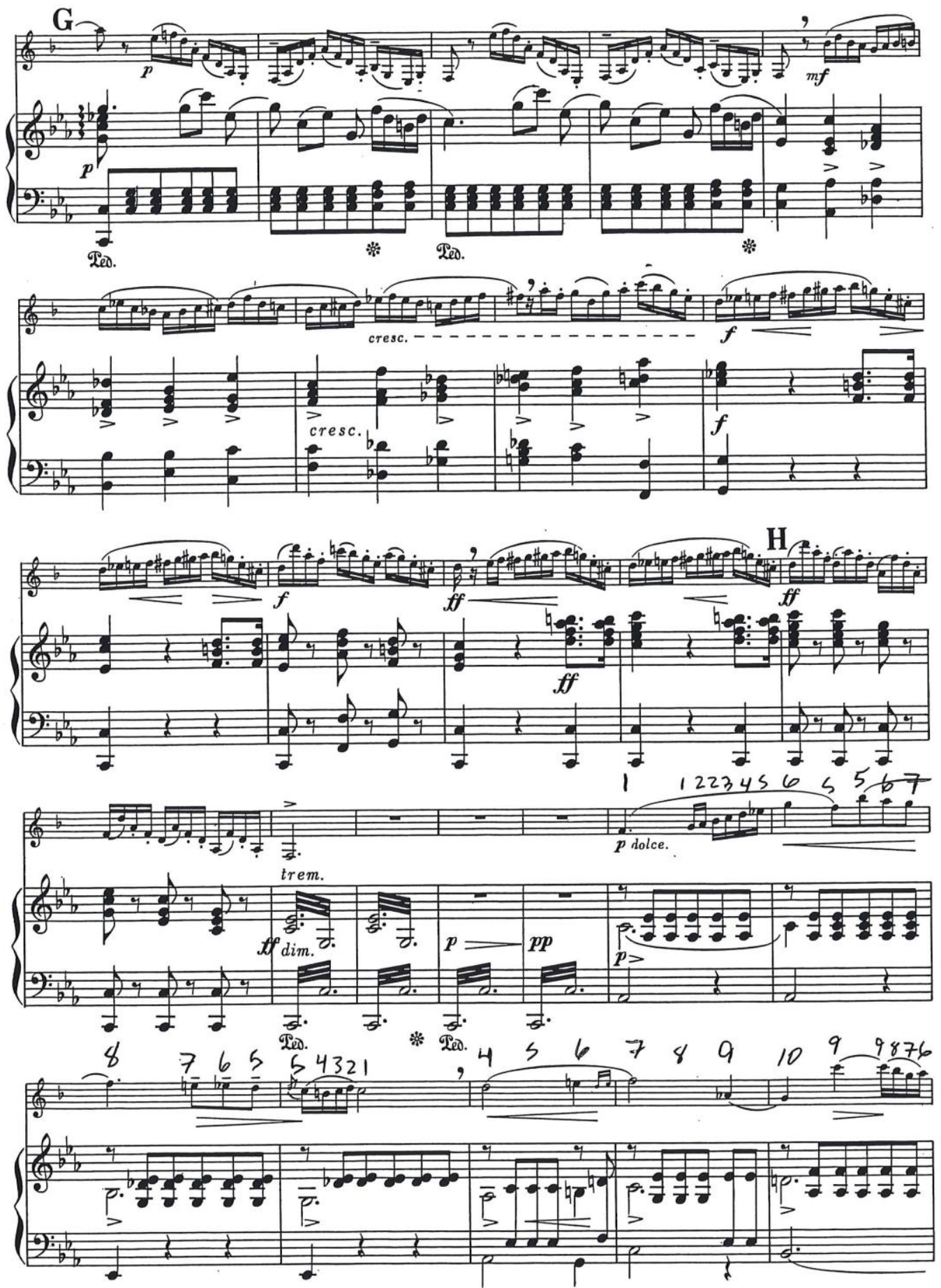

ST -86 

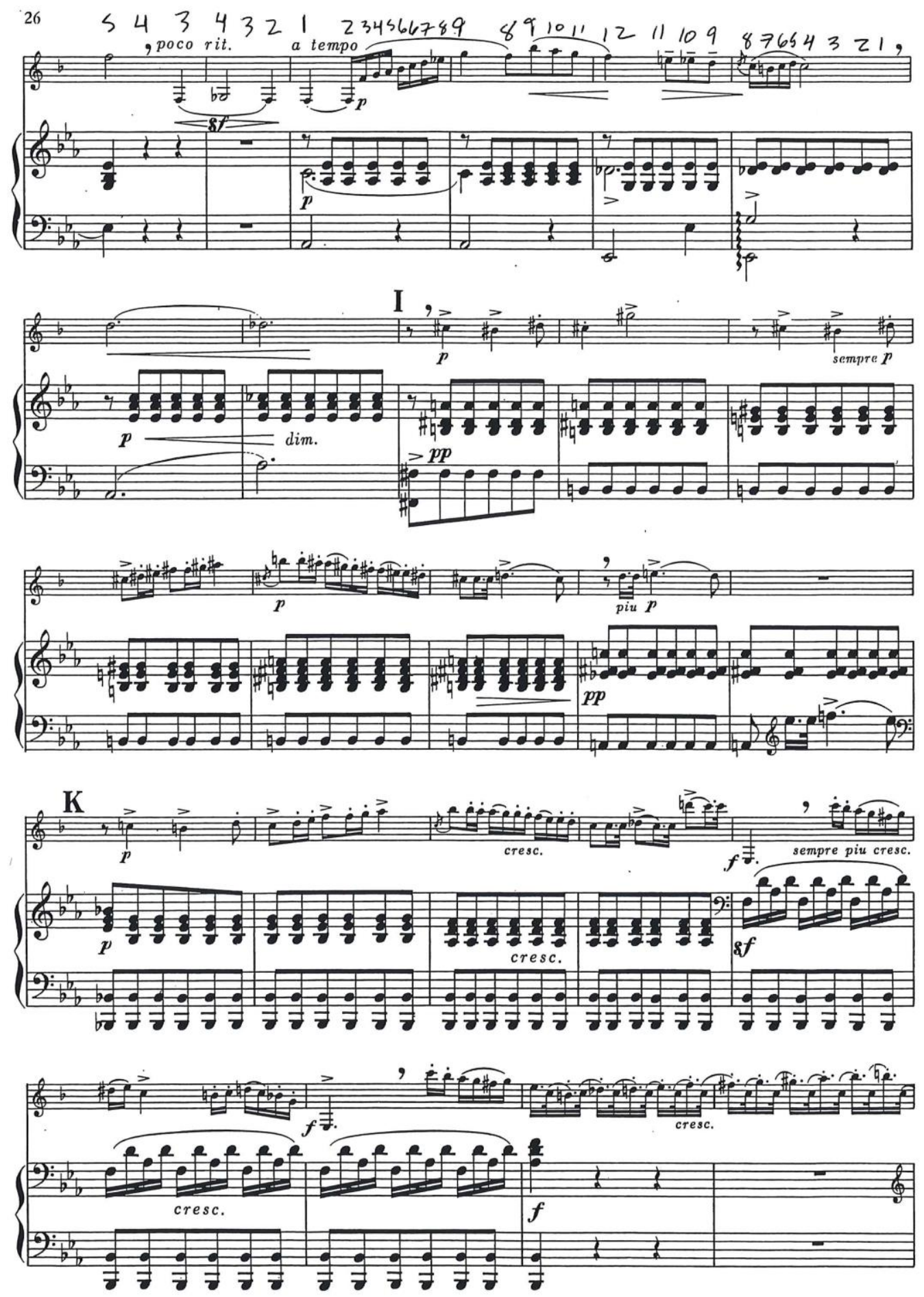

ST -86 


\section{Conclusion}

Today, many musicians continue to use Tabuteau's system of phrasing. However, it is uncertain if a step by step process for implementation exists. Below is a brief summary for incorporation of each part of the system.

Step 1: As explained in Chapter 3, the Interrogative/Affirmative/More-Affirmative are selected depending upon the harmonic movement in the phrase. In this example, the Interrogative is the first two measures of the phrase and moves from the tonic triad in root position to a dominant seventh chord in second inversion. The Affirmative begins in the third measure and continues until beat one of the fourth measure where the harmony shifts from the dominant back to a first inversion tonic triad. The fourth and fifth measures are the More-

Affirmative extension to the phrase. The harmony in these two measures shifts from the first inversion supertonic triad to the dominant seventh chord in root position culminating the phrase.

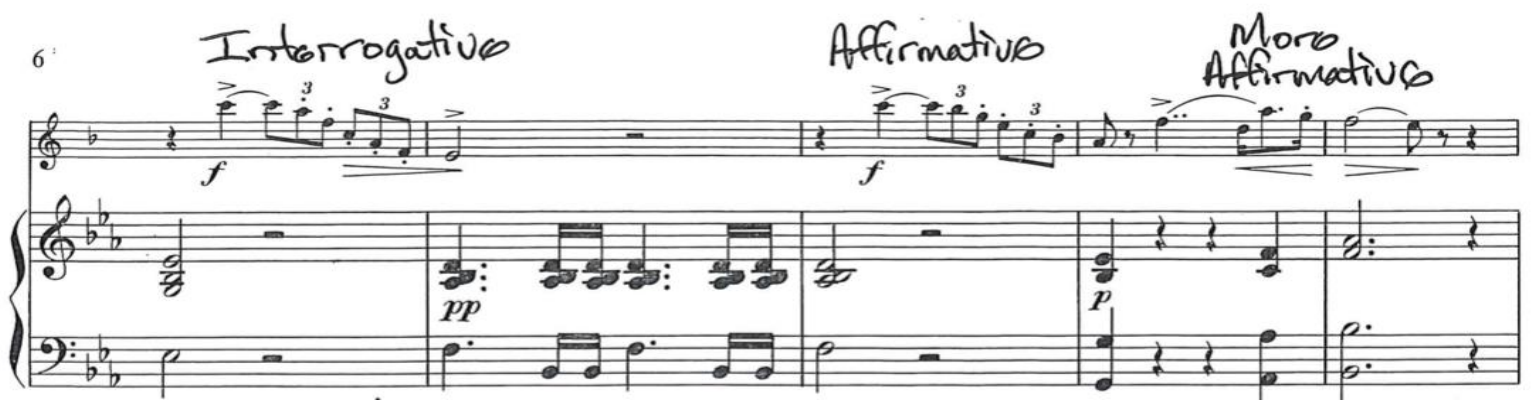

Step 2: As explained in chapter 4, note groupings are an essential addition to the Interrogative/Affirmative/More-Affirmative selections made in the previous step. These also serve as a preface for the third and fourth steps of the system by laying the foundation for musical expressivity. Groupings one through three 
are part of the Interrogative and support the tonic to dominant shift in measures one to two. Groupings four, five, and six are all a part of the Affirmative. These groupings support the shift from the dominant back to the tonic in measures three and four. Groupings seven and eight are part of the More-Affirmative portion of the phrase in measures four and five. These two groupings aid the shift from the supertonic triad in first-inversion to the dominant seventh chord in the following measure.

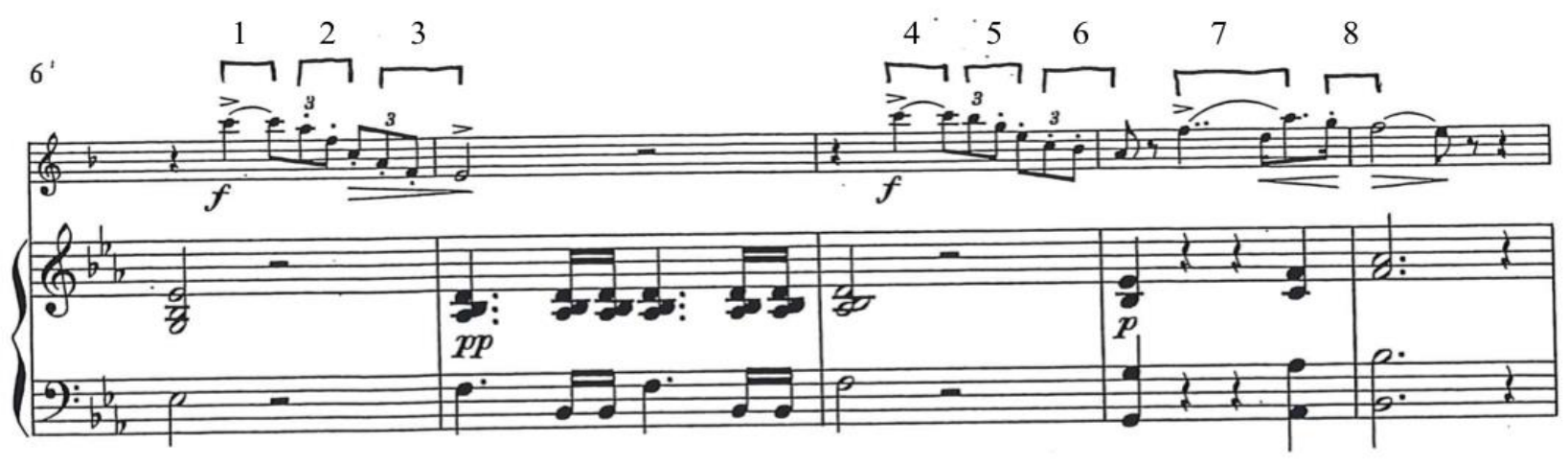

Step 3: As explained in chapter 5, add the Up/Down gestures to both the Interrogative/Affirmative/More-Affirmative and note groupings already applied in the previous two steps. The Up/Down gestures supply musical direction to the phrase by the Up gestures moving towards Down gestures. Gestures one through three all support the movement from tonic to dominant in the Interrogative. Gestures four through six support the dominant to tonic movement in the Affirmative in measures three and four. The final two gestures support the More-Affirmative in the shift from the supertonic triad in first inversion to the dominant seventh chord in root position. 


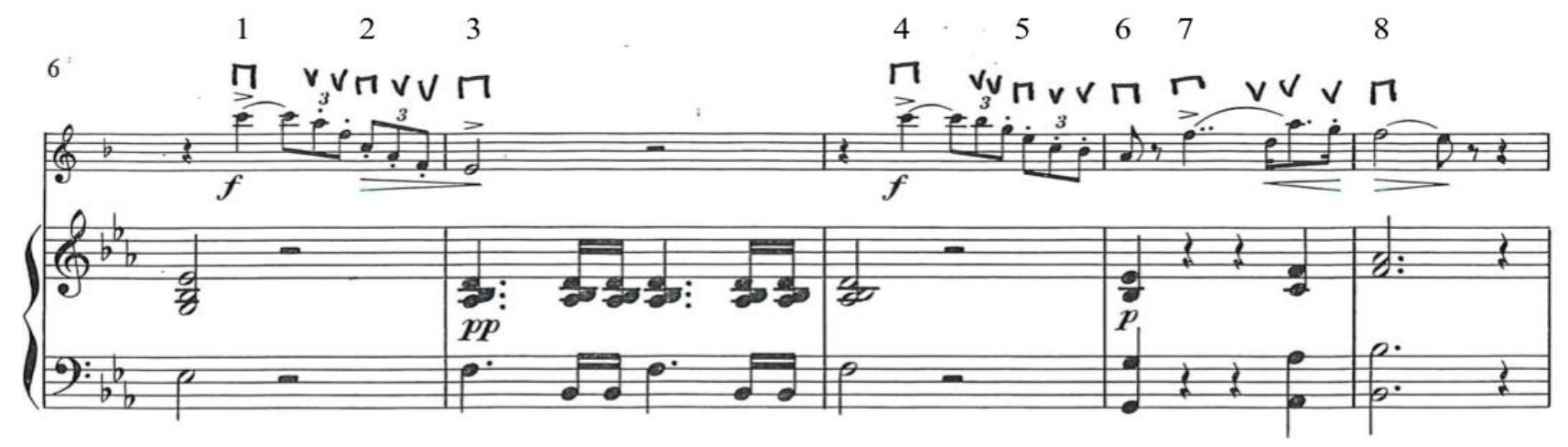

Step 4: As explained in chapter 6, phrasing numbers are added to the ideas from the previous three steps next. Numbers one to five are used in the Interrogative to support the increase in volume alongside the harmony's movement from tonic to dominant. The Affirmative, in measures three and four, contains the phrasing numbers five to one because of a decrease in volume due to the harmonic shift back to the tonic in measure four. The next series of phrasing numbers are located in the More-Affirmative and articulate the climax of the phrase in the final measure by increasing in volume from two to six and then back to one. The volume increases to level six instead of five because of the root position dominant chord on the downbeat of measure five.

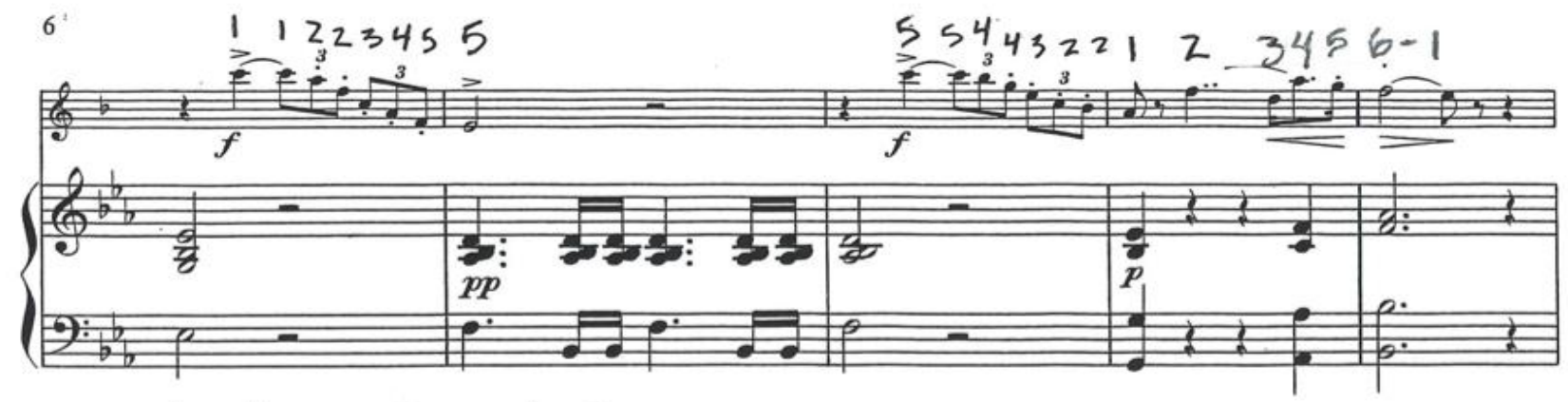

Although individually implemented, the result is a highly sophisticated performance that remains true to the composer's intent. The intent is the most crucial part of musical 
performance and study. If a masterful musical plan is not created supporting the composer's intent, the music runs the risk of becoming a fraudulent creation that could potentially lose its compositional value. Ultimately, the process above offers a unique strategy to achieve a higher level of performance and simultaneously retain the composer's intentions. 
Rhadames Angelucci

Perry Bauman

Robert Bloom

William Criss

John de Lancie

Alfred Genovese

Harold Gomberg

Ralph Gomberg

Felix Krauss

Marc Lifschey

John Mack

Arno Mmariotti

John Minsker

Charles Morris

Louis Rosenblatt
Principal, Minnesota Orchestra

Principal, Toronto Symphony

Principal, NBC Symphony

English Horn, Philadelphia Orchestra

Principal, Metropolitan Opera

Principal, Philadelphia Orchestra

Pittsburgh Symphony

Principal, Boston Symphony

Metropolitan Opera

Baltimore Symphony

Principal, New York Philharmonic

Toronto Symphony

Saint Louis Symphony

Principal, Boston Symphony

English Horn/Second, Cleveland Orchestra

Principal, Cleveland Orchestra

Metropolitan Opera

San Francisco Symphony

Buffalo Philharmonic

National Symphony

Principal, Cleveland Orchestra

National Symphony

New Orleans Symphony

Principal, Detroit Symphony

Pittsburgh Symphony

English Horn, Philadelphia Orchestra

Detroit Symphony

Second/Assistant Principal, Philadelphia Orchestra

English Horn, Philadelphia Orchestra 
Martha Scherer-Alfee

Harry Schulman

Laila Storch
English Horn, Buffalo Philharmonic

Principal, NBC Symphony

Pittsburgh Symphony

ABC Orchestra

Principal, Houston Symphony 


\section{Appendix B: Interrogative/Affirmative/More-Affirmative}

Marc Mostovoy, Founder, Director, and Conductor of the Chamber Orchestra of Philadelphia studied with Tabuteau from 1962-1964:

\section{INTERROGATIVE/AFFIRMATIVE:}

"You can break down the groups into affirmative and interrogative in many different respects [ways]. [For this phrase, there are 16 possibilities; 6 are shown below.]"

Composed by Tabuteau for pedagogical purposes
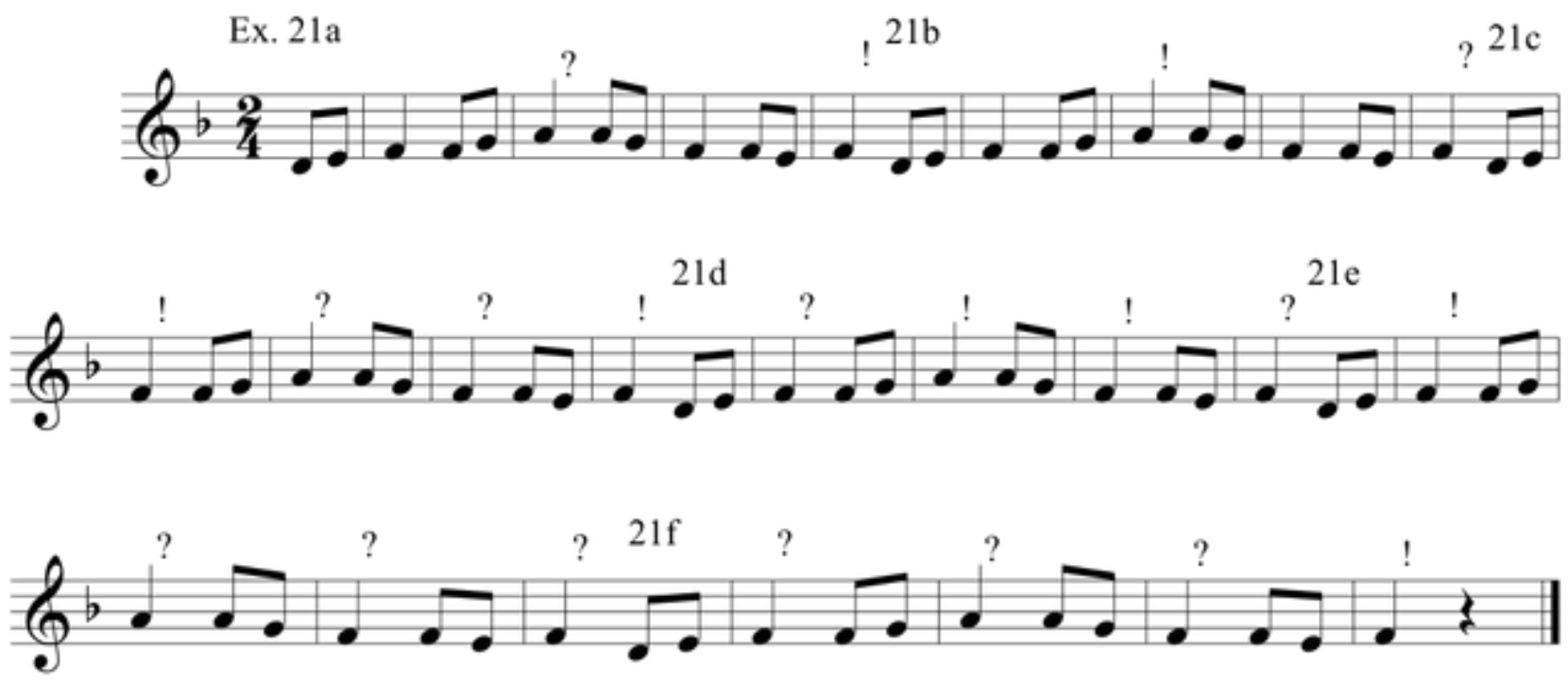

"Always be conscious of the interrogative and affirmative [in music]. Find the elements of interrogative and affirmative-question, answer."

"It's not always just interrogative-affirmative; there is also affirmative-affirmative. Always remember there are plateaus in music. You don't always [just] go up and down a mountain; there are also plateaus."

"There are often three elements - interrogative, affirmative, and then an affirmative even more positive. [T speaking about the final movement of J. S. Bach Orchestral Suite No. 2]: Badinarie! I salute. [Referring to the opening 3 statements]:" 
Mostovoy continued:

Ex. 37: Bach-Suite No. 2, Badinerie.

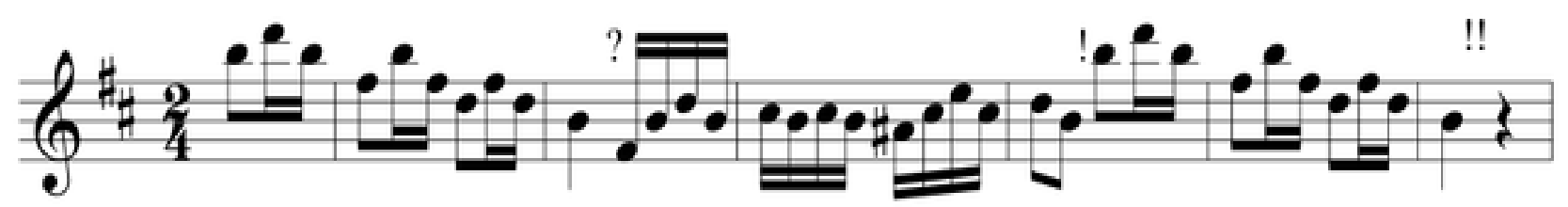

\section{DISSONANCE/CONSONANCE:}

"The position and placement of the chord is very important in deciding whether it is dissonant or consonant in feeling."

"A dissonance is interrogative; a consonance is affirmative."

\section{RESOLUTION:}

"A seventh chord is always interrogative; the resolution is affirmative."

"The dissonant chords are the interrogative; all need resolution."

"The leading tone gets more color, but the note of resolution has more weight."

"Almost always, notes resolve on the first beat of each measure."

"Either resolve on 1 or 3 [when in 4]."

"Regardless of long or short [note length], you have to resolve the note [requiring resolution]."

Wayne Rapier, former Oboist of the Boston Symphony Orchestra who studied with Tabuteau from 1951-1954:

\section{INTERROGATIVE MODE:}

"I am quite sure you understood the importance of the up-down distribution which I like to believe determine an affirmative expression or conclusion. I think it is time now to initiate you to the fun you can have with the down-up distribution which, in my mind, determines the interrogative mode."

"I am going to illustrate to you how to practice a certain pattern of articulation. The one selected will be: tee taa long taa tee, taa long taa tee! Two notes on the down inflection - two notes on the up inflection! - Tee, taa long taa tee! Resolve, the taa on tee!" 
Mostovoy continued:

"The taa tee express affirmative. The taa long, taa long - interrogative. In my opinion, the result is well balanced and singing. You will then have noticed that it takes five notes to express a group of four." 


\section{Appendix C: Note Grouping}

Marc Mostovoy, Founder, Director, and Conductor of the Chamber Orchestra of Philadelphia studied with Tabuteau from 1962-1964:

\section{GROUPING/GROUPS:}

"Your arm is made up of many joints, from the joints of your finger to your shoulder; the music is also made of joints or groups. Before you play a line, you must break it up in your mind into small [note] groups and inner [sub] groupings and finally put it together-then you have your arm together."

Composed by Tabuteau for pedagogical purposes:

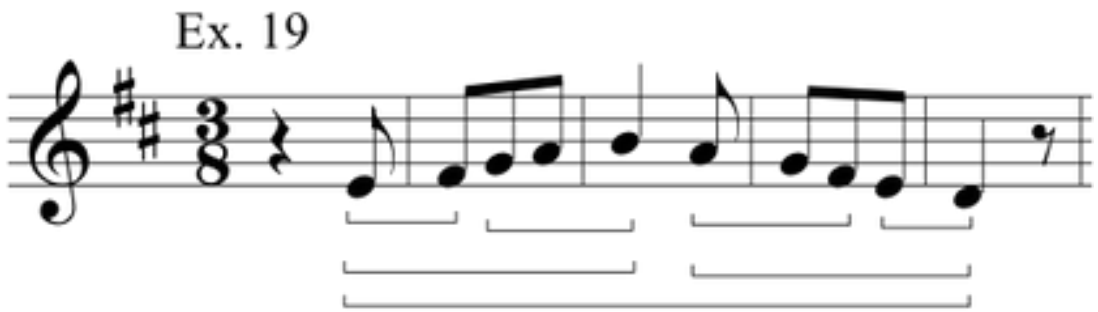

"Your groupings are living and can be expressed as inhaling and exhaling; groups and inner groups make the music live."

"A composition [complete score] must be studied thoroughly and each passage grouped correctly."

"Grouping depends much on the function."

"Ta-bu-teau: 2-2-4; Mos-to-voy: 3-2-3; both have eight letters and three syllables but they are grouped differently."

\section{WHY GROUP?}

"Grouping the right way helps in rhythmic security. [T asked me to insert bar lines in cadenza passages to determine grouping, up-down, etc.] The music will sound more flowing and more together even though the "negative" [as in photography] will be heard by the audience in many cases." 
Mostovoy continued:

\section{PSYCHOLOGICAL ASPECT:}

"Even though you think of a grouping one way, it can still sound [to the listener as] another; always play the learned [correct] grouping even though it may seem wrong. The audience will still hear it the written way; it's a psychological change [illusion]."

Composed by Tabuteau for pedagogical purposes:

Ex. 20a

Grouping as played:
Ex. 20b

Grouping as probably heard

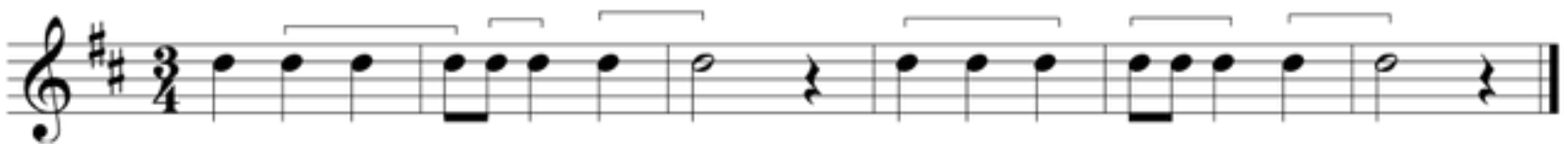

"Always start your groups with [after] the denomination of the time signature, for example: $4 / 4$ $4123|4 ; 5 / 4-51234| 5$ et cetera; the inflections determine the measure signature."

Ex. 22a

Ex. $22 b$

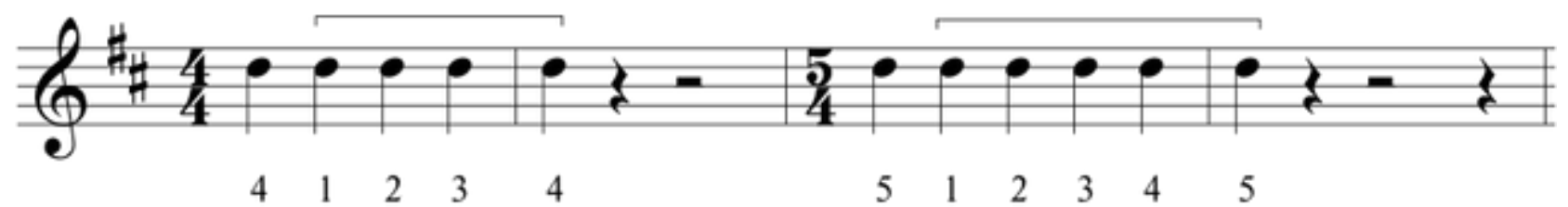

"In grouping, always count the first note of a bar as an ending from [the bar] before. A grouping usually ends on the first beat of the next measure."

Ex. 23

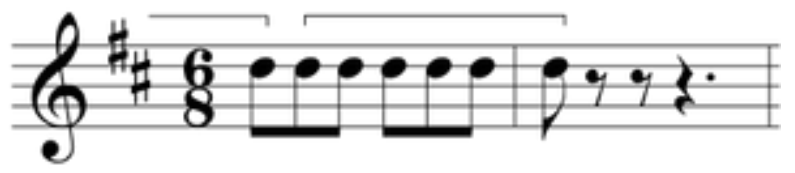

"One [The first beat] is never the most important note of a group as it is usually the last of the group before." 


\section{Mostovoy continued:}

"Many times, a dynamic change falls on the first beat [of a measure] but you can still start the new group on the second note."

Composed by Tabuteau for pedagogical purposes:

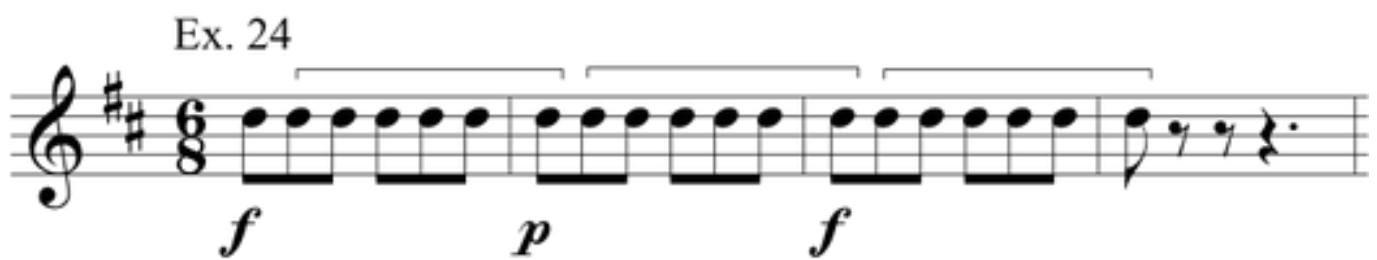

"Even though the grouping is down-down-up-up|down, you can still group the second down with the following group."

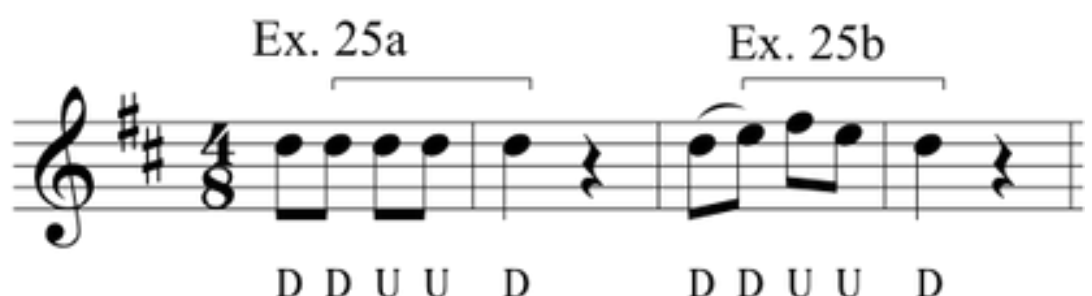

"And on a dotted eighth, sixteenth, eighth group, think the first note as an ending note."

\section{Ex. 26a: Correct $\quad$ Ex. 26b: Incorrect}

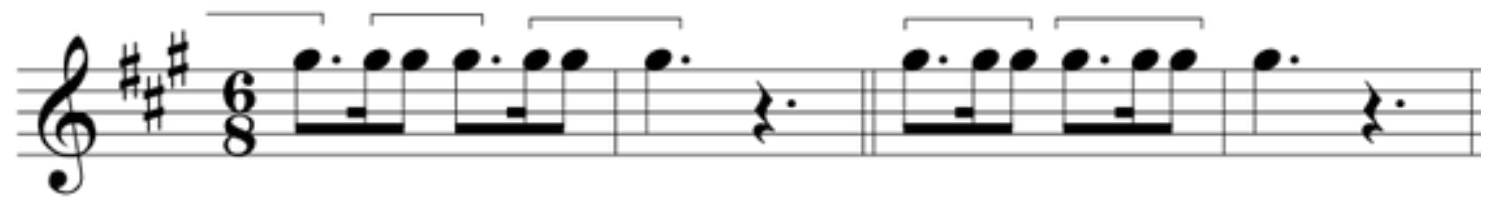

"There are so many ways of grouping some passages; it is left to the choice of the interpreter how to form the groups and inner groups."

"Grouping in 5, 6 or 7 can alternate in music. In a 6/4 or 6/8 passage, for example, there are many different combinations; your [grouping] distribution could be very different depending where your ups and downs are: $2+4 ; 4+2 ; 3+3 ; 2+2+2$. Always see [find] the root [notes] - the trick [secret] is the distribution." 
Mostovoy continued:

"When in 3, don't group after [beat] 3."

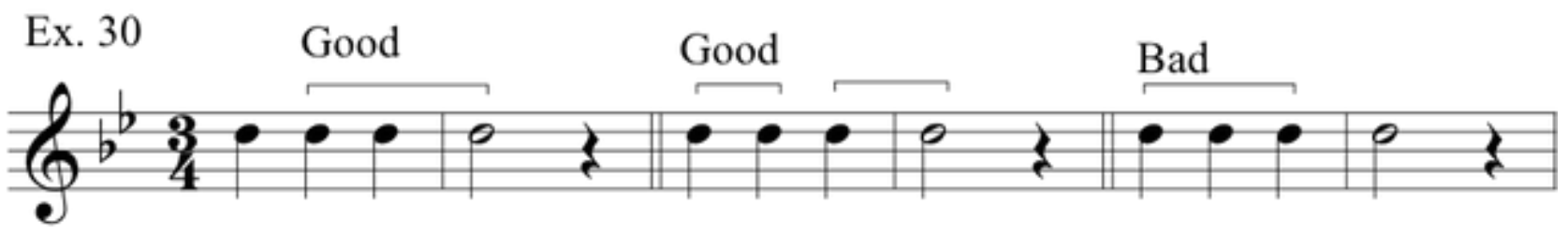

\section{ARTICULATION/SLURS:}

"The form [grouping] has no connection to (nothing to do with) the dynamics and articulation (slurring, et cetera). Slurs are not important; it's how you group the notes."

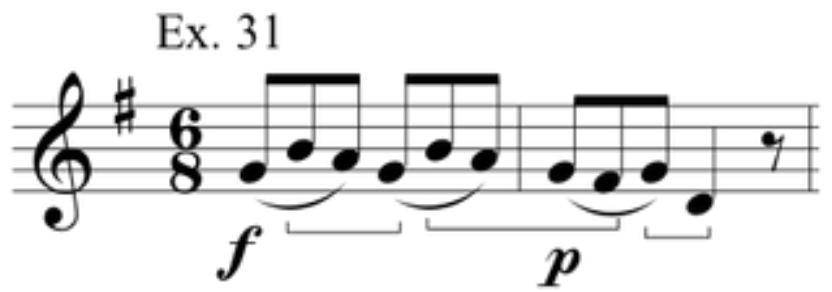

"The trick and wit is to bow what is written [the written articulation] and yet do the inner workthe grouping - differently."

\section{Ex. 32: The witty way}

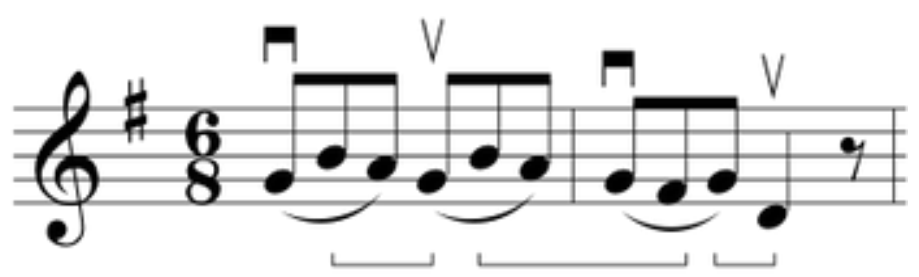


Mostovoy continued:

PRACTICING:

Composed by Tabuteau for pedagogical purposes:

Ex. 34a

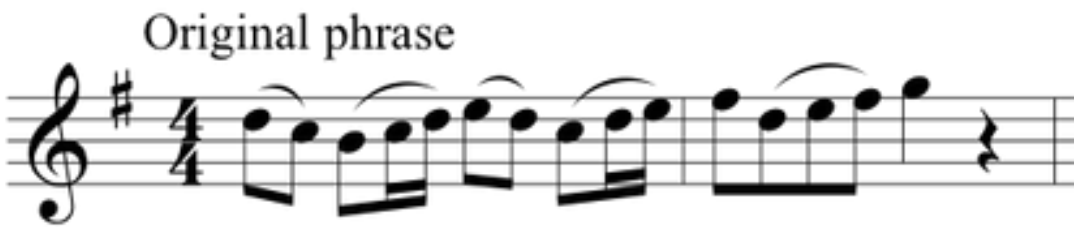

"Practice the groupings alone [separately]; then put them together."

"Practice [grouping with] separate articulations [first]:"

Ex. 34b

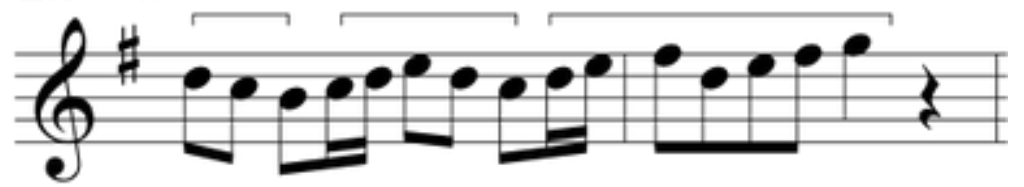

"[Then] Articulate the inner groupings:"

Ex. 34c

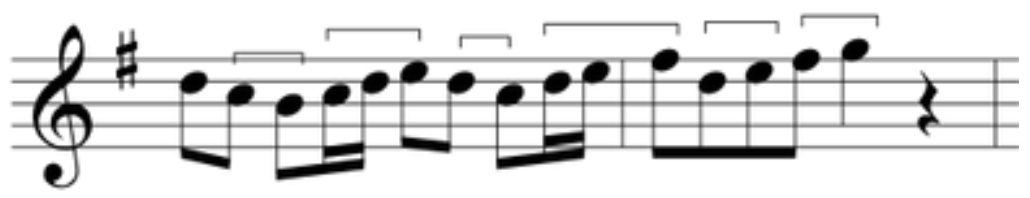

"[And] Then slur:"

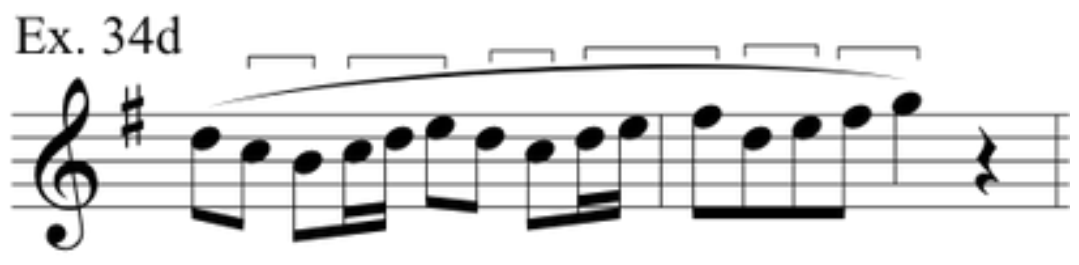


Mostovoy continued:

Practice the groups so that they become natural:"

Ex. 34e

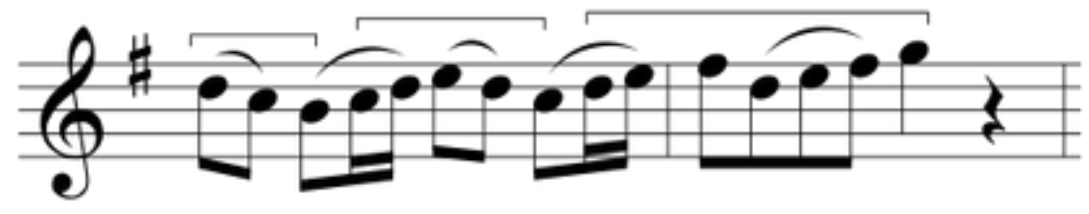

GOAL:

"Eventually, you combine your grouping — which is related to rhythm - with your coloring which is related to the melodic line and harmony. Get the right grouping!" 


\section{Appendix D: Up/Down Gestures}

Don Baker, former Principal Oboist of the Detroit Symphony Orchestra studied with Tabuteau in the summer of 1963:

"In re-solve [V7-I]: re is Up; solve is Down."

"You can’t make a Down without going Up, and vice versa."

$\mathrm{D}=$ down; $\mathrm{U}=$ up:

Composed by Tabuteau for pedagogical purposes:

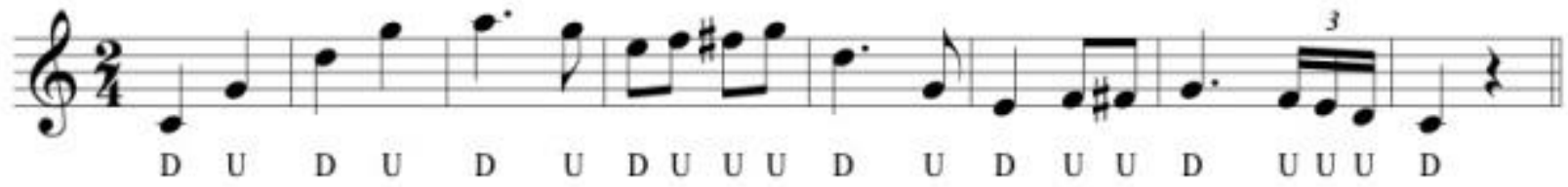

"Never breathe between an Up and a Down!"

"Breathe after a Down!"

$\underline{\text { Rowland Floyd, former Principal Oboist of the National Arts Centre Orchestra of Canada }}$ (Ottawa) studied with Tabuteau in 1965:

"In a scale of 2 octaves, breathe only after a down impulse. For example:"

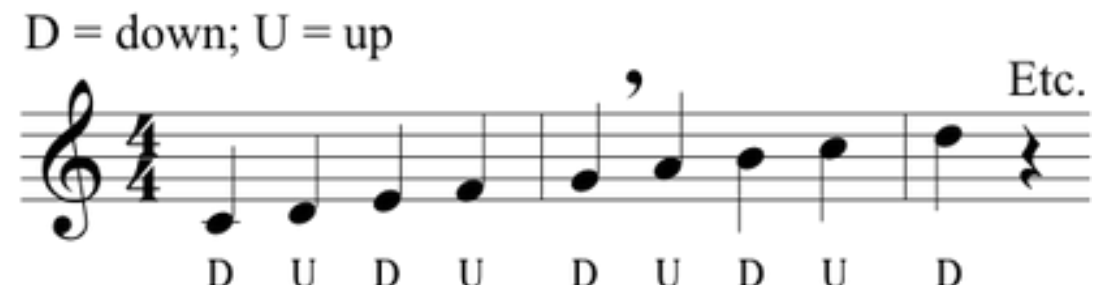

"When playing scales, for the sake of practice and to meet physical demands musically, breathe after every $9^{\text {th }}$ note. For example:" 
Floyd continued:

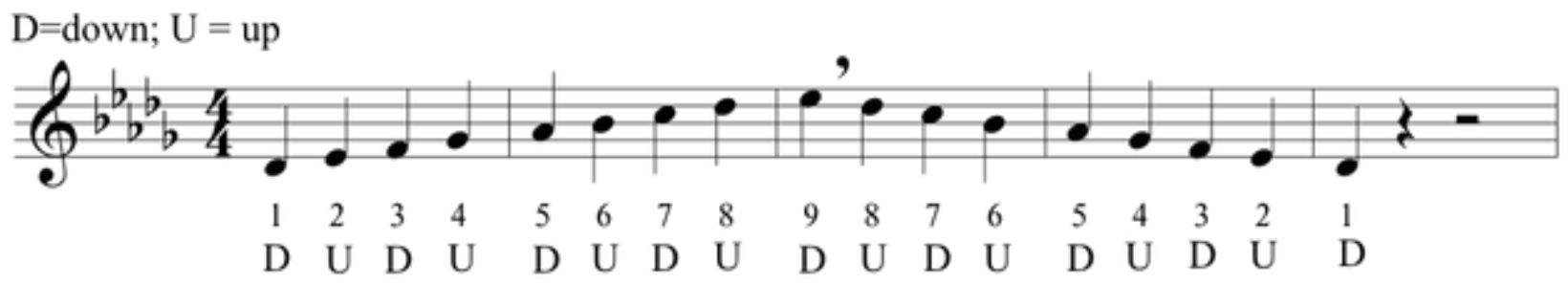

"The breath mark occurs after a down-beat, and is musically not disturbing as it would be before the final note of the scale - the $\mathrm{Db}$ in measure 2."

"The pattern for the above is verbalized as levels 1-9, alternating down and up: $1234 \mid 5678$ (ex-)|9(hale) breathe 876|5432|1.”

"The chromatic scale also should be scaled in groups of nines."

"Use violinist bow-marks for marking phrases with up and down beats - it is easier to read. Each week bring a short passage marked in phrase numbers, plus up and down beats."

self-composed

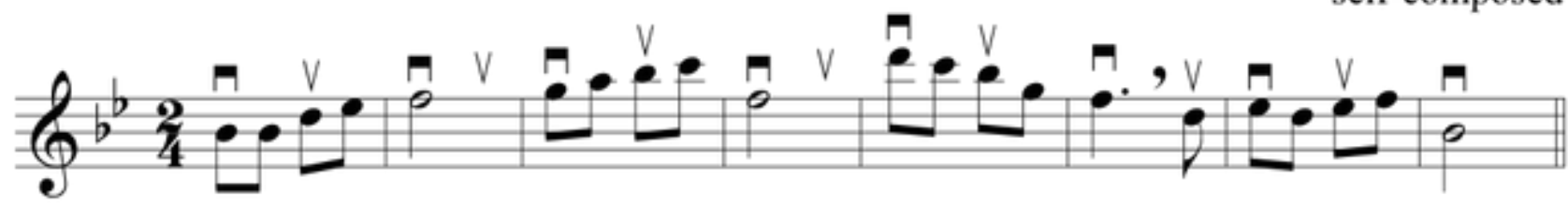

[Rowland's $V_{\text {and }} \boldsymbol{m}$ markings represent up and down inflections and not actual bowings.]

"Mark the brush [up and down impulses] in the following Haydn Symphony excerpt:"

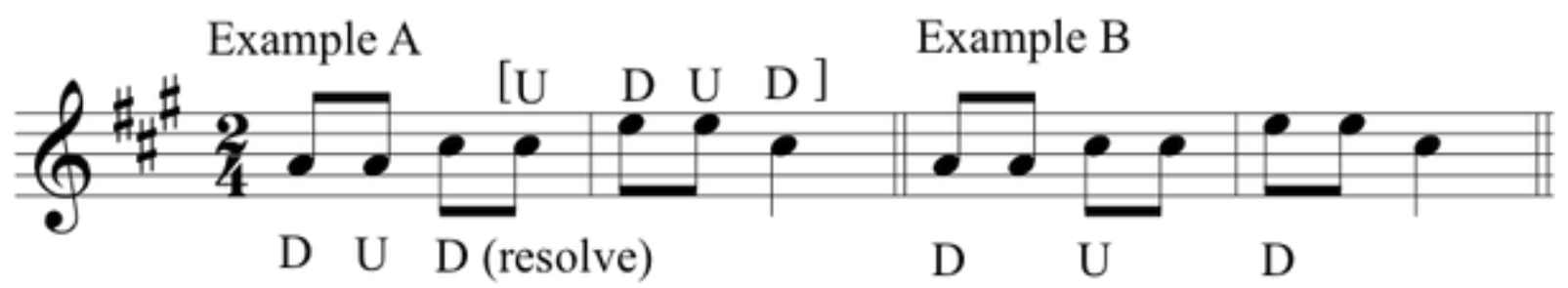

When I asked which of the two excerpts above is better, T said: "It is a matter of choice; I would choose the latter. The difference is the same as between the tempo [movement] of a horse - one which trots and one which gallops. A jockey rides not each individual step of a horse, but the upand-down movement as a whole."

(Continuing the discussion of the Haydn example): "When proceeding faster, the change is between the $2^{\text {nd }}$ and $3^{\text {rd }}$ eighth notes." 
Floyd continued:

"But not, for example:"

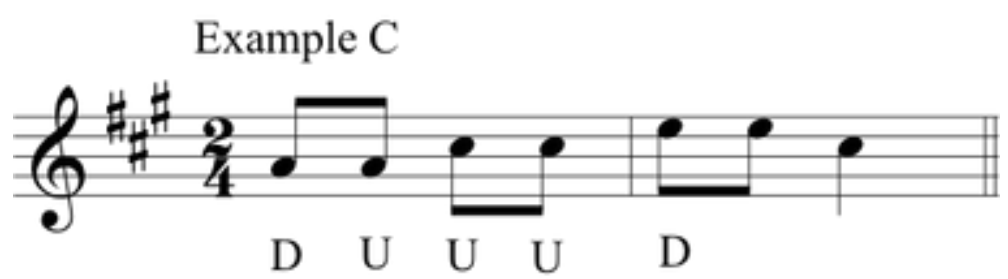

"Thus: Example B is my first choice, A my second choice, and C the worst choice.

For some reason, $\mathrm{T}$ plays the opening to Beethoven's $5^{\text {th }}$ Symphony as follows:

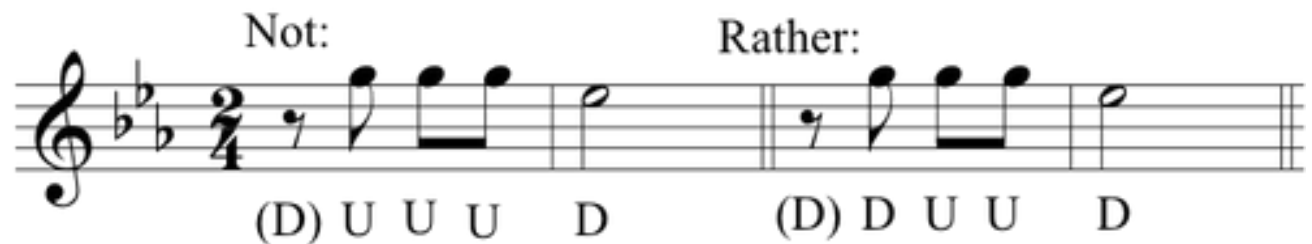

"The first example is for show rather than for music."

"Scales are all-important. Strive to make them beautiful. Give more emphasis to the up and down on each group of 4 notes:"

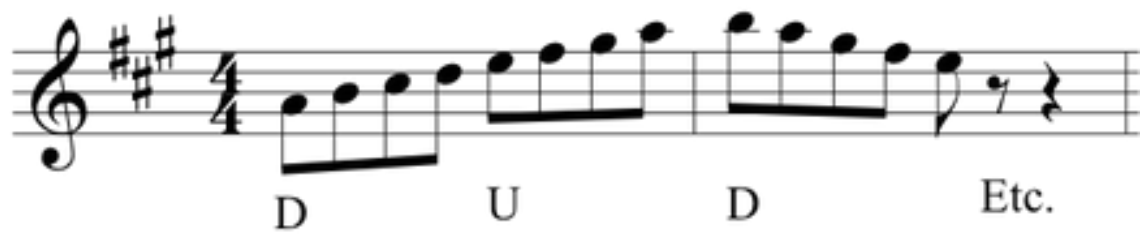

"In grouping, often the fact of thinking is sufficient. Don't overdo it."

"Remember: Down-Up equals question, and Up-Down equals answer."

"Never take a breath between an up and a down, especially before the last note of a scale (resolve), or you will receive Capital Punishment!"

"Breathe between two ups, but never between up and down." 
Composed by Tabuteau for pedagogical purposes:

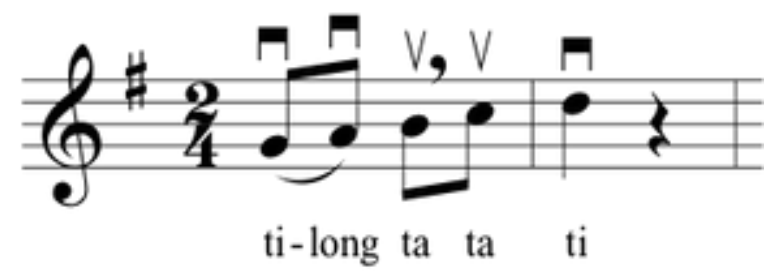

"Up-down is like a two-stage rocket; but when down-down, two ups always follow:"

Adrian Gnam, former Principal Oboist of the Cleveland Orchestra and the American Symphony studied with Tabuteau in 1965:

Composed by Tabuteau for pedagogical purposes:

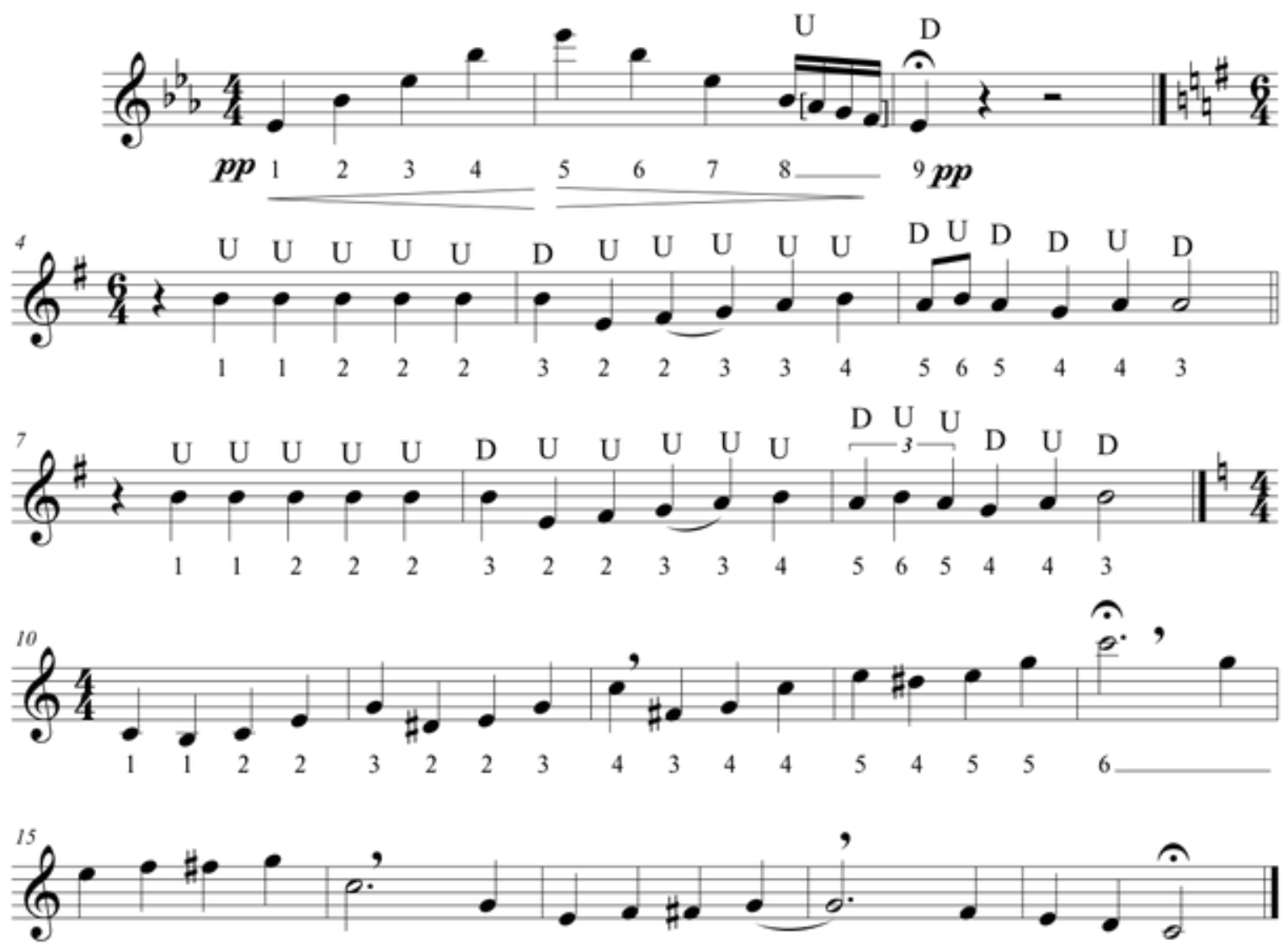

"The hardest thing to play in music is the scale; but it is also the most important. Play each note as if it were the most important note ever written. 
John Krell, former Piccolo performer in the Philadelphia Orchestra studied under Tabuteau in his woodwind courses at the Curtis Institute of Music, as interviewed by Melissa Stevens:

Stevens: Did Tabuteau ever explain to you how the down and up impulses related to wind playing and did you ever practice playing them?

Krell: "He related everything so much to the fiddle, to string playing, except he'd find string players used the wrong bowing. He had all the impulses of bowing. He insisted there was a difference between a down bow and an up bow. He insisted we think about them. In the thinking, you realized it was a listing and resolution. Downbeat, a lift to the next beat and then a resolution. That is the way it generally happened harmonically also. There is a resolution on the beat notes. He scolded us for phrasing on the beat notes. 1, up, up, up, down. The impulses added something to the length of notes too. It's in the mind, but it makes a difference in the playing."

Marc Mostovoy, Founder, Director, and Conductor of the Chamber Orchestra of Philadelphia studied with Tabuteau from 1962-1964:

"Other notes in the phrase require what we can call inflections because of the part they play either rhythmically or harmonically in the phrase. These inflections are opposite in feeling to the rebound. Notes with inflection are played with a slight nudging feeling or small push such as when a child playfully nudges his friend during a game. Both the inflection and rebound are inward feelings or reactions, something that must be felt-not done with obvious accents. Each note can have an "up" or "down" feeling or what we may call inhalation and exhalation. The rebound can usually be considered as an "up" feeling and inflection as "down," although it is possible to have rebounds on notes that are "down" and inflections on notes with "up" feeling. The amount of coloring each note receives and the proper distribution of inflections and rebounds must be carefully considered."

\section{INHALE/EXHALE:}

"It is always two elements which create a meaning. Your line [phrase] is a continuous disturbance of inhale and exhale. Music is living and must breathe."

"Everything occurs in pairs: High tide/low tide, day/night, inhaling/exhaling, et cetera; that is life."

\section{UP/DOWN INFLECTIONS:}

"You can have up inflections and down inflections. Inhales are up in feeling, exhales are down in feeling. Up equals energy — down equals weight."

"An oboist always blows out, yet he must make ups and downs."

"Downs are heavier than ups. Before you have a down inflection, you should go up." 


\section{Mostovoy continued:}

"An inflection up is suspense; when you go up you must come down, unless [you wish to remain] suspended."

"Even though the up is more intense, you must make the down sound down. The inflections must be correct: up and down."

"Practice up-down and down-up; there's a world of difference."

"Sometimes you have an up and a down [inflection] on [within] the same note."

"If you think down on the wrong note, then you are cooked!"

"Stravinsky, for example, wrote music in complex time signatures and changing ones, so that the up and down inflections fall at the right place."

\section{SIDE INFLECTIONS:}

"Some notes cannot be classed as up or down inflections but feel to the side*- to the left or to the right. North and south are not enough-you must have the east and west."

\section{Ex. 3: Beethoven-Symphony No. 1, second movement.}

\section{Andante cantabile con moto}

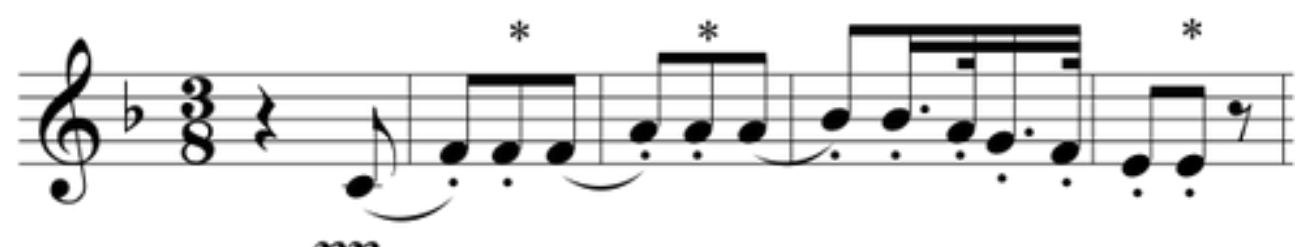

\section{$\boldsymbol{p p}$}

\section{UP/DOWN DISTRIBUTION:}

"Play with a continuous distribution of inhales and exhales [ups and downs]."

"There are many ways to distribute ups and downs. Different forms of music call for different distributions of up and down. In many passages, it is possible to have your up and down feelings varied according to interpretation."

"Do [Practice] your distribution first with a [tapping] pencil. Practice all the articulations distributing the downs and ups in different places." 
Mostovoy continued:

\section{FIRST/LAST BEAT:}

"You always have your inflection on the first beat-a down feeling, and always an up on the last beat of a measure; the others can be up or down."

"[In 4] You must have a down on the first beat and an up on the fourth beat; if you have a down on the fourth beat and an up on the first beat, then your measure [time] signature is probably wrong."

\section{THE DOTTED NOTE:}

"A dot is always a down inflection."

Composed by Tabuteau for pedagogical purposes:

Ex. 5

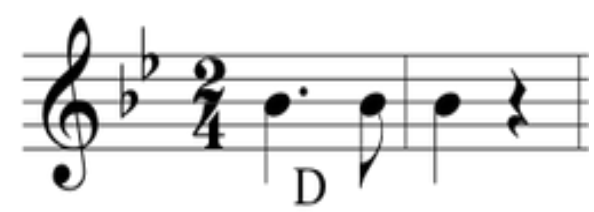

\section{TIME SIGNATURES:}

"3/8 [in 1] is a feeling of down|down|down [on each measure], a gallop type of feeling."

Composed by Tabuteau for pedagogical purposes:

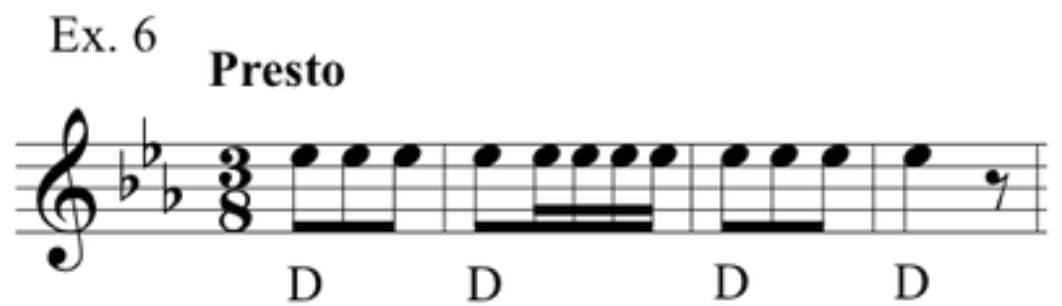

"In a fast 6/8 [in 2], you always have an up and down inflection [up on 2 and down on 1]; the second beat is up-always. On the second beat you often have a concluding note; this would be a kind of suspense having a concluding note on an up inflection." 
Mostovoy continued:

Composed by Tabuteau for pedagogical purposes:

\section{Ex. 7}

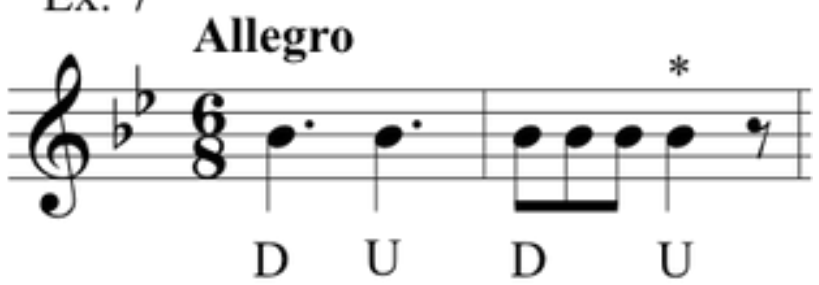

"In a slow 6/8 [in 6], you [can] have any combination [of up and down]. If you had a down-upup-down-up-up|down, it would really be a $3 / 8$ rhythm [Ex. 8e]."

Some Examples composed by Tabuteau:

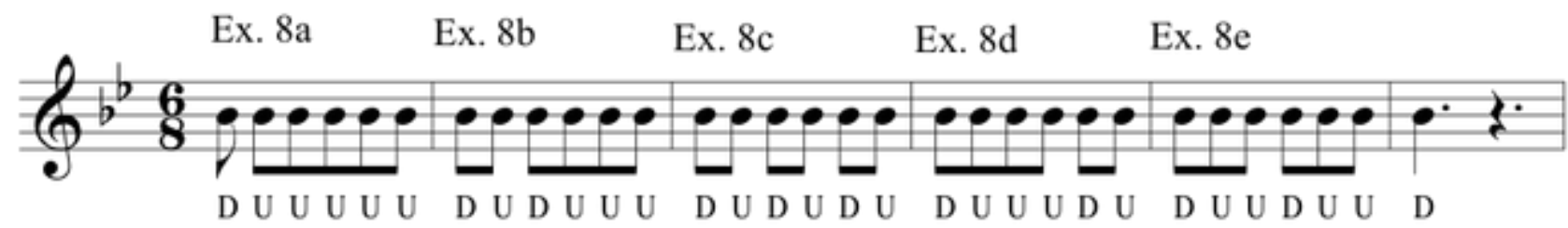

"Your downs and ups influence [your interpretation]. 12/8 could be considered, for example, in [3 groups of] 4 or in four groups of $3 / 8$; it depends where the up and down inflections fall."

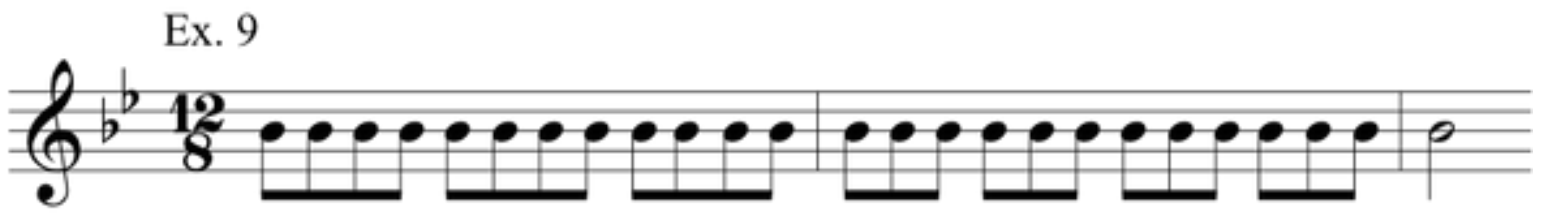


Mostovoy continued:

[Tabuteau speaking about Beethoven $6^{\text {th }}$ Symphony, second movement 12/8]: Put weight on each beat; a feeling of down, down, down, down - a [slow] gallop type of feeling.

\section{Ex. 10: Beethoven-Symphony No. 6, second movement.}

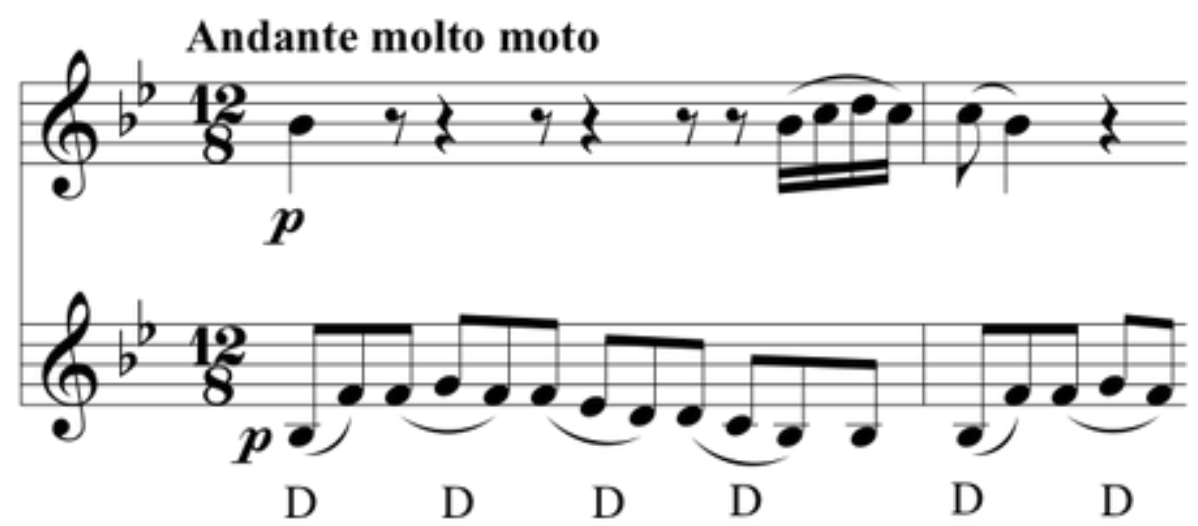

"Subdivisions are sometimes necessary; you very rarely, if ever, have in $6 / 4$ for example, downup-up-up-up-up|down."

Composed by Tabuteau for pedagogical purposes:

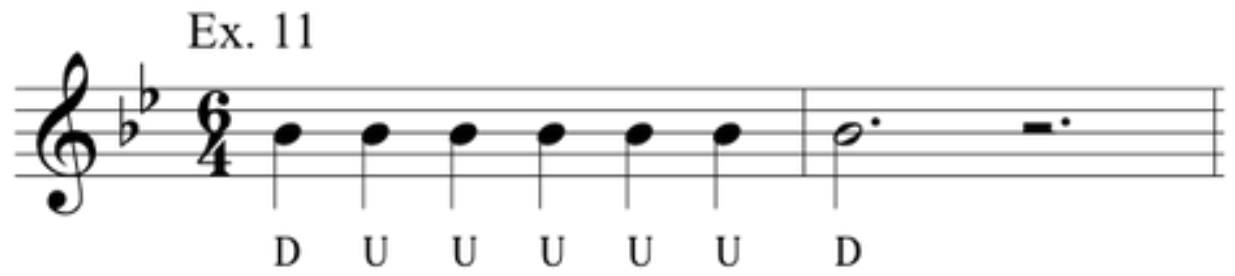

"In 4/4, you can have down-up-up-up|down, down-down-up-up|down, and down-down-downup|down. Down-up-down-up|down would really be two bars of 2/4."

Ex. 12

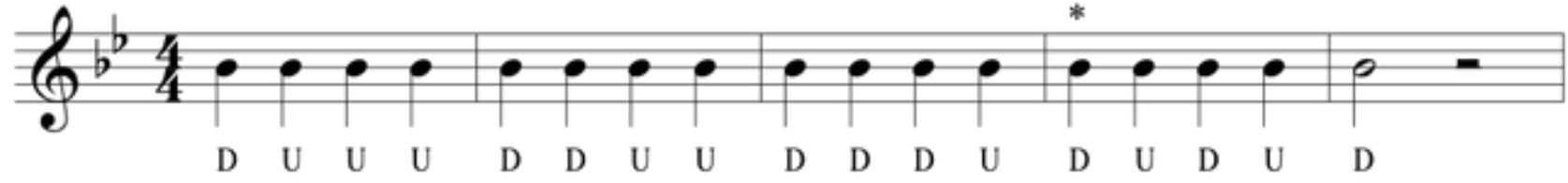

"Your distribution - practice down-down-up-up|down, down-up-up-up|down and down-downdown-up|down" 
Mostovoy continued:

Ex. 13

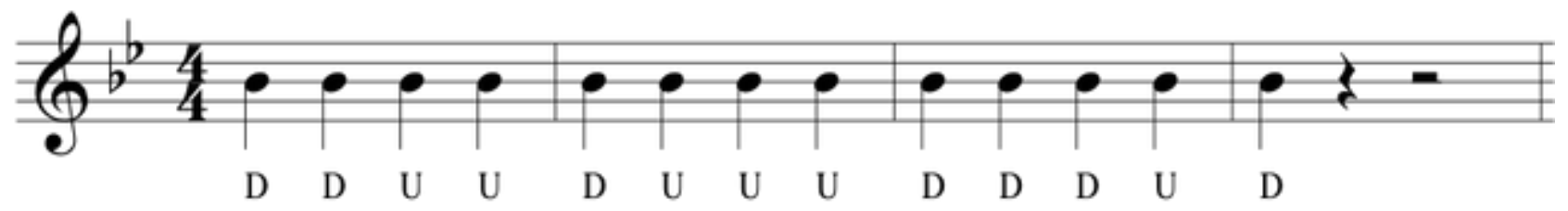

"For practice, change notes [pitch] on [up and down] inflection changes."

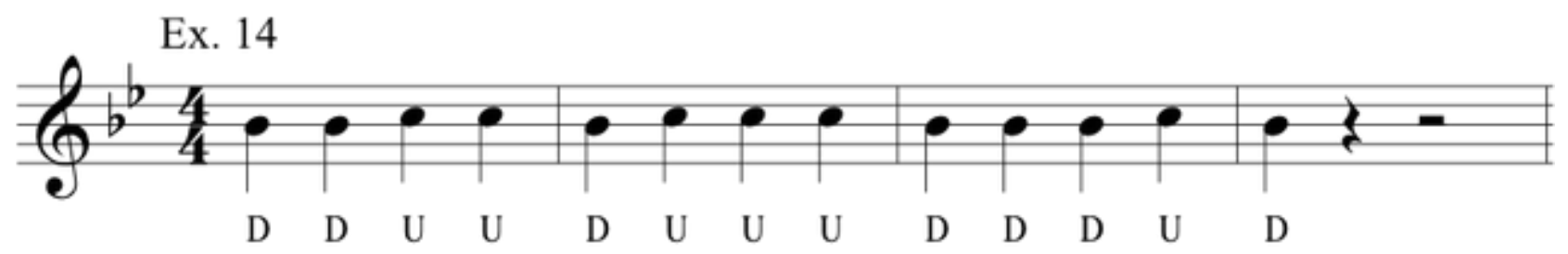

"In 3/4 you can have two feelings-down-down-up|down or down-up-up|down."

Composed by Tabuteau for pedagogical purposes:

Ex. 15

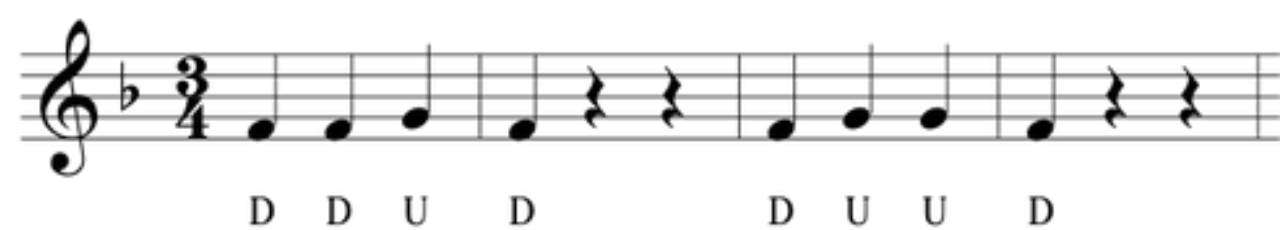

Donald Hefner, former solo oboist of the U.S. Marine Band studied with Tabuteau for two years in the 1950's:

"Not only do the bowing marks [in an example at hand] appear to bind the figures into one-bar units, but the heavy beam that binds the eighth notes adds to the illusion. And each bar line appears to be a dam or obstruction. The actual grouping of the figures in the sense of the phrase is, of course, in direct contradiction to the appearance of the notation. Occasional attempts have been made to revise the notation of the music so that it more clearly shows the relationship of the notes, but the old system has prevailed. Students must be taught to feel the real relationships within the music. This was Tabuteau's supreme gift to his students."

"To quote an example, remembered exactly from an ensemble class [Hefner presents a wellknown melody here]: Note that the rise in intensity is not necessarily synonymous with a rise in pitch. This phrase derives its increasing tension from the sequential repetition of a two "syllable" 


\section{$\underline{\text { Hefner continued: }}$}

motive. When the numbers progress, that signifies an "up-down" inflection. When the number repeats, it means that these adjacent notes are unrelated. When the phrase is progressing toward its climax, the "down" inflection has more weight than the" up." Tabuteau would illustrate this point by pretending to hold a carpenter's hammer. He would make a violent upstroke and a soft down stroke and say, "You can't drive nails in like that!" In the course of resolution, however, as the decreasing numbers indicate, the opposite is true."

Joseph Robinson, former Principal Oboist of the Atlanta Symphony and New York Philharmonic Orchestras studied with Tabuteau in 1963:

The following quotations are borrowed from his book Long Winded.

"From now on, he said, every note must have inflection! (By which he meant must have an inclination up or down, faster or slower, forward or back!) That required me to play in $4 / 4$ time: down on 1, up on 2, down on 3, up on 4, down on 5, and so on. (Actually, in 4/4, three other expressions of inflection exist at the same time - down, down, up, up; down, up, up, up; and down, down, down, up.) He often described "up" as smoke rising into air, suggesting that an "up" inflection was more a matter of suspension than of loudness per se. Playing violin as a Robinson continued:

young man had convinced Tabuteau that the up-down motion of the bow simulated the necessary human business of inhaling and exhaling, with its inherent alternation of tension and release. He determined that oboe play must replicate the process "in order to sound alive." (pg. 162)

"There are many overlapping layers of "up and down" in music, with larger diamonds continually subsuming and enveloping smaller ones. Inflection slopes extending "up" far enough constitute "the interrogative mode" (musical questions), while groups of notes starting loud and falling away on the other side constitute "the declarative (affirmative) mode" (musical answers). (Answers always begin a bit louder than the end of the questions). Tabuteau believed the length of these extensions was limited only by the imagination, discipline and skill of the player expressing them; and longer extensions are absolutely more sophisticated than shorter ones." (pg. 162-163)

Wayne Rapier, former Oboist of the Boston Symphony Orchestra studied with Tabuteau from 1951-1954:

"My own version of survival in producing Mr. Tabuteau's desired results might be useful for understanding his references to numbers and "up and down." Producing acceptable ups might be produced by increasing:"

1) The speed of vibrato or intensity

2) The accompanying speed of the air (or bow) plus

3) Placement of pitch 


\section{$\underline{\text { Rapier continued: }}$}

"The ups would follow harmonic progressions with increasing intensity to the resolution. The beginning of the downs at the resolution should contain the most intense motion before relaxing after that resolution point."

\section{INFLECTION DISTRIBUTION:}

"We will have today a lesson on distribution of inflection."

"One down - one up; One down, one up!"

"Now, two down; one up!"

"One down; three ups!"

"You will excuse me with my "up and down" but, to me, it is very important!"

"In my opinion, the oboe technique is similar to the human voice technique."

Waldemar Wolsing, former Oboist of the Danish National Radio Orchestra studied with Tabuteau in 1950 and 1953:

\section{PATTERNS. UP AND DOWN. LOGIC.}

"The pattern is two "down" and one "up." (Plays) Now, one "down"- two "up." (Plays) Let's hear that. (Sings) Up, down - up, down. Up, up, down. That's my distribution W. Yes. (Plays Massenet: Elégie) You see, let's hear that. T. Don't you think it is interesting? W. Yes. Very interesting. . .the life. . .T. Sure. If you play only one, one-way traffic - you see-it's meaningless. You understand that? W. Of course. T. To make it short, life is like our system. It exhales and inhale. You see, that's what I mean by up and down. It is like breathing. You see what I mean. Taking a breath to keep alive. When you don't do that your music is dead. Like you would die, or would be dead if you don't — if you stop breathing — breathing, I mean to say. I must not pronounce it "breathing" and "breathing." It is not the same thing, you know. You can play soft—you can play forte - you can play slow—you can play, you know, volume - sixtyfooter - thirty-footer. Small . . . But it is dead, because you always play on one jet. It never- -it never-it does not belong to an orbit. It's like a-it's like a star who don't belong to the system. It's called a comet, you know. All right. The organ music is like a comet—sshht!, and you never see it again, except maybe thousands of years-But when you have the right distribution, you know, that you —you, you play down, you play up —it's like breathing, I mean to say-you see? Up and down. It's like inhale and exhaling, you know? W. Yes. T. That means life in your music. T. That's all. You see what I mean? W. Yes. T. That's all the understanding that we should all have. W. Yes. T. And it is easy to see that way. Very easy. It does not mean a 


\section{Wolsing continued:}

crescendo. On the contrary. When I go up, I think of smoke who is lighter than air and goes up, you see. W. Yes. T. Most of people they go up, they play louder, you know, crescendo going up - diminuendo going down. I do exactly the contrary. To me, a diminuendo-—it's a sign of ascending. W. Umm? T. Like this. (Plays Don Juan) You see? My notes are going up: d-ef\#-g. Going up, but I go up and make a diminuendo. You see that. W. Yes. Yes, yes. T. It's like a crossing move. W. Yes, yes. T. That's why I know-I had so much fun in music. You know, I really had fun, because there is all the keys of logic and truth in music, you see, when you are willing to feel it the right way. W. Yes. T. (Plays) You see, I don't make a crescendo. My notes are going up but I don't make a crescendo. (Plays Lakmé) I want to-up-up. Now I am going to do-(P[ay5). That was up and down, you see? You see the two different ways. W. That's clear. T. You understand that? W. Yes. T. You see? Look here. (Plays) Up-I don't — W. Diminuendo-Up is speed and down is slow. T. That's right, like that, you see. (Sings) Faster here and slower and faster. You know when you turn a wheel, you push. Going up you don't have to push. The weight of the machine takes it up. You only have to push it down. W. Yes, yes. That's the same thing. That's why we could learn so much only with a willingness to go with logic. That's all."

Felix Kraus, former Oboist/English Horn in the Cleveland Orchestra studied with Tabuteau from 1950 to 1952 as interviewed by Melissa Stevens:

Stevens: Did he (Tabuteau) ever have you play scales thinking inflections?

Krauss: "Of course, anytime he applied the number system. There was no such thing as not knowing whether you were thinking up or down. That was as basic as not breathing on a bar line. Breathing on a bar line meant that you had taken a breath on an up inflection. Other instrumentalists and teachers do this naturally sometimes, I'm sure."

Louis Rosenblatt, former Oboist in the Philadelphia Orchestra studied with Tabuteau from 1948 to 1951 as interviewed by Melissa Stevens:

Stevens: How did Tabuteau Teach Inflections?

Rosenblatt: "He would use the idea of bowing as in string instruments, very often. When he had string classes he would tell them how to bow, but I don't think he knew very much about the technicalities of bowing a string instrument. He thought, if one note leads to another note, you use an up bow. All his oboe students attended most of his string classes because it was very interesting to hear how he taught them. He often spoke about bowing, but I never heard him use a word that is technically associated with bowing. He used the example of bowing but would just say "up" and "down" to explain inflections." 


\section{Appendix E: The Phrasing Number System}

Don Baker, former Principal Oboist of the Detroit Symphony Orchestra studied with Tabuteau in the summer of 1963:

Exercises for long tones:

"13 up, 13 down, played sustained and detached."
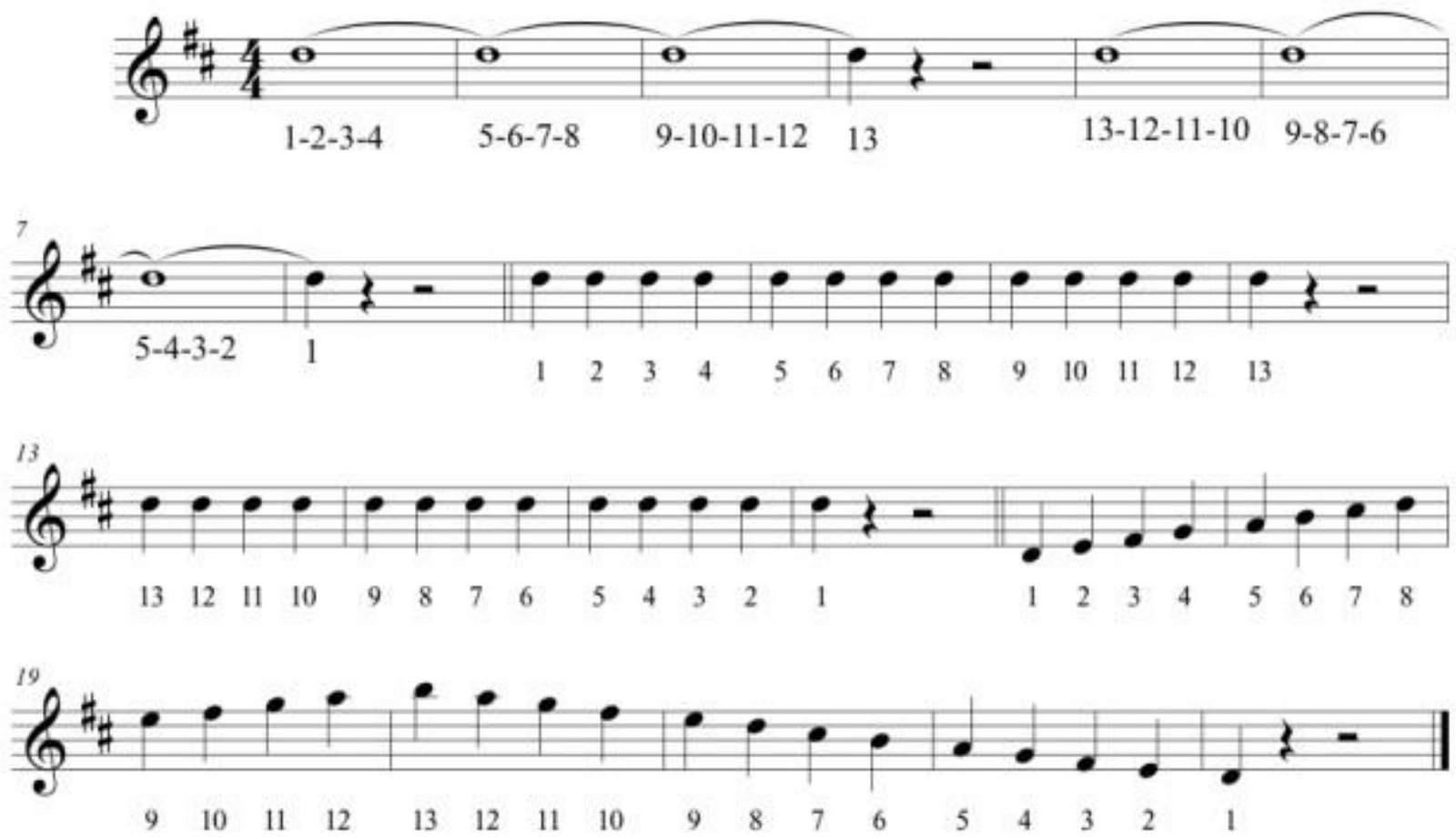

\section{$7^{\text {th }}$ Lesson}

Exercise: $1-14$ on E, then play 15 on high D:

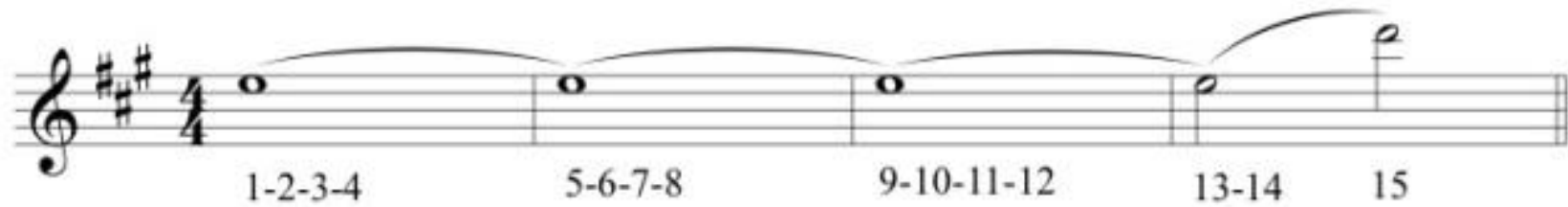


$\underline{\text { Baker continued: }}$

Robert Schumann: Drei Romanzen, No. 3.

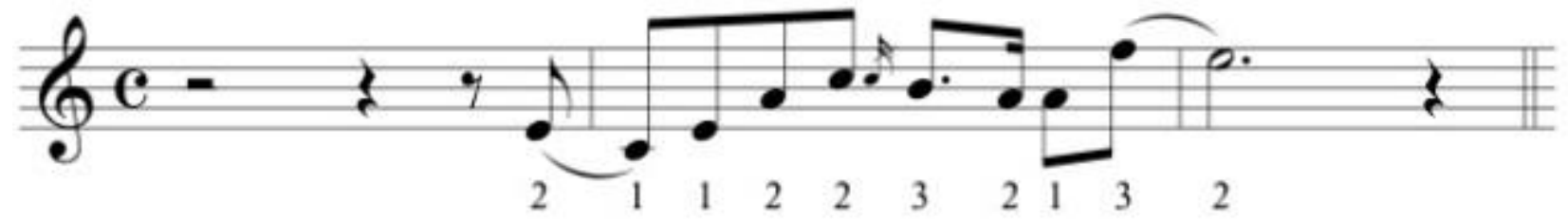

"Note that in this movement, an interrogative is always followed by an affirmative."

"Begin practicing this piece as birds teach their young."

"Play the little syllables several times over until they are perfect. Then put them together for the complete movement."

"Play all intervals as if they were a comma, that is, an eighth of a tone." [Don explained that Tabuteau wanted a very smooth line without reaching across intervals-a minimum of adjustment.]

"Drive: Play the space."

"The artist plays the space between the chair and the stand; the amateur plays the chair or the stand."

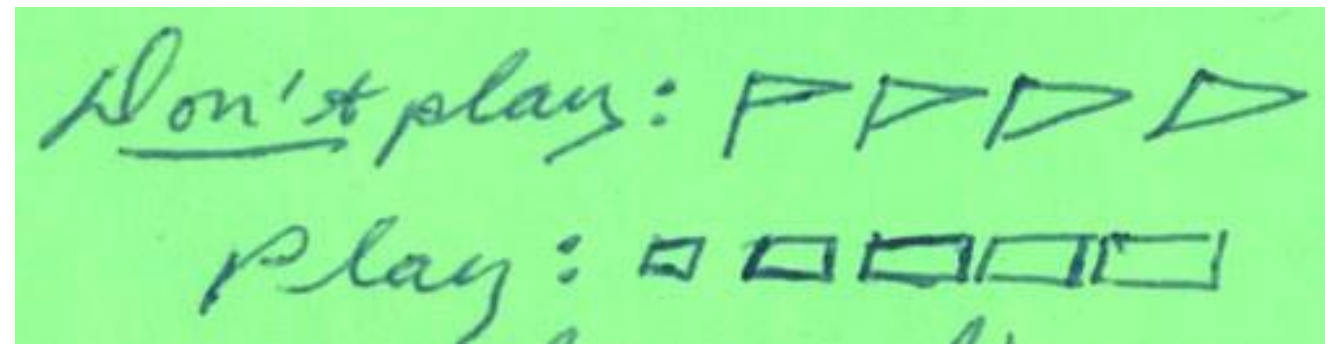

"Scale everything, especially the space between the notes:"

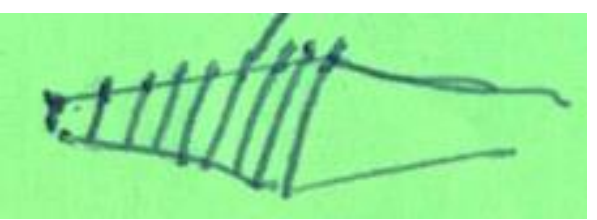

Level $1=$ little bow. 


\section{$\underline{\text { Baker continued: }}$}

Level 9 = full bow

"If you scale the length of notes, then you will scale the space. Use more space between smaller numbers than full-bowed large numbers. Always touch level 1 on which you begin and on which you end."

An exercise:

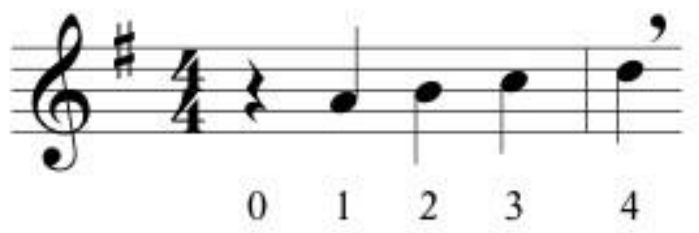

"It takes two notes to make an interval. Also, it takes two strikes to make a rhythm."

Baker states, "This was given by Tabuteau to explain the importance and significance of level 0."

Practice the following concepts on a line comprised of the same note: pressure, wind, inflection, punctuation, and grouping. Then add the melodic pattern:

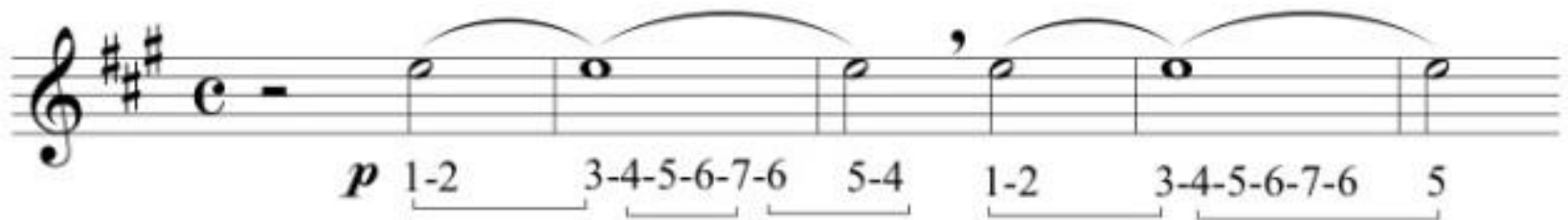

2.

ROM A N E I

ROBERT SCHUMANN.

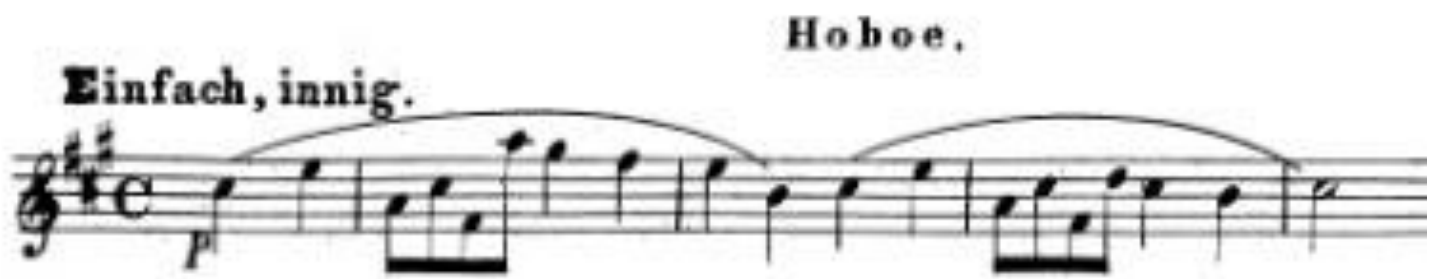


Rowland Floyd, former Principal Oboist of the National Arts Centre Orchestra of Canada (Ottawa) studied with Tabuteau in 1965:

"There are many oboe players around, but herein is the difference: Like a billiard ball — one must direct the sound by way of phrasing; otherwise, it will go over the side of the pool table from being hit too hard. One can visualize this in the following example:"

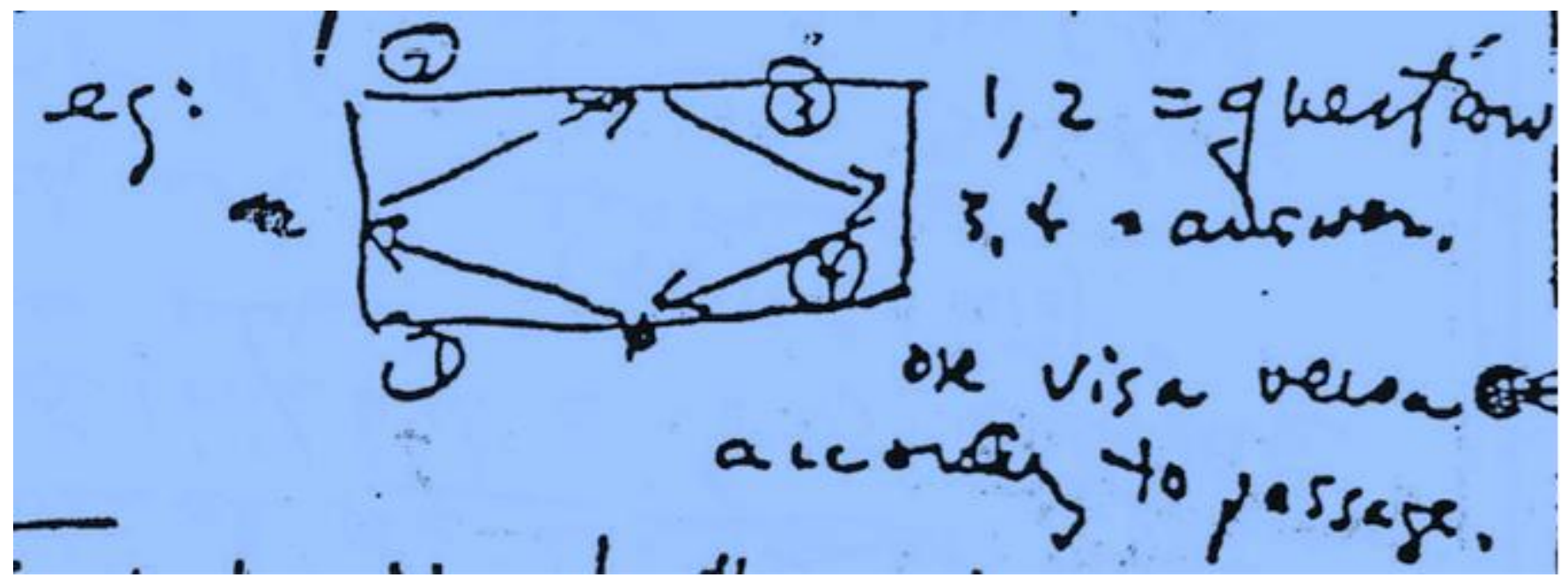

1,2 = question; $3,4=$ answer; or vise versa according to passage.

Regarding the control of a phrase: "It is like butter in a pan, it melts, it runs; otherwise, it is like a rock in a hot pan. The notes of a phrase should be played on the wind in each direction, up and down, not as individual static notes."

Following are the formulas in increasing and decreasing the sound from level 1 that he presented to me:

$1-2-3-2-1$

$1-2-3-4-3-2-1$

$1-2-3-4-5-4-3-2-1$

"And Tabuteau was adamant that one must have a true level 1." 
Floyd continued:

"One should think of the natural direction of a brush ( $\mathrm{T}$ used a feather gently against the wall to demonstrate). After the brush goes up and starts the direction downward, note the tip of the feather: it takes a moment to follow. This is the loop."

Diagram by Tabuteau:

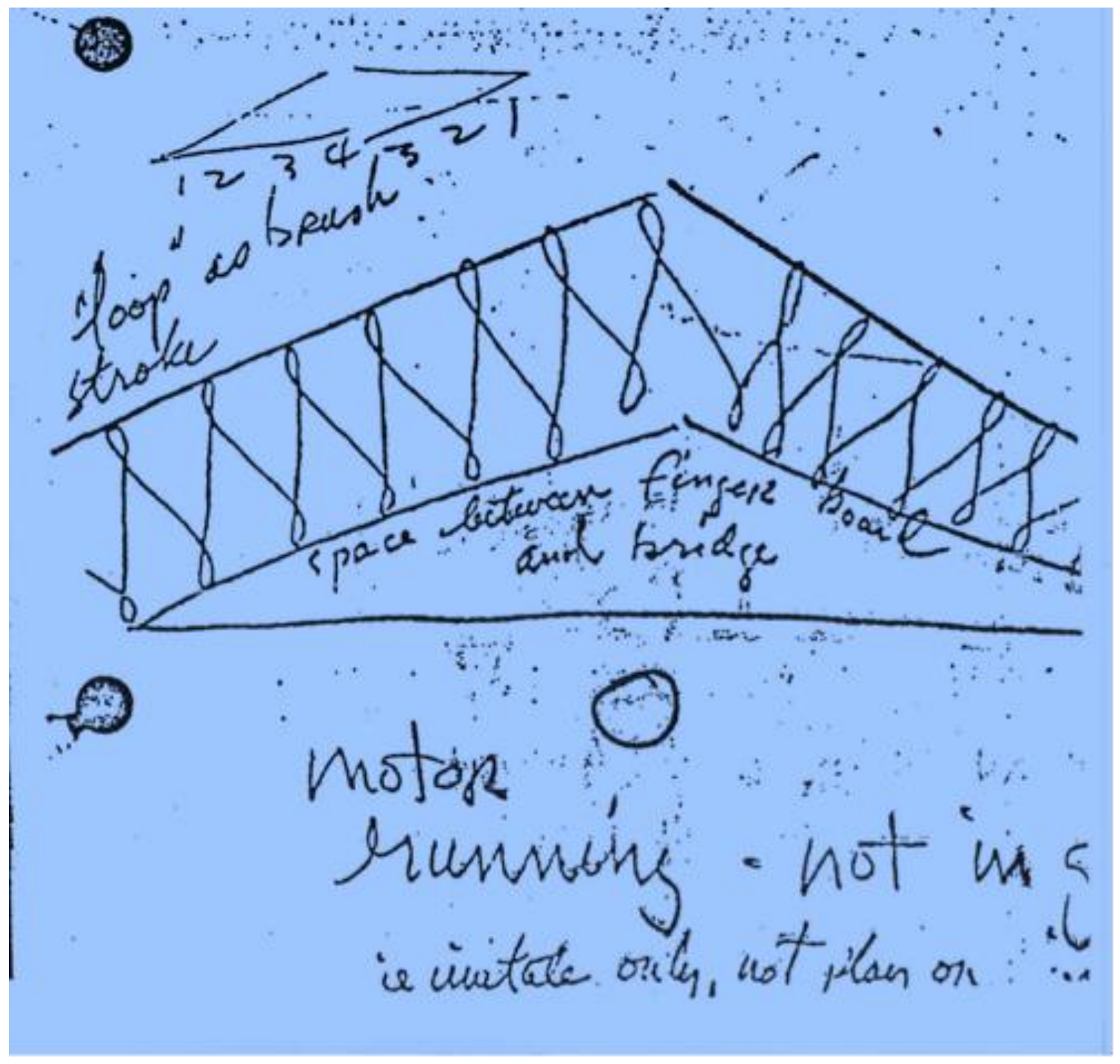

"Loop as brush stroke / space between fingerboard and bridge / motor running" 
Floyd continued:

"If level 1 is not down pat, including the attacks, then this is like building a house on a shaky foundation."

Composed by Tabuteau for pedagogical purposes:

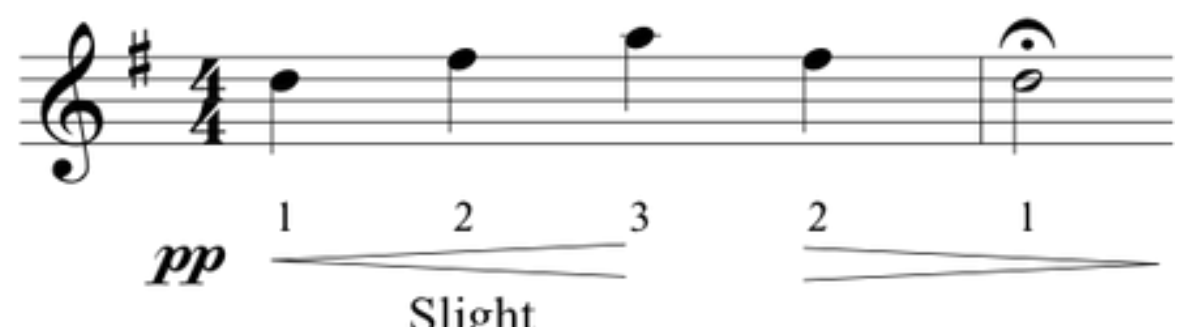

"Adding to the example of the loop and brush-stroke idea - think of an athlete chinning on a bar: When he lifts his arms up, and chins himself up, he can go only to the chin position. If he would like to go higher, then he must make a transition - his arms push him up and above:"

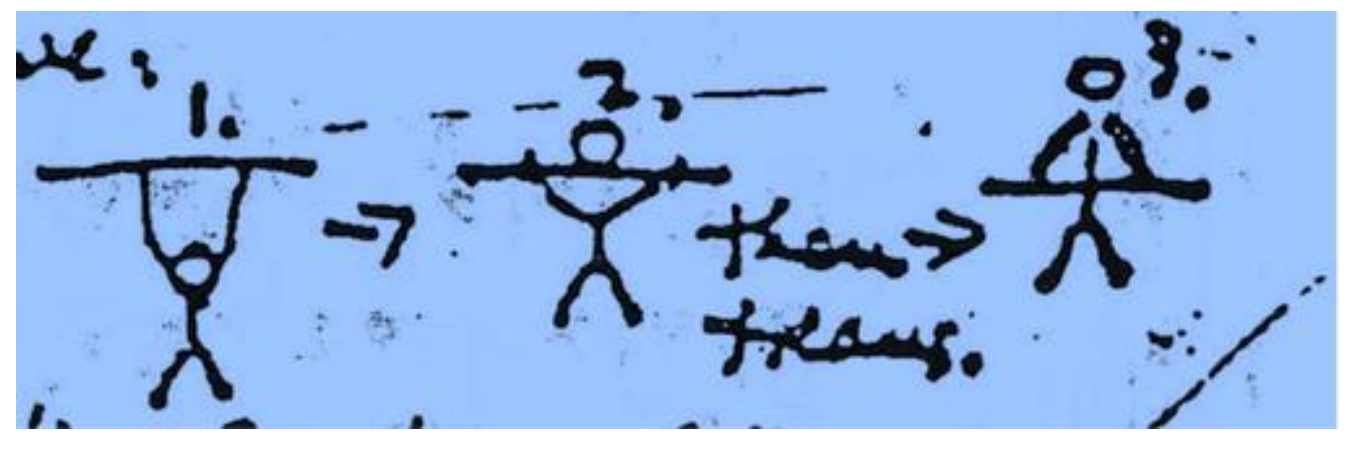

"This transitional stage (2 to 3 in the illustration) is the loop or change in brush stroke."

My (Rowland Floyd) assignment:

1. C major scale on level 1 to high $\mathrm{F}$ - two octaves and articulated

2. A minor scale likewise

3. Levels $1-9-1$ on the same note (an A) and in the combination A-B2- A, tongued and slurred, carefully observing pitch and dynamics:

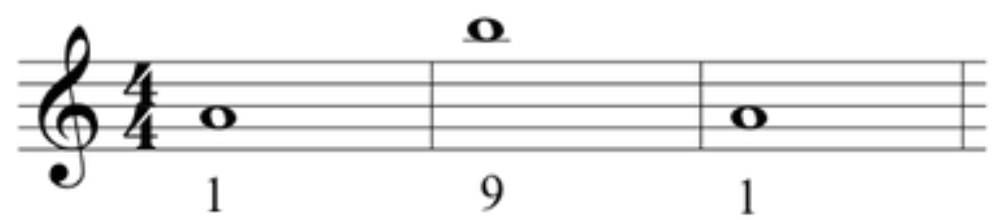




\section{Floyd continued:}

In addition:

1. Db major scale on level 1

2. Bb minor scale on level 1

3. Chromatic scale: Low $\mathrm{C}$ to high $\mathrm{E}$ on level 1 and return. Note that levels 1-9 and 1-5 must return back to level 1

4. Make up pitches to fit the following pattern [a scale]:

$1122|3456| 77654|3432| 1$ (question and answer phrases).

Many misunderstand what Tabuteau means in his numbering system. His numbers refer to:

1. speed

2. direction

3. groupings

4. scale

"Regarding the oboe's sound, the head sound versus chest sound is like the register factor in the human voice: The head voice to the chest voice, and back to the head voice, is 1 to 5 and 5 to 1 . The chest voice to the head voice, and back to the chest voice, is 5 to 1 and 1 to $5 . "$

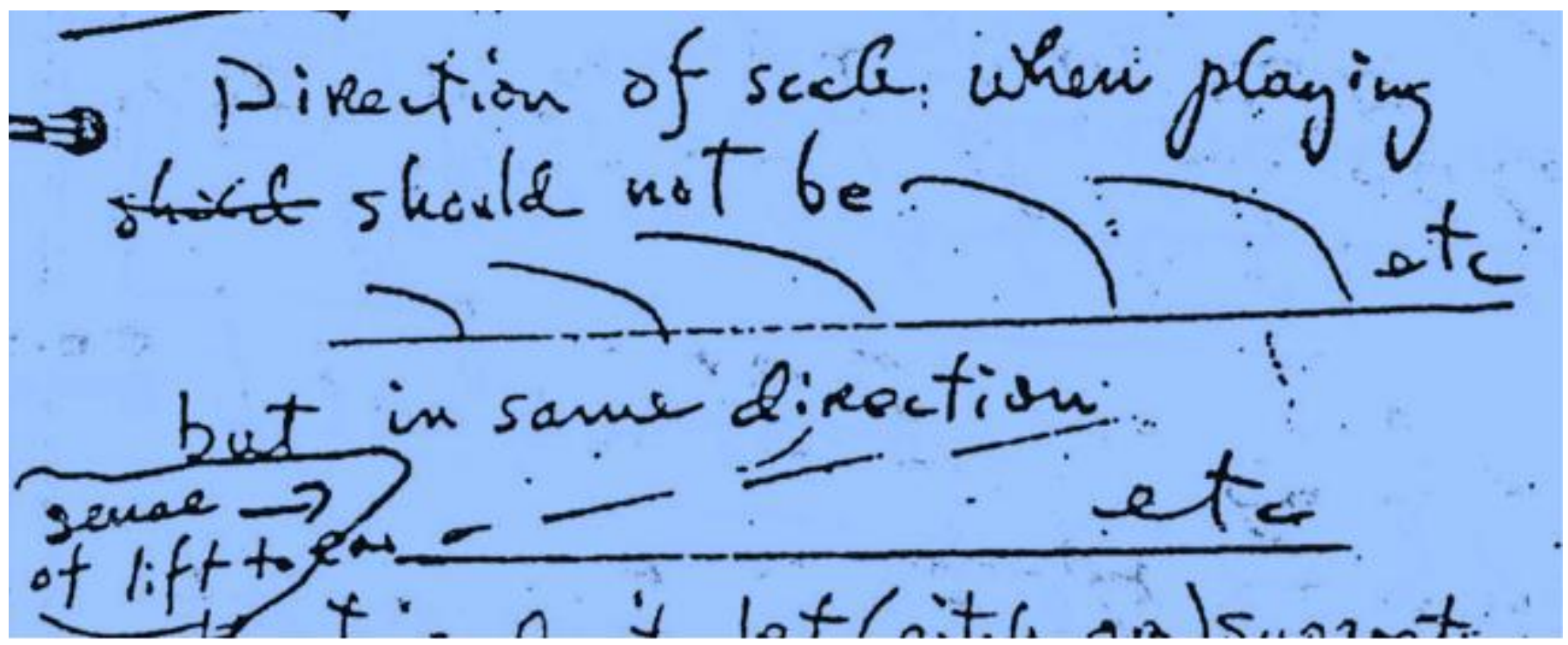

"The direction of scale when playing should not be (example above), but in the same direction. There is a sense of lift into to each note."

"Practice scales using only 5-1 and 1-5. The landing and the takeoff: These constitute the hardest part, as in flying an airplane; so it is in playing a scale." 
Floyd continued:

"In practicing a 5-1 scale (whether slurred or not), remember to keep the air pressure constant, the dynamics, the attack on 1 to 0 , and the landing."

"Also the pulse in the 5-1 scale is:"

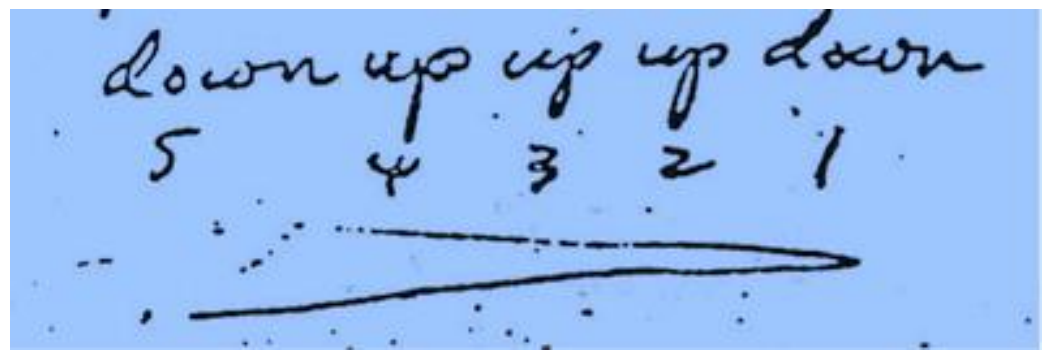

"Level 1 attacked and sustained, followed by touching 0, gives the following effect:"

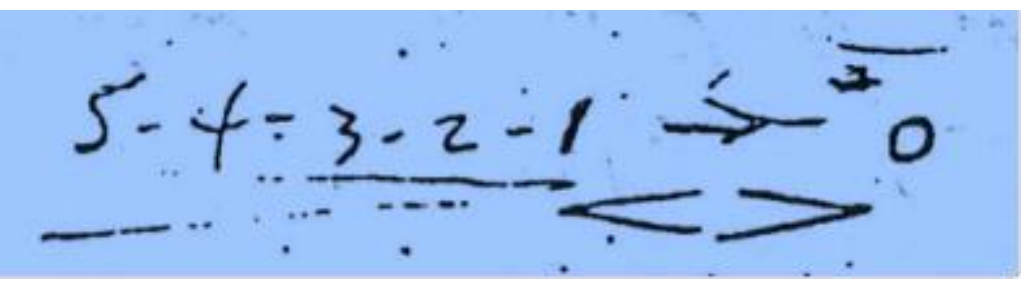

"That is, the air spins:"

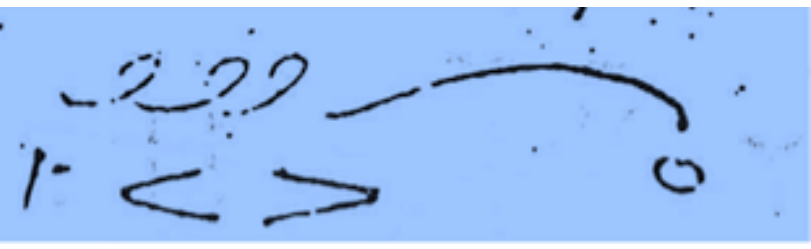

"Change as in the loop -- at exactly the right time."

"Pianiss-iss-iss-iss-issimo is not all on zero (0); that equals death. Even at the lowest dynamic level, there must be some direction." 
Floyd continued:

"As in the numbers on the board at a stock exchange, all changes are made gradually. Don't increase from 1 to 20 with one leap and bound. Connect!"

Tabuteau gave me this assignment: "Practice the $\mathrm{Bb}$ major scale articulated then slurred. Use the full length of the bow at 9: 1 to 9 to $1 . "$

Diagram by Tabuteau:

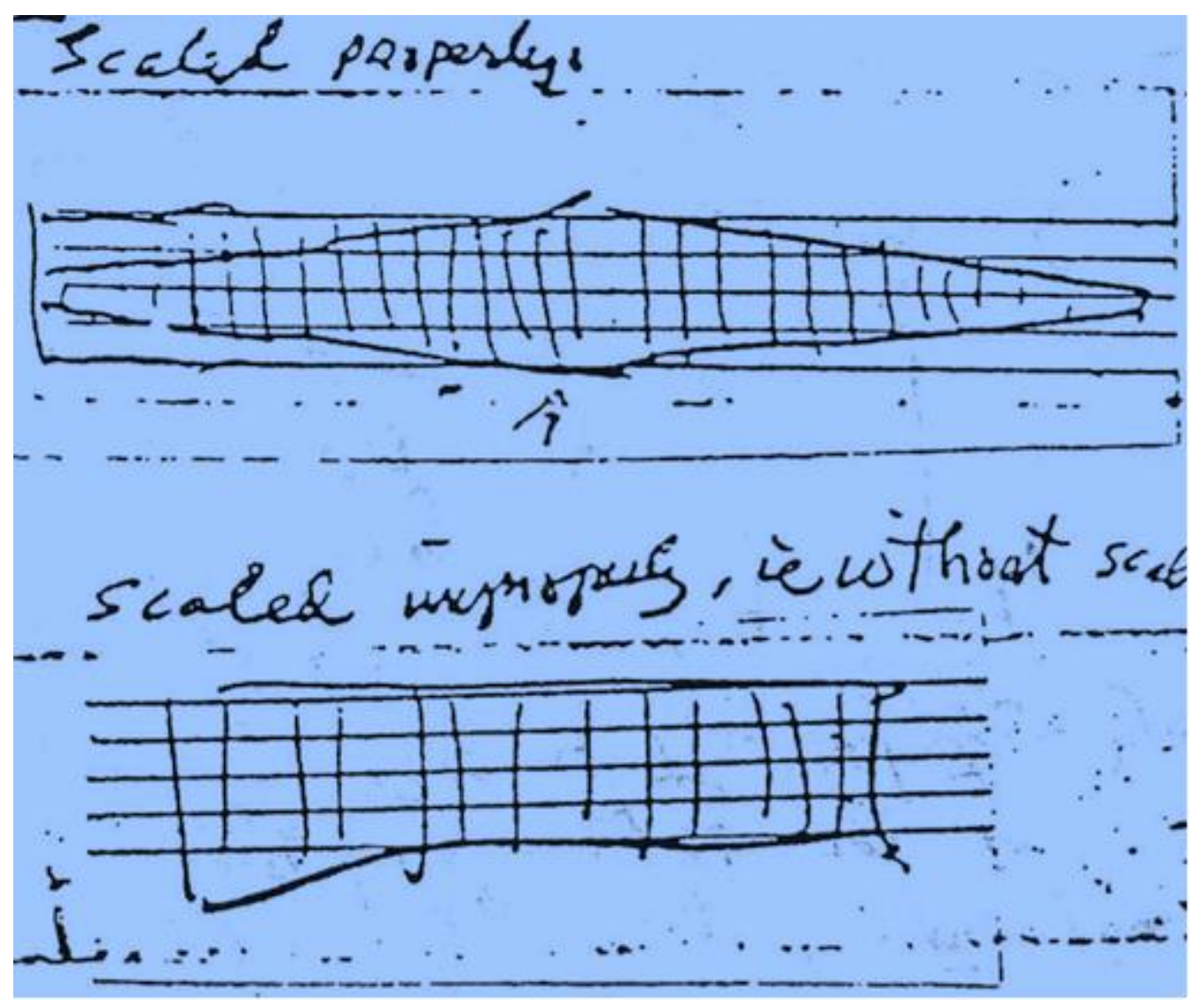

"Above: Scaled properly / Scaled improperly, without scaling." 
Floyd continued:

\section{Diagram by Tabuteau:}

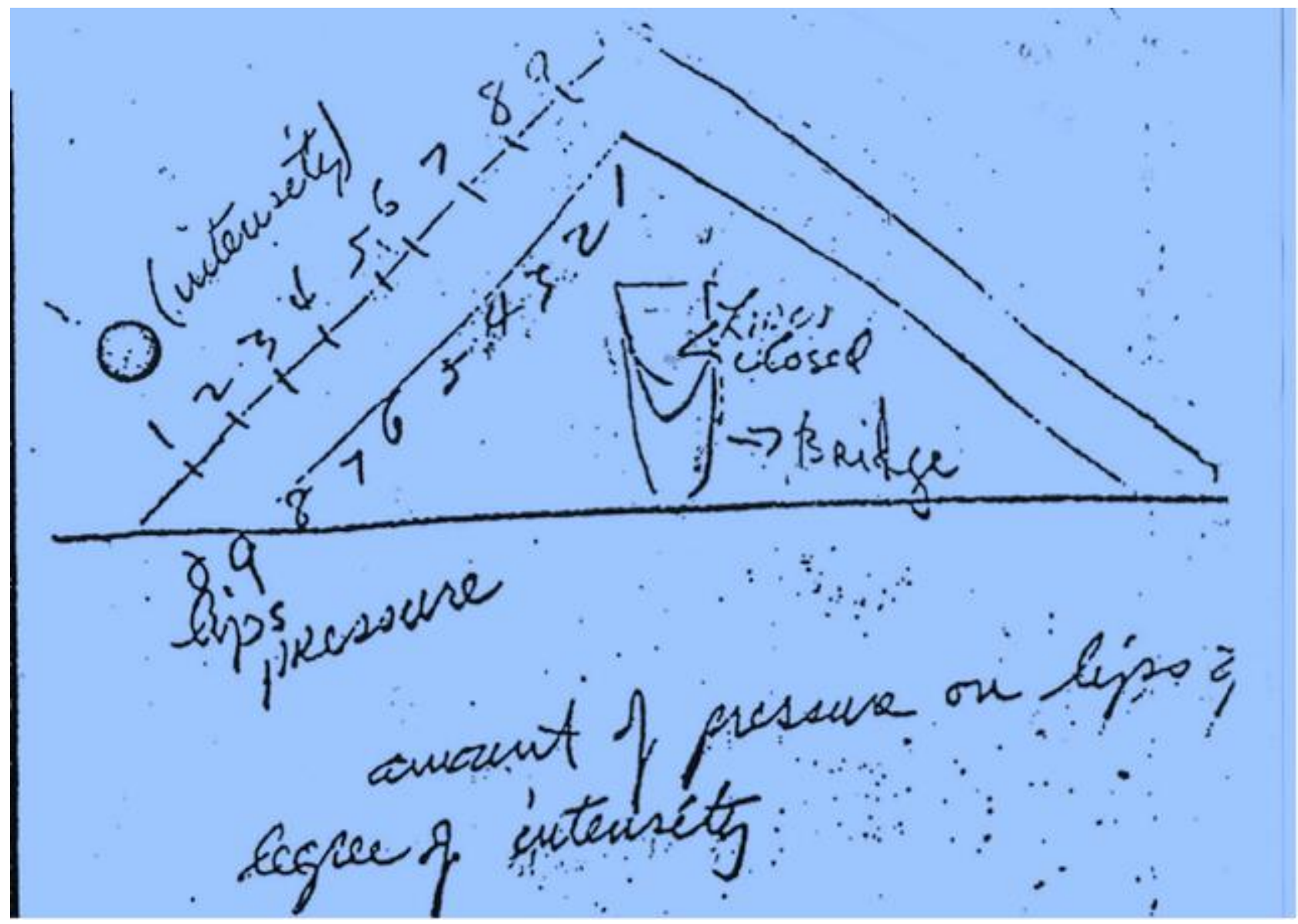

"When you start the car, you start in zero, then gears 1, 2 et cetera. Do not begin in high gear."

"Scale your levels 1-9 et cetera on the embouchure and space, not on volume. Then the quality will carry. Volume will not."

"The musician who can only name chords is like the grammarian who can name parts of speech but cannot say anything. Naming chords is concerned only with the vertical. I am the expert in the horizontal." 
Floyd continued:

"For example, on the same note, proceed as follows:"

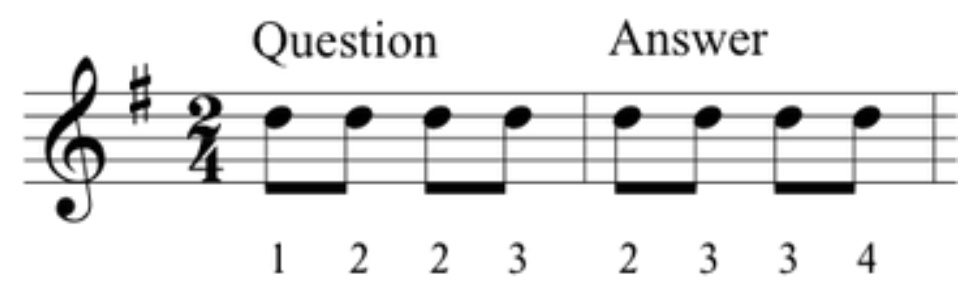

"One may ask: Why not return to level 1 in the answer part of phrase? If one did, the answer would be doubtful. The distribution number is, therefore, just as important as the tonal strength." 
Adrian Gnam, former Principal Oboist of the Cleveland Orchestra and the American Symphony studied with Tabuteau in 1965:

Composed by Tabuteau for pedagogical purposes:
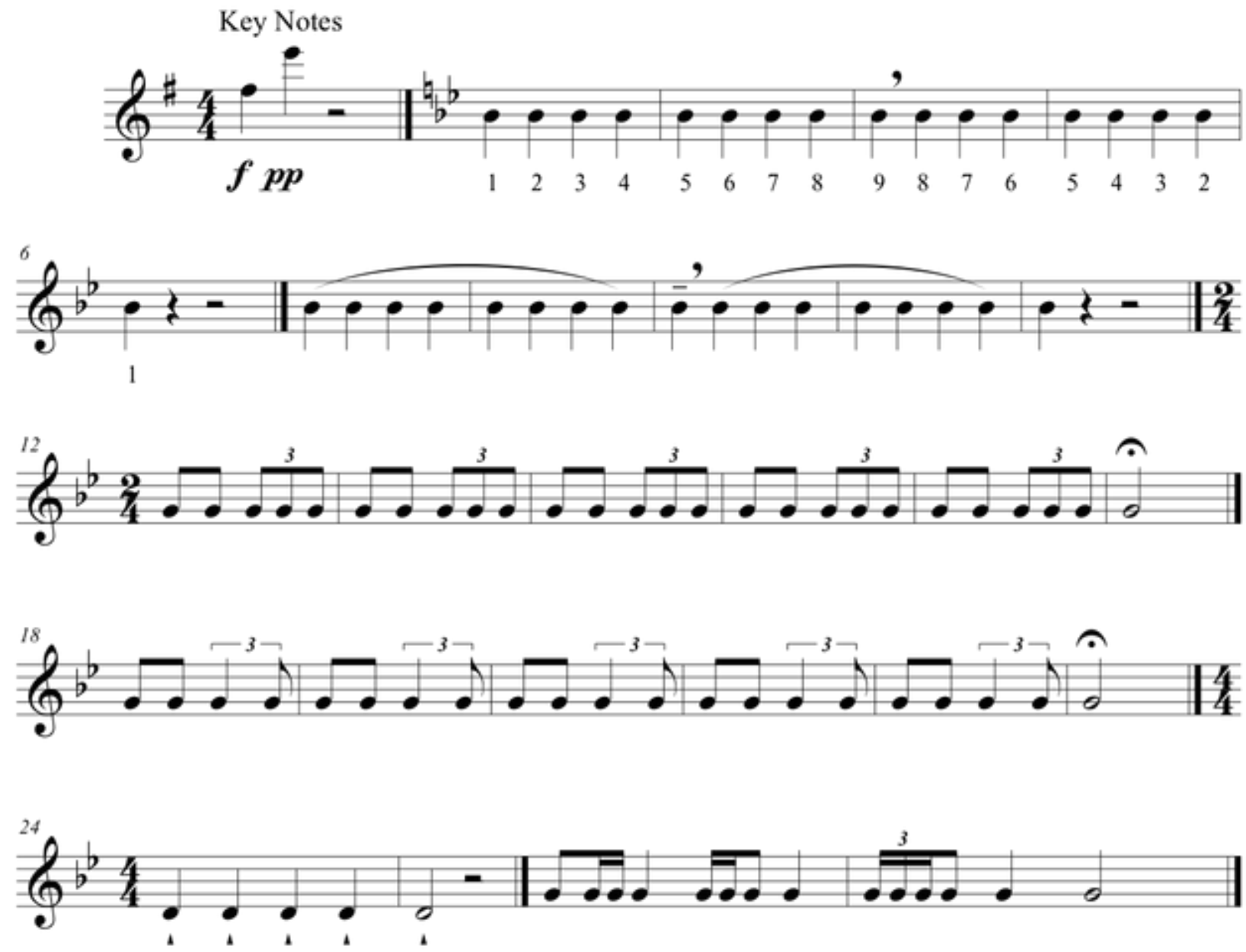

Total dynamics from 1-30 (1 is next to zero): pp: 1 / mp: 5 / mf: 9 / f: 13 / ff: 30 . 
John Krell, former Piccolo performer in the Philadelphia Orchestra studied under Tabuteau in his woodwind courses at the Curtis Institute of Music as interviewed by Melissa Stevens:

Stevens: How were the classes run? Would he speak about his musical concepts as you worked on pieces?

Krell: With his oboe students, he used to do an intensity drive.

Stevens: A long tone?

Krell: Yes. Every time the kids came in they had to do an intensity drive from 1 to 10 . He was not just talking about making a crescendo, this was intensifying the quality of sound, having assigned these numbers, they scaled the whole crescendo. I remember John de Lancie playing, and the tone would come out of the orchestra's fabric and then once he reached the top he would put a little vibrato on the note. It was like a blooming. Tabuteau used the number technique, and he insisted we memorize $1-1,2,3,4-2,3,4,5-3,4,5,6$. He would describe a phrase in terms of numbers in order to meticulously scale what he wanted you to do. Sometimes we had people who were not very musical, and he would give them the numbers, and they would sound pretty good.

Marc Mostovy, Founder, Director, and Conductor of the Chamber Orchestra of Philadelphia studied with Tabuteau from 1962-1964:

"Nevertheless, note grouping is only the beginning. Our next step is to combine or synchronize the group patterns with varied colors, inflections, et cetera. Let us use numbers to represent the amount of color a certain note is to receive. This is perhaps an artificial way of expressing the color but it is good for getting the idea across as we must have some unit of measure. The higher the number, the more color or density the note will have and the lower the number, less color. There should be constant variation. However, it is not good to give every note a different color or number, as the phrase will lose its backbone. The phrase must retain a definite form or skeleton. Our main object is to give the phrase life and yet to keep it on as smooth a curve as possible. We must both ascend and descend in the most even and musical way we can. We should also constantly be on guard not to play on the "zero" level or to use the same numbers over and over again in succession. The music would then stand still and die. It could be compared to a man trying to go somewhere but who marks time in place instead of walking ahead to his destination. The music must remain in constant motion. It must stay alive. [J. J. Rousseau idea: We too often believe we are doing the expected thing by playing the right note, yet we neglect to do justice to the real life of the notevibration.]"

"We cannot use numbers in any haphazard fashion but rather in logical and consistent patterns. So, as stated earlier, we combine the grouping patterns with the coloring of each note. The numbers may either ascend or descend according to what the phrase calls for rhythmically, harmonically and melodically. Whenever we desire a group change or when the rhythm definitely calls for one, 


\section{Mostovoy Continued:}

we apply the same number to the last note of the preceding group and to the first note of the new group, thereby serving a three-fold purpose: to distinguish between the two groups, to give

backbone to the phrase, and to help give the phrase a smooth curve. The second repeated number automatically calls for a type of rebound. We could compare it to a billiard ball bouncing off the side of the table, or when someone reaches for a piece of food, which is too hot; he touches it and quickly pulls his hand back. This is what we mean by a rebound."

"A word of caution at this point: The amount of coloring or density a note receives should not be mistaken for the dynamic level which is something else again. Numbers or coloring may increase over both a crescendo and a decrescendo and vice versa. The two have no definite relationship to one another. The basic difference between dynamic and color can be illustrated as follows: On a stringed instrument, the amount of color is related to the speed of the bow across the strings and at what point between the bridge and fingerboard the bow is being drawn. The dynamic level is directly related to the amount of pressure being exerted by the bow on the string. Therefore, it is possible to have a fff with little or no color and quite dead, or a ppp with a high number bursting apart at the seams with color and excitement. Of course, the reverse could be true."

"On a wind instrument, the changes of color are achieved by the speed of the air blown through the instrument, by the position of the lips, and the amount of pressure applied to the reed or mouthpiece. The dynamics are affected by the amount of air forced through the instrument. On a string or a wind instrument, then, we can see how we get various tone colors over many different dynamic levels. It stands to reason that the more proficient the player, the more coloring he is able to produce. It is extremely important not to confuse the two terms, dynamics and coloring."

\section{Tabuteau's Own Words by Marc Mostovy:}

\section{Numbering System:}

"Tabuteau used numbers as a vehicle to demonstrate many of his ideas and to help solve musical problems in various areas."

"There are numbers for grouping and other things in music. Numbers are the answer to many problems - an artificial way to help determine things."

"Numbers are color."

"The numbering of groupings depends solely on the rhythmic structure; the coloring of each note depends on the melodic and harmonic structure." 


\section{Mostovoy Continued:}

\section{COLOR:}

"The color shall be indicated by the numbers. The higher number means more color, the lower number means less color. Shoot for different colors."

"Numbers are your inner self; you give more from within."

"A single note could contain one or more numbers of color."

"You must vary your numbers with the feeling and direction of the melodic line"

'It isn't enough to play $\mathrm{F}$ and $\mathrm{G}$ with the difference being only the physical reaction of the instrument; you must think of the $\mathrm{G}$ having more vibrations and therefore more color, in other words your numbers must reflect this."

\section{DYNAMICS VS. COLOR:}

"The numbers we use are not dynamics; the numbers are colors. The higher number does not necessarily mean a higher dynamic level. You can have your numbers increase or decrease on a diminuendo or a crescendo. The numbers can go up (you can go up in color) and a diminuendo can take place at the same time." 


\section{Mostovoy Continued:}

\section{RANGE:}

"You have a range of twenty-five or so numbers, but instead of continuing one after the other until you reach twenty-five, take nine or ten at the most, and transpose it on different dynamic levels. Your numbers will be at different levels according to the dynamic level you are playing in."

\section{UP|DOWN}

"You must often play an up-down where the numbers are 2|1. Even though the up is more intense then the down, the inflection must be correct - up and down."

"It is possible to have a 6 to a 5 upbeat to downbeat and still be heavier on the 5 because it is a down inflection; downs are heavier than ups."

“1-1-2-3|2: Practice coming down on [the second] 2, * yet lighter less color."

Composed by Tabuteau for pedagogical purposes:

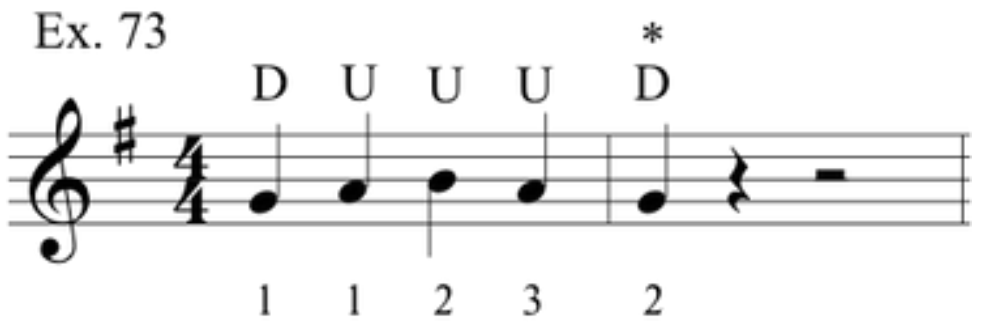

\section{INFLECTIONS:}

"A change of number indicates an inflection where needed; not all changes are inflections."

"An inflection is not a repetition of number, a passing note or inhale; it is the resolution of a group."

"The important inflection of notes does not necessarily have to be the higher number."

"When you start practicing a passage, practice everything on " 1 " [one color] with inflection and articulation." 


\section{Mostovoy Continued:}

\section{CONCLUSIVE ENDINGS:}

"When you have a down concluding note of a group, it is often not necessary to increase your number. The fact that it is a definite conclusive down, you can decrease the number and it will still sound concluding; numbers can decrease and still be a conclusion."

"When a more definite conclusion is wanted at the end of the phrase, increase your number of color, and when a lighter more indefinite conclusion is wanted, decrease the numbers. A higher

number at the end means a more conclusive ending. $3 \mid 4$ is more conclusive than $3 \mid 2$. In a $5 / 4$ [measure] 2-1-2-2-3|2 would not be an end; 2-1-2-2-3|4 would be an end."

\section{Ex. 74}

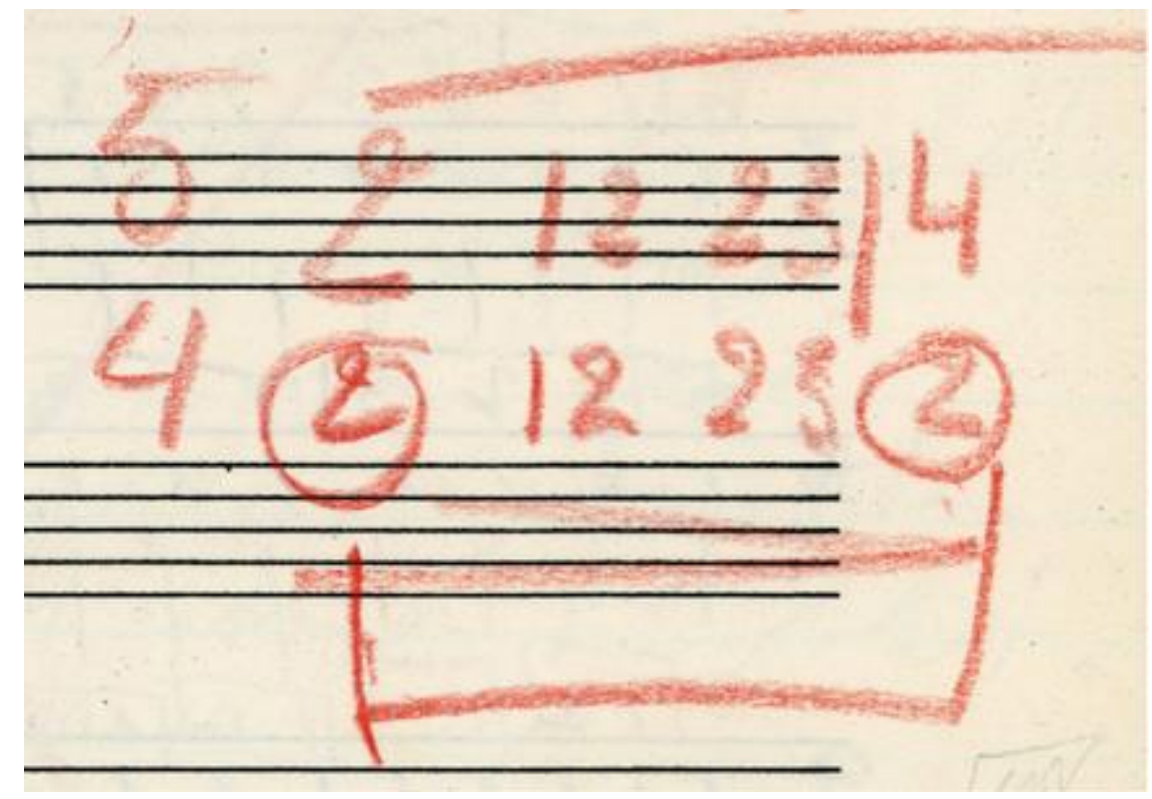

\section{AFFIRMATIVE/INTERROGATIVE:}

"Usually, if the phrase is affirmative, the numbers increase, and if [the phrase is] interrogative, they decrease." (Affirmative-increase; interrogative - decrease.)

\section{ASCENDING/DESCENDING LINE:}

"When your melodic line is going up, your numbers should also go up, not down, and vice versa." 


\section{Mostovoy Continued:}

"When ascending, you usually have an increase of number on the first note of the bar, but you may have otherwise a decrease in number in some instances, especially in building great suspense and vice versa"

"When numbering a group in an ascending pattern, the number following the first note of the measure must either be the same or below—not above — and vice versa in descending patterns."

\section{Ex. 75}

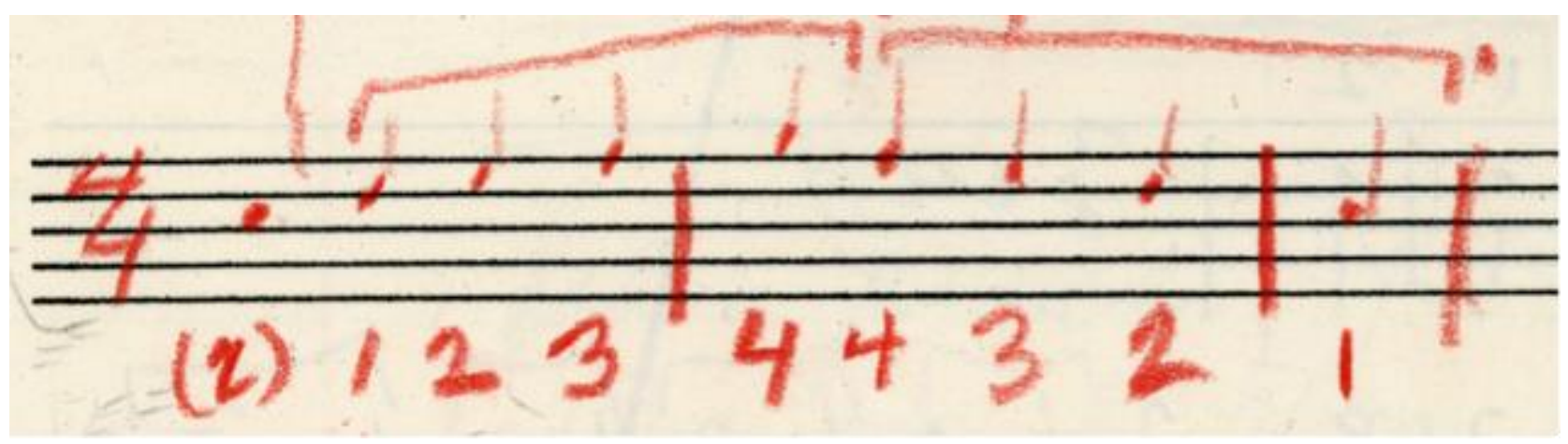

\section{CLIMAX:}

"Your numbers of color ascend or descend according to where the line goes; they ascend towards the climax and descend going away from it."

"When you are reaching towards a climax, you raise your numbers slowly but surely, for example $2-1-2-2-3|4-2-3-3-4| 5-3-4-4-5 \mid 6$ et cetera and vice versa."

\section{Ex. 76}

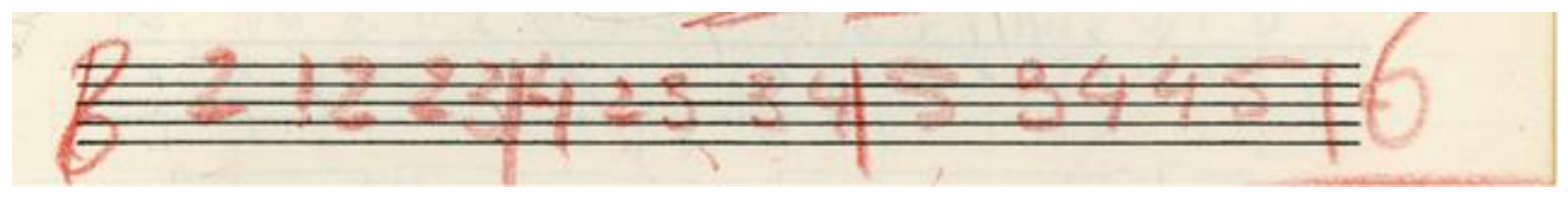

\section{LONG NOTES:}

"On long notes, make interesting inner work; for example, 0-1-1-2-2-3-3-2-2-1; this is very important. Think of the moving numbers. On long notes, you must often think of them in small number patterns." 
Mostovoy Continued:

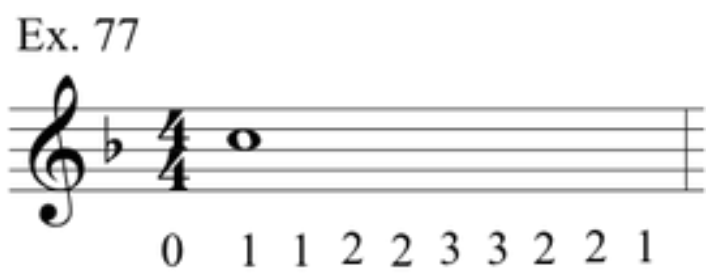

"Play the number pattern on long notes as in the moving passages."

Ex. 78

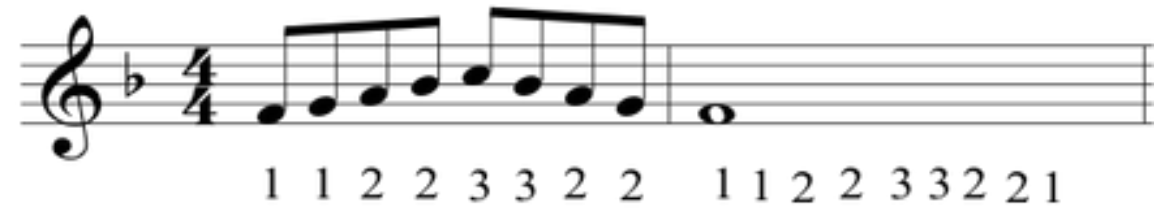

\section{CONCLUDING NOTES:}

"At the end of a phrase on a long note, you must move [increase/decrease your numbers]. When you have a long note concluding, come to it decreasing in numbers so that you can increase color on the long note; you have to come down in numbers in order to go up." [See Ex. 78 above.]

\section{SMOOTH LINE:}

"The numbers are related to the melodic line to keep the line (curve) smooth. Except under a few rare instances, when changing numbers, do it only by one and not more to keep the line as smooth as possible."

Composed by Tabuteau for pedagogical purposes:

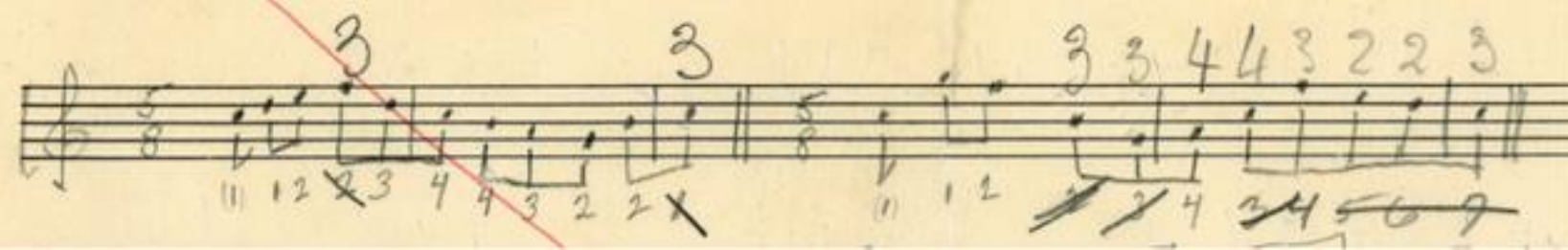

INTERVAL SKIPS:

"When combining numbers with intensity, use lower numbers on the skips up and higher numbers on the skips down." 
Mostovoy Continued:

Composed by Tabuteau for pedagogical purposes:

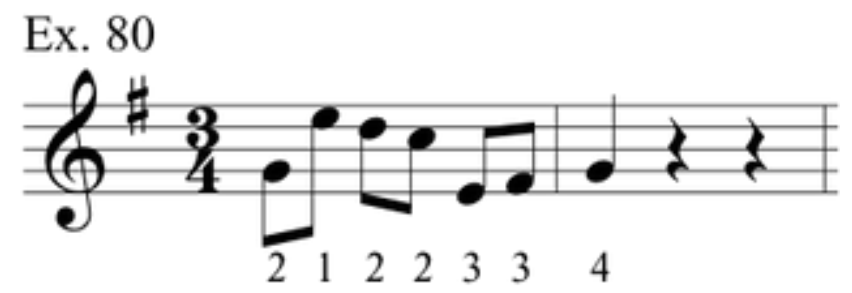

"Practice higher numbers on lower notes and vice versa."

\section{REPEATED NUMBERS:}

Never repeat a number over a bar, or on a weak pulse going to a strong one-for example in $4 / 4$ with four quarter notes, on 2 and going to 3 .

Composed by Tabuteau for pedagogical purposes:

\section{Ex. 81}

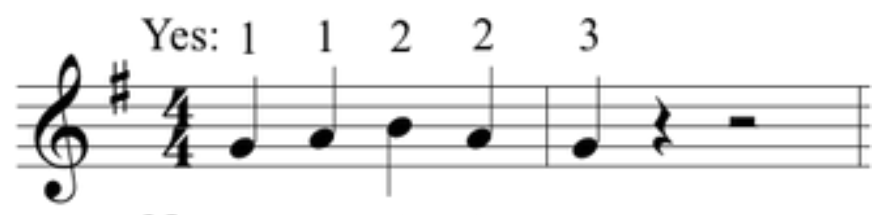

No: $1 \quad 2 \quad 2 \quad 3 \quad 3$

"On a repetition of number, the second note is more intense; more speed."

"You very rarely, if ever, lower a number in a grouping when ascending other than after the first beat and vice versa; you will get repetition of a number." 


\section{Mostovoy Continued:}

\section{REPEATED NUMBERS: INTERROGATIVE/AFFIRMATIVE:}

"The same repeated number can mean the change from interrogative to affirmative.

\section{Ex. 82}

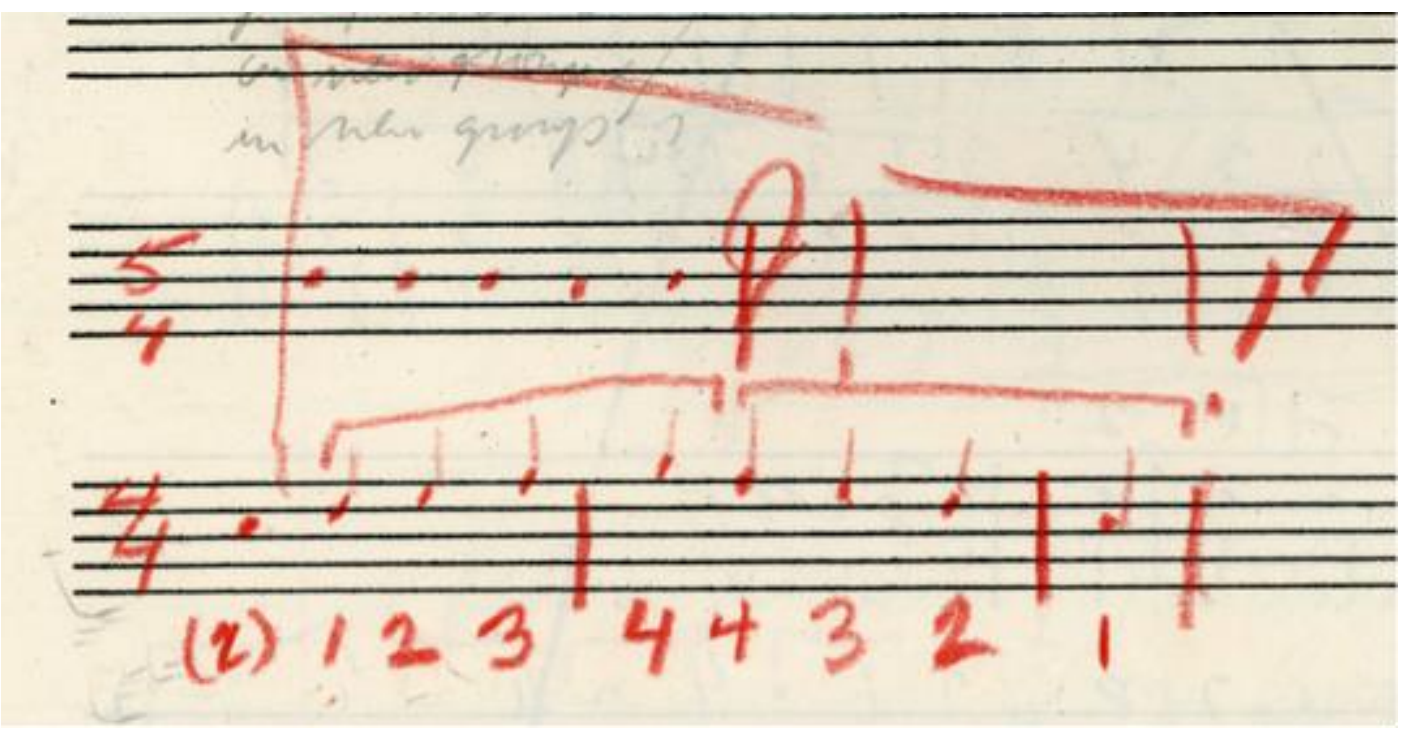

\section{REPEATED NUMBERS: REBOUNDS:}

"When you see two numbers the same, they are like rebounds; you never have the same number over the bar."

"It doesn't make such a difference whether your numbers go up or down as much as where your rebounds double numbers are. The placement of the rebounds is what's important."

"When you repeat a number, your rebound is like a ball rebounding on a pool table."

"After a rebound, or a change of direction, don't repeat your number again."

"A double number isn't the only time you will have an inflection and rebound."

\section{REPEATED NUMBERS: BACKBONE/FORM:}

"You must keep your color the same sometimes or the line will be without form; you must use some repeated numbers to give the phrase backbone. If you change [a number on] every note, there is no backbone or form." 


\section{Mostovoy Continued:}

"A group of notes can have many different number combinations but they cannot constantly skip around; they (the numbers) must be next to each other continuous."

\section{REPEATED NUMBERS: ZERO LEVEL:}

"Never play on zero or mark time or repeat numbers. Avoid repeating numbers like 2-3-3, 2-3-3 et cetera; it is not too good-you're playing on zero level."

\section{RECURRING FIGURES:}

"Sometimes if you have a recurring figure, you can make changes of color, in other words 2-1, 23 such as in Brahms Fourth Symphony; carry on the dialogue-every group: 2-1, 1-2; question and answer."

\section{Ex. 84: Brahms-Symphony No. 4, first movement.}

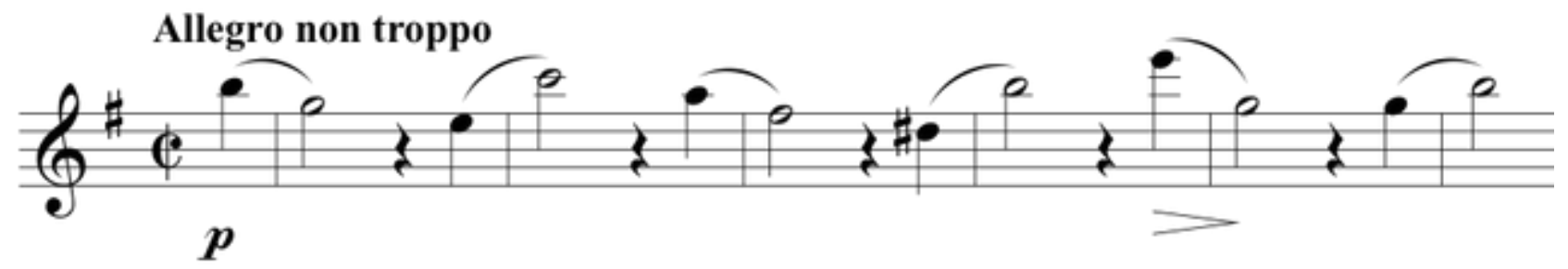

GOAL:

"So, we have the system of numbering of color with rebounds, inflections and notes being given special attention; we must combine all this into one."

\section{PATTERNS:}

"The key to even counting of 2,3,4,5 and 6 beats to a bar consecutively: $2,1-3,1-2-4,1-2-3-5,1$ 2-3-4-6, et cetera. [Each measure gets one beat; the beat stays constant; six beats in total in this example]." 
Mostovoy Continued:

Composed by Tabuteau for pedagogical purposes:

Ex. 86

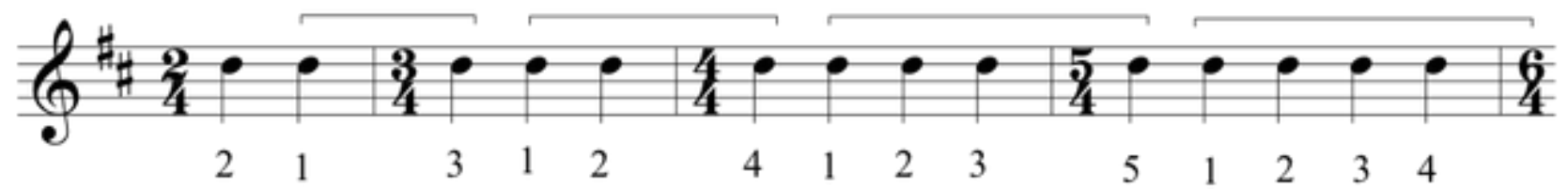

"In fast runs with many notes, gallop like a horse. Use numbers like 1-1-2-3-4-3-4-5-6-7-8-8-7-89 or 2-3-4-3-4-5-4-5-6-7-8-8-9 et cetera; you can backtrack your numbers and continue."

"Find the rhythmic counterpoint; find the rhyme; look for the like pattern on long notes as in the moving passages."

\section{THE LOOP/TURN:}

"The turn (loop) is a time element; you place the note a fraction of a second late (different)."

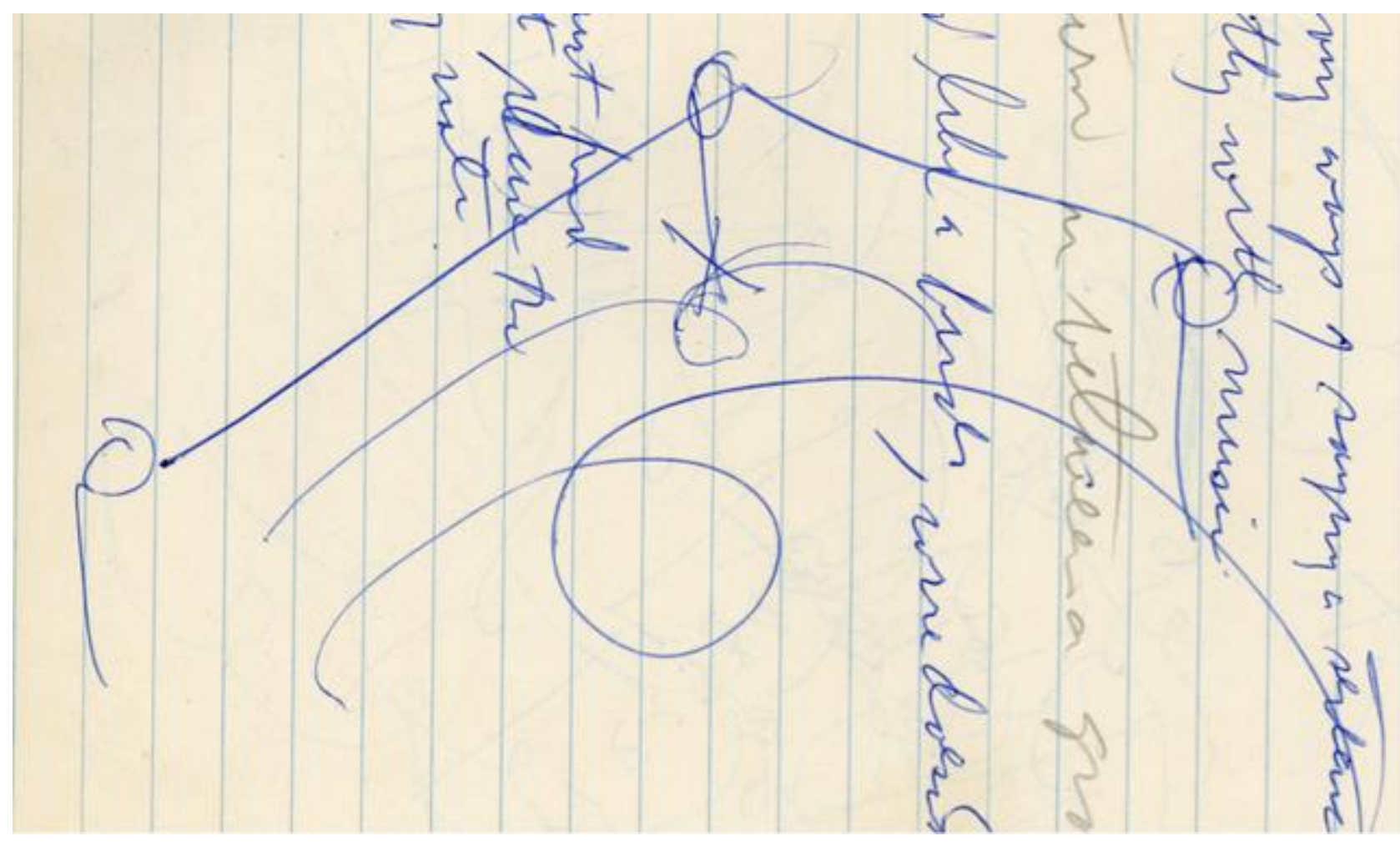




\section{Mostovoy Continued:}

"Your line is never just an arc, but always an arc with loops in both directions, upper and lower. Those turns and circles are extremely important. Play the note on the loop—on the turn."

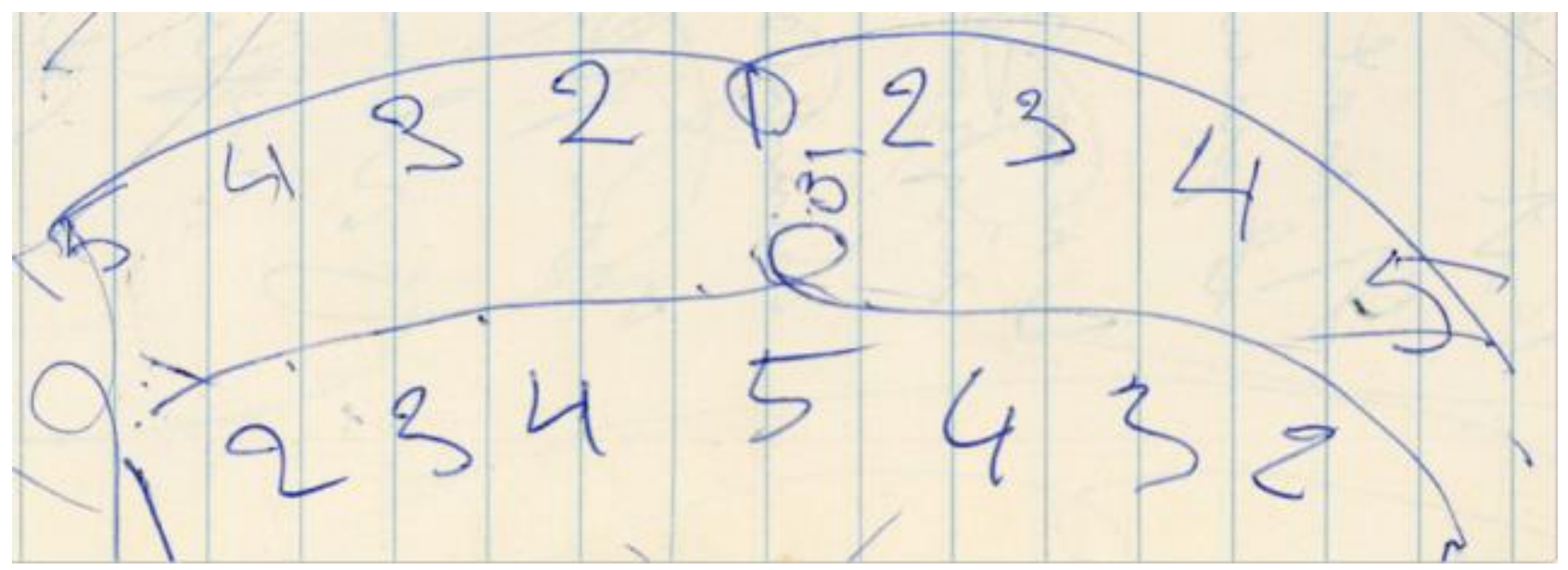

"The turns (loops) occur between groups. There could be many notes or one note in a turn (loop)."

Laila Storch, former Principal Oboist of the Houston Symphony studied with Tabuteau from 1943 to $1945:$

"Tabuteau's use of numbers was a means to a musical end, not an end in itself. But in his various applications of the 'number system,' he was able to impart his ideas about rhythm, dynamic range, tone color, and the all-important shaping of a musical phrase, with an exactness and accuracy which I do not feel has been attained by any other artist or teacher."

"None of his pupils are likely to forget their first introduction to 'numbers,' the $1-9-1$ 'drive' on one note - the aim being that of range and the increase of intensity from the softest beginning, with the speed of the wind increasing to 9 and then back to 1, this done both on one continuous tone and with each degree or the 'drive' attacked separately."

Variations of this exercise included increasing it from 1-13-1, and changing notes, for example playing:

EXAMPLE 1

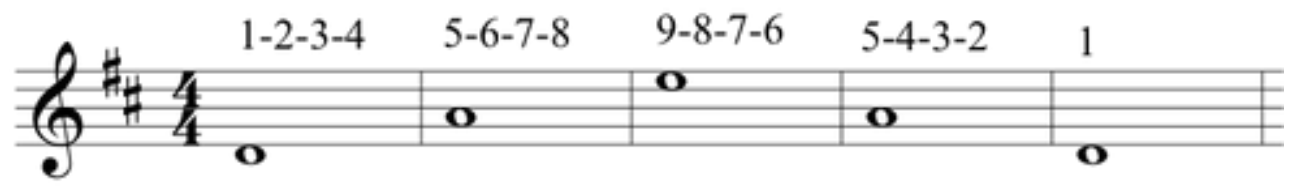




\section{$\underline{\text { Storch continued: }}$}

"He also evolved his "number system" as a way to impart in an extremely precise manner his ideas of rhythm, dynamic range, and the shaping of musical phrases. However, applying numbers to explain the minute gradations of intensity and nuance in a line of music did not preclude his use of colorful examples to help put across a point. Sometimes it was by means of the "golf player."

"Wind control and numbers: He returned to the things he had emphasized in my first lessons of five years earlier. Practice 1-2-3-4-5-4-3-2-1 on one note and then in fifths (A-E-A) detached and slurred. From a low C, play 1-13 (to high A) and then the opposite. Do the same, playing all the notes in between. Practice all the intervals, then when you have a little solo, you have something to play on. Exaggerate-but in the right direction. Always let the music determine the numbers and try to come as close as possible to what fits you and the music the best. Don't force the pattern on the music. Always keep the line. Each note must take its cue of placement from the note you are on. You must get beyond just playing the notes on the oboe. There must be distribution and form and then the real spirit and life besides. Play to the last fellow in the balcony. Travel!"

Donald Hefner, former solo oboist of the U.S. Marine Band studied with Tabuteau for two years in the 1950's:

“Tabuteau's Number System, the subject of so much discussion, was a way to more precisely chart the rise in intensity of a phrase and to indicate the smallest elements (he called them "syllables") toward the peak and away again. This system was, in Tabuteau's own words, subjective and applied inconsistently. This writer's impression was that it would be applied only to phrases where the groupings were relatively clear and simple."

"To quote an example, remembered exactly from an ensemble class [Hefner presents a well-known melody here]: Note that the rise in intensity is not necessarily synonymous with a rise in pitch. This phrase derives its increasing tension from the sequential repetition of a two "syllable" motive. When the numbers progress, that signifies an "up-down" inflection. When the number repeats, it means that these adjacent notes are unrelated. When the phrase is progressing toward its climax, the "down" inflection has more weight than the " up ."

"Tabuteau would illustrate this point by pretending to hold a carpenter's hammer. He would make a violent upstroke and a soft downstroke and say, "You can't drive nails in like that!" In the course of resolution, however, as the decreasing numbers indicate, the opposite is true."

"There are, of course, other means of increasing tension than simple repetition. Rising pitch can be a contributing factor, as can harmonic movement, the introduction of active rhythmic figures, and above all, dissonance." 
Waldemar Wolsing, former Oboist of the Danish National Radio Orchestra studied with Tabuteau in 1950 and 1953:

\section{Siegfried's Rhine Journey. Numbers. Speed of wind}

"I would say-—when they had something to play—a call--a horn call--(Sings) I would explain to them that-(Sings) 1-1 1-2, 2-2, 3-3, 3-4. See, and then I would say, never mind the horn. Put your horn - put your horn on your knees and simply for few minutes say: 1-1 1-2, 2-2, 3-3, 3-4. No, no notes, no melody. 1-1 1-2 123-234. 1-1 1-2-1-1 1-2 1-1 2-2 2-3 1-1 2-2 3-4 for the continuity, you see what I mean? And after doing that for one minute or two, I said, "now take your horn." Would you believe that they would play it as well as any, as any professional? You understand the idea? W. Yes, yes, T. Because they had, the, the, the directive of their mind. You see? (Sings again) Bon bon, bon-bon. Bon-bon con-nect. Bon-1, 2-2, 2-3 or 1-1, 2-2, 3-4. You see, the distribution as you want. 1-1, 1-2,1-1, 2-2, 2-3-1-1, 1-2 and then the second one: 2-2, 2$3,2-3,4-4,4-5$. See, there is always a progression and you keep your line. W. Yes. T. You see. So, I only say that to you to explain that the little problem, the little game of distribution and speed of the wind with the pressure of the lips, you know? W. Yes .T. It works for every wind instrument. It works with any kind of wind instrument. You see, because when you, you increase the, the speed of the wind, you don't have to press so much with your lips. You know, it's like the train on the railroad track. You see? W. Um hum. T. The train is at the stop in the station, but it is going to receive the order from the chef de gare to - to go again. You know, to run again. So, watch the locomotive. The locomotive-you know? It's heavy on the track ... psssh -pssh-pssh ... (imitates the engine gaining speed) You know when they have the speed, there is not so much weight on the track as when they start. Well, it is the same thing with your embouchure. Do you understand? W. I must start? T. With pressure. With pressure? T. Because your wind is not at full speed. When the wind is at full speed - full speed - full speed (pronounces more exactly!) W. Yes, yes, yes. T. You can open your lips. It's like the, the, the train on the track is less-has less weight as when it starts to pull the twenty cars behind the locomotive. You understand? W. Yes. T. When they have the speed, they almost fly on the track. W. Uh hum. T. So it is the same principe for any wind instrument. (Blows on reed) You see when I play on "one," I press more. I press more when I am going to reach twenty or ten or nine-you see, I press here, because I have no speed, but (demonstrates), I open my-my, my, my lips like a carp-W. Yes. T. - taking air out of the water. You see what I mean? W. Here? (Wolsing doesn't understand T's pronunciation, "hair" for "air"!) You see, I don't pinch. The speed of the wind push the tone up! W. Yes, yes, yes. T. You know, like the train when it goes ninety miles an hour, has less weight on the track as when it start to, to roll. That's exactly-when I was speaking about logic a little while ago, that's what I mean by logic.

W. Yes. T. That's all. (Plays Siegfried again) You see? 12 2-3, 2-2, 3-3, 3-4. (Plays) You see. Now I sustain the ta-ta - ta-ta-ta. (Plays) You see what I mean? W. Yes. T. You keep the line and you have the swing to-Hum-m? (Blows on reed)" 
John Mack, former Oboist in the Cleveland Orchestra that studied with Tabuteau from 1944 to 1945 and 1948 to 1951 as interviewed by Melissa Stevens:

"The overt reason for using his number system was to get you to control what he would call your "givings." In other words, scale things so they sound reasonable and continuous. He did not use that word, but that is what he obviously meant-continuous on the way up and continuous on the way down, with very few exceptions. Every now and then there would be an exception. "Grand Etude" number five from Barret is an example of an exception. The explosion is called for on the accented notes."

"The covert purposes of the number system would be to get you to see things his way. In other words, he would have you scaling things the way he wanted them to be done and gradually you would absorb this."

Louis Reosenblatt, former Oboist in the Philadelphia Orchestra that studied with Tabuteau from 1948 to 1951 as interviewed by Melissa Stevens:

"Tabuteau's number system was actually not hard to comprehend. It was a quite simple system. It became legendary but there was little to it, really. It was very inspiring because he not only said or sang the numbers, but also explained how the numbers should be applied. These numbers were his "scientific" way of explaining how to bring out the expression of a passage. It had value because, instead of merely suggesting a poetic way of expressing the notes, "Play this passage and imagine the sun rising over the horizon," he proposed numbers, i.e., as the numbers got larger you were to play louder, and that sort of thing. It was a way of making the expression more concrete than by simply using very poetic words, He also sang or played how he wanted it to sound and one then understood. That was the inspiring part, not just the numbers by themselves, but how he sang them. His manner of explaining was very inspiring. The numbers were an interesting device, but it was the way he used them that was so great. His students went out into the world and used the "number system" with their own students, but it probably did not work quite as well as when he used it."

Wayne Rapier, former Oboist of the Boston Symphony Orchestra who studied with Tabuteau from 1951-1954:

"My first lessons with Mr. Tabuteau usually began on slow scales which included dynamic, intensity and tone color control. The first scale might cover five notes which started on 1 (which was next to zero in dynamics) and crescendo to 5 , which was the loudest for your available equipment. The 1 would be a down impulse; 2,3 and 4 would be ups with increasing intensity through the beginning of 5; the dynamics decrescendo to 1 but with increasing intensity. If I survived 1-5-1, I would progress to 1-5-9-5-1; and then to 1-5-9-13-8-5-1, and then from 1-17 and back to 1 . The typical scale might follow this harmonic progression:" 


\section{Bibliography}

Galbraith, Amy M. 2011. "The American School of Oboe Playing: Robert Bloom, John De Lancie, John Mack, and the Influence of Marcel Tabuteau." Order No. 3476409, West Virginia University. https://search.proquest.com/docview/894212495?accountid=34539.

Hefner, Donald L. 1984. "The Tradition of the Paris Conservatory School of Oboe Playing with Special Attention to the Influence of Marcel Tabuteau (Georges Gillet; France)." Order No. 8426540, The Catholic University of America. https://search.proquest.com/docview/303355014? accountid=34539.

Lehrer, Charles. "Marcel Tabuteau First-Hand.” Marceltabuteau.com. https://marceltabuteau.com (accessed October 9, 2017).

McGill, David. Sound in motion: a performer's guide to greater musical expression. Bloomington, IN: Indiana University Press, 2007.

New York Times. "Elaine Shaffer, Flutist, 47, Dies." https://www.nytimes.com/1973/02/19/archives/elaine-shaffer-flutist-47-dies-touredworld-capitals-as-soloist.html (accessed June 6, 2018)

Robinson, Joseph L. Long Winded. An Oboist's Incredible Journey to the New York Philharmonic. Joseph Tree Publishing; 1 edition, 2018.

Stevens, Melissa A. 1999. "Marcel Tabuteau. Pedagogical Concepts and Practices for Teaching Musical Expressiveness: An Oral History." Order No. 9931680, The Ohio State University. https://search.proquest.com/docview/304539699?accountid=34539.

Storch, Laila. Marcel Tabuteau: how do you expect to play the oboe if you can't peel a mushroom? Bloomington: Indiana University Press, 2008.

Thomason, Eliza E. 2010. "Marcel Tabuteau and His Art of Phrasing: Applied to Suite no. 6 for Cello (Transcribed for Viola) in G Major, by J. S. Bach." Order No. 3432342, University of Cincinnati. https://search.proquest.com/docview/853165803 accountid=34539.

Thompson, Shannon Lannigan. 1998. "A History and Analysis of the Philadelphia School of Clarinet Playing." Order No. 9838184, The University of Texas at Austin. https://search.proquest.com/docview/304457408?accountid=34539. 